Exploração de métodos de sumarização automática multidocumento com base em conhecimento semânticodiscursivo

\author{
Paula Christina Figueira Cardoso
}





\title{
Exploração de métodos de sumarização automática multidocumento com base em conhecimento semântico- discursivo
}

\author{
Paula Christina Figueira Cardoso \\ Orientador: Prof. Dr. Thiago Alexandre Salgueiro Pardo
}

Tese apresentada ao Instituto de Ciências Matemáticas e de Computação - ICMC-USP como parte dos requisitos para obtenção do título de Doutor em Ciências de Computação e Matemática Computacional. VERSÃO REVISADA.

USP - São Carlos

Novembro de 2014 
Ficha catalográfica elaborada pela Biblioteca Prof. Achille Bassi e Seção Técnica de Informática, ICMC/USP,

com os dados fornecidos pelo(a) autor(a)

Cardoso, Paula Christina Figueira

Exploraçāo de métodos de sumarizaçāo automática multidocumento com base em conhecimento semânticodiscursivo / Paula Christina Figueira Cardoso; orientador Thiago Alexandre Salgueiro Pardo. -- São Carlos, 2014.

$180 \mathrm{p}$.

Tese (Doutorado - Programa de Pós-Graduação em Ciências de Computação e Matemática Computacional) -Instituto de Ciências Matemáticas e de Computação, Universidade de São Paulo, 2014.

1. Processamento de Lingua Natural. 2. Análise Discursiva. 3. Sumarizaçāo Automática. I. Pardo, Thiago Alexandre Salgueiro, orient. II. Título. 


\section{AGRADECIMENTOS}

Por tudo, agradeço a Deus.

Ao Victor, meu companheiro e amigo generoso, pela paciência, amor e companheirismo. À minha família, pelo apoio incondicional.

Ao meu orientador Prof. Dr. Thiago Pardo, que nesses anos de convivência muito me ensinou, contribuindo para minha formação acadêmica e crescimento intelectual, sempre mostrando novos horizontes.

À Profa. Dra. Maite Taboada, pela orientação durante o estágio de doutorado-sanduíche e pela amizade.

A todos os professores do NILC, pelas sugestões para o desenvolvimento deste trabalho.

A todos os anotadores de córpus, que sem eles, não teríamos como avançar na pesquisa.

Aos colegas do NILC, pelos momentos de estudo e descontração.

À USP, por todo apoio.

Às agências de fomento à pesquisa CAPES e CNPq. 


\section{RESUMO}

A sumarização automática multidocumento visa à produção de um sumário a partir de um conjunto de textos relacionados, para ser utilizado por um usuário particular e/ou para determinada tarefa. Com o crescimento exponencial das informações disponíveis e a necessidade das pessoas obterem a informação em um curto espaço de tempo, a tarefa de sumarização automática tem recebido muita atenção nos últimos tempos. Sabe-se que em um conjunto de textos relacionados existem informações redundantes, contraditórias e complementares, que representam os fenômenos multidocumento. Em cada texto-fonte, o assunto principal é descrito em uma sequência de subtópicos. Além disso, as sentenças de um texto-fonte possuem graus de relevância diferentes. Nesse contexto, espera-se que um sumário multidocumento consista das informações relevantes que representem o total de textos do conjunto. No entanto, as estratégias de sumarização automática multidocumento adotadas até o presente utilizam somente os relacionamentos entre textos e descartam a análise da estrutura textual de cada texto-fonte, resultando em sumários que são pouco representativos dos subtópicos textuais e menos informativos do que poderiam ser. A fim de tratar adequadamente a relevância das informações, os fenômenos multidocumento e a distribuição de subtópicos, neste trabalho de doutorado, investigou-se como modelar o processo de sumarização automática usando o conhecimento semântico-discursivo em métodos de seleção de conteúdo e o impacto disso para a produção de sumários mais informativos e representativos dos textos-fonte. Na formalização do conhecimento semântico-discursivo, foram utilizadas as teorias semântico-discursivas RST (Rhetorical Structure Theory) e CST (Cross-document Structure Theory). Para apoiar o trabalho, um córpus multidocumento foi anotado com RST e subtópicos, consistindo em um recurso disponível para outras pesquisas. A partir da análise de córpus, foram propostos 10 métodos de segmentação em subtópicos e 13 métodos inovadores de sumarização automática. A avaliação dos métodos de segmentação em subtópicos mostrou que existe uma forte relação entre a estrutura de subtópicos e a análise retórica de um texto. Quanto à avaliação dos métodos de sumarização automática, os resultados indicam que o uso do conhecimento semântico-discursivo em boas estratégias de seleção de conteúdo afeta positivamente a produção de sumários informativos. 


\begin{abstract}
The multi-document summarization aims at producing a summary from a set of related texts to be used for an individual or/and a particular task. Nowadays, with the exponential growth of available information and the people's need to obtain information in a short time, the task of automatic summarization has received wide attention. It is known that in a set of related texts there are pieces of redundant, contradictory and complementary information that represent the multi-document phenomenon. In each source text, the main subject is described in a sequence of subtopics. Furthermore, some sentences in the same text are more relevant than others. Considering this context, it is expected that a multi-document summary consists of relevant information that represents a set of texts. However, strategies for automatic multidocument summarization adopted until now have used only the relationships between texts and dismissed the analysis of textual structure of each source text, resulting in summaries that are less representative of subtopics and less informative than they could be. In order to properly treat the relevance of information, multi-document phenomena and distribution of subtopics, in this thesis, we investigated how to model the summarization process using the semantic-discursive knowledge and its impact for producing more informative and representative summaries from source texts. In order to formalize the semantic-discursive knowledge, we adopted RST (Rhetorical Structure Theory) and CST (Cross-document Structure Theory) theories. To support the work, a multi-document corpus was annotated with RST and subtopics, consisting of a new resource available for other researchers. From the corpus analysis, 10 methods for subtopic segmentation and 13 orignal methods for automatic summarization were proposed. The assessment of methods for subtopic segmentation showed that there is a strong relationship between the subtopics structure and the rhetorical analysis of a text. In regards to the assessment of the methods for automatic summarization, the results indicate that the use of semantic-discursive knowledge in good strategies for content selection affects positively the production of informative summaries.
\end{abstract}




\section{ÍNDICE}

1 INTRODUÇÃO

2 CONCEITOS BÁSICOS DE SUMARIZAÇÃO AUTOMÁTICA.......................................................22

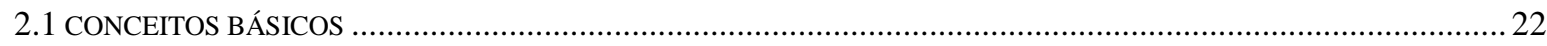

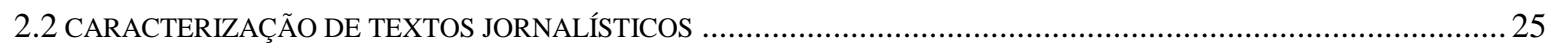

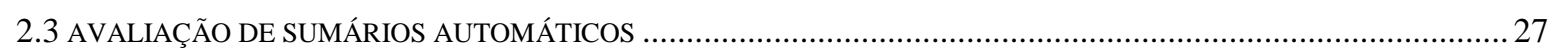

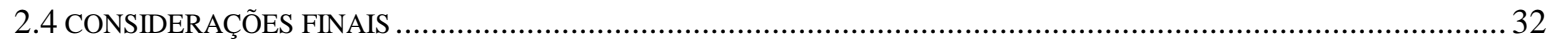

3 DISCURSO: RELAÇÕES RETÓRICAS E SEMÂNTICAS ...........................................................................33

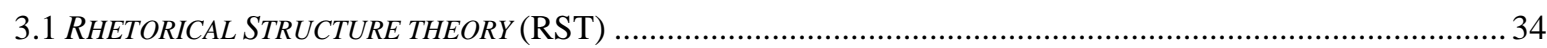

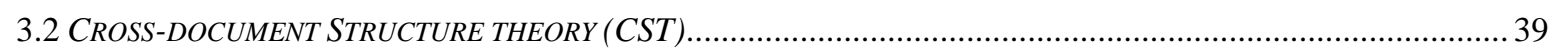

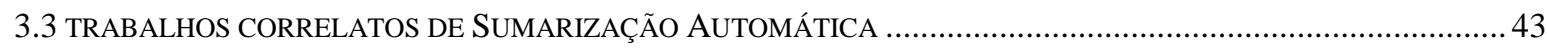

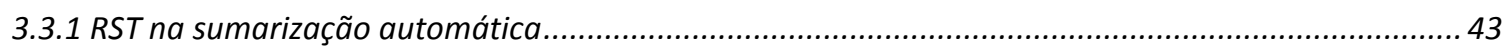

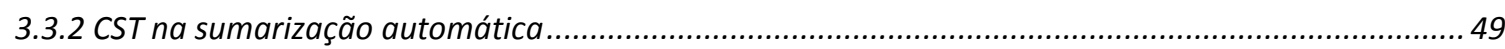

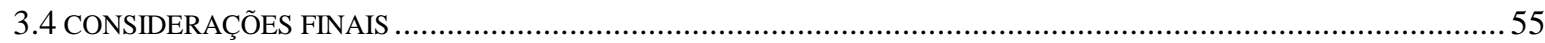

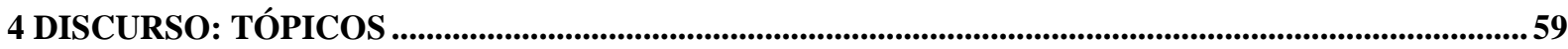

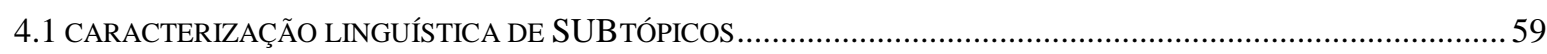

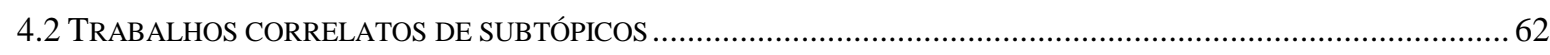

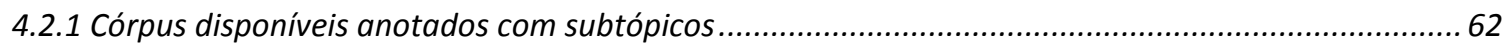

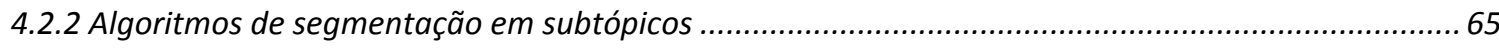

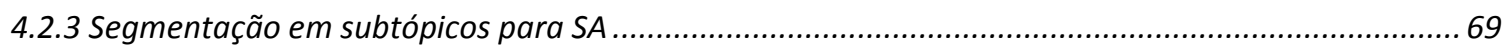

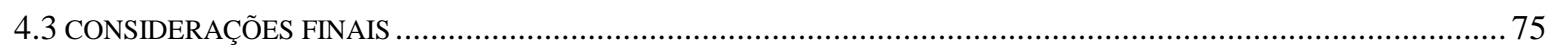

5 SELEÇÃO, ANOTAÇÃO E ANÁLISE DE CÓRPUS.........................................................................77

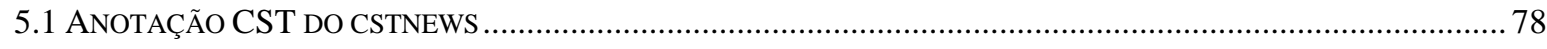

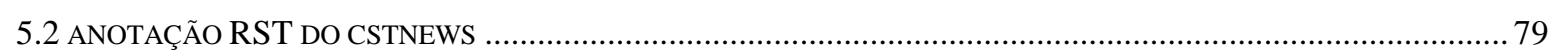

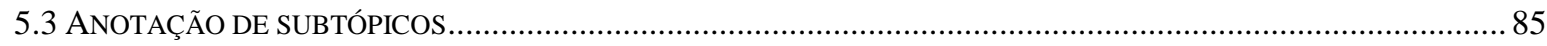

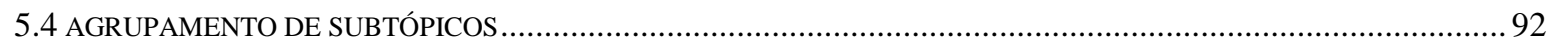

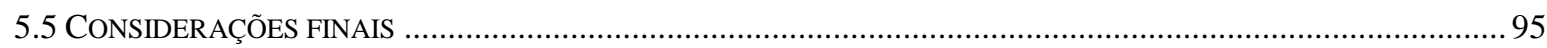


6 DESENVOLVIMENTO DE MÉTODOS DE SEgMENTAÇÃO E AGRUPAMENTO DE

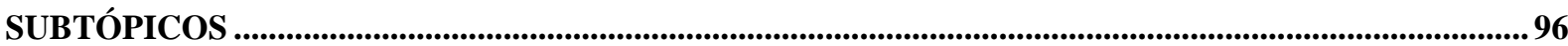

6.1 MÉTODOS DE SEGMENTAÇ̃̃O AUTOMÁTICA EM SUBTÓPICOS ...................................................................96

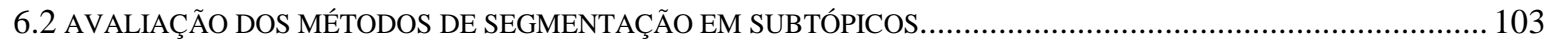

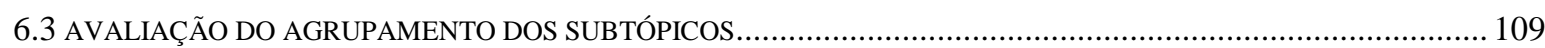

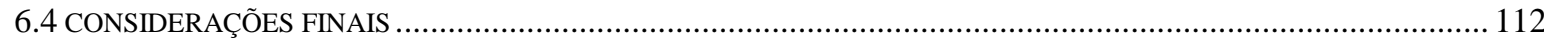

7 EXPLORAÇÃO DE MÉTODOS DE SUMARIZAÇÃO AUTOMÁTICA COM BASE EM CONHECIMENTO SEMÂNTICO-DISCURSIVO .........................................................................................113

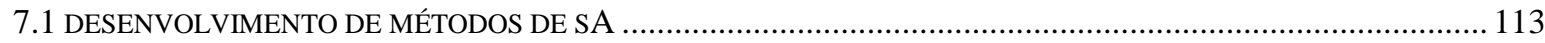

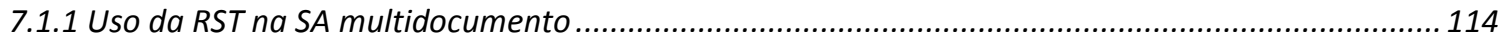

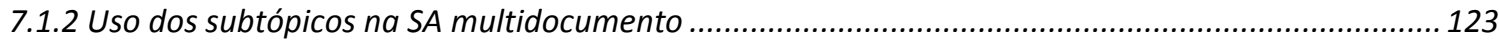

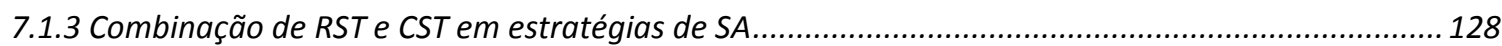

7.1.4 Combinação de RST, CST e subtópicos em estratégias de SA..................................................... 137

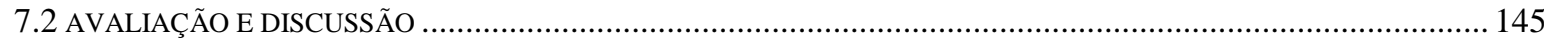

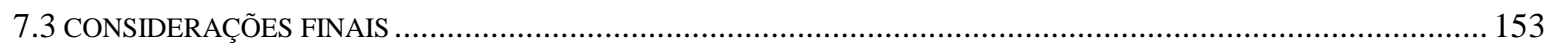

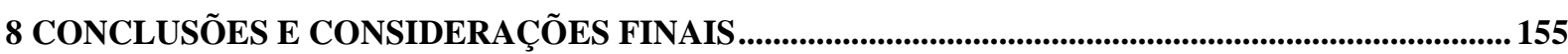

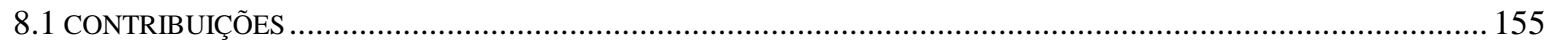

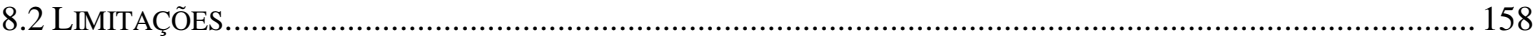

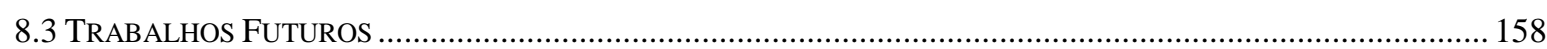

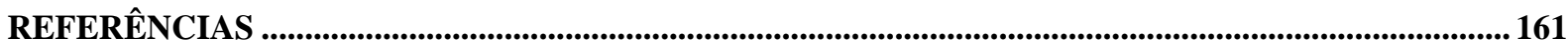

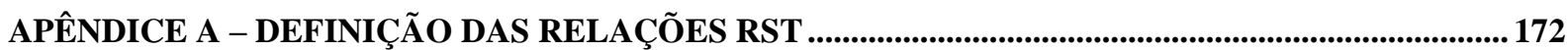

APÊNDICE B - DEFINIÇÃO DAS RELAÇÕES CST ........................................................................178 


\section{LISTA DE FIGURAS}

Figura 1.1: Exemplo de sumário multidocumento 'Fabiana Murer' ....................................... 15

Figura 1.2: Exemplo de texto com segmentação topical .................................................... 16

Figura 1.3: Exemplo de sumário multidocumento baseado em frequência de palavras............ 17

Figura 1.4: Exemplo de sumário multidocumento baseado nos relacionamentos entre sentenças

Figura 1.5: Exemplo de sumário multidocumento ............................................................... 18

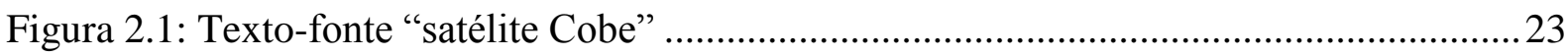

Figura 2.2: Exemplo de extrato para o texto-fonte "satélite Cobe" ........................................ 23

Figura 2.3: Exemplo de abstract para o texto-fonte "satélite Cobe" .......................................23

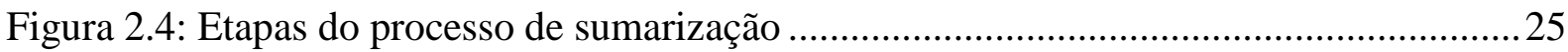

Figura 2.5: Estrutura do texto jornalístico (pirâmide invertida) ...............................................26

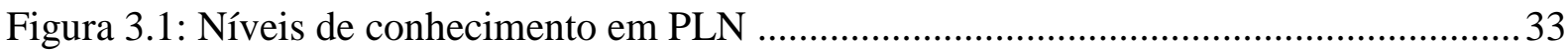

Figura 3.2: Definição da relação CONDITION (Mann e Thompson, 1987) ........................... 36

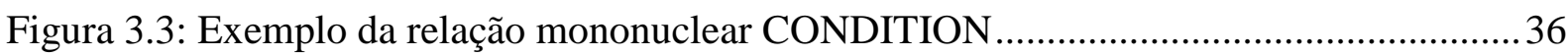

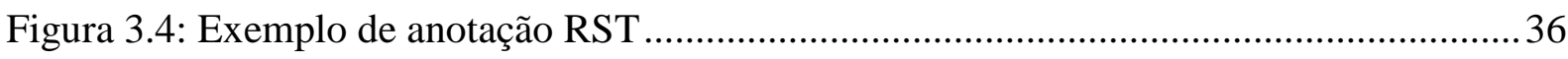

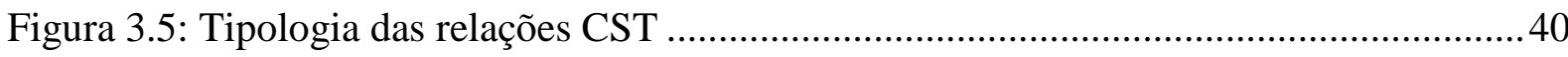

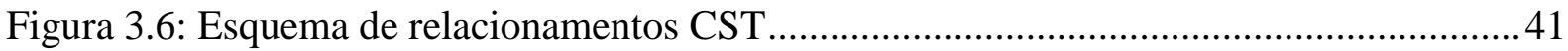

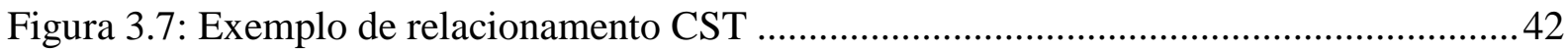

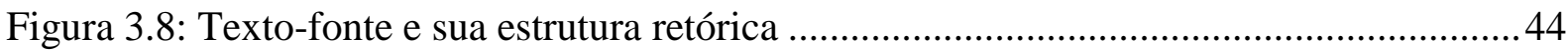

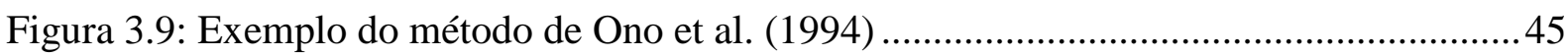

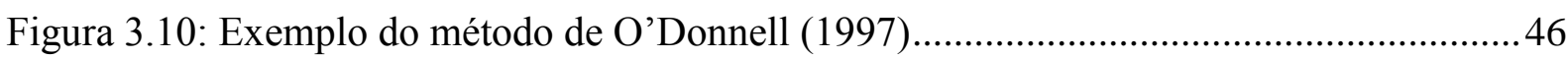

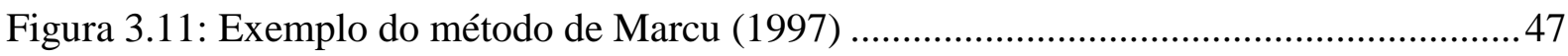

Figura 3.12: Exemplo do método de Marcu modificado (1998a) .......................................... 47

Figura 3.13: Exemplo do método de Uzêda et al. (2010) ....................................................... 48

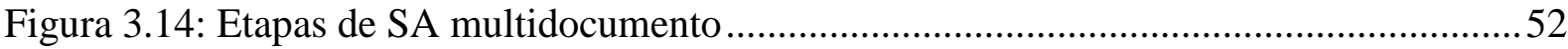

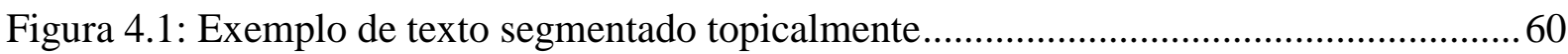

Figura 4.2: Exemplo da estratégia comparação de blocos adjacentes .......................................66

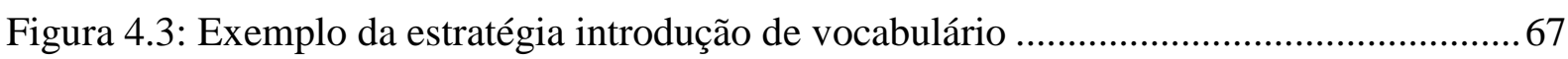

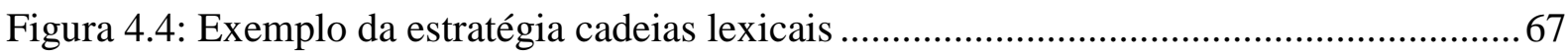

Figura 4.5: Exemplo de cálculo da similaridade entre palavras-chave ...................................69 


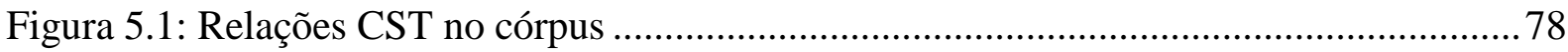

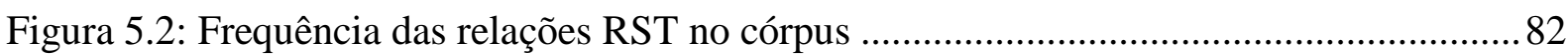

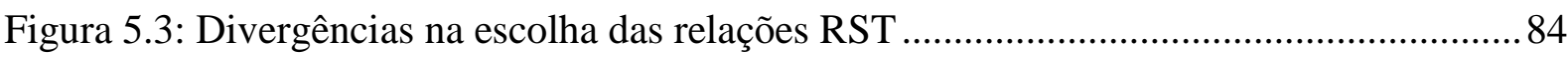

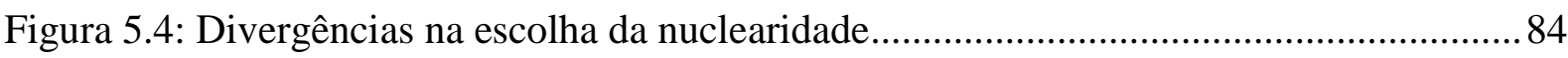

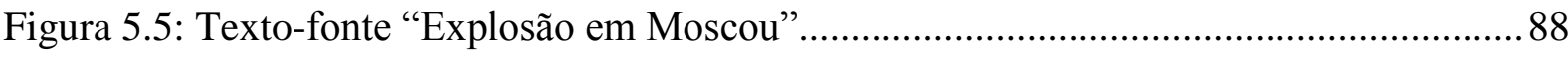

Figura 5.6: Segmentação topical do texto "Explosão em Moscou” ........................................... 88

Figura 5.7: Texto com duas segmentações de referência ......................................................... 89

Figura 5.8: Texto com concordância total na segmentação de subtópicos..............................90

Figura 5.9: Número de subtópicos por texto-fonte ............................................................ 92

Figura 5.10: Exemplo de agrupamento manual de subtópicos.............................................93

Figura 5.11: Número de subtópicos por texto-fonte após agrupamento..................................95

Figura 6.1: Texto "Parlamentares" com a segmentação de subtópicos de referência ...............98

Figura 6.2: Estrutura RST com segmentação de subtópicos pelo método Cosseno Simples ...98

Figura 6.3: Estrutura RST do texto "Parlamentares" com segmentação em subtópicos pelo

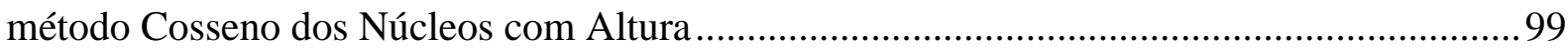

Figura 6.4: Frequência das relações RST entre sentenças no córpus CSTNews..................... 100

Figura 6.5: Frequência das relações RST nas mudanças de subtópicos encontradas no córpus CSTNews. 100

Figura 6.6: Estrutura RST do texto "Parlamentares" com segmentação em subtópicos pelo

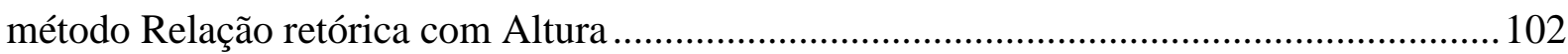

Figura 6.7: Exemplo de segmentações para cálculo de WD ................................................ 105

Figura 6.8: Resumo da avaliação dos algoritmos de segmentação em subtópicos (parte 1).. 108 Figura 6.9: Resumo da avaliação dos algoritmos de segmentação em subtópicos (parte 2).. 109 Figura 6.10: Algoritmo Single-pass adaptado para subtópicos ............................................ 110

Figura 7.1: Organização dos métodos de SA ……............................................................. 114

Figura 7.2: Métodos de SA multidocumento com RST ........................................................ 115

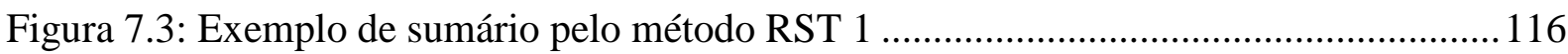

Figura 7.4: Exemplo de sumário ruim pelo método RST 1 ….............................................. 117

Figura 7.5: Exemplos de árvores discursivas com alturas diferentes ....................................118

Figura 7.6: Exemplo de sumário pelo método RST 2 ....................................................... 120

Figura 7.7: Exemplo de sumário com o método RST 3 ..................................................... 121

Figura 7.8: Métodos de SA multidocumento baseados em subtópicos ................................. 123

Figura 7.9: Representação do método Subtópico Denso .................................................... 125 
Figura 7.10: Exemplo de sumário pelo método Subtópico Denso ........................................126

Figura 7.11: Exemplo de sumário pelo método Maior Subtópico........................................... 128

Figura 7.12: Métodos de SA multidocumento baseados em RST e CST .............................. 129

Figura 7.13: Representação de relacionamentos para o método RC-1 ................................. 131

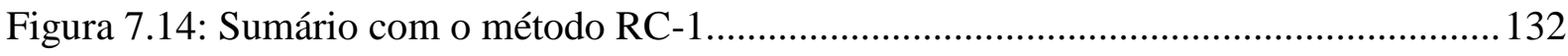

Figura 7.15: Exemplo de eliminação de satélites e mudança da relação CST ........................ 133

Figura 7.16: Proposta de pesos para relações CST .............................................................. 134

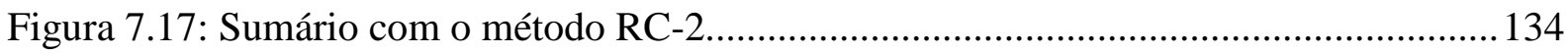

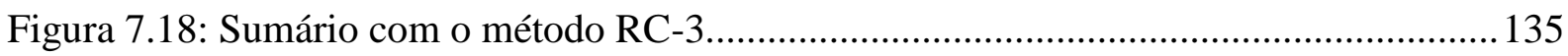

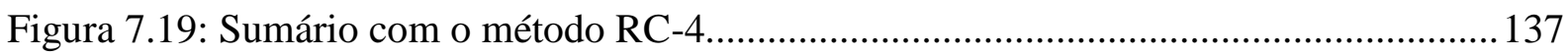

Figura 7.20: Etapas de sumarização dos métodos que combinam RST, CST e subtópicos ... 138

Figura 7.21: Métodos baseados em RST, CST e subtópicos para SA multidocumento.......... 139

Figura 7.22: Sumário (a) pelo Método RCT-1 ...................................................................... 141

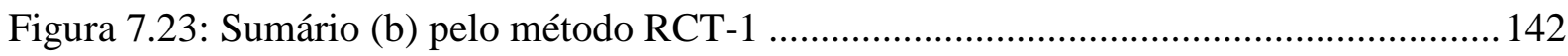

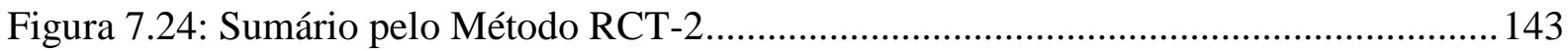

Figura 7.25: Exemplo de sumário pelo método RCT-3..................................................... 144

Figura 7.26: Exemplo de sumário pelo método RCT-4....................................................... 144 


\section{LISTA DE QUADROS}

Quadro 2.1: Resumo das diferentes métricas de avaliação de sumários ................................. 30

Quadro 3.1: Conjunto de relações RST (Pardo e Nunes, 2008) .............................................. 35

Quadro 3.2: Exemplo de um template do sistema SUMMONS .............................................50

Quadro 3.3: Exemplo da especificação de mensagens ...........................................................51

Quadro 3.4: Exemplo de instanciação e relacionamento entre mensagens .............................51

Quadro 3.5: Operador de exibição de informações contraditórias ..........................................54

Quadro 3.6: Resumo das propostas de SA monodocumento com RST ..................................56

Quadro 3.7: Resumo das propostas de SA multidocumento com CST ..................................57

Quadro 5.1: Regras de segmentação adaptadas para o córpus CSTNews............................... 80

Quadro 5.2: Descrições dos subtópicos para o texto "Explosão em Moscou"..........................89

Quadro 5.3: Descrições para os subtópicos do texto "Brasil leva ouro no revezamento" .......91

Quadro 6.1: Classificação das relações RST para segmentação em subtópicos ..................... 101

Quadro 7.1: Método de sumarização automática RST 1 .................................................... 115

Quadro 7.2: Método de sumarização automática RST 2 ..................................................... 119

Quadro 7.3: Método de sumarização automática Subtópico Denso ....................................... 124

Quadro 7.4: Método de sumarização automática Maior Subtópico ...................................... 127

Quadro 7.5: Método de sumarização automática RC-1 ....................................................... 129

Quadro 7.6: Tratamento para os relacionamentos de redundância total................................. 130

Quadro 7.7: Método de sumarização automática RC-4 .......................................................... 136

Quadro 7.8: Método de sumarização multidocumento RCT-1 ........................................... 139

Quadro 7.9: Ranque interno de um subtópico ...................................................................... 140 


\section{LISTA DE TABELAS}

Tabela 5.1: Kappa e porcentagem de concordância (em \%) da anotação CST 79

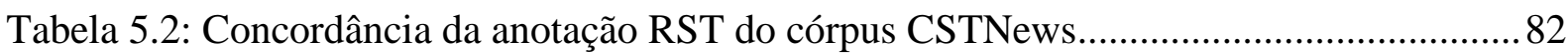

Tabela 5.3: Concordância da anotação RST de Marcu (2000b) ................................................ 83

Tabela 5.4: Concordância da anotação RST de da Cunha et al., (2011) .................................. 83

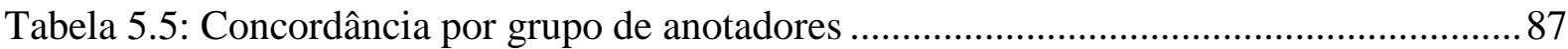

Tabela 5.6: Total de subtópicos por coleção de texto-fonte ....................................................95

Tabela 6.1: Avaliação de algoritmos de segmentação subtopical ........................................106

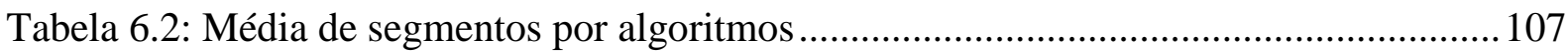

Tabela 6.3: Avaliação do agrupamento automático da segmentação de subtópicos de

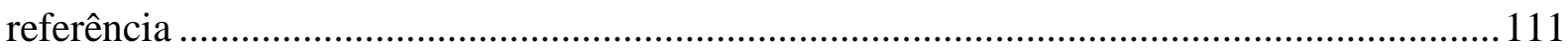

Tabela 6.4: Média de subtópicos por coleção ....................................................................... 111

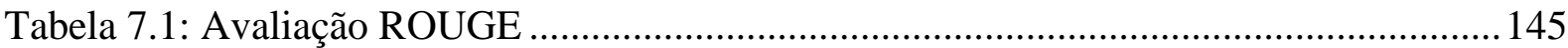

Tabela 7.2: Segmentação RST x TextTiling na SA.............................................................. 150

Tabela 7.3: Porcentagem de proposições nos sumários em relação aos textos-fonte..............151

Tabela 7.4: Porcentagem de núcleos nos sumários em relação aos núcleos dos textos-fonte 152 Tabela 7.5: Proporção de núcleos e satélites no sumários 


\section{LISTA DE SIGLAS}

CST: Cross-document Structure Theory

D: métrica Desvio da segmentação

DUC: Document Understanding Conference

EDU: Elementary Discourse Units

GSDT: Grosz and Sidner Discourse Theory

IDC: International Data Corporation

NILC: Núcleo Interinstitucional de Linguística Computacional

PLN: Processamento de Linguagem Natural

SA: sumarização automática

SCU: Summarization Content Units (método da pirâmide)

RC: grupo de métodos de sumarização que usam RST e CST

RCT: grupo de métodos de sumarização que usam RST, CST e subtópicos

ROUGE: Recall-Oriented Understudy for Gisting Evaluation

RSD: relações sincrônicas e diacrônicas

RST: Rhetorical Structure Theory

TAC: Text Analysis Conference

TF-ISF: Term frequency - inverse sentence frequency

TF-IDF: Term frequency - inverse document frequency

TR: Taxa de retenção

WD: métrica WindowDiff

Wol: Word Overlap 


\section{INTRODUÇÃO}

A sumarização automática (SA) multidocumento visa à seleção das informações mais importantes de um conjunto de textos relacionados para produzir um sumário, que será utilizado por um usuário particular e/ou em uma determinada tarefa (Mani, 2001). No cenário atual, em que a quantidade de informação cresce de forma exponencial juntamente com os desafios que as pessoas têm para localizarem a informação de seu interesse, os sumários automáticos ganham importância em diversas tarefas. Para a recuperação de informação, por exemplo, os sumários podem determinar se algum dos textos recuperados é relevante (evitando que o usuário faça a leitura daqueles que não são) ou pode ser lido no lugar de vários textos. Os sistemas de perguntas e respostas, que buscam responder perguntas por meio de uma consulta a uma coleção de textos, podem fornecer um sumário com foco no interesse do usuário. Os sumários também podem beneficiar pessoas que precisam ler biografias ou coleções de documentos.

Para reforçar ainda mais a necessidade de aplicações de SA multidocumento, um estudo realizado pela empresa de consultoria International Data Corporation (IDC, 2012) mostrou que o volume dos conteúdos digitais crescerá para 8 ZB (zettabytes) em 2015, impulsionado pelo crescimento constante de utilizadores da internet, das redes sociais e dos dispositivos inteligentes, que permitem novas formas de trabalho e de comunicação. Já para 2020, há previsão de que o mundo terá produzido 40 ZB de informações (Taufer, 2013). Diante dessa realidade, a SA multidocumento aparece como uma ferramenta que pode auxiliar pessoas que buscam adquirir informação em um curto espaço de tempo. Os sistemas de sumarização podem ser aplicados a notícias, e-mails, documentos médicos, artigos científicos, documentos legais, dados multimídia ou diálogos de reuniões.

Embora a SA tenha iniciado atrair a atenção da comunidade científica por volta de 1950 (Luhn, 1950), alguns esforços ainda são necessários devido à quantidade de desafios, que podem ser observados em várias frentes. Por exemplo, na Figura 1.1 há um exemplo de sumário multidocumento que descreve a vitória da atleta Fabiana Murer no salto com vara. O sumário contém três sentenças, identificadas por S1 a S3. Observa-se que entre as sentenças S1 e S2 há informações redundantes (destacadas em negrito): ambas relatam a vitória da atleta. As sentenças S1 e S2 também apresentam outros detalhes da competição, por exemplo, em S1, destaca-se que é o primeiro ouro do Brasil na modalidade e, em S2, destaca-se que a 
altura do salto é o novo recorde pan-americano. A sentença S3 apresenta detalhes sobre outros atletas que participaram da mesma competição.

[S1] A brasileira Fabiana Murer conquistou o primeiro ouro do atletismo para o Brasil, nesta segundafeira, na prova de salto com vara.

[S2] Depois da queda de April Steiner, a brasileira Fabiana Murer leva a medalha de ouro no salto com vara, com $4 \mathrm{~m} 50$ - novo recorde pan-americano.

[S3] A medalha de prata ficou com a americana April Steiner, com a marca de $4 \mathrm{~m} 40$ e o bronze foi para a cubana Yarisley Silva, com $4 \mathrm{~m} 30$.

Figura 1.1: Exemplo de sumário multidocumento 'Fabiana Murer'

Maziero et al. (2010) mostraram que existem fenômenos sistemáticos entre textos relacionados: os chamados fenômenos multidocumento. No sumário da Figura 1.1, observamse dois desses fenômenos: redundância e complementaridade. A redundância indica importância: as informações mais repetidas e elaboradas entre as fontes são ditas as mais importantes (Mani, 2001). A complementaridade representa informações mais detalhadas sobre um fato, anteriomente descrito por outras fontes. Além desses fenômenos, pode haver contradição, isto é, quando duas fontes relatam informações conflitantes sobre o mesmo evento. Nesse caso, as informações podem representar fatos que ainda não são claros ou que uma das fontes contém uma informação mais atualizada. Diante disso, a SA tem como desafio lidar com o tratamento de informações redundantes, complementares e contraditórias, provenientes de diferentes fontes e produzidas com estilos de escrita diversos.

Além dos fenômenos multidocumento, acredita-se que a estrutura dos textos fornecem pistas para encontrar conteúdo relevante. Salton et al. (1997) investigaram a estrutura dos textos usando um mapa de relacionamentos. No mapa, os nós podem representar textos, parágrafos ou sentenças, e as conexões entre dois nós indicam que há similaridade. Com o mapa de relacionamentos de um ou mais textos, é possível distinguir áreas (conjuntos de nós) mais conectadas do que outras. Segundo Salton et al., nós bem conectados a outros nós provavelmente discutem um mesmo assunto ou subtópico, portanto, são semanticamente relacionados. Por outro lado, se um nó é pouco conectado a outros nós, é possível que eles discutam assuntos diferentes. Tipicamente, um conjunto de nós bem conectado pode conter material introdutório e outro conjunto de nós pode descrever os resultados. Dessa forma, dizse que um ou mais textos têm um tópico principal, que é o assunto sobre o qual se escreve ou discute, geralmente organizado em uma sequência de discussões divididas em subtópicos (Salton et al., 1997; Hearst, 1997; Biryukov et al., 2005; Hennig, 2009; Hovy, 2009). Para a 
SA, conhecer os subtópicos dos textos ajuda na produção de sumários que cobrem diferentes aspectos de um tópico principal (Wan, 2008).

Para exemplificar a questão relacionada aos subtópicos, considere a Figura 1.2, na qual se apresentam dois textos segmentados em subtópicos. O tópico principal de ambos é a saúde do ex-jogador argentino Maradona. Os subtópicos são identificados por um rótulo dentro dos símbolos "<" e ">”. Subtópicos com o mesmo rótulo em textos diferentes tratam de um mesmo aspecto do tópico principal.

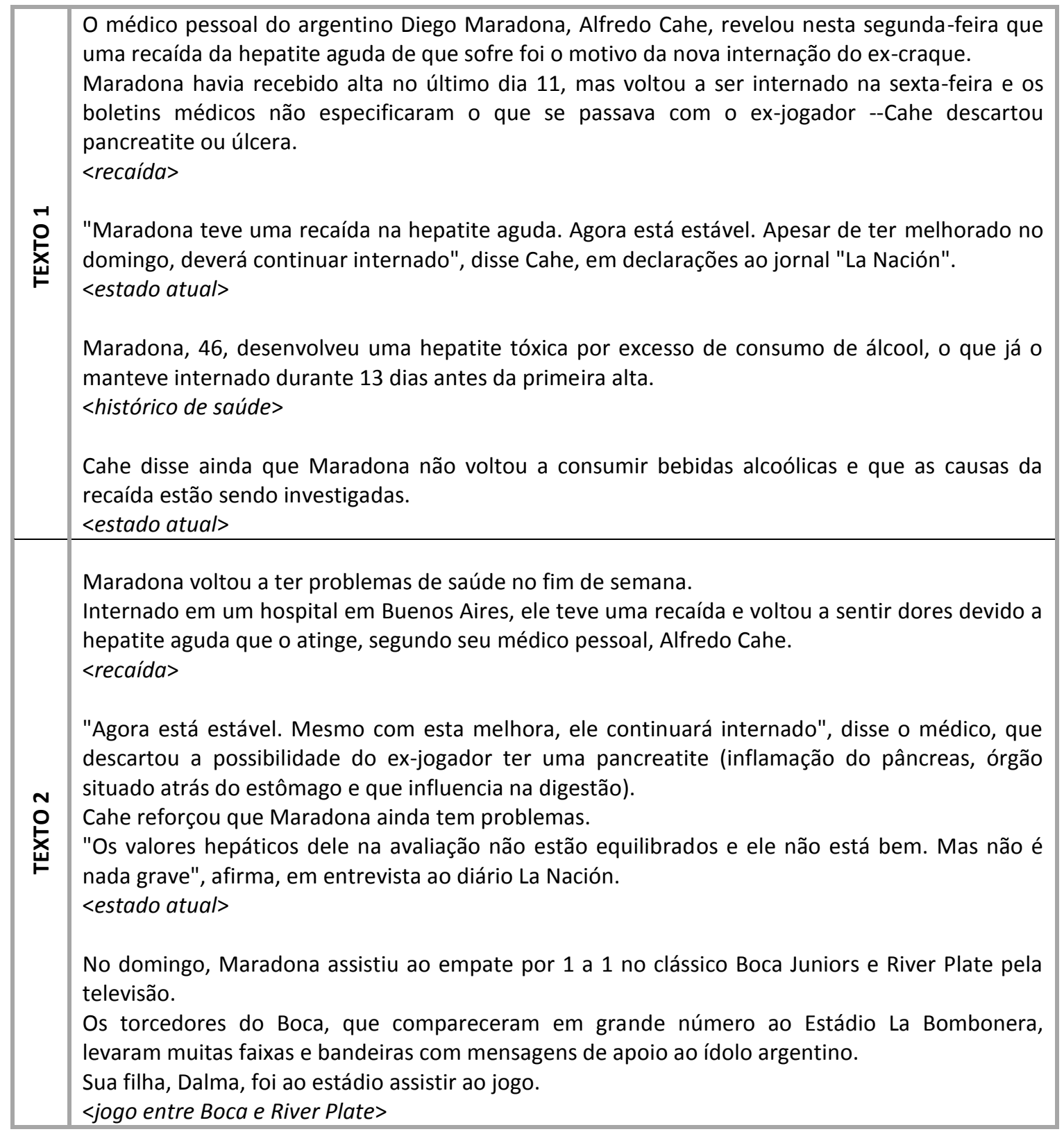

Figura 1.2: Exemplo de texto com segmentação topical 
Percebe-se que os textos contêm detalhes sobre uma "recaída da doença de Maradona”, “o estado de saúde atual do jogador", "histórico de saúde" e "uma partida de futebol entre os times Boca Juniors e River Plate". No total, os dois textos apresentam quatro subtópicos diferentes.

Na Figura 1.3, apresenta-se um sumário multidocumento para os textos da Figura 1.2, produzido com base na frequência de palavras, isto é, as sentenças importantes são aquelas que possuem as palavras mais frequentes dos textos (Luhn, 1958). No sumário, foi dada ênfase apenas ao subtópico "estado atual”, que é a informação mais repetida entre as fontes. Os outros subtópicos "recaída", "histórico de saúde" e "jogo entre Boca e River Plate” foram deixados de fora. Outro detalhe é que o sumário contém informações repetidas: Maradona está estável e continuará internado.

[S1] "Maradona teve uma recaída na hepatite aguda. Agora está estável. Apesar de ter melhorado no domingo, deverá continuar internado", disse Cahe, em declarações ao jornal "La Nación".

[S2] "Agora está estável. Mesmo com esta melhora, ele continuará internado", disse o médico, que descartou a possibilidade do ex-jogador ter uma pancreatite (inflamação do pâncreas, órgão situado atrás do estômago e que influencia na digestão).

Figura 1.3: Exemplo de sumário multidocumento baseado em frequência de palavras

Na Figura 1.4, mostra-se outro sumário multidocumento para o mesmo conjunto de textos da Figura 1.2, produzido com base nos relacionamentos semânticos entre as fontes. $\mathrm{O}$ sumário contém informações referentes aos subtópicos "recaída" e "estado atual” de Maradona. Mais uma vez, os outros subtópicos ficaram de fora do sumário. O sumário ainda contém informações repetidas: Maradona teve uma recaída devido uma hepatite aguda.

[S1] Maradona teve uma recaída na hepatite aguda. Agora está estável. Apesar de ter melhorado no domingo, deverá continuar internado, disse Cahe, em declarações ao jornal "La Nación".

[S2] Internado em um hospital em Buenos Aires, ele teve uma recaída e voltou a sentir dores devido a hepatite aguda que o atinge, segundo seu médico pessoal, Alfredo Cahe.

[S3] Cahe disse ainda que Maradona não voltou a consumir bebidas alcoólicas e que as causas da recaída estão sendo investigadas.

Figura 1.4: Exemplo de sumário multidocumento baseado nos relacionamentos entre sentenças

O fato dos sumários das Figuras 1.3 e 1.4 não contemplarem todos os subtópicos é devido aos sistemas de SA não terem conhecimento dos subtópicos. Dessa forma, além de tratar os fenômenos multidocumento já descritos, outro desafio para os sistemas de SA é reconhecer e tratar adequadamente textos que contêm passagens como variações de subtópicos relacionados ao tópico principal. 
Outra questão relacionada com SA é que um ou mais textos possuem diversas sentenças com graus de relevância diferentes. Baxendale (1958) mostrou que a posição de uma sentença poderia indicar a sua importância. Por exemplo, a primeira e a última sentença de um parágrafo podem conter sua informação principal. No caso de textos jornalísticos, as informações localizadas no início do texto expressam o fato principal de uma notícia (Canavillas, 2007; Saggion and Poibeau, 2013), por isso, devem ser selecionadas para compor um sumário. Em resumo, as sentenças de um texto e/ou de uma coleção têm importâncias diferentes e, por isso, não devem ser tratadas de maneira uniforme (Wan, 2008; Wan e Yang, 2008).

Considere o sumário multidocumento da Figura 1.5, produzido com os mesmos textosfonte da Figura 1.2. O sumário traz informações sobre a recaída de Maradona (S1), seu estado atual (S2) e que sua filha assistiu um jogo (S3). A última sentença parece irrelevante para estar no sumário, pois seu conteúdo não está muito relacionado com o problema de saúde de Maradona, descrito nas sentenças S1 e S2.

[S1] Internado em um hospital em Buenos Aires, ele teve uma recaída e voltou a sentir dores devido a hepatite aguda que o atinge, segundo seu médico pessoal, Alfredo Cahe.

[S2] Cahe disse ainda que Maradona não voltou a consumir bebidas alcoólicas e que as causas da recaída estão sendo investigadas.

[S3] Sua filha, Dalma, foi ao estádio assistir ao jogo.

Figura 1.5: Exemplo de sumário multidocumento

Sumários como os da Figura 1.5 são assim produzidos devido à relevância das informações não ter sido modelada adequadamente, causando a seleção de conteúdo pouco informativo. Sabe-se que um texto possui uma estrutura subjacente altamente elaborada, que relaciona todo o seu conteúdo, atribuindo-lhe coerência. A essa estrutura dá-se o nome de estrutura discursiva e por meio dela, é possível identificar as informações relevantes de um texto (Ono et al. 1994; O’Donnell, 1997; Marcu, 1997; Rino, 1996; Pardo e Rino, 2002; Seno e Rino, 2005) e selecioná-las para o sumário.

Outras questões desafiadoras para a comunidade cientfica de SA são:

a) corrigir problemas relacionados a correferências, que geralmente são muito frequentes quando se trata de sumários multidocumento. Considere os dois trechos de textos:

(1) Mário ganhou mais uma corrida de kart.

(2) O piloto foi o maior campeão de todos os tempos. 
Se somente a segunda sentença for selecionada para o sumário, o leitor não compreenderá de qual piloto se fala.

b) fornecer contexto suficiente para que o leitor possa compreender o sumário;

c) manter a coesão e a coerência do sumário. A coerência é o que faz com que o texto tenha sentido para os leitores e a coesão auxilia no estabelecimento da coerência por meio da conexão entre os elementos que constituem a superfície textual (Koch e Travaglia, 1996). A coerência é afetada por vários fatores, como a presença de informações redundantes e/ou contraditórias, falta de sequência entre as informações. A coesão, por sua vez, é influenciada por fatores como uso apropriado de itens lexicais, anáforas e sinais de pontuação;

d) organizar as sentenças do sumário, pois a ordem da narração dos fatos/eventos influencia diretamente a coerência e coesão (Barzilay et al., 2001; Zhang et al., 2002; Lima e Pardo, 2012). Além disso, na SA multidocumento, os textos-fonte podem se apresentar em tempos verbais diferentes.

e) tratar informações contraditórias, pois é comum haver descrições sobre um mesmo evento com diferentes perspectivas ou que apresentem conflitos entre si (Zhang et al., 2002).

Considerando os sumários apresentados, pode-se dizer que o processo de SA ainda não é modelado de forma adequada que garanta o tratamento dos fenômenos multidocumento, a representatividade dos subtópicos e a relevância das informações. De acordo com Mani e Maybury (1999), um sumário informativo abrange os aspectos principais dos textos-fonte e dispensa a leitura dos textos de origem. Se, além da informação esperada ou previsível, o sumário tiver informação não previsível, ele terá maior grau de informatividade (Koch e Travaglia, 1996).

Nesse cenário de SA multidocumento, esta tese de doutorado investiga como explorar a relevância das informações e a representatividade dos subtópicos em conjunto com os fenômenos multidocumento, para guiar estratégias de seleção de conteúdo. Para isso, adotamse as teorias semântico-discursivas Rhetorical Structure Theory (RST - Mann e Thompson, 1987) e Cross-document Structure Theory (CST - Radev, 2000). A RST é uma teoria linguística descritiva que classifica os segmentos discursivos em núcleo (a informação principal) ou satélite (informação adicional), relacionando-os por meio de relações retóricas. A RST tornou-se importante para a SA monodocumento devido à nuclearidade dos segmentos textuais indicar informações relevantes em um texto para compor um sumário. Isso favoreceu 
o desenvolvimento de diversas estratégias de sumarização (Ono et al. 1994; O’Donnell, 1997; Marcu, 1997; Rino, 1996; Pardo e Rino, 2002; Seno e Rino, 2005; Uzêda et al., 2010). A CST é uma teoria semântico-discursiva composta por um conjunto de relações que detectam as similaridades, diferenças, informações complementares e diversidade de estilos de escrita entre textos relacionados. O conhecimento dessas informações permite estudar e tratar melhor os desafios da sumarização multidocumento (Zhang et al., 2002; Otterbacher et al., 2002; Jorge e Pardo, 2010 e 2011). Essas teorias são independentes de domínio e de gênero textual, e as mais utilizadas em SA.

A tese de pesquisa é que o uso de conhecimento semântico-discursivo tem impacto positivo na tarefa de SA. As hipóteses subjacentes são: 1) de que é possível extrair a estrutura de subtópicos de um texto a partir da estrutura discursiva; 2) a RST indica quais unidades textuais de cada texto são relevantes para o sumário final; 3) a CST consegue tratar todos os fenômenos multidocumento; e 4) é possível combinar diferentes modelos semânticodiscursivos em estratégias de SA que tragam mais informatividade aos sumários.

O método de trabalho desta investigação foi exploratório, baseado em córpus anotado com subtópicos, RST e CST. O córpus multidocumento utilizado foi o CSTNews $^{1}$ (Aleixo e Pardo, 2008b; Cardoso et al., 2011a) (será abordado com mais detalhes no Capítulo 5). Tratase de um córpus de referência composto de textos jornalísticos em português do Brasil, bastante utilizado para subsidiar pesquisas de SA. Durante o desenvolvimento deste trabalho, o córpus foi anotado com RST e subtópicos, constituindo-se um recurso a mais para o desenvolvimento de outras pesquisas relacionadas. A partir do estudo dessas anotações, foram desenvolvidos 10 métodos automáticos de segmentação em subtópicos, baseados em características superficiais e profundas de estruturação de textos. Os métodos de segmentação profundos apoiam-se em RST e apresentam melhor desempenho nessa tarefa, indicando que há uma forte correlação entre a estrutura de subtópicos e a análise retórica de um texto.

Além de métodos de segmentação em subtópicos, foram elaborados 13 inovadores métodos de SA que combinam subtópicos, RST e CST para selecionar conteúdo relevante. Dessa forma, neste trabalho mostra-se como modelar o processo de SA usando diferentes conhecimentos semântico-discursivos, que resultam em sumários mais informativos e confirmam a principal hipótese de pesquisa. Antes de selecionar conteúdo, os subtópicos semelhantes são agrupados por meio de uma técnica desenvolvida por Ribaldo et al. (2013).

\footnotetext{
${ }^{1}$ http://www.icmc.usp.br/pessoas/taspardo/sucinto/cstnews.html
} 
Ainda que haja intervenção da RST na indicação de unidades de conteúdo relevante, o tratamento de redundância é subsidiado pela CST.

Este trabalho faz parte de um projeto maior de sumarização multidocumento, intitulado "Projeto SUCINTO2", que investiga e explora técnicas de sumarização multidocumento para proporcionar um acesso mais viável e inteligente à informação on-line fornecida por agências de notícias. O projeto também examina tarefas relacionadas, com a análise do discurso, ordenação temporal, resolução de correferência e processamento multilíngue. O projeto é desenvolvido no Núcleo Interinstitucional de Linguística Computacional (NILC) ${ }^{3}$, que é um dos maiores grupos de pesquisa em Processamento de Língua Natural (PLN) no Brasil e é pioneiro nas pesquisas em análise discursiva automática e SA para o português.

Esta tese organiza-se em mais 8 capítulos, além desta introdução. No Capítulo 2, descrevem-se os conceitos básicos de SA, caracterização de textos jornalísticos e métricas de avaliação de sumários. No Capítulo 3, apresentam-se as teorias semântico-discursivas RST e CST e sua aplicação na SA. No Capítulo 4, apresenta-se a caracterização de tópico e subtópicos, bem como córpus existente, algoritmos de segmentação e a maneira como os subtópicos foram empregados na área de SA. No Capítulo 5, descreve-se a construção do córpus de trabalho e suas características. No Capítulo 6, apresentam-se os métodos de segmentação em subtópicos desenvolvidos e suas avaliações. No Capítulo 7, descreve-se a modelagem do processo de SA multidocumento com conhecimento semântico-discursivo, as lições aprendidas e os resultados mais promissores. Por fim, no Capítulo 8, apresentam-se as conclusões do trabalho, principais contribuições e possibilidades de trabalhos futuros.

\footnotetext{
${ }^{2}$ http://www.icmc.usp.br/ taspardo/sucinto

${ }^{3}$ http://www.nilc.icmc.usp.br/nilc
} 


\section{CONCEITOS BÁSICOS DE SUMARIZAÇÃO AUTOMÁTICA}

Na Seção 2.1, apresentam conceitos básicos relacionados à SA, tais como, tipos de sumários, conhecimento empregado na SA, taxa de compressão e fases de um sistema de SA. Na Seção 2.2, apresenta-se uma caracterização de textos jornalísticos, visto que esse é o gênero no qual esta investigação foi instanciada. Na Seção 2.3, descrevem-se formas extrínseca e intrínseca de avalição de sumários, incluindo métricas automáticas e manuais. Dá-se ênfase a avaliação intrínseca, pois foi utilizada neste trabalho.

\subsection{CONCEITOS BÁSICOS}

Dependendo do número de textos a serem sumarizados, a SA pode ser monodocumento, quando se processa um texto-fonte, ou multidocumento, quando se processa vários textosfonte.

Quanto ao tipo, um sumário pode ser extrato ou abstract. Um extrato é um sumário formado pela junção de passagens inalteradas do texto-fonte, preservando a ordem original. No abstract, podem ocorrer algumas adaptações e reescritas no texto, mas de forma que não modifiquem a informação principal. A Figura 2.1 contém um texto-fonte do córpus Summ-it (Collovini et al., 2007) e nas Figuras 2.2 e 2.3 apresentam-se exemplos de extrato e abstract, respectivamente, para esse texto. O texto-fonte descreve "descobertas científicas realizadas com auxílio do satélite Cobe e com a participação do cientista George Smooth”. No extrato, a sentença selecionada para sua formação foi a sentença S2 do texto-fonte. O abstract, construído manualmente, apresenta reescrita do texto-fonte, de forma que é possível recuperar quem foi o cientista e detalhes sobre as flutuações, o mesmo não acontece com o extrato, no qual não é possível recuperar de quem se fala. 
[S1]George Smoot é figurinha carimbada no estudo da radiação cósmica de fundo. [S2]Foi o principal cientista ligado ao satélite Cobe (Cosmic Background Explorer), que em 1992 revelou flutuações de "temperatura" na radiação_na verdade um eco do Big Bang, explosão que teria dado origem ao Universo.

[S3]Ela foi descoberta em 1965, depois de ter sido prevista pelo modelo do Big Bang criado pelo russo-americano George Gamow. [S4]Mas ninguém conseguira detectar flutuações até o Cobe.

[S5]A partir das flutuações, é possível estimar a quantidade de matéria e energia existente no Universo e a idade do cosmos, entre outras descobertas importantes.

[S6]Os resultados do Cobe foram relevantes, mas o estado da arte são as imagens do satélite WMAP (Wilkinson Microwave Anisotropy Probe), cujos primeiros dados saíram em 2003.

Figura 2.1: Texto-fonte "satélite Cobe"

Fonte: Collovini et al., 2007

Foi o principal cientista ligado ao satélite Cobe (Cosmic Background Explorer), que em 1992 revelou flutuações de "temperatura" na radiação_na verdade um eco do Big Bang, explosão que teria dado origem ao Universo.

Figura 2.2: Exemplo de extrato para o texto-fonte "satélite Cobe"

Fonte: Collovini et al., 2007

George Smoot foi o principal cientista ligado ao satélite Cobe (Cosmic Background Explorer), que em 1992 revelou flutuações de "temperatura" na radiação _na verdade um eco do Big Bang. A partir dessas flutuações, é possível estimar a quantidade de matéria e energia existente no Universo e a idade do cosmos.

Figura 2.3: Exemplo de abstract para o texto-fonte "satélite Cobe"

Fonte: Collovini et al., 2007

Quanto à função, os sumários são classificados em indicativos, informativos ou avaliativos/críticos (Mani e Maybury, 1999). Sumários indicativos não substituem os textosfonte, pois só fornecem os tópicos essenciais sobre a fonte, tais como, índices de livros. Os sumários informativos geralmente abrangem todos os aspectos principais da fonte, e o leitor pode dispensar o texto de origem, e, ainda, apreender as informações principais. Os sumários avaliativos, por sua vez, avaliam ou comentam o conteúdo de sua fonte. Resenhas de livros são exemplos de sumários avaliativos.

Em relação à audiência, os sumários podem ser genéricos ou centrados nos interesses do usuário (Mani e Maybury, 1999). Quando genérico, o sumário apresenta as informações mais importantes, com vista a uma ampla quantidade de leitores. Os sumários centrados nos interesses do usuário, por sua vez, podem servir a leitores leigos ou especialistas, variando de acordo com as informações apresentadas. 
Quanto à quantidade de línguas, a SA pode ser monolíngue ou multilíngue. A SA monolíngue processa textos-fonte em uma língua e produz um sumário nessa mesma língua. Na SA multilíngue, os textos-fonte podem estar em duas ou mais línguas e o sumário poderá ser em qualquer uma das línguas dos textos de origem. Apesar de a maioria dos sumarizadores automáticos ser monolíngue, os sumários multilíngues vêm ganhando importância, devido principalmente ao crescimento de informação na web. Um leitor que queira saber o que os principais jornais internacionais relataram sobre a Copa do Mundo de 2014 terá que recorrer a um sistema de SA multilíngue. Os sistemas SUMMARIST (Lin e Hovy, 2000), MEAD (Radev et al., 2001) e o Columbia Newsblaster ${ }^{4}$ (Mckeown et al., 2003) são exemplos de sistemas multilíngues. Tosta et al. (2013) também apresentam alguns métodos para SA multilíngue, porém ainda não implementados.

Além de encontrar a informação relevante, o sumarizador automático deve decidir quanto dessa informação será incluída no sumário. Essa quantidade é estabelecida em função da taxa de compressão, que é a razão entre o tamanho do sumário e o tamanho do texto fonte (Mani, 2001). No caso da SA multidocumento, geralmente adota-se o tamanho do maior texto. Um sumário com taxa de compressão de $70 \%$ apresenta tamanho equivalente a $30 \%$ do tamanho do texto-fonte, geralmente medido em número de palavras.

Para estudar a SA, existem duas abordagens, uma chamada de abordagem superficial e outra de abordagem profunda. A abordagem superficial utiliza dados estatísticos ou empíricos e pouco conhecimento linguístico para encontrar a informação principal. Por exemplo, um método que produz um sumário a partir da seleção e justaposição das sentenças que possuem as palavras dos títulos dos textos-fonte é dito superficial. Em geral, os métodos da abordagem superficial são relativamente simples e de baixo custo computacional quando comparados aos métodos da abordagem profunda. A abordagem profunda, por sua vez, caracteriza-se por métodos mais sofisticados, que utilizam modelos linguísticos, regras gramaticais, conhecimento semântico, discursivo e de mundo. Os métodos da abordagem profunda normalmente produzem resultados melhores em relação aos métodos da abordagem superficial (Marcu, 1997; Leite et al., 2007; Uzêda et al., 2010; Jorge e Pardo, 2010 e 2011), porém são mais complexos e a maioria tem custo computacional elevado.

Independentemente da abordagem a ser utilizada, a arquitetura genérica de um sistema de SA divide-se nas etapas de Análise, Transformação e Síntese (Sparck Jones, 1998), como ilustrado na Figura 2.4.

\footnotetext{
${ }^{4}$ http://newsblaster.cs.columbia.edu
} 


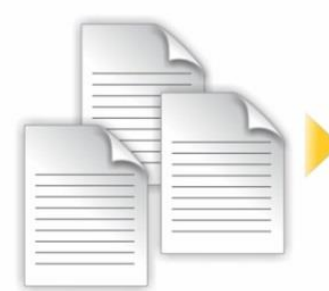

Textos de Entrada
Análise

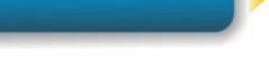

Transformação

\section{Figura 2.4: Etapas do processo de sumarização}

Fonte: Adaptado de Sparck Jones, 1998

A entrada para o processo de sumarização consiste de um ou mais textos-fonte. A Análise visa interpretar um ou mais textos-fonte e extrair uma representação formal do conteúdo textual que possa ser processada automaticamente. Durante a Análise, podem ser utilizados analisadores morfológicos, sintáticos, semânticos e/ou discursivos. A Transformação é a principal etapa da SA e tem o propósito de produzir uma representação interna do sumário a partir da representação fornecida na etapa anterior, usando métodos de seleção de conteúdo relevante. Nessa etapa, também podem ser utilizados métodos de agregação e substituição para compactar o conteúdo dos textos-fonte, produzindo uma mensagem que corresponderá ao sumário, mas não necessariamente textual. A Síntese visa gerar em linguagem natural a representação interna condensada em um sumário propriamente dito. Na Síntese, podem ser utilizados métodos de tratamento de correferência, fusão, linearização, justaposição e ordenação de sentenças. Essas três fases não são necessariamente independentes, de modo que alguns métodos que, ocorrem na Síntese também poderiam estar na fase de Transformação, e vice-versa.

Neste trabalho produziram-se métodos de SA multidocumento que foram aplicados para textos do gênero jornalístico em português do Brasil, cuja caracterização apresenta-se na próxima seção.

\subsection{CARACTERIZAÇÃO DE TEXTOS JORNALÍSTICOS}

Textos jornalísticos são tradicionalmente estruturados no formato de uma pirâmide invertida, conforme a Figura 2.5. Segundo Canavillas (2007), a técnica da pirâmide invertida pode-se resumir em: a redação de uma notícia começa pelos dados mais importantes organizados no lead, seguidas de informações complementares dispostas em blocos decrescentes de interesse. O termo pirâmide invertida refere-se, portanto, ao fato de que a sua base, aquilo que é 
noticiosamente mais importante, se encontra no topo. Além dessas partes, o texto jornalístico tem um título.

O lead compreende o primeiro ou os dois primeiros parágrafos do texto e contém a resposta para as seis perguntas básicas: o quê (o fato ocorrido), quem (o personagem envolvido), onde (o local do fato), quando (o momento do fato), por quê (a causa do fato) e como (o modo como o fato ocorreu). O lead tem forte relação com o título da notícia que por sua vez, é geralmente um resumo do texto. Nos dados secundários, encontram-se detalhes (relevantes ou não) como causas e consequências dos fatos relatados. O jornalista deve organizar no final do texto as informações menos importantes. Devido às informações localizadas no início dos textos expressarem o fato principal de uma notícia, elas são geralmente selecionadas para um sumário.

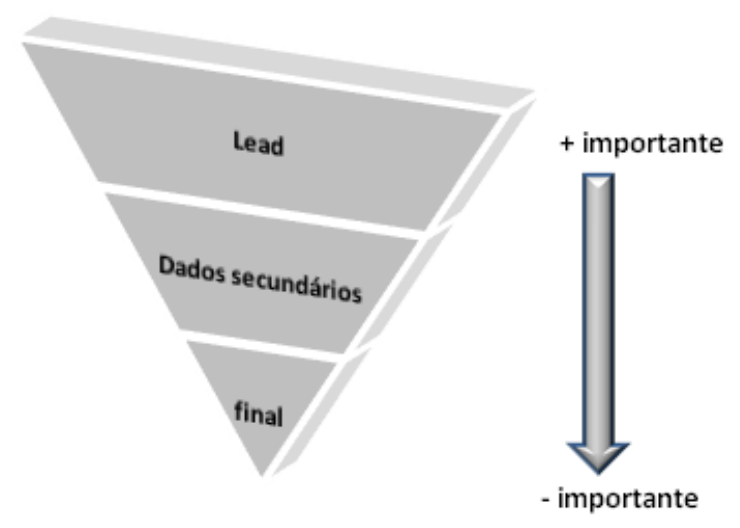

Figura 2.5: Estrutura do texto jornalístico (pirâmide invertida)

Fonte: Canavillas, 2007

Além da estrutura de pirâmide, são características do gênero jornalístico: objetividade, imparcialidade, simplicidade e linguagem direta. A objetividade deve dirigir o texto, o autor não deve colocar impressões ou comentários sobre o que se observa. Essa restrição não se aplica a textos de caráter avaliativo ou opinativo. O texto deve ser imparcial no sentido de não expressar a opinião de quem escreve, mas deixar para que o leitor faça seu próprio julgamento. O texto deve ser simples e ter linguagem direta.

O texto jornalístico está fortemente relacionado com o tipo de sumário que se deseja produzir neste trabalho: sumário informativo e genérico. Em geral, tais textos não possuem marcas explícitas de subtópicos. 


\subsection{AVALIAÇÃO DE SUMÁRIOS AUTOMÁTICOS}

A avaliação de sumários automáticos é dividida em extrínseca e intrínseca (Mani e Mayburi, 1999; Mani, 2001). Na avaliação extrínseca, avalia-se quanto um sistema de sumarização afeta a conclusão de alguma outra tarefa. Na avaliação intrínseca, verifica-se o desempenho do sistema por meio da análise dos seus sumários. Essa última é a mais utilizada nas pesquisas de SA, inclusive neste trabalho, portanto, será bem detalhada.

$\mathrm{Na}$ avaliação intrínseca, mede-se a informatividade e qualidade dos sumários automáticos. A informatividade geralmente é calculada de forma automática e consiste em verificar quanto da informação relevante dos textos-fonte é preservada no sumário automático. A avaliação da qualidade, por sua vez, é realizada por humanos, pois o foco reside na análise de aspectos relacionados à gramaticalidade, coesão e coerência, foco e clareza referencial, para os quais ainda não há uma forma de medir automaticamente.

Para medir a informatividade, a métrica mais conhecida é o pacote de medidas ROUGE (Recall-Oriented Understudy for Gisting Evaluation - Lin, 2004). A ROUGE compara automaticamente a quantidade de n-gramas (conjunto de palavras em sequência) em comum entre um sumário automático e um ou mais de referência. O resultado é dado em termos de precisão (equação 1), cobertura (equação 2) e medida-f (equação 3) e possuem grande correlação com a avaliação humana. A precisão $(\mathrm{P})$ expressa a proporção de n-gramas coincidentes entre os sumários automático e de referência em relação ao número de n-gramas do sumário automático. A cobertura $(\mathrm{C})$ representa a proporção de n-gramas coincidentes entre os sumários automático e de referência em relação ao número de n-gramas do sumário de referência. Tais medidas são complementares e por isso, costuma-se utilizar a medida $f(F)$ que representa a média harmônica entre precisão e cobertura. Como precisão e cobertura são inversamente relacionadas, uma tende a diminuir quando a outra sofre um aumento. Por ser rápida, barata e não sujeita à subjetividade, a ROUGE é uma das medidas mais populares para avaliar sumários. A correlação da ROUGE com o julgamento humano aumenta quando se utilizam vários sumários de referência, mas essa medida não fornece indícios sobre os pontos fortes ou fracos dos sumários (Carenini e Cheung, 2008).

$$
\text { Precisão }=\frac{\text { Número de } n-\text { gramas em comum com o sumário de referência }}{\text { Número de } n \text {-gramas do sumário automático }}
$$




$$
F=\frac{2 * P * C}{P * C}
$$

Outra medida é a taxa de retenção (retention ratio) que calcula a razão entre a quantidade de informação nos sumários e nos textos-fonte (Hovy, 2009). A informação pode ser medida em número de palavras, sentenças, letras, orações, etc. Quanto menor for a taxa de compressão, maior será o valor de retenção.

Apesar de medidas automáticas, como a ROUGE e taxa de retenção, serem rápidas e fornecerem avaliações consistentes, só abordam características superficiais, tais como a correspondência de n-gramas, ignorando qualidade linguística necessária aos sumários.

Para promover o progresso da área de SA, iniciou-se em 2001 a DUC (Document Understanding Conference) (Dang, 2005), que foi responsável por realizar avaliações em larga escala de inúmeros sistemas de SA utilizando um conjunto de dados comum. Em 2008, a DUC passou a se chamar TAC (Text Analysis Conference). Ao longo dos anos, os critérios de avaliação foram mudando e em 2005, a DUC ${ }^{5}$ sugeriu cinco propriedades linguísticas para verificar a qualidade dos sumários. As propriedades linguísticas são:

(i) gramaticalidade: que diz respeito à ausência de erros de ortografia, pontuação e sintaxe;

(ii) não redundância: que se refere à ausência de informações repetidas;

(iii) clareza referencial: que diz respeito à clara identificação dos componentes da superfície textual que fazem remissão a outro(s) elemento(s) do sumário;

(iv) foco: se refere ao fato de que as informações de uma sentença devem se relacionar com as informações do restante do sumário;

(v) estrutura e coerência: que diz respeito à organização do sumário considerando sua textualidade.

Para avaliar os sumários automáticos com os critérios da DUC, coleta-se a opinião de um grupo de juízes sobre um mesmo sumário e calcula-se a média para cada critério julgado. Cada anotador atribui uma nota que varia de 1 (muito ruim) a 5 (muito bom). Apesar de esse tipo de avaliação não usar o sumário de referência, ela pode beneficiar sumários automáticos que sejam bastante diferentes dos sumários de referência. Provavelmente esses sumários

\footnotetext{
${ }^{5}$ http://duc.nist.gov/duc2005/quality-questions.txt
} 
automáticos teriam notas muito baixas pela ROUGE, mas ainda assim, poderiam ser considerados informativos e coerentes.

Outras medidas que verificam qualidade e conteúdo são coverage, responsiveness, método da pirâmide e medida de utilidade relativa. A medida de cobertura coverage ${ }^{6}$ avalia quanto do sumário de referência é expresso no sumário automático. Essa medida não verifica questões de qualidade do texto, mas sim de conteúdo. O sumário de referência é dividido em orações que representam segmentos em avaliação. Para cada segmento, o avaliador especifica a extensão que seu conteúdo é expresso no sumário automático e atribui uma nota que varia de 4 (tudo) a 0 (nenhum). A média com que as unidades informativas do sumário de referência aparecem no sumário automático representa o valor total de coverage. Essa medida foi utilizada nos primeiros anos da DUC. A partir de 2005, a medida coverage foi substituída pelo método da pirâmide.

O método da pirâmide (Nenkova e Passonneau, 2004), por sua vez, necessita de um conjunto de sumários de referência, dos quais se extraem manualmente "unidades de conteúdo do sumário" (SCUs - Summarization Content Units) que são usadas na avaliação dos sumários automáticos. A intuição é que SCUs mencionadas somente em um sumário de referência são menos importantes do que aquelas mencionadas em vários sumários de referência. Cada SCU recebe um peso que é igual ao número de sumários de referência que a contém. A pirâmide é formada após a anotação de SCUs: no topo ficam as unidades que aparecem em mais de um sumário, portanto, são as SCUs com melhores notas; na base ficam as unidades que aparecem em poucos sumários, portanto, possuem notas mais baixas. $\mathrm{O}$ sumário automático ideal deve conter o subconjunto de SCUs das posições mais altas da pirâmide. Apesar de a construção da pirâmide ser muito trabalhosa, essa é uma forma de avaliar que incorpora a variedade do julgamento humano, já observado em diversos trabalhos.

A responsiveness é uma medida de qualidade total que combina seleção de conteúdo e qualidade linguística do sumário, ou seja, o sumário deve apresentar conteúdo importante e de forma organizada, a fim de melhor satisfazer a necessidade do usuário (Louis e Nenkova, 2009). Trata-se de uma avaliação manual, na qual um juiz atribui uma nota que varia de 1 (pobre) a 5 (sumário excelente), sem utilizar sumários de referência. Em 2005, essa medida passou a fazer parte do grupo de medidas utilizado na $\mathrm{DUC}^{7}$.

A medida de utilidade relativa (Relative Utility) (Radev e Tam, 2003), diz que um sumário ideal representa todas as sentenças do conjunto de entrada que possuem boas notas de

\footnotetext{
${ }^{6}$ http://www-nlpir.nist.gov/projects/duc/duc2002/covbrev.html

${ }^{7}$ http://duc.nist.gov/duc2005/responsiveness.assessment.instructions
} 
utilidade para sua inclusão no sumário. Tais notas são atribuídas por juízes para todas as $n$ sentenças de um conjunto de documentos. A medida de utilidade relativa é também uma forma de reduzir a variação da avaliação humana. Por exemplo, um documento com 5 sentenças é representado como $\{1 / 10,2 / 9,3 / 9,4 / 2,5 / 4\}$. O segundo número em cada par indica a utilidade da sentença, ou seja, o grau em que cada sentença deveria aparecer no sumário. A medida utilidade relativa não depende do tamanho esperado do sumário, mas sim do tamanho dos textos de entrada e do julgamento humano. No exemplo, um sistema que selecionar as sentenças $\{1,2\}$ e outro que selecionar as sentenças $\{1,3\}$, ambos produzirão bons sumários.

No Quadro 2.1, apresenta-se um resumo dessas medidas. Observa-se que todas as medidas descritas dependem do trabalho humano, seja na elaboração de sumários de referência ou no julgamento de critérios. Se há julgamento humano, há variabilidade: humanos diferem na escolha de conteúdo e como o expressam no sumário (por exemplo, foco e estilo) (Harman e Over, 2004).

\begin{tabular}{|l|c|c|c|}
\hline \multicolumn{1}{|c|}{ Medida } & Tipo de avaliação & Critério & Usa sumário de referência \\
\hline Coverage & manual & conteúdo & sim \\
\hline Pirâmide & manual & conteúdo & sim \\
\hline Responsiveness & manual & qualidade & não \\
\hline ROUGE & automática & conteúdo & sim \\
\hline Taxa de retenção & automática & conteúdo & não \\
\hline Utilidade relativa & manual & conteúdo & não \\
\hline
\end{tabular}

Quadro 2.1: Resumo das diferentes métricas de avaliação de sumários

No caso da etapa de seleção de conteúdo, estudos mostraram que os humanos divergem quanto às informações extraídas dos textos-fonte, revelando baixa concordância quanto ao conteúdo selecionado (Salton et al., 1997; Radev e Tam, 2003). Salton et al. (1997) evidenciaram isso ao analisarem os sumários extrativos, produzidos por 2 pessoas sobre textos de uma enciclopédia inglesa. Os autores perceberam que a sobreposição de conteúdo entre os sumários foi em média de $46 \%$ ao escolher os parágrafos mais importantes. Isso sugere que dois humanos discordaram sobre mais da metade dos parágrafos selecionados, ou seja, há baixa concordância e esta pode ser influenciada por diversos fatores. É possível que uma mesma pessoa ao sumarizar novamente um texto-fonte, produza um sumário totalmente diferente do anterior. Assim, mesmo que se tenha um conjunto de sumários de referência, torna-se difícil dizer qual é o sumário ideal, devido a falta de padrão na seleção de conteúdo por humanos. Para Luhn (1958), a produção de sumários é uma tarefa intelectual e que sofre influência da familiaridade com o assunto, atitude e disposição do produtor. Luhn também 
sugere que a produção de sumários de referência pode depender dos interesses do autor, dos interesses dos leitores e da importância subjetiva que o autor atribui às informações textuais.

Se as pessoas discordam na escolha de informações importantes dos textos-fonte, eles também divergem entre si ao avaliar sumários (Harman e Over, 2004). Uma forma de reduzir a subjetividade na etapa de avaliação é ter disponíveis vários sumários de referência por diferentes produtores para um mesmo sumário automático. Mas nem sempre isso é possível, pois são necessários vários autores, que precisam ler os textos-fonte e criar os sumários, tornando o processo demorado. Em geral, as avaliações contam com um único sumário de referência. Nesses casos, métodos como o da pirâmide, que visa evitar bias na avaliação baseando-se na opinião de vários produtores de sumários, tornam-se inviáveis. Mas ainda assim, quando se tem diversos sumários modelos, pode-se alternar entre os mesmos na comparação com o sumário automático, levando a diferentes resultados (Salton et al., 1997; Harman e Over, 2004).

$\mathrm{Na}$ tentativa de reduzir a influência humana, vários pesquisadores propuseram diferentes estratégias de avaliar sumários automáticos. Louis e Nenkova (2013) formalizaram esses estudos e sugeriram três formas de avaliar: 1) comparar o conteúdo dos sumários com seus textos-fonte; 2) acrescentar bons sumários automáticos ao conjunto de sumários de referência; e 3) utilizar somente sumários automáticos no conjunto de referência.

$\mathrm{Na}$ primeira forma de avaliação, busca-se medir a similaridade entre textos-fonte e sumários. Assume-se que bons sumários tendem ter similaridade alta com seus textos-fonte. Nesse caso, não é necessário ter sumários de referência. Os resultados mostraram que esse tipo de avaliação produz ranques muito similares a aqueles produzidos por humanos e pela medida ROUGE.

A segunda forma de avaliar é uma sugestão para quando se tem a disposição um único sumário de referência. Louis e Nenkova sugerem ampliar o conjunto inicial de referência adicionando bons sumários automáticos, chamados pseudomodelos. Para determinar os pseudomodelos, organiza-se um ranque dos melhores sistemas de SA, cujos resultados foram satisfatórios na comparação com algum sumário de referência e selecionam-se os melhores sumários. A avaliação final é realizada com base na comparação desse conjunto de referência expandido, contendo sumários manuais e pseudomodelos, com novos sumários automáticos. Essa forma de avaliar também mostrou correlação com a medida ROUGE.

Sabendo que expandir o conjunto de referência com sumários automáticos pode ser utilizado na avaliação, Louis e Nenkova sugerem que considerar somente sumários 
automáticos como modelos traz os mesmos benefícios. Nessa situação, a informação comum aos sumários automáticos de diferentes sistemas representa o conteúdo importante e funciona como referência. Pode-se dizer que isso é similar ao método da pirâmide: informações importantes são aquelas mencionadas na maioria dos sumários automáticos. Logo, na terceira forma de avaliação, utiliza-se a informação consensual entre bons sistemas de SA, calculamse as probabilidades das palavras do conjunto (distribuição global) e compara-as com a distribuição do conteúdo de um sumário automático. Bons sumários automáticos terão propriedades similares à distribuição global. A avaliação deste método também se mostrou similar aos resultados quando se utiliza sumários produzidos por humanos.

Nenhuma das métricas formalizadas em Louis e Nenkova (2013) verifica a qualidade linguística. Assim, os critérios de qualidade linguística da DUC ainda são utilizados na maioria dos trabalhos de SA que aplicam avaliação de qualidade. Dentre as medidas de informatividade (conteúdo), a ROUGE ainda é a mais utilizada.

\subsection{CONSIDERAÇÕES FINAIS}

Neste Capítulo, introduziram-se os conceitos básicos de SA. O foco deste trabalho é na etapa de Transformação, especificamente a seleção de conteúdo. Dentre os tipos de sumários, o sumário informativo e genérico é particularmente de interesse desta pesquisa. Apresentou-se uma breve caracterização do gênero jornalístico por ser o tipo de texto empregado no desenvolvimento desta pesquisa. Além disso, mostraram-se várias métricas de avaliação, das quais, escolhem-se as medidas ROUGE e taxa de retenção para avaliar os sumários deste trabalho. 


\section{DISCURSO: RELAÇÕES RETÓRICAS E SEMÂNTICAS}

Segundo Allen (1995), em PLN existem diferentes níveis de conhecimento linguístico que interagem entre si, como se mostra na Figura 3.1. A fonética estuda como os seres humanos produzem, transmitem e recebem sons, independentemente da língua. A fonologia investiga o estudo dos sons em uma língua específica. A morfologia se preocupa com a estrutura e formação das palavras. A sintaxe estuda como as palavras podem ser combinadas para formar sentenças e o papel de cada palavra na sentença. A semântica, por sua vez, trata dos significados dos itens lexicais levando em consideração o contexto em que aparecem. $\mathrm{O}$ discurso se ocupa dos objetivos e intenções do autor do texto. A pragmática estuda a intenção do autor ao produzir um texto e seu contexto de uso. Quanto mais se sobe em direção ao nível Pragmático/Discurso, mais complexos se tornam a modelagem e o tratamento computacional. O foco deste trabalho são as relações semânticas e relações discursivas na SA, que ajudam, por exemplo, como estruturar o discurso e compactar seu conteúdo para produção de sumários.

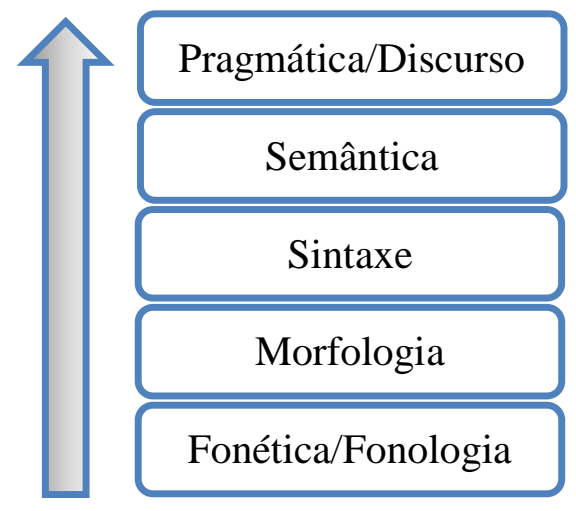

Figura 3.1: Níveis de conhecimento em PLN

No nível do discurso, diversas teorias discursivas propõem modelos que relacionam os segmentos textuais por meio de (a) relações retóricas, como a RST (Mann e Thompson, 1987), (b) de relações intencionais, como a GSDT (Grosz and Sidner Discourse Theory Grosz e Sidner, 1986) e (c) de relações semânticas, como as de Jordan (1992) e CST (Radev, 2000). Algumas dessas e outras teorias discursivas são difíceis de serem tratadas computacionalmente, dada à subjetividade, complexidade e ambiguidade existentes nesse nível. 
Esta proposta de SA multidocumento baseia-se na análise discursiva de textos, especificamente com as teorias RST e CST. A escolha da RST é devido ao seu destaque na SA monodocumento ao indicar os segmentos relevantes de um texto para formar um sumário (Ono et al., 1994; O’Donnell, 1997; Marcu, 1997; Rino, 1996; Pardo e Rino, 2002; Seno e Rino, 2005; Uzêda et al., 2010). A CST, por sua vez, auxilia na identificação e tratamento de informações similares, diferentes, contraditórias, complementares e diversidade de estilos de escrita em textos relacionados, melhorando a qualidade dos sumários multidocumento (por exemplo, Zhang et al., 2002, Jorge e Pardo, 2010 e 2011; Ribaldo, 2013). Nas Seções 3.1 e 3.2, descrevem-se as teorias RST e CST, respectivamente.

\subsection{RHETORICAL STRUCTURE THEORY (RST)}

A RST foi proposta por Mann e Thompson (1987) como uma teoria descritiva dos principais aspectos da organização de um texto. A ideia principal é a de que um texto coerente é formado por unidades mínimas de discurso (Elementary Discourse Units - EDUs) que desempenham uma função para que o objetivo do texto seja atingido. Cada EDU é classificada em núcleo (informação principal) ou satélites (informação adicional). Tais unidades são ligadas umas às outras por meio de relações retóricas (também chamadas de relações de coerência ou discurso), formando uma estrutura discursiva totalmente conectada, representada na forma de árvore. Em casos padrões, as relações se estabelecem entre duas EDUs, expressas por segmentos adjacentes no texto. Quando a relação conecta um núcleo e um satélite, ela é chamada de mononuclear. Por outro lado, se a relação conectar somente núcleos, ela é chamada de multinuclear.

O primeiro passo ao analizar um texto com RST consiste em segmentá-lo em EDUs. Segundo Mann e Thompson (1987), EDUs são proposições (orações), mas existem outras possibilidades de segmentação. Uma das mais conhecidas é de Carlson et al. (2003), para segmentação do RST Discourse Treebank, na qual propõem uma segmentação refinada em complementos, orações relativas e apostos. Para Carlson e Marcu (2001) e Iruskieta et al. (2014), caracterizam as EDUs como orações e devem ter um verbo. 
Mann e Thompson estabeleceram um conjunto de 23 relações retóricas que podem ser aplicadas a uma grande variedade de textos. Nesse conjunto, cada relação é classificada em semântica (subject-matter) ou intencional (presentational). As relações semânticas são aquelas que informam o leitor sobre algo, por exemplo, a relação SEQUENCE, cujo efeito pretendido é que o leitor reconheça que há uma sucessão temporal dos eventos apresentados. As relações intencionais alteram a inclinação do leitor para algo, por exemplo, a relação JUSTIFY, cujo efeito pretendido é que o leitor passe a aceitar melhor o direito do escritor de apresentar o núcleo.

Outros pesquisadores, tais como Marcu (1997) e Pardo e Nunes (2008) modificaram e/ou complementaram a especificação da RST, buscando maior clareza das relações. Marcu (1997) acrescentou diversas relações ao conjunto original, destacando-se as chamadas relações estruturais, que conectam proposições que foram quebradas no fluxo do texto. Um exemplo de relação estrutural é PARENTHETICAL, que indica que o satélite apresenta uma informação extra-relacionada ao núcleo, que não está expressa no fluxo principal do texto, aparecendo geralmente entre parênteses, colchetes ou chaves. Marcu também incluiu relações que conectam segmentos encaixados, que são aqueles introduzidos por orações subordinas relativas. Tais relações são indicadas por "- $e$ " no final de seu nome (embedded, no inglês) e apresentam o mesmo significado das relações tradicionais. Pardo e Nunes (2008) definiram um conjunto formado pelas relações de Mann e Thompson e algumas de Marcu, totalizando 32 relações. No Quadro 3.1, apresenta-se o conjunto de relações de Pardo e Nunes e o tipo de cada relação. As relações multinucleares estão marcadas com um asterisco.

\begin{tabular}{|l|l|l|l|}
\hline \multicolumn{1}{|c|}{ Relação } & \multicolumn{1}{c|}{ Tipo de relação } & \multicolumn{1}{c|}{ Relação } & \multicolumn{1}{c|}{ Tipo de relação } \\
\hline ANTITHESIS & Intencional & MOTIVATION & Intencional \\
\hline ATTRIBUTION & Estrutural & NON-VOLITIONAL CAUSE & Semântica \\
\hline BACKGROUND & Intencional & NON-VOLITIONAL RESULT & Semântica \\
\hline CIRCUMSTANCE & Semântica & OTHERWISE & Semântica \\
\hline COMPARISON & Semântica & PARENTHETICAL & Estrutural \\
\hline CONCESSION & Intencional & PURPOSE & Semântica \\
\hline CONCLUSION & Semântica & RESTATEMENT & Semântica \\
\hline CONDITION & Semântica & SOLUTIONHOOD & Semântica \\
\hline ELABORATION & Semântica & SUMMARY & Semântica \\
\hline ENABLEMENT & Intencional & VOLITIONAL CAUSE & Semântica \\
\hline EVALUATION & Semântica & VOLITIONAL RESULT & Semântica \\
\hline EVIDENCE & Intencional & CONTRAST * & Semântica \\
\hline EXPLANATION & Semântica & JOINT & Semântica \\
\hline INTERPRETATION & Semântica & LIST & Semântica \\
\hline JUSTIFY & Intencional & SAME-UNIT * & Estrutural \\
\hline MEANS & Semântica & SEQUENCE * & Semântica \\
\hline
\end{tabular}

Quadro 3.1: Conjunto de relações RST (Pardo e Nunes, 2008) 
Mann e Thompson (1987) definiram as relações em termos de quatro campos, que devem ser observados pelo analista de um texto durante o processo de construção da estrutura RST. Os campos são restrições sobre o núcleo $(\mathrm{N})$, restrições sobre o satélite $(\mathrm{S})$, restrições sobre a combinação de núcleo e satélite e o efeito que a relação em questão pode causar no leitor. $\mathrm{Na}$ Figura 3.2, apresenta-se a definição da relação CONDITION.

Nome da relação: CONDITION

Restrições sobre N: não há

Restrições sobre S: S apresenta uma situação hipotética, futura ou não realizada

Restrições sobre $\mathrm{N}+\mathrm{S}$ : a realização de $\mathrm{N}$ depende da realização de $\mathrm{S}$

Efeito: o leitor reconhece que a realização de $\mathrm{N}$ depende da realização de $\mathrm{S}$

Figura 3.2: Definição da relação CONDITION (Mann e Thompson, 1987) Fonte: Córpus CSTNews

Para exemplificar relacionamentos RST, considere as Figuras 3.3 e 3.4, as quais ilustram relações mononucleares e multinucleares, respectivamente, extraídas do córpus CSTNews (será detalhado no Capítulo 5). Na Figura 3.3, o texto foi segmentado em duas proposições: a proposição 1 é o satélite $(\mathrm{S})$ e a proposição 2 é o núcleo $(\mathrm{N})$ da relação retórica CONDITION. Na Figura 3.4, o texto foi segmentado em três proposições: a proposição 2 é um segmento encaixado, conectado a proposição 1 pela relação ELABORATION-E, formando uma subárvore chamada de span textual; essa subárvore conecta-se a proposição 3 pela relação LIST.

${ }^{[1]}$ Se a eleição fosse hoje, ${ }^{[2]}$ o presidente Luiz Inácio
Lula da Silva teria $44 \%$ das intenções de voto contra
$25 \%$ do tucano Geraldo Alckmin.

Figura 3.3: Exemplo da relação mononuclear CONDITION

\footnotetext{
${ }^{[1]}$ Nove pessoas morreram, ${ }^{[2]}$ três delas crianças, ${ }^{[3]} \mathrm{e}$ outras 25 ficaram feridas nesta segunda-feira em uma explosão ocorrida em um mercado de Moscou.
}

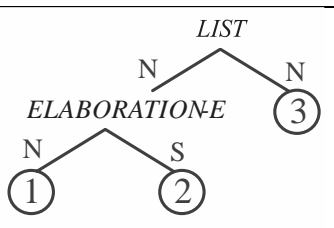

Figura 3.4: Exemplo de anotação RST 
De acordo com os autores da teoria, é previsível que para um mesmo texto haja mais de uma análise RST (Mann e Thompson, 1987). Isso ocorre devido à estrutura discursiva subjacente a um texto depender da interpretação do mesmo pelo leitor, ou seja, a identificação da estrutura discursiva é uma tarefa subjetiva. Além disso, leitores, ao analisarem o mesmo texto, podem discordar em vários aspectos, que vão desde a identificação de proposições à definição das relações e nuclearidade. Para exemplificar essa ambiguidade, considere o trecho de texto a seguir:

[1] Um dos passageiros teve um "surto" ${ }^{[2]}$ e tentou abrir a porta de emergência do avião durante o voo. no qual é possível ter várias análises discursivas. O analista poderia dizer que há uma relação de sequência entre as duas proposições, ou ainda, que há uma relação de causa-efeito. Para amenizar tal situação, o analista deve olhar para o campo efeito da definição das possíveis relações e identificar aquele que está mais saliente para o objetivo do autor (Mann e Thompson, 1987).

Para fazer a análise RST de um texto, várias estratégias podem ser utilizadas. Carlson e Marcu (2001) apontam que uma estratégia bem aceita é fazer uma análise incremental, isto é, relacionar primeiro as proposições de uma sentença, o que resultará em uma subestrutura RST, a qual, por sua vez, será relacionada a outra subestrutura. Podem-se montar subestruturas de cada parágrafo do texto isoladamente e depois integrá-las, formando uma única estrutura RST. Se o analista decide por esse tipo de análise, ele pode tirar proveito da estrutura organizacional dada pelo produtor do texto. Por exemplo, se duas proposições estão diretamente relacionadas por CONDITION, é provável que elas sejam expressas em uma única sentença.

A RST é provavelmente uma das teorias discursivas mais difundidas na Linguística Computacional e tem sido utilizada em várias pesquisas de PLN, como SA, resolução de anáfora, tradução automática, classificação da polaridade de sentenças em blogs de opinião, etc. Na SA, por exemplo, por meio da estrutura discursiva de um texto e da nuclearidade, é possível identificar quais são os segmentos textuais mais relevantes para o sumário final (por exemplo, Sparck Jones, 1993; Ono et al., 1994; Rino, 1996; O’Donnell, 1997; Marcu, 1997; Pardo e Rino, 2002; Seno e Rino, 2005; da Cunha, 2008; Uzêda et al., 2010). Na resolução de anáfora, com base na estruturação RST, a Teoria das Veias (Veins Theory) ${ }^{8}$ delimita o domínio de acessibilidade referencial para cada unidade do discurso na forma de veias,

\footnotetext{
${ }^{8}$ Veins Theory (Teoria das Veias) é um modelo de coerência global do discurso, que delimita o domínio de acessibilidade referencial para cada unidade do discurso na forma de veias, indicando limites nos quais o antecedente de uma anáfora pode ocorrer ao longo do discurso.
} 
indicando os locais em que o referente de uma anáfora pode estar (Cristea et al., 1998). Na tradução automática, a mesma informação pode ser realizada por diferentes estruturas retóricas, dependendo da língua. Nesse caso, a RST ajuda a modelar a estrutura discursiva de um texto na língua fonte para posteriores adaptações à estrutura discursiva do texto na língua destino (Marcu et al., 2000). Ainda na linha de tradução automática, Guzmán et al. (2014) propõem utilizar a estrutura discursiva para complementar a avaliação de traduções automáticas. Na classificação da polaridade de sentenças em blogs de opinião, as relações retóricas podem orientar a interpretação das mensagens e fornecer notas para os sentimentos encontrados (Chenlo et al., 2013).

Para apoiar tais pesquisas, se faz necessária a construção de recursos, como analisadores discursivos e córpus anotados. A anotação da estrutura discursiva de um texto pode ser feita de forma manual ou automática. A anotação manual requer humanos treinados, tornando o processo caro e demorado. Para facilitar a anotação manual está disponível a ferramenta RSTTool $^{9}$ (O’Donnell, 2000). Por meio da ferramenta é possível segmentar um texto em proposições, conectá-los com relações RST e visualizar graficamente a estrutura de árvore, representando a análise final.

A anotação automática, por sua vez, é realizada por analisadores discursivos, que são ferramentas que detectam automaticamente as relações entre os segmentos de um texto e constroem sua estrutura discursiva. Há analisadores discursivos para as línguas inglesa (Marcu, 2000a), espanhola (Maziero et al., 2011) e portuguesa (Pardo e Nunes, 2008). Especificamente falando da língua portuguesa, o parser discursivo DiZer ${ }^{10}$ tem desempenho médio de 56,8\% na segmentação textual, $62,5 \%$ na detecção de relações e $81 \%$ na determinação da nuclearidade. Esse parser utiliza padrões extraídos de um córpus de textos científicos e sua aplicação a outro domínio textual pode ter desempenho inferior.

Além de analisadores discursivos, há córpus anotados com RST para diversas línguas. Por exemplo, para a língua inglesa, existem o Discourse Treebank (Carlson et al., 2003), o Discourse Relations Reference Corpus (Taboada e Renkema, 2008) e o Penn Discourse Treebank (Prasad et al., 2008); para o espanhol, há o RST Spanish Treebank ${ }^{11}$ (da Cunha et al., 2011); para o basco, o RST Basque Treebank ${ }^{12}$ (Iruskieta et al., 2013); para o alemão, o Potsdam Commentary Corpus (Stede, 2004); para o holândes, o Discourse-Annotated Dutch

\footnotetext{
${ }^{9}$ http://www.wagsoft.com/RSTTool/

${ }^{10} \mathrm{http}: / /$ www.nilc.icmc.usp.br/dizer2/

${ }^{11} \mathrm{http}: / / \mathrm{www}$. corpus.unam.mx/rst/

${ }^{12} \mathrm{http} / / /$ ixa2.si.ehu.es/diskurtsoa/en/index.php
} 
corpus (van der Vliet et al., 2011); para a língua portuguesa, há o CorpusTCC (Pardo e Nunes, 2004) ${ }^{13}$, o Rhetalho (Pardo e Seno, 2005) ${ }^{14}$, o Summ-it (Collovini et al., 2007) e o CSTNews (Aleixo e Pardo, 2008b; Cardoso et al., 2011a) ${ }^{15}$. O córpus CSTNews foi utilizado neste trabalho e será detalhado mais adiante.

\subsection{CROSS-DOCUMENT STRUCTURE THEORY (CST)}

Inspirada na RST e em trabalhos relacionados (Trigg, 1983; Radev e McKeown, 1998), foi proposta a CST por Radev (2000) como uma teoria semântico-discursiva que relaciona partes de diversos textos sobre um mesmo assunto ou tópicos relacionados. A ideia principal é que textos relacionados possuem informações redundantes, contraditórias, complementares e diferentes estilos de escrita e organização, e essas informações podem ser identificadas pelas relações CST.

Assim como aconteceu com a RST, pesquisadores aplicaram a CST e modificaram o conjunto original de 24 relações. Zhang et al. (2003) realizaram um experimento com textos da língua inglesa, no qual perceberam que algumas relações eram ambíguas. Como resultado, os autores propuseram um refinamento para 18 relações. Aleixo e Pardo (2008b) aplicaram o conjunto de Zhang et al. (2003) em textos da língua portuguesa, verificaram que algumas relações ainda eram redundantes ou ambíguas e sugeriram um novo refinamento para 14 relações.

A partir do refinamento de Aleixo e Pardo, Maziero et al. (2010) determinaram uma tipologia das relações, que é apresentada na Figura 3.5. Na tipologia, as relações foram divididas em 2 grupos principais: o primeiro grupo abrange as relações cuja finalidade é principalmente relacionar o conteúdo de segmentos e o segundo grupo contêm as relações de apresentação e forma, que capturam os estilos de escrita e organização dos textos. Cada grupo ainda foi dividido em mais categorias. No grupo de conteúdo, as relações são classificadas em redundância, complemento ou contradição, representando os fenômenos multidocumento. $\mathrm{O}$ subgrupo redundância expressa níveis diferentes de sobreposição de conteúdo e por isso, é dividido em redundância total e redundância parcial. O subgrupo complemento relaciona informações que se complementam e se referem a fatos temporais ou não. $\mathrm{O}$ grupo de

\footnotetext{
${ }^{13}$ http://www.icmc.usp.br/ taspardo/CorpusTCC.zip

${ }^{14} \mathrm{http}: / / \mathrm{www} . \mathrm{icmc}$. usp.br/ taspardo/rhetalho.zip

${ }^{15} \mathrm{http}: / /$ www.icmc.usp.br/ taspardo/sucinto/cstnews.html
} 
apresentação e forma é dividido em dois subgrupos: de fonte/autoria e estilo. Algumas relações CST possuem direcionalidade (relações assimétricas) e outras não (simétricas), estas são identificadas por um asterisco ao lado do nome da relação na Figura 3.5. Por exemplo, a relação CONTRADICTION é simétrica, pois não importa a ordem em que as sentenças são lidas: uma sempre contradiz a outra. Já a relação ATTRIBUTION é assimétrica, pois as sentenças compartilham a mesma informação, mas somente uma delas possui a fonte. Os relacionamentos CST são independentes de domínio (Zhang et al., 2002).

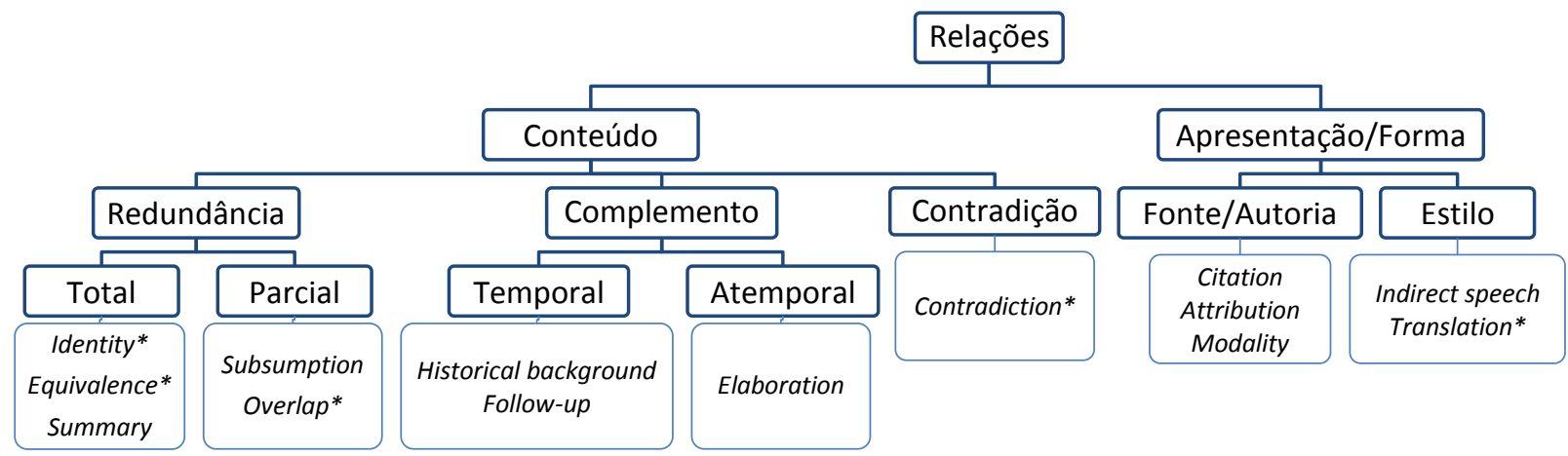

Figura 3.5: Tipologia das relações CST

Fonte: Maziero et al., 2010

Entre um mesmo par de unidades informativas pode acontecer mais de uma relação, desde que as relações façam parte de diferentes categorias. Por exemplo, entre duas unidades informativas não pode ocorrer uma relação de redundância total e parcial ao mesmo tempo. Por outro lado, as relações do grupo de apresentação/forma geralmente acontecem com as relações do grupo de conteúdo.

Radev (2000) apresentou um formalismo na forma de um grafo que mostra que os relacionamentos CST podem ocorrer entre diferentes unidades informativas, tais como, palavras, sintagmas, sentenças, parágrafos e documentos. Na Figura 3.6, mostra-se o grafo de relacionamentos entre textos, representado pelas linhas tracejadas, e os subgrafos menores que reproduzem os relacionamentos dentro de cada texto, representado pelas linhas mais grossas e que podem ser relacionamentos RST, sintaxe, etc. Os documentos similares são representados numa hierarquia de palavras, sintagmas, sentenças e os próprios documentos, ou seja, todos esses níveis são considerados na análise. Em cada nível da hierarquia podem ocorrer relações CST, apesar de sentenças serem usualmente mais utilizadas nos trabalhos da área. O grafo resultante da anotação é provavelmente desconectado, pois nem todos os segmentos dos textos em análise precisam estar relacionados: podem existir segmentos que não se referem diretamente ao mesmo assunto. 


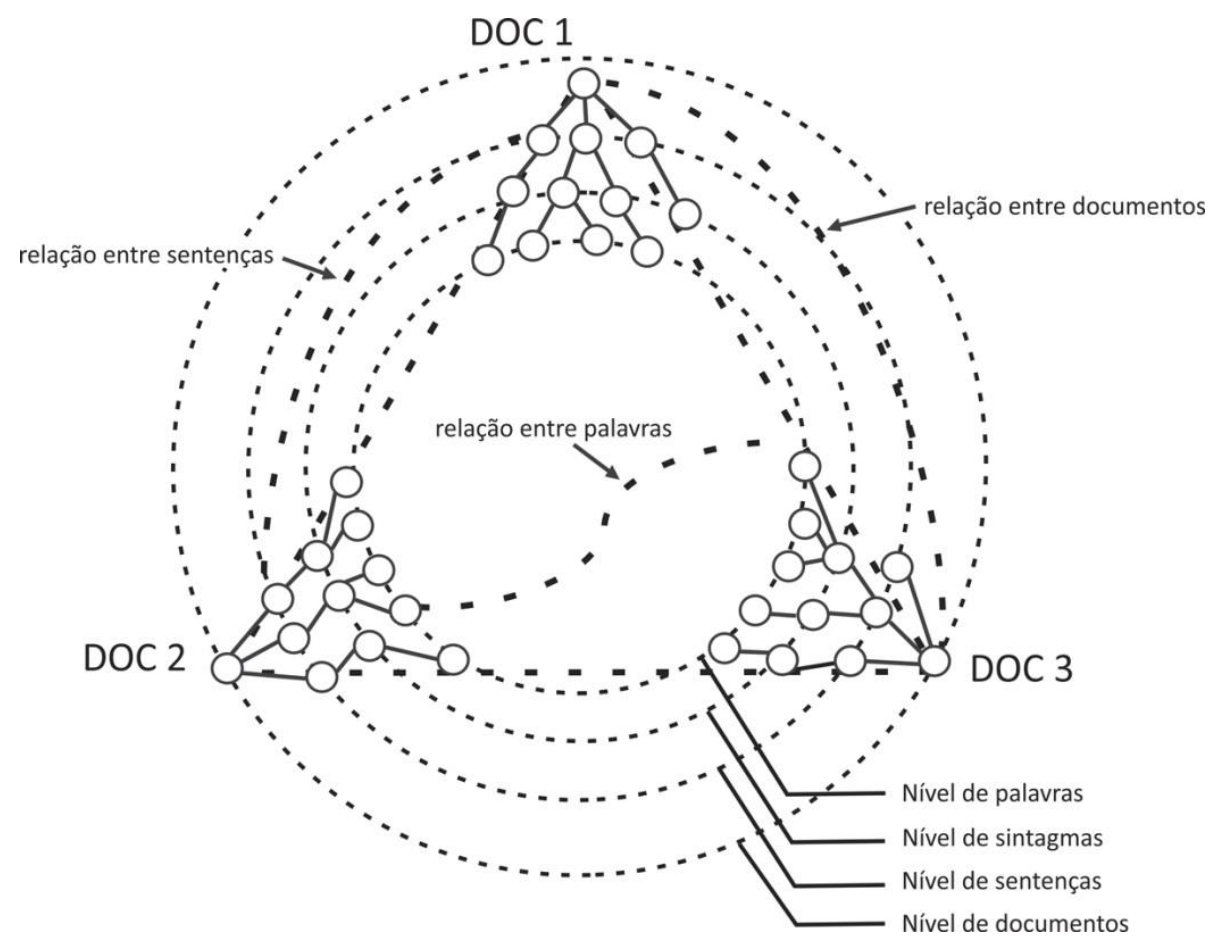

Figura 3.6: Esquema de relacionamentos CST

Fonte: Radev, 2000, p. 5

Zhang et al. (2003) realizaram diversos experimentos e observaram que as relações CST ocorrem principalmente entre segmentos que têm alguma similaridade lexical entre si. Embora isso nem sempre seja verdade, é uma forma de minimizar o número de pares de sentenças a analisar, uma vez que evidências empíricas demonstram que humanos são capazes de dar sentido a sentenças muito diferentes, resultando em uma explosão do número de relações CST. Mesmo para textos curtos, por exemplo, dois textos com 6 sentenças cada, humanos seriam capazes de relacionar cada possível par de sentença, que facilmente chegariam a 36 relações. Considerando que um par de sentenças pode ter mais de uma relação CST, esse cenário se tornaria incontrolável.

Um exemplo de relacionamento CST é dado na Figura 3.7. As sentenças estão relacionadas por SUBSUMPTION e ATTRIBUTION. A relação de SUBSUMPTION ocorre entre trechos parcialmente redundantes e um dos segmentos contém alguma informação adicional em relação ao outro. A relação ATTRIBUTION ocorre entre segmentos que possuem informação em comum e um deles atribui essa informação a uma fonte/autoria. No exemplo da Figura 3.7, em ambos os relacionamentos, a direcionalidade é Texto $2 \rightarrow$ Texto 1, ou seja, o Texto 2 engloba o Texto 1 e o Texto 2 contém a fonte da informação do Texto 1. Como acontece com outras análises, existe ambiguidade na análise CST, portanto, diferentes analisadores poderiam identificar outras relações entre as mesmas unidades informativas. 
Ao menos 17 pessoas morreram após a queda de um avião de passageiros na República Democrática do Congo.
Um acidente aéreo na localidade de Bukavu, no leste da República Democrática do Congo, matou 17 pessoas na quinta-feira à tarde, informou hoje um porta-voz das Nações Unidas.

Figura 3.7: Exemplo de relacionamento CST

Fonte: Córpus CSTNews

A CST já foi empregada em pesquisas de SA multidocumento para textos da língua inglesa (Zhang et al., 2002) e da língua portuguesa (Jorge e Pardo, 2010, Jorge e Pardo, 2011; Jorge e Pardo, 2012; Ribaldo, 2013). Essas pesquisas tiram proveito dos relacionamentos CST indicarem informações relevantes entre as fontes e ainda facilitarem o tratamento dos fenômenos multidocumento. Quanto aos córpus anotados com CST, existem poucos: CSTBank (Radev et al., 2004b) ${ }^{16}$, para língua inglesa e CSTNews (Aleixo e Pardo, 2008a; Cardoso et al., 2011a), para língua portuguesa.

Para auxiliar a criação de córpus anotados com CST, foi desenvolvida a ferramenta CSTTool (Aleixo e Pardo, 2008a). A CSTTool recebe como entrada dois textos-fonte e segmenta-os em sentenças. Em seguida, a ferramenta indica quais pares de sentenças são fortes candidatos a possuirem uma relação CST, usando cálculo de similaridade por meio da medida Word Overlap (equação 4). Por essa medida, divide-se o número de palavras em comum entre duas sentenças pela soma do número de palavras nas duas sentenças. $\mathrm{O}$ resultado será entre 0 e 1 , de forma que quanto mais próximo de 1 for a Wol, mais redundante será o par entre si, e quanto mais próximo de 0 , menos redundante.

$$
\text { Wol }(S 1, S 2)=\frac{\# \text { Palavras em comum }}{\# \text { Palavras }(S 1)+\# \text { Palavras }(S 2)}
$$

O cálculo de similaridade entre sentenças evita que haja uma explosão do campo de busca, evitando o trabalho árduo de se ter que olhar todas as combinações possíveis entre textos. Zhang et al. (2003) exploraram várias medidas de similaridade e concluiram que a medida Word Overlap é eficiente nessa tarefa. Depois que a CSTTool indica os possíveis pares relacionados, cabe ao anotador escolher uma relação CST adequada.

Quanto aos parsers disponíveis, há somente 2, dos quais um é para a língua inglesa (Zhang e Radev, 2005) e outro, o CSTparser ${ }^{17}$ para a língua portuguesa (Maziero e Pardo, 2012; Maziero et al., 2014). Especificamente o CSTparser recebe como entrada documentos relacionados e segmenta-os em sentenças. Após isso, busca os pares de sentenças mais

\footnotetext{
${ }^{16}$ http://clair.si.umich.edu/clair/CSTBank/

${ }^{17}$ http://www.nilc.icmc.usp.br/CSTParser/
} 
prováveis de terem algum relacionamento multidocumento por meio de medidas de similaridade. Os pares selecionados são analizados por diferentes ferramentas (etiquetador morfológico e sintático, reconhecedor de entidade nomeada) assistidas por diferentes recursos (thesaurus, lista de verbos, etc.) a fim de extrair atributos relevantes para cada par de sentenças. A identificação das relações CST ocorre de duas formas: (1) usando classificadores automáticos e (2) aplicando regras criadas manualmente após análise de córpus. Os classificadores buscam as relações de conteúdo e as regras, as relações de forma. O resultado é um grafo multidocumento, cujos nós representam sentenças e as arestas são relações. O parser tem acurácia geral de $68,13 \%$.

\subsection{TRABALHOS CORRELATOS DE SUMARIZAÇÃO AUTOMÁTICA}

Nas Seções 3.3.1 e 3.3.2, descrevem-se alguns trabalhos de SA monodocumento e multidocumento, respectivamente. Dentre os trabalhos de SA monodocumento, destacam-se os que utilizaram a teoria RST para criar estratégias de SA. Dentre os trabalhos de SA multidocumento, são descritas as pesquisas que utilizaram técnicas de abordagem profunda.

\subsubsection{RST na sumarização automática}

A RST oferece vantagens para a SA monodocumento por identificar o núcleo como informação mais saliente quando comparado com o satélite, que, por sua vez, em algumas situações, pode ser omitido sem prejuízo para a interpretação do texto. Essas informações destacam quais proposições devem compor o sumário. Usando esse princípio de nuclearidade, vários métodos de sumarização foram propostos e cada um aplica critérios diferentes para eliminar satélites, tais como os métodos clássicos de Ono et al. (1994), O’Donnell (1997) e Marcu (1997, 1998a). Para exemplificar como esses métodos determinam quais proposições são candidatas ao sumário, será usada a árvore da Figura 3.8. A árvore corresponde à análise humana do texto-fonte que aparece no lado esquerdo da figura. $\mathrm{O}$ texto, que contém quatro sentenças, descreve o desempenho da seleção brasileira em um jogo de vôlei. 
[1] O Brasil arrasou a Finlândia no primeiro confronto entre as seleções, nesta sexta-feira, na cidade de Tampere, pela Liga Mundial de Vôlei 2006.

[2] Amanhã, as equipes voltam a se enfrentar, às $12 \mathrm{~h} 30$ no mesmo local.

[3] Com o resultado, o Brasil continua sendo a única equipe invicta da competição, [4] mantendo a liderança do Grupo B da Liga, com sete vitórias em sete partidas.

[5] O time está perto da classificação para a próxima fase.

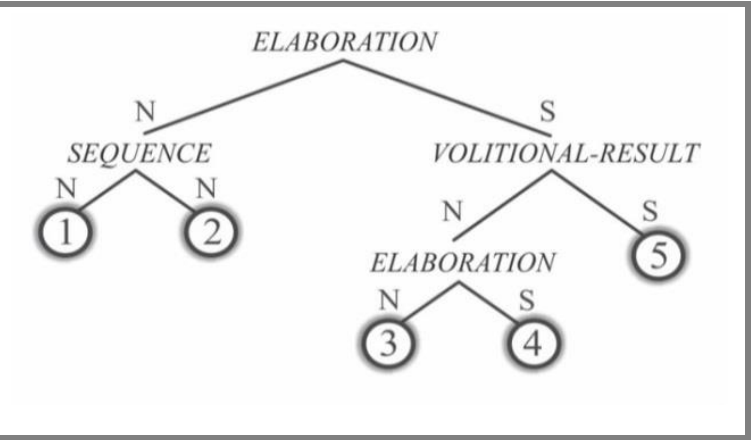

Figura 3.8: Texto-fonte e sua estrutura retórica

Fonte: Córpus CSTNews, C8_D3

Um dos primeiros métodos de SA com base em RST foi de Ono et al. (1994). Nesse método, a pontuação de cada proposição é calculada com base na importância relativa das relações retóricas, as quais são classificadas em três tipos: RightNucleus, LeftNucleus e BothNucleus. Para as relações classificadas em RightNucleus, o nó direito de um ramo da árvore é considerado mais importante que o nó esquerdo, enquanto que, para as relações LeftNucleus, o nó esquerdo de um ramo da árvore é o mais importante em relação ao nó direito. Para as relações BothNucleus, ambos os nós têm a mesma importância.

Com base nessa classificação, o sistema impõe uma penalidade para os nós de uma relação retórica de acordo com sua importância relativa: para o nó da esquerda de uma relação RightNucleus e para o nó da direita de uma relação LeftNucleus. Com isso, a partir do nó raiz até os nós terminais, é possível calcular a pontuação de todos os nós. Todos os nós iniciam com a pontuação 0. Para cada satélite encontrado no percurso de um nó-folha até a raiz da árvore, soma-se 1. Ao final, os nós mais importantes terão as menores pontuações.

Na Figura 3.9, ilustra-se a pontuação obtida pelo método de Ono et al. para cada nó da árvore. $\mathrm{O}$ nó 5 , por exemplo, recebeu a pontuação 2 , pois, ao se percorrer da raiz em sua direção, existem 2 satélites no caminho, $\log 0+2=2$. A ordem parcial de segmentos para a estrutura é $\{1,2\}>3>\{4,5\}$, onde > indica prioridade à esquerda para compor o sumário e as chaves indicam proposições com a mesma pontuação. A ordenação é chamada de parcial devido à presença de proposições com a mesma pontuação. Esse método é simples e usa somente as informações disponíveis na árvore, mas pode resultar em muitos nós com a mesma pontuação, dificultando a seleção de sentenças para o sumário. 


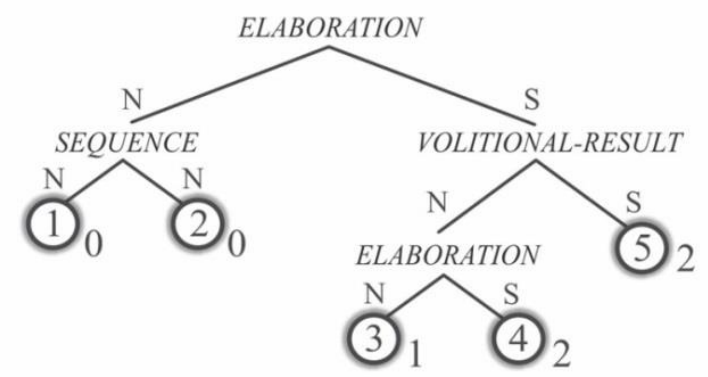

Figura 3.9: Exemplo do método de Ono et al. (1994)

Para avaliar o método, Ono et al. utilizaram 30 textos jornalísticos e 42 textos técnicos no idioma japonês. Os autores compararam os seus sumários automáticos com os sumários manuais e ainda analisaram se o sumário automático incluía a sentença principal do textofonte. Os autores relatam que no melhor dos casos, os sumários preservaram $51 \%$ das sentenças mais importantes e que 74\% tinham a sentença mais importante dos textos.

O'Donnell (1997) apresentou outro método no qual assume que cada relação tem uma pontuação associada que indica quão importantes são os segmentos/subárvores do texto. Por exemplo, a relação ELABORATION pode ter uma pontuação menor do que a relação VOLITIONAL-RESULT, pois a primeira relaciona detalhes, enquanto que a segunda é uma relação de causa e efeito, sendo mais importante que a elaboração. A pontuação de cada relação é definida de forma empírica, variando entre 0 e 1 . Para definir a pontuação de cada proposição, atribui-se 1 ponto à raiz da árvore. Em seguida, percorre-se a árvore em profundidade e, para cada um dos nós restantes, é atribuída uma relevância baseada no valor do nó mais nuclear mais próximo ao nó avaliado, multiplicado pela pontuação da relação retórica que domina o nó mais nuclear.

A Figura 3.10 ilustra a pontuação final de cada nó depois de aplicar o método de O’Donnell. No exemplo, assume-se hipoteticamente que o valor de importância das relações é: VOLITIONAL-RESULT $=0.8$, SEQUENCE $=0.5$ e ELABORATION $=0.4$. Analisando-se passo a passo o processo de atribuição da pontuação de cada proposição, tem-se que:

- os nós mais nucleares (nó 1 e 2) receberam a pontuação máxima 1.0;

- a pontuação do nó 3 é igual à pontuação do nó mais nuclear mais próximo, que são os nós 1 e 2, multiplicado pelo valor da relação ELABORATION, ou seja, 1x0.4=0.4;

- a pontuação do nó 4 é igual à pontuação do nó 3, que é o nó nuclear mais próximo do nó 4, multiplicado pelo valor da relação ELABORATION que está acima do nó atual, ou seja, $0.4 \times 0.4=0.16$; 
- a pontuação do nó 5 é igual à pontuação do nó 3, que é o nó nuclear mais próximo, multiplicado pelo valor da relação VOLITIONAL-RESULT, ou seja, 0.4x0.8=0.32.

A ordem parcial dos segmentos é $\{1,2\}>3>4>5$. A dificuldade desse método está no fato de que a importância de cada relação é definida empiricamente. Apesar disso, a possibilidade de nós com a mesma pontuação diminui bastante. O’Donnell não apresentou uma avaliação do seu método, mas o autor afirma que o método produz sumários de qualidade.

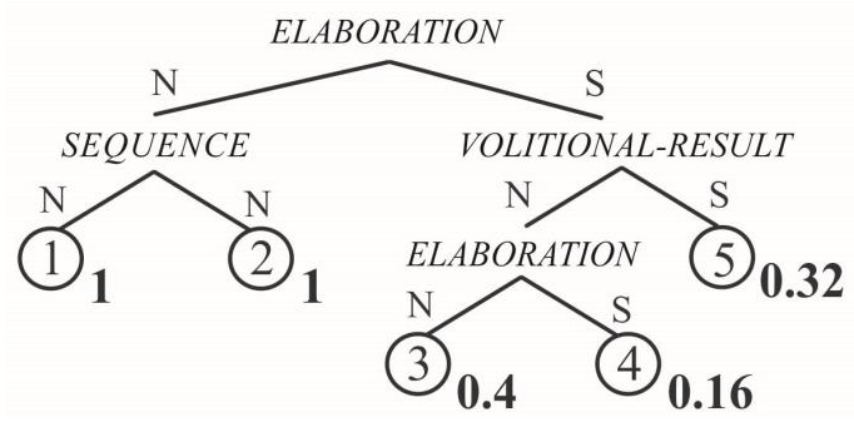

Figura 3.10: Exemplo do método de O’Donnell (1997)

Marcu (1997) propõe o uso de um conjunto promocional, que é composto pelas unidades mais salientes de uma subárvore. O conjunto promocional para cada nó da árvore é construído de maneira ascendente, de forma que: o conjunto promocional de um nó-folha é composto dele mesmo; cada nó interno da árvore inclui em seu conjunto promocional a união dos conjuntos promocionais de seus filhos nucleares. Para pontuar cada segmento, Marcu atribui à raiz uma pontuação correspondente ao número de níveis da árvore; então percorre a árvore em direção ao segmento sob avaliação. Cada vez que o segmento não está no conjunto promocional de um nó durante o percurso, o segmento tem a pontuação decrementada de 1 . A ideia é que as unidades textuais que estão no conjunto promocional do topo de uma árvore são mais importantes do que as unidades encontradas mais abaixo. A Figura 3.11 ilustra esse método e os elementos do conjunto promocional de cada nível aparecem entre chaves. A raiz inicia com a pontuação 4, que corresponde ao seu número de níveis da árvore. O nó 5, por exemplo, recebe a pontuação 2, pois ao se percorrer da raiz em sua direção, existem 2 satélites no caminho, $\log 04-2=2$. A ordem parcial dos segmentos para esta estrutura é $\{1,2\}>3>5>4$. Marcu utilizou 5 textos científicos com os sumários manuais para avaliar o seu método. O resultado da avaliação mostrou que o método determinava as unidades mais informativas com $70 \%$ de precisão e cobertura. Além disso, Marcu descreve que os seus resultados confirmam que há uma forte relação entre o núcleo da árvore RST e aquilo que os leitores acham ser importante em um texto. 


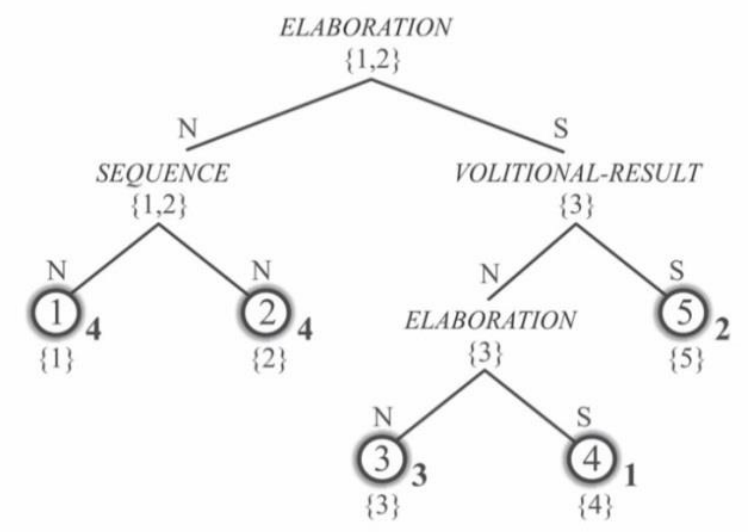

Figura 3.11: Exemplo do método de Marcu (1997)

Marcu (1998a) realizou outro experimento, no qual ele comparou o seu método com os resultados alcançados por Ono et al. (1994). O autor observou que a sua abordagem de conjunto promocional associada a cada nó habilita a produção de sumários melhores do que aqueles que são baseados somente na nuclearidade. Marcu propôs uma modificação do seu método, que consiste basicamente na adição da pontuação obtida pelo processo anterior ao número de níveis em que um segmento pertence ao conjunto promocional. $\mathrm{O}$ autor acreditava que, dessa forma, estaria reforçando a importância das proposições nucleares ao considerar quantas vezes elas estavam no conjunto promocional. Aplicando a modificação, as proposições 1 e 2, por exemplo, teriam suas pontuações incrementadas em 3, pois aparecem 3 vezes em um conjunto promocional. A ordem parcial de segmentos seria $\{1,2\}>3>5>4$. A Figura 3.12 ilustra esse processo. Nesse caso, em particular, a ordenação não é alterada.

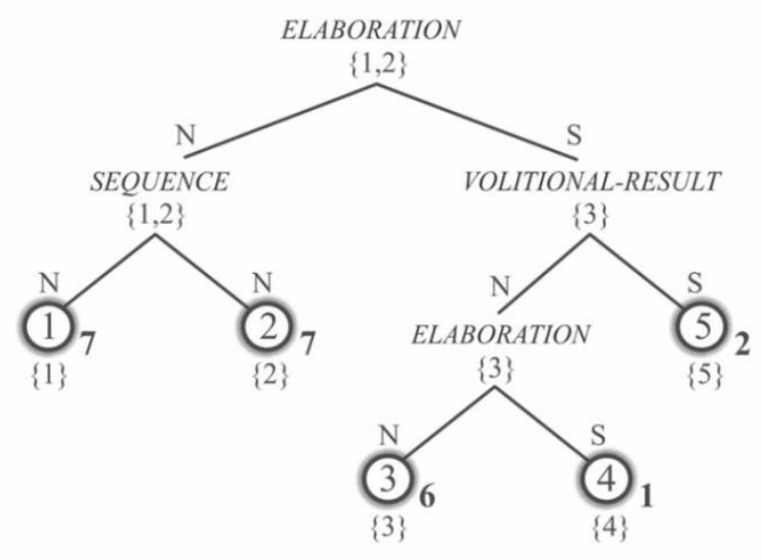

Figura 3.12: Exemplo do método de Marcu modificado (1998a)

Nos exemplos mostrados, os métodos de Ono et al., O’Donnell e Marcu definiram ordens de relevância diferentes para as proposições, mas as proposições consideradas como as mais 
salientes se mantiveram nas 4 abordagens, ou seja, as proposições 1 e 2 . Vale ressaltar que esses não são os únicos métodos de sumarização encontrados na literatura, mas pode-se dizer que as propostas de Ono et al., O’Donnell e Marcu são as mais referenciadas. Dessa forma, esses trabalhos dão suporte às estratégias de SA, discutidas no Capítulo 7.

Baseando-se nos métodos acima, Uzêda et al. (2010) elaboraram uma forma de combinar as características que esses métodos apresentam. Os autores levaram em conta o conjunto promocional proposto por Marcu, a nuclearidade de Ono et al. e um fator de importância dependente de cada relação, como fez O'Donnell. Inicialmente, atribui-se à raiz uma pontuação que corresponde ao número de níveis que a árvore tem multiplicado por 2. Em seguida, percorre-se a árvore em profundidade em busca de cada segmento. Se o segmento em questão pertence ao conjunto de promoção do nó atual, a pontuação é a atual. Se não, a pontuação do segmento é diminuída pelo complemento do fator de importância da relação acima do nó atual (ou seja, 1 - fator de importância da relação), e, se no percurso houver um satélite, subtrai-se ainda mais uma unidade. Iniciando a pontuação da raiz da árvore com o número de níveis multiplicado por 2, garante-se que não haja nós com pontuação negativa. $\mathrm{Na}$ Figura 3.13, ilustra-se o processo de Uzêda et al. (2010). Considere os valores de importância das relações definidos em O’Donnell (1997). A ordem parcial das proposições é: $\{1,2\}>3>$ $5>$ 4. Por exemplo, a pontuação do nó 3 foi definida da seguinte forma:

- 1-0.4 (importância da relação ELABORATION)=0.6;

- 8 (raiz da árvore) $-0.6=7.4$.

Como no percurso do nó há um satélite, diminui-se ainda uma unidade $=6.4$.

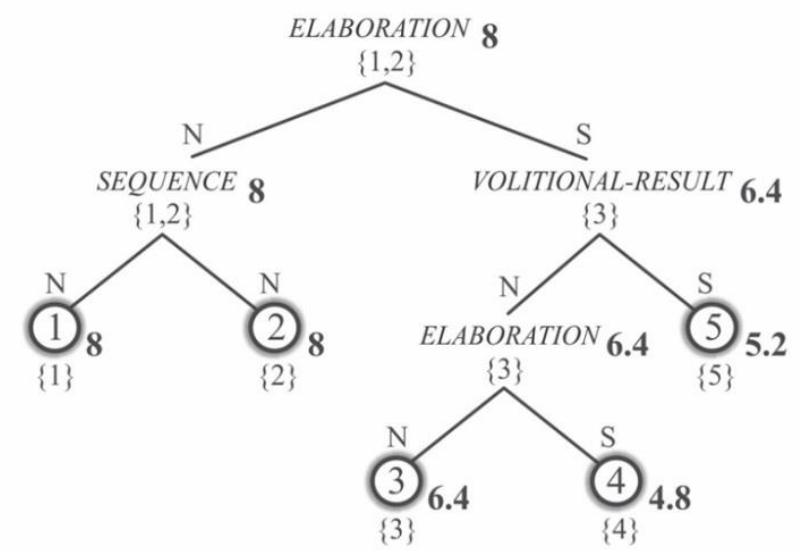

Figura 3.13: Exemplo do método de Uzêda et al. (2010) 
Uzêda et al. (2010) realizaram uma avaliação comparativa entre os métodos de SA baseados RST. A principal conclusão foi que os métodos RST apresentaram desempenho semelhante para textos em inglês e português.

Outros pesquisadores que exploraram a RST para SA, combinaram diferentes conhecimentos a aquelas estratégias já citadas, consideradas clássicas. Um desses trabalhos é de Pardo e Rino (2002), que desenvolveram o sumarizador automático DMSumm (Discourse Modeling Summarizer $)^{18}$. O DMSumm tem um modelo de discurso que faz um mapeamento entre relações discursivas (semânticas, retóricas e intencionais) para extrair o conteúdo de sumários. Para avaliar, foi utilizado um córpus constituído de 10 introduções de teses e dissertações, obtendo-se 0.44 de precisão, 0.54 de cobertura e 0.48 de medida-f.

Seno e Rino (2005) desenvolveram o sistema RHeSumaRST, que consiste em um conjunto de heurísticas para identificar e excluir informações supérfluas em uma estrutura RST durante a construção do sumário. O método de SA baseia-se tanto no modelo de saliência de Marcu, para classificar as unidades discursivas, e na Teoria das Veias (Cristea et al., 1998), para preservar os elos referenciais. Assim, satélites que contêm antecedentes de termos anafóricos já inclusos no sumário não podem ser excluídos. Na avaliação do sistema com a medida ROUGE-1 obteve-se 0.5373 .

Carbonel (2007), por sua vez, sugeriu algumas modificações na proposta de Seno e Rino (2005) e propôs o sistema VeinSum. Basicamente, as modificações foram na estratégia de seleção de proposições, que continuou baseada no método de Marcu, mas objetivou manter os elos referenciais ao mesmo tempo em que mantinha a taxa de compressão, que era corrompida na proposta de Seno e Rino. A avaliação do sistema com a ROUGE-1 foi 0.5807 .

\subsubsection{CST na sumarização automática}

Nesta seção, descrevem-se algumas propostas que utilizaram os relacionamentos entre textos que versam sobre o mesmo assunto para criar estratégias de SA multidocumento.

Radev e Mckeown (1998) desenvolveram o sistema SUMMONS (SUMMarizing Online NewS articles), que produz sumários multidocumento a partir de um conjunto de templates que indicam quais podem ser as informações salientes dos textos de entrada. Para gerar informações para os templates, o SUMMONS tem um módulo que utiliza componentes de

\footnotetext{
${ }^{18}$ http://www.icmc.usp.br/pessoas/taspardo/DMSumm.zip
} 
extração de informação. O sistema tem domínio restrito, especificamente, somente para textos jornalísticos sobre terrorismo. O córpus utilizado contém textos dos jornais Wall Street Journal e The Associated Press. Nesse caso, as informações contidas nos templates podem ser sobre as vítimas, o(s) terrorista(s), tipo de evento, etc. Um exemplo de template utilizado no SUMMONS é dado no Quadro 3.2, com os nomes dos campos e valores como no trabalho original. No Quadro 3.2, os valores da segunda coluna instanciam os atributos da primeira coluna. O template diz que a fonte Reuters divulgou sobre um incidente com bombas em Jerusalém que deixou 18 mortos e 10 feridos.

Cada template é composto de 25 atributos que correspondem a informações como fonte, sequestrador, local do crime, vítimas, local, etc., extraídos de vários documentos. Os templates são conectados uns aos outros por meio de operadores, que lhes atribuem uma pontuação de acordo com a importância dos templates. Os operadores representam relações similares às relações CST, por exemplo, CONTRADICTION, EQUIVALENCE e BACKGROUND. A importância é definida em função da repetição e do tipo de conteúdo do template, por exemplo, a informação que aparece somente em um template tem menos relevância do que aquela que aparece em vários. Após a definição da importância, alguns templates são combinados em novos templates mais genéricos ou específicos, e outros são excluídos. Ao final, os templates mais bem pontuados são selecionados e, com base nas informações contidas neles, o sistema utiliza técnicas de geração de linguagem para produzir o sumário final. Os autores não descrevem nenhum tipo de avaliação. Uma limitação do trabalho, indicada pelos autores, é a falta de informações sobre conexões diretas entre textos, limitação que pode ser suprida pela CST.

\begin{tabular}{l|l|}
\hline MESSAGE: ID & TST-REU-0001 \\
SECSOURCE: SOURCE & Reuters \\
SECSOURCE: DATE & March 3, 1996 11:30 \\
PRIMSOURCE: SOURCE & \\
INCIDENT: DATE & March 3, 1996 \\
INCIDENT: LOCATION & Jerusalem \\
INCIDENT: TYPE & Bombing \\
HUM TGT: NUMBER & "killed: 18" \\
PERP: ORGANIZATION ID & "wounded: 10" \\
\hline
\end{tabular}

Afantenos et al. $(2004,2007)$ defendem uma metodologia de SA multidocumento na qual as relações são definidas em função do domínio dos textos. Os autores dividem as suas relações 
em sincrônicas e diacrônicas (RSD) entre mensagens de textos relacionados. No primeiro caso, a preocupação é com a concordância entre várias fontes dentro de um mesmo período de tempo, enquanto que, no segundo caso, a preocupação é com a evolução de um evento para uma mesma fonte. A metodologia divide-se em fase de análise e fase de implementação.

A fase de análise objetiva fornecer o conhecimento necessário sobre o problema. Nessa fase, se produz uma ontologia de domínio, a especificação das mensagens e das RSD, e anotação de córpus. Por exemplo, se o domínio dos textos for sobre um campeonato de futebol, a ontologia incluiria conceitos como pessoa (jogador, assistente, organizadores, árbitro), duração (primeiro tempo, segundo tempo, acréscimo), cartão (amarelo, vermelho), etc. A partir da ontologia, ocorrem definição dos tipos de mensagens e seus argumentos. No caso do futebol, uma mensagem poderia ser o desempenho de um jogador em uma partida. No Quadro 3.3, há um exemplo de especificação da mensagem performance e uma lista de argumentos, cujos nomes foram mantidos como no trabalho original. Os argumentos da mensagem identificam de quem é o desempenho (jogador ou equipe), em qual área do campo ele atua, em qual momento da partida e uma nota para o desempenho do jogador ou da equipe.

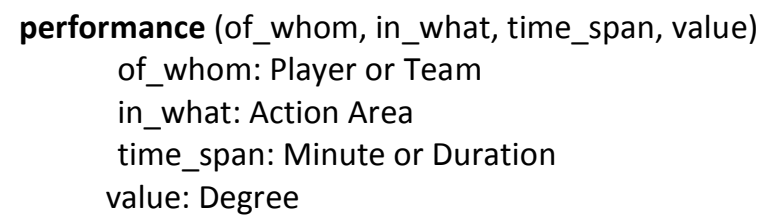

Quadro 3.3: Exemplo da especificação de mensagens

Fonte: Afantenos et al., 2007, p. 20

Uma vez que as mensagens são extraídas, são identificados os tipos de relações (sincrônicas ou diacrônicas) entre mensagens. Essa informação é usada pelo componente de geração textual para produzir o sumário. Um exemplo de relação diacrônica é dado no Quadro 3.4, que segundo uma mesma fonte, o jogador Georgeas manteve um bom desempenho durante duas partidas seguidas. Nesse caso, diz-se que é uma relação de estabilidade. A proposta de Afantenos et al. não foi implementada.

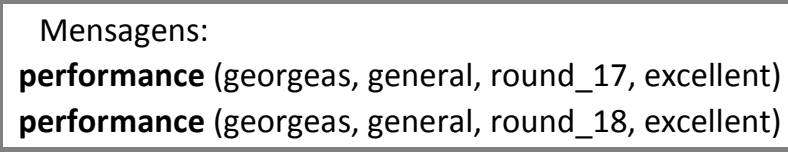

Quadro 3.4: Exemplo de instanciação e relacionamento entre mensagens

Fonte: Afantenos et al., 2004, p. 416 
Além de propor a teoria CST, Radev (2000) descreve uma metodologia de SA dividida em 4 etapas, como se mostra na Figura 3.14. Na primeira etapa, os textos são agrupados por conteúdo. Na segunda etapa, os textos de cada grupo são internamente analisados considerando-se a estrutura interna de sentenças, sintagmas ou palavras contidas no texto. $\mathrm{Na}$ terceira etapa, os textos são relacionados segundo o modelo CST. Na última etapa, ocorre a sumarização propriamente dita.
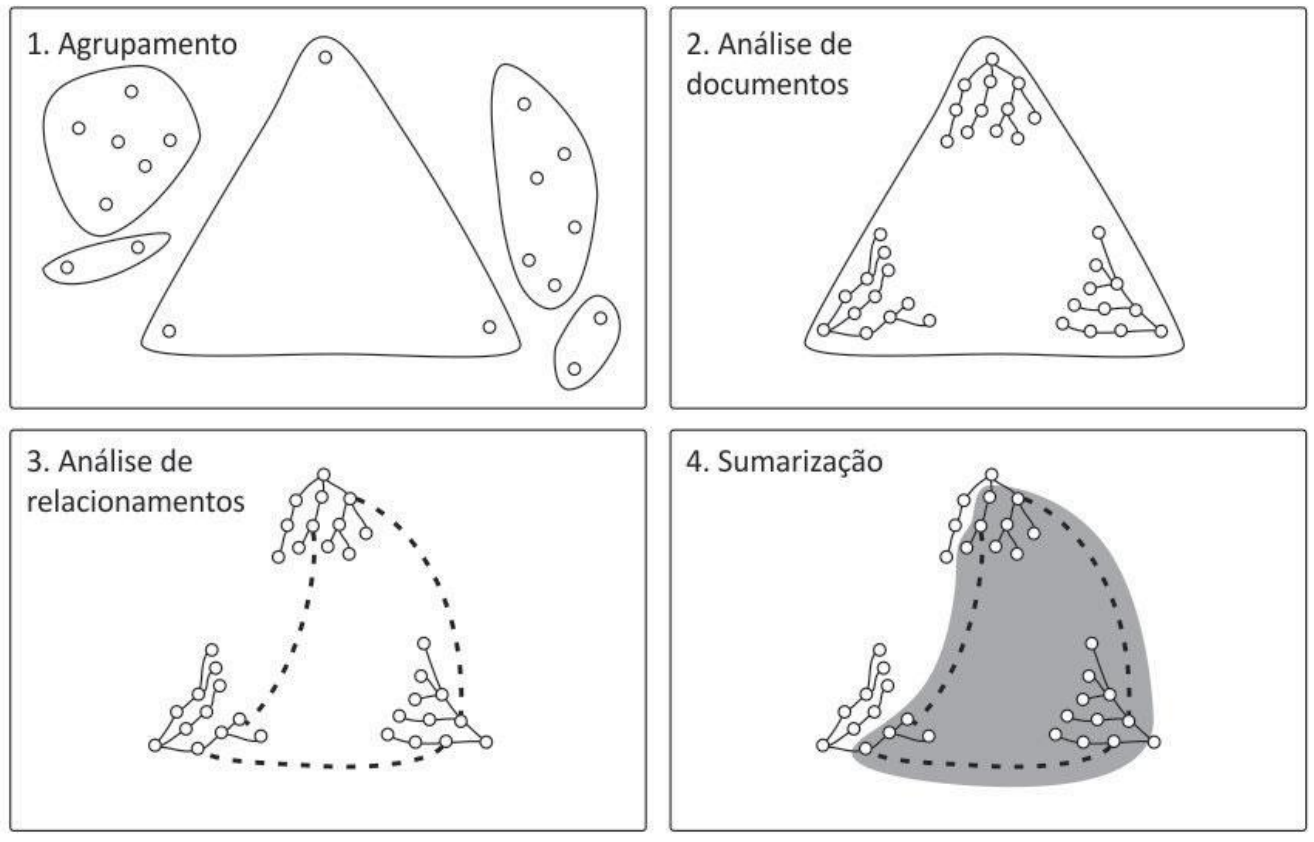

Figura 3.14: Etapas de SA multidocumento

Fonte: Radev, 2000, p. 8

Radev et al. (2000, 2004a) produziram o sumarizador multilíngüe MEAD, que gera sumários usando clusters de centroides produzidos por um sistema de detecção e rastreamento de tópicos. Um centroide representa um grupo de palavras que são estatisticamente representativas para um conjunto de textos. Como tal, centroides podem ser usados tanto para classificar textos relevantes e como para identificar sentenças importantes em um conjunto. No MEAD, a importância de uma sentença é calculada com base na sua distância em relação ao centroide dos textos, na distância em relação ao início do documento e em relação à primeira sentença do documento. As sentenças mais representativas de um conjunto de textos são selecionadas para o sumário. Os autores avaliaram o sistema utilizando textos jornalísticos e a medida de utilidade relativa (Radev e Tam, 2003). Os autores concluíram que o MEAD produz sumários que são similares, em termos de qualidade, àqueles produzidos por humanos. Os resultados variaram de 0.87 para a menor taxa de compressão $(10 \%)$ a 0.97 para a maior 
taxa (90\%). Os autores utilizaram algumas relações de similaridade da CST, tais como SUBSUMPTION E EQUIVALENCE.

Zhang et al. (2002) modificaram o sistema MEAD e acrescentaram as relações CST para medir a influência da teoria na qualidade dos sumários. Com a modificação, as sentenças são selecionadas pelo número de relacionamentos CST que possuem. Para avaliar, utilizaram textos jornalísticos escritos na língua inglesa. Os sumários automáticos foram comparados à sumários gerados pelo MEAD original, usando uma medida de utilidade similar à utilidade relativa (que verifica conteúdo, descrita no Capítulo 2). A avaliação mostrou que: (1) a seleção de sentenças com mais relações CST trouxe mais informatividade ao sumário e (2) que não faz diferença a direcionalidade da relação. Os autores também perceberam que a seleção de sentenças relacionadas por diferentes relações CST afeta de várias maneiras a qualidade do sumário. Por exemplo, a inclusão de duas sentenças que tenham uma relação de BACKGROUND entre elas reduz a qualidade do sumário e, por outro lado, as relações EQUIVALENCE e SUBSUMPTION melhoram.

Otterbacher et al. (2002) utilizaram as relações CST para melhorar a coesão em sumários multidocumento. A entrada do sistema é um conjunto de textos jornalísticos relacionados, do qual são extraídas as sentenças consideradas importantes pelo sistema MEAD original (Radev et al., 2001). A saída é um conjunto de sentenças que são tratadas antes de formarem o sumário final. Nesse tratamento, são identificados os relacionamentos CST entre essas sentenças. As sentenças que possuem mais relações CST entre si podem aparecer próximas no sumário e serem reordenadas de acordo com, por exemplo, as suas relações temporais ou organização de subtópicos.

Jorge e Pardo (2010, 2012) exploraram a CST aplicando operadores de seleção de conteúdo com base nas preferências do usuário. Primeiramente, é produzido um ranque inicial de sentenças usando como critério o número de relações CST. Quanto mais relações CST uma sentença tiver, mais alta é sua posição no ranque. A partir do ranque inicial e da preferência do usuário, são aplicados os operadores de seleção de conteúdo para produzir um ranque refinado, de tal forma que as unidades informativas mais relevantes melhorem sua posição no ranque. Ao final, são selecionadas as sentenças mais importantes levando em consideração a taxa de compressão. Nessa proposta, foram formalizados 5 operadores que representam possíveis preferências do usuário, são eles: (a) de apresentação de informação contextual, (b) apresentação de eventos que evoluem no tempo, (c) exibição de informações contraditórias, (d) identificação de autoria e (e) tratamento de redundância. Os operadores foram definidos 
em formato de templates, contendo um conjunto de regras. As regras são especificadas por meio de condições e restrições, as quais, caso sejam satisfeitas, ativam funções de manipulação da informação já classificada (ranque). O Quadro 3.5 exemplifica o operador de exibição de informações contraditórias. A regra se aplica quando duas sentenças $\mathrm{Si}$ e $\mathrm{Sj}$ possuem uma relação CONTRADICTION entre elas. Nesse caso, Sj é colocada em uma posição imediatamente após Si no ranque, considerando que Si sempre estará em uma posição $\mathrm{Sj}$ no ranque. Os autores avaliaram com um córpus de textos jornalísticos e usaram a medida ROUGE, obtendo os seguintes resultados: 0.3557 de cobertura, 0.4472 de precisão e 0.3864 de medida-f para a ROUGE-1. O trabalho mostrou que a CST pode ser aplicada para textos da língua portuguesa; que os operadores formalizados podem ser aplicados a textos de outras línguas, desde que devidamente modelados com CST; e que a CST ajuda na seleção de conteúdo, melhorando a informatividade e coerência nos sumários finais.

\begin{tabular}{|l|l|}
\hline Nome & Exibição de informações contraditórias \\
\hline Descrição & Preferência por informações contraditórias \\
\hline Regras & CONDIÇÃO (Si, Sj, - , Contradiction) $\rightarrow$ SOBE (Si, Sj) \\
\hline
\end{tabular}

Quadro 3.5: Operador de exibição de informações contraditórias

Fonte: Jorge e Pardo, 2010

Jorge et al. (2011) investigaram uma abordagem com aprendizado de máquina para SA multidocumento, representando a tarefa de seleção de conteúdo como um problema de classificação supervisionada. A metodologia consiste na criação do grafo de relacionamentos CST, seleção de atributos, classificação e construção do sumário. A partir do grafo, selecionam-se os atributos que descrevem as sentenças do córpus. Os atributos podem ser superficiais e profundos. Os atributos superficiais correspondem ao tamanho e a posição da sentença. Os atributos profundos são o centroide do grupo de textos, similaridade com o centroide, coeficiente de agrupamento e as relações CST. Vários algoritmos de classificação (Naïve Bayes, Suport Vector Machine, One Rule e o algoritmo de árvore de decisão J48) foram usados para decidir quais sentenças iriam para o sumário. Os autores conduziram diversos experimentos e observaram que o algoritmo J48 foi o que obteve a melhor taxa de classificação de sentenças. Os atributos relacionados à redundância, complementaridade e posição da sentença foram considerados os melhores para a classificação. Isso evidencia que atributos profundos fornecem informações importantes para a classificação de sentenças e reforça o pressuposto da SA multidocumento, de que as informações repetidas tendem ser as mais importantes. Como o J48 obteve melhor desempenho, ele foi utilizado para produzir 10 
sumários de conjuntos de textos diferentes. Os sumários foram avaliados com a ROUGE, alcançando 0.537 de precisão, 0.550 de cobertura e 0.542 para a medida-f. Os resultados são satisfatórios e superiores aos resultados de Jorge e Pardo (2010 e 2012) para o mesmo córpus e ainda mostram que a CST ajuda a produzir um bom modelo de classificação de sentenças.

Almahy et al. (2014) apresentam uma proposta para sumarizar um conjunto de e-mails do córpus BC3 (Ulrich et al., 2008). Na proposta, as únicas relações utilizadas foram IDENTITY, SUBSUMPTION, DESCRIPTION e OVERLAP. Inicialmente, as mensagens são préprocessadas para fins de normalização. Em seguida, as relações CST são identificadas automaticamente por um modelo de aprendizado de máquina. No próximo passo, selecionamse as sentenças que possuem mais relações CST. A fim de melhorar o sumário, o modelo de sumarização atribui diferentes pesos para cada relação e iterativamente busca pesos ideais que produzam um bom sumário. A cada iteração, os sumários são avaliados com a medida ROUGE e os valores são comparados com os de cada iteração. Os autores descrevem que os resultados não foram tao bons e que é necessário investigar novas relações de acordo com a natureza do conteúdo das mensagens.

\subsection{CONSIDERAÇÕES FINAIS}

Nesse capítulo, foram introduzidas as teorias que apoiam este trabalho na seleção de conteúdo em SA multidocumento extrativa. Em resumo, a RST ajuda na identificação de segmentos nucleares em cada texto e a CST auxilia na identificação e tratamento dos fenômenos multidocumento.

Especificamente para a tarefa de SA, a RST ajuda na análise da estrutura discursiva de um texto, bem como na classificação de segmentos nucleares (mais importantes) e satélites (menos relevantes) e por isso, ela é bem aceita em SA monodocumento. No Quadro 3.6, apresenta-se um comparativo entre as propostas de SA monodocumento que utilizaram a RST. 


\begin{tabular}{|c|c|c|}
\hline AUTOR & PROPOSTA & LÍNGUA \\
\hline $\begin{array}{l}\text { Ono et al. } \\
(1994)\end{array}$ & $\begin{array}{l}\text { Utilizaram somente as informações de nuclearidade da árvore para } \\
\text { definir a pontuação de cada proposição. } \\
\text { A estratégia pode levar a muitos nós com a mesma pontuação. }\end{array}$ & japonês \\
\hline $\begin{array}{l}\text { O’Donnell } \\
\text { (1997) }\end{array}$ & $\begin{array}{l}\text { Acrescentou um valor de importância definido de forma empírica } \\
\text { para cada relação. } \\
\text { A estratégia diminui o número de nós com a mesma pontuação. } \\
\text { Devido a subjetividade de definir a importância de uma relação, } \\
\text { torna difícil sua aplicação. }\end{array}$ & inglês \\
\hline Marcu (1997) & $\begin{array}{l}\text { Utilizou o princípio de nuclearidade para criar conjuntos } \\
\text { promocionais para subárvores RST. } \\
\text { Cada conjunto promocional é formado pelas unidades mais } \\
\text { nucleares de uma subárvore. } \\
\text { As unidades textuais que estão no conjunto promocional do topo } \\
\text { de uma árvore discursiva, são mais salientes que os nós } \\
\text { encontrados na parte inferior. } \\
\text { É a estratégia mais explorada em pesquisas de SA monodocumento. }\end{array}$ & inglês \\
\hline Marcu (1998) & $\begin{array}{l}\text { Reforçou a importância do conjunto promocional de uma subárvore } \\
\text { contabilizando quantas vezes cada proposição nuclear permanecia } \\
\text { no conjunto promocional. }\end{array}$ & inglês \\
\hline $\begin{array}{l}\text { Uzêda et al. } \\
\qquad(2010)\end{array}$ & $\begin{array}{l}\text { Criaram uma estratégia de sumarização baseada no conjunto } \\
\text { promocional de Marcu, a nuclearidade de Ono et al. e o fator de } \\
\text { relevância de O’Donnell. }\end{array}$ & Inglês e português \\
\hline
\end{tabular}

Quadro 3.6: Resumo das propostas de SA monodocumento com RST

Considerando que esses trabalhos são de SA monodocumento, conclui-se que eles apresentam desempenho razoável em termos de informatividade dos sumários automáticos. Ressalta-se que quando a RST é utilizada para selecionar conteúdo relevante, é esperado que os sumários apresentem problemas de qualidade linguística, não capturados pela medida ROUGE. De acordo com a literatura, a RST ainda não foi empregada para sumarização multidocumento. Apesar disso, neste trabalho, acredita-se que essa teoria tem forte potencial tanto para indicar o conteúdo relevante de uma coleção de textos, como para orientar formas de eliminar conteúdo pouco informativo.

Quanto à CST, a teoria foi utilizada para mapear os relacionamentos entre textos, indicar as sentenças importantes de uma coleção e até mesmo ordenar o conteúdo selecionado. Observou-se que nenhum dos trabalhos se dedicou a investigar se uma sentença que era importante para a coleção de textos, também era importante no seu texto-fonte. Esses trabalhos consideraram somente a importância das sentenças para a coleção de textos. No Quadro 3.7, apresenta-se um resumo dos trabalhos concluídos de SA multidocumento que utilizaram a CST propriamente dita. 


\begin{tabular}{|c|c|c|}
\hline AUTOR & PROPOSTA & LÍNGUA \\
\hline $\begin{array}{l}\text { Zhang et al. } \\
\qquad(2002)\end{array}$ & $\begin{array}{l}\text { Acrescentaram as relações CST no sistema MEAD para medir a } \\
\text { influência da teoria na qualidade do sumário. } \\
\text { Os autores concluíram que: } \\
\text { - a seleção de sentenças com mais relações CST trouxe mais } \\
\text { informatividade ao sumário; } \\
\text { - a seleção de sentenças relacionadas por diferentes relações CST } \\
\text { afeta de várias maneiras a qualidade do sumário; } \\
\text { - e que a direcionalidade das relações não interferem no sumário. }\end{array}$ & inglês \\
\hline $\begin{array}{l}\text { Otterbacher et } \\
\text { al. (2002) }\end{array}$ & $\begin{array}{l}\text { Utilizaram a CST para melhorar a coesão em sumários } \\
\text { multidocumento. } \\
\text { Observaram que as sentenças que possuem mais relações CST } \\
\text { entre si devem aparecer próximas uma das outras no sumário. }\end{array}$ & Inglês \\
\hline $\begin{array}{c}\text { Jorge e Pardo } \\
(2010,2012)\end{array}$ & $\begin{array}{l}\text { Criaram operadores de seleção de conteúdo com base nas } \\
\text { preferências do usuário. } \\
\text { Os operadores são na forma de templates, contendo um conjunto } \\
\text { de regras. } \\
\text { As regras são especificadas por condições e restrições, as quais, } \\
\text { caso sejam satisfeitas, ativam funções de manipulação sobre as } \\
\text { sentenças que possuem mais relações CST. } \\
\text { É o primeiro trabalho de SA multidocumento com CST para língua } \\
\text { portuguesa. } \\
\text { Observaram que a CST ajuda na seleção de conteúdo, } \\
\text { melhorando a informatividade e coerência nos sumários finais. }\end{array}$ & português \\
\hline $\begin{array}{l}\text { Jorge et al. } \\
\text { (2011) }\end{array}$ & $\begin{array}{l}\text { Combinaram as relações CST com características superficiais para } \\
\text { orientar a classificação de sentenças importantes que deveriam } \\
\text { compor o sumário. } \\
\text { Concluíram que a CST ajuda a produzir um bom modelo } \\
\text { classificador de sentenças. }\end{array}$ & português \\
\hline
\end{tabular}

Quadro 3.7: Resumo das propostas de SA multidocumento com CST

Apesar de ambas as teorias já terem sido bastante utilizadas em trabalhos de PLN, alguns pesquisadores fazem criticas. Em relação à RST, vários pesquisadores apontam que as relações são ambíguas e que falta uma formalização robusta da teoria que facilite a escolha de uma única relação retórica para relacionar trechos de texto baseando-se somente nas definições das relações fornecidas pelos seus autores. Diz-se também que as intenções estão ligadas a escolha de uma relação retórica, contudo, não são explicitadas pelas relações. Wolf e Gibson (2005) também criticam a forma de representação da análise. Os autores realizaram uma anotação de córpus que mostrou que os anotadores encontraram relações não possíveis de representar na forma de árvore, como um nó que participa de mais de uma relação. Assim, eles propõem que a estrutura discursiva seja no formato de um grafo, sem as restrições de formação da árvore.

Em relação à CST, Afantenos et al. (2007) criticam alguns pontos da teoria. Eles argumentam que Radev (2000) propôs inicialmente 24 relações multidocumento e que Zhang 
et al. (2002) com base em experimentos de anotação, reduziram o conjunto para 17. Afantenos et al. criticam o fato de que os anotadores consideraram somente relacionamentos entre sentenças, ignorando totalmente outros níveis que são sugeridos na teoria: "os relacionamentos CST podem ser entre sintagmas, parágrafos ou documentos". Ao contrário de Radev (2000), Afantenos et al. acreditam que as relações CST são dependentes de domínio e defendem que as relações sejam definidas em função do domínio dos textos.

Apesar de todas as criticas sobre RST e CST, essas são provavelmente as teorias discursivas mais empregadas no contexto de SA.

A seguir, no Capítulo 4, descrevem-se os trabalhos relacionados a subtópicos e discurso. 


\section{DISCURSO: TÓPICOS}

Koch (2009) afirma que um texto compõe-se de segmentos topicais, direta ou indiretamente relacionados com o tema geral ou tópico discursivo. Um segmento topical, quando introduzido, mantém-se por um determinado tempo, após o qual, com ou sem intervalo de transição, ocorre a introdução de um novo segmento topical. A tarefa de segmentação topical, portanto, visa dividir um texto em segmentos topicalmente coerentes. Essa tarefa pode ser útil para várias aplicações de PLN, por exemplo, recuperação de informação, sistemas de perguntas e respostas e sumarização automática.

Prince e Labadié (2007) explicam que, para a recuperação de informação, que busca documentos relevantes para uma dada consulta do usuário, além desses documentos, podem ser fornecidos fragmentos de texto que estejam semanticamente e topicalmente relacionados a uma consulta. Isso permite que o usuário encontrar rapidamente a informação de seu interesse. Para Oh et al. (2007), um sistema de perguntas e respostas pode mapear essa consulta para os subtópicos, de forma a facilitar a localização da resposta de forma mais rápida. No caso da SA, Wan (2008) diz que a partir da segmentação topical dos textos-fonte podem ser produzidos sumários melhores que cobrem diferentes aspectos de um tópico principal.

Neste trabalho, adota-se que um ou mais textos têm um tópico principal, que é o assunto sobre o qual se escreve ou discute. Um tópico pode ser descrito em uma sequência de discussões divididas em subtópicos (Salton et al., 1996; Hearst, 1997; Biryukov et al., 2005; Hennig, 2009; Hovy, 2009). Por exemplo, um conjunto de textos sobre um terremoto tipicamente contém informações sobre a magnitude do terremoto, sua localização, causalidades e medidas que estejam sendo tomadas para tratar os danos (Bollegala et al., 2009). Na próxima seção, apresenta-se a caracterização linguística de subtópicos.

\subsection{CARACTERIZAÇÃO LINGUÍSTICA DE SUBTÓPICOS}

Os subtópicos mudam continuamente; algumas mudanças são sutis, outras são mais proeminentes (Kazantseva e Szpakowicz, 2012). Algumas vezes, a estrutura de subtópicos é marcada em textos técnicos e científicos por cabeçalhos de seções, que dividem o texto em 
segmentos coerentes. Entretanto, há textos que quase não possuem marcação explícita de subtópicos, tais como textos jornalísticos, cartas, blogs e mensagens em redes sociais.

$\mathrm{Na}$ Figura 4.1, apresenta-se um exemplo de texto jornalístico segmentado topicalmente. O texto está organizado em cinco parágrafos, identificados de P1 a P5. Algumas características de subtópicos podem ser encontradas nesse texto que tem como tópico principal "Cielo leva ouro nos 100m nos Estados Unidos". O texto traz distintas informações que sugerem a segmentação indicada na figura. O subtópico que descreve sobre o nadador "Cielo" é apresentado nos parágrafos P1 e P5, ou seja, "Cielo" aparece no início e no fím do texto. Isso indica que um subtópico que já foi descrito pode voltar após um determinado tempo no texto, caracterizando que os segmentos de um mesmo subtópico nem sempre são adjacentes. O subtópico "Nicolas" é formado por um parágrafo e os demais subtópicos contêm mais de um parágrafo. Além disso, os subtópicos podem ser formados por uma ou mais sentenças. Assim, pode-se afirmar que a granularidade de um subtópico é variável.

\begin{tabular}{|c|c|}
\hline Subtópico & Texto \\
\hline Cielo & $\begin{array}{l}\text { [P1] O nadador brasileiro César Cielo confirmou o favoritismo neste domingo e } \\
\text { conquistou o segundo ouro no Grand Prix de natação do Missouri, nos Estados Unidos. } \\
\text { O campeão olímpico venceu a final dos } 100 \mathrm{~m} \text { livre fazendo 50s57, à frente do } \\
\text { canadense Richard Hortness e do americano Matt Grevers. }\end{array}$ \\
\hline Nicolas & $\begin{array}{l}\text { [P2] Nicolas Oliveira foi outro brasileiro a competir na final dos } 100 \mathrm{~m} \text { livre, mas ficou } \\
\text { longe do pódio: terminou apenas no sexto lugar, à frente de Jason Lezak e de Colin } \\
\text { Russell. }\end{array}$ \\
\hline $\begin{array}{c}\text { Equipe } \\
\text { brasileira }\end{array}$ & $\begin{array}{l}\text { [P3] A vitória encerra a participação brasileira na competição. Ao todo, foram } \\
\text { conquistadas } 10 \text { medalhas - Cielo também venceu os } 50 \mathrm{~m} \text { livre. Além dele, ficaram com } \\
\text { o ouro Felipe Lima, nos } 100 \mathrm{~m} \text { peito; Thiago Pereira, nos } 200 \mathrm{~m} \text { medley; e Joanna } \\
\text { Maranhão, nos } 200 \mathrm{~m} \text { borboleta. O país ainda conquistou duas de prata e três de } \\
\text { bronze. } \\
\text { [P4] Os nadadores brasileiros encerram, assim, o período de treinamento no exterior de } \\
\text { olho na Olimpíada de Londres } 2012 \text {. Os atletas permaneceram trabalhando em La Loma, } \\
\text { localizado em San Luis Potosí, no México, onde fizeram a preparação para os Jogos Pan- } \\
\text { Americanos de Guadalajara, em } 2011 \text {. }\end{array}$ \\
\hline Cielo & $\begin{array}{l}\text { [P5] "Essa competição era um desafio a mais para a cabeça dele, o de tentar levar o } \\
\text { corpo brigando pelo primeiro lugar em todas as provas. Está muito cansado, era mesmo } \\
\text { um desafio", exaltou Albertinho, técnico de Cielo no Projeto Rumo ao Ouro } 2016 \text {. }\end{array}$ \\
\hline
\end{tabular}

Figura 4.1: Exemplo de texto segmentado topicalmente

Para Jubran et al. (1992), uma sequência discursiva apresenta organização topical que pode ser observada em dois níveis: no plano hierárquico e no plano sequencial. No plano hierárquico, os segmentos textuais se apresentam como supertópicos e subtópicos, 
caracterizando que um tópico mais abrangente (supertópico) apresenta divisões em tópicos constituintes (subtópicos). No texto da Figura 4.1, o supertópico "Cielo leva ouro nos 100m nos Estados Unidos" é constituído por vários subtópicos: "Cielo", "Nicolas" e "Equipe brasileira". No que diz respeito ao plano sequencial (progressão topical), dois processos básicos caracterizam a distribuição de subtópicos na linearidade discursiva: a continuidade e descontinuidade. A continuidade se caracteriza por uma relação de adjacência entre dois subtópicos, com abertura de um subtópico subsequente somente quando o anterior é esgotado. A descontinuidade (mudança de subtópico) decorre de uma perturbação da sequencialidade linear, causada ou por uma suspensão definitiva de um subtópico, ou pela divisão de um subtópico em partes, que se apresentam de forma não adjacente. No texto da Figura 4.1, a continuidade se apresenta no subtópico "Equipe brasileira", pois esse se manteve nos parágrafos P3 e P4. A descontinuidade, por sua vez, aparece no subtópico "Cielo", dividido em duas partes.

Koch (2009) acrescenta que, para que um texto seja considerado coerente, é preciso que o mesmo apresente continuidade topical, ou seja, que a progressão topical em ambos os níveis se realize de forma que não ocorram rupturas definitivas ou interrupções excessivamente longas do subtópico em andamento. Portanto, a topicalidade constitui um princípio organizador do discurso.

Carlson e Marcu (2001) definem duas relações discursivas que identificam a mudança ou não de subtópico. Quando há fortes indícios de mudança de tópico entre duas sentenças ou dois parágrafos, ocorre a relação topic-shift. Por outro lado, quando a mudança de tópicos entre duas sentenças ou dois parágrafos é suave, a relação que ocorre é topic-drift. Relacionando ao que foi mencionado por Jubran et al. (1992), a relação topic-shift indica descontinuidade e a relação topic-drift designa continuidade.

É interessante notar que muitos desses trabalhos não fazem a distinção entre tópicos e subtópicos e usam os termos de forma intercambiável. Neste trabalho, adotam-se os termos de forma diferenciada. Tal distinção está de acordo com o trabalho renomado de segmentação topical de Hearst (1997), que caracteriza a estrutura de um texto como uma sequência de subtópicos que descrevem o tópico principal.

Na próxima seção, descrevem-se trabalhos de anotação e aplicações relacionadas com subtópicos. 


\subsection{TRABALHOS CORRELATOS DE SUBTÓPICOS}

Dada a utilidade da tarefa, é comum preparar uma segmentação de referência que não somente ajude no estudo e na compreensão do fenômeno sob investigação, mas também no desenvolvimento e na avaliação de sistemas de segmentação de subtópicos. Na literatura, há relatos de diversos córpus e alguns são descritos na Subseção 4.2.1. Há também vários algoritmos de segmentação em subtópicos, e esses são descritos na Subseção 4.2.2. Na Subseção 4.2.3, descreve-se como a segmentação em subtópicos já foi empregada na SA, que é o foco deste trabalho.

\subsubsection{Córpus disponíveis anotados com subtópicos}

Hearst (1997) produziu um córpus com 12 textos expositivos que tiveram seus subtópicos segmentados por sete anotadores. Os tamanhos dos textos variavam de 1.800 a 2.500 palavras e tinham pouca demarcação estrutural. Esse córpus serviu de base para avaliação do TextTiling, um algoritmo bastante conhecido na área de segmentação em subtópicos. Os anotadores foram orientados a colocar uma marcação de quebra entre parágrafos quando houvesse mudança de subtópico. Além disso, eles não receberam informações quanto a granularidade dos segmentos, portanto, um subtópico poderia ser formado por mais de um parágrafo. A fim de certificar que as instruções foram suficientemente claras e os anotadores de fato anotaram o mesmo fenômeno, foi medida a concordância entre anotadores por meio da medida Kappa (k) (Carletta, 1996). A kappa é uma medida clássica de concordância em PLN, indicando a concordância entre anotadores ao mesmo tempo em que desconta a concordância ao acaso, por sorte. Na equação 5, apresenta-se a fórmula da $\mathrm{K}$, onde $\mathrm{P}(\mathrm{A})$ é a proporção de vezes que os anotadores concordam e $\mathrm{P}(\mathrm{E})$ é a proporção de vezes que os anotadores concordam ao acaso. Apesar de não existir um valor específico a partir do qual se deva considerar o valor da kappa como adequado, encontram-se na literatura algumas sugestões que orientam esta decisão: um valor menor do que 0.4 pode indicar uma anotação na qual não se pode confiar; se estiver entre 0.4 e 0.75 , a anotação é satisfatória; e, se for maior do que 0.75 é muito boa. Hearst obteve $\mathrm{k}=0.647$, portanto, diz-se concordância satisfatória. Hearst compilou as várias segmentações e produziu uma anotação de referência. Para isso, a autora 
definiu que a concordância de pelo menos três anotadores para uma mesma quebra era suficiente para determinar se a quebra seria de referência.

$$
K=\frac{P(A)-P(E)}{1-P(E)}
$$

Kazantseva e Szpakowicz (2012), por sua vez, escolheram um livro de ficção científica (com 20 capítulos) que foi segmentado por pelo menos quatro alunos de graduação. Os anotadores trabalharam em capítulos individuais e segmentaram em parágrafos sempre que identificaram mudança de subtópico. Para cada segmento, o anotador acrescentava uma breve descrição do subtópico identificado. Os autores observaram que 50\% de todas as quebras foram indicadas por quase metade dos anotadores, enquanto que a outra metade foi marcada por uma minoria. A concordância entre anotadores foi de k=0.29. Dessa forma, Kazantseva e Szpakowicz não produziram uma segmentação de referência e sugeriram ser importante utilizar todas as segmentações disponíveis.

Passonneau e Litman (1997) selecionaram um córpus contendo 20 transcrições de narrações de diversas pessoas sobre um filme ${ }^{19}$ para ser segmentado linearmente por 7 anotadores. Os anotadores foram orientados a escolher seus próprios critérios de segmentação e ainda descrever rapidamente a intenção do falante associada com cada segmento topical. Para definir a marcação de referência, considerava-se a opinião de pelo menos quatro anotadores. Os autores relatam que a porcentagem de concordância (a taxa de concordância observada com a opinião da maioria) foi somente de $60 \%$.

Galley et al. (2003) trabalharam em uma amostra de 25 reuniões (diálogos) transcritas do córpus ICSI Meeting (Janin et al., 2003). Cada reunião tem em média 60 minutos de duração e participavam de seis a oito pessoas. Para cada reunião, identificam-se falantes, inicio e fim de fala e conteúdo. As transcrições foram segmentadas por pelo menos três juízes, que ainda deveriam classificar cada mudança de falante em uma quebra potencial ou não. Os autores relatam que a concordância foi significativa para grande parte do córpus. Ao final, uma segmentação de referência foi organizada considerando a opinião da maioria de anotadores.

Gruenstein et al. (2007) usaram 40 reuniões do córpus ICSI Meeting (Janin et al., 2003) e mais 16 do ISL Meeting Corpus (Burger et al., 2002). Dois anotadores segmentaram o córpus em dois níveis: macro e micro. No nível macro, uma reunião é segmentada

\footnotetext{
${ }^{19}$ O córpus é conhecido como Pear stories, originalmente coletado por Chafe (1980).
} 
linearmente e cada segmento representa mudanças altamente salientes ou partes do discurso em que há uma diferença muito grande de conteúdo. No nível micro, segmentos macro são opcionalmente segmentados e podem representar tanto uma digressão temporária ou uma discussão mais focada, embora ainda sejam diretamente relevantes para o segmento principal. Para cada segmento subtopical, os anotadores deveriam dar breves descrições. A concordância entre anotadores no nível macro foi $\mathrm{k}=0.47$ e no nível micro foi $\mathrm{k}=0.46$. Devido a baixa concordância da anotação, os autores não produziram uma segmentação de referência, pois muitas quebras topicais que foram identificadas por um anotador como micro, por outro anotador era macro.

Ambwani e Davis (2010) selecionaram 12 programas de televisão (documentários, notícias, episódio de drama, etc.) para os quais estavam disponíveis as legendas. Detalhes como entonação, análise de vídeo ou metadados ${ }^{20}$ foram ignorados. Cinco anotadores participaram da anotação e não foram orientados sobre como fazer a segmentação em subtópicos. Assim como nos outros trabalhos já descritos, não havia um limite específico de quantidade de quebras. Os anotadores deviam informar a importância dos subtópicos em uma escala de cinco pontos, incentivando-os indicar segmentos menores (subtópicos) dentro do grande tópico. Embora não houvesse muita consistência entre os anotadores ao atribuir uma nota, observou-se certa concordância em relação ao local de quebra. Para formar a segmentação de referência, os autores adotaram a opinião da maioria, sendo necessário pelo menos três anotadores concordantes.

Choi (2000), por sua vez, produziu automaticamente uma segmentação de referência a partir de um córpus compilado com 700 documentos do Brown Corpus. O processo de geração de documentos consiste em extrair e concatenar os primeiros dez segmentos de textos selecionados aleatoriamente do córpus. Assim, um subtópico é formado das primeiras 3-11 sentenças de um texto.

É interessante observar que há variações no processo de anotação dos trabalhos anteriores. Isso é esperado, uma vez que córpus são criados para diversos fins (linguísticos ou computacionais). No entanto, algumas questões podem ser observadas. Nos córpus de referência observou-se que a concordância entre anotadores geralmente é baixa (Kazantseva e Szpakowicz, 2012; Galley et al., 2003; Passonneau e Litman, 1997). Os pesquisadores relatam que a principal diferença nas anotações é na granularidade: alguns anotadores marcam somente as quebras mais proeminentes (granularidade grossa) e outros encontram mudanças

\footnotetext{
${ }^{20}$ Metadados de vídeo são dados que descrevem detalhes de um arquivo de vídeo, tais como nome do vídeo e data de criação.
} 
mais sutis (granularidade fina/segmentos menores). Em geral, na segmentação de subtópicos pede-se que o anotador coloque uma marcação de quebra e uma breve descrição. Ainda que os humanos discordem bastante ao segmentar em subtópicos, alguma concordância pode ser encontrada e é suficiente para demonstrar que os anotadores são consistentes em relação aos grandes subtópicos. A fim de produzir uma segmentação/anotação de referência de subtópicos geralmente contabiliza-se a opinião da maioria dos anotadores. Outro ponto interessante é que em nenhum dos trabalhos foi relatado como as descrições sobre os subtópicos fornecidas pelos anotadores foram utilizadas. Acredita-se que de alguma forma essas descrições serviram para que os organizadores da tarefa percebessem se os participantes haviam entendido o fenômeno investigado. Em relação ao número mínimo de anotadores concordantes ser 3, um número ímpar, acredita-se que é para evitar empates na decisão de uma quebra ser de referência ou não.

\subsubsection{Algoritmos de segmentação em subtópicos}

Um dos primeiros algoritmos propostos é o TextTiling, que segmenta textos expositivos em parágrafos (Hearst, 1997). Trata-se de uma técnica de segmentação linear e não supervisionada. Na proposta, assume-se que um conjunto de itens lexicais é usado durante o desenvolvimento de um subtópico e, quando ele muda, uma proporção significante de vocabulário também muda. Para encontrar tais subtópicos, o sistema pode utilizar três diferentes estratégias: comparação de blocos adjacentes de texto, introdução de vocabulário e cadeias lexicais. Antes de aplicar qualquer uma das estratégias, realiza-se um préprocessamento que consiste em: delimitar as palavras do texto, remover stopwords e aplicar stemmer sobre o conteúdo restante. Em seguida, divide-se o texto em pseudosentenças de tamanhos pré-definidos e associa-se uma nota para cada pseudosentença de acordo com a técnica de segmentação escolhida.

Para achar as notas das pseudosentenças pela estratégia de comparação de blocos adjacentes, elas são organizadas em blocos de tamanho fixo. Os blocos são comparados entre si por meio da medida do cosseno (Salton, 1988) (equação 6). Quanto mais palavras os blocos têm em comum, maior a pontuação lexical entre eles. Se uma nota baixa é precedida por e seguida por notas altas, assume-se que a nota baixa indica mudança no vocabulário e, portanto, corresponde a uma mudança de subtópico. O tamanho do bloco, representado por k, 
é aproximadamente a média do tamanho do parágrafo. Hearst adotou k=6 para textos expositivos e diz que esse parâmetro pode ser reconfigurado de acordo com os textos a serem segmentados. Para exemplificar a aplicação da estratégia de comparação de blocos, considere a Figura 4.2, na qual as letras (A, B, C, D e E) representam palavras quaisquer das pseudosentenças que formam os blocos e os números indicam sentenças. Para os dois primeiros blocos, a nota é calculada como $2 * 1($ para $\mathrm{A})+1 * 1($ para $\mathrm{B})+2 * 1($ para $\mathrm{C})+1 * 1$ $($ para $\mathrm{D})+1 * 2($ para $\mathrm{E})$.

$$
\cos (S 1, S 2)=\frac{S 1 * S 2}{|S 1| *|S 2|}
$$

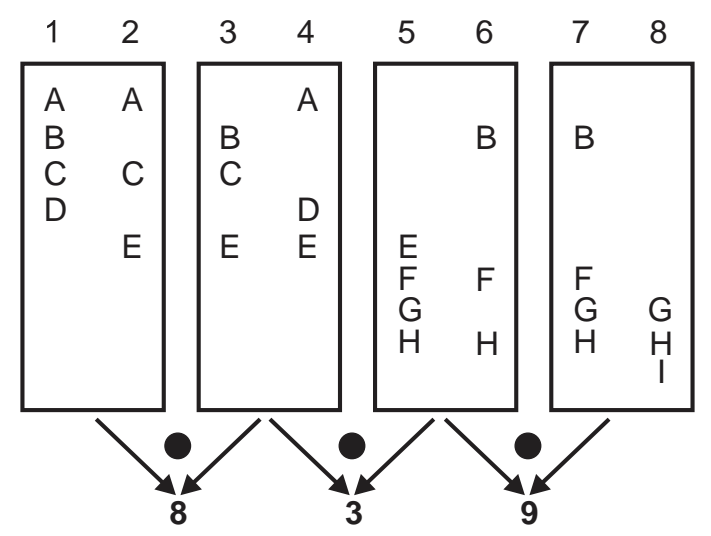

Figura 4.2: Exemplo da estratégia comparação de blocos adjacentes

Fonte: Hearst, 1997

Usando a estratégia introdução de vocabulário, computa-se o número de palavras novas introduzidas nos blocos. Se o número de palavras novas em cada bloco for muito alto, significa que houve mudança de subtópico. Na Figura 4.3, as palavras novas estão em círculos escuros. No exemplo, a nota entre os dois primeiros blocos seria calculada como 5 (cinco palavras novas introduzidas: A, B, C, D e E) + 0 (nenhuma palavra nova introduzida). 


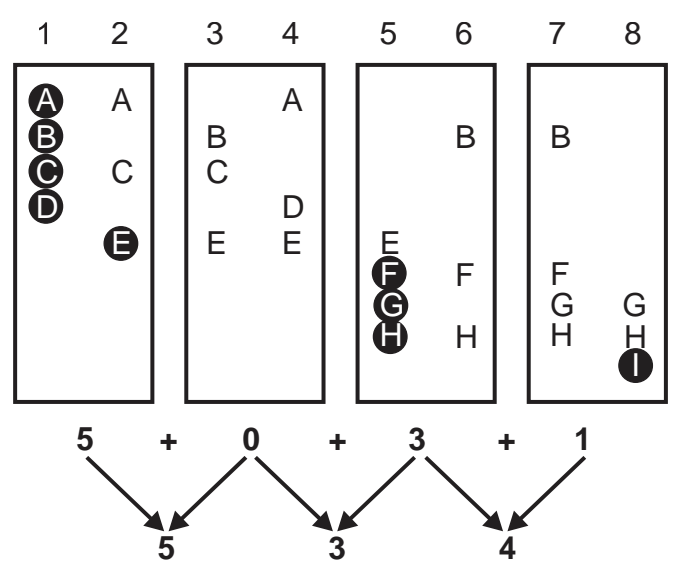

Figura 4.3: Exemplo da estratégia introdução de vocabulário

Fonte: Hearst, 1997

Hearst também utilizou o conceito de cadeias lexicais para segmentar textos. Uma cadeia lexical é uma sequência de palavras relacionadas. Pela estratégia com cadeias lexicais, assume-se que a repetição de um termo $t$ e suas variantes morfológicas formam uma cadeia que é considerada ativa dentro de uma determinada distância. $\mathrm{O}$ algoritmo busca sequências de palavras similares distribuídas entre as pseudosentenças e assume que a extensão das cadeias de palavras corresponde à extensão do segmento, caso as palavras similares estejam a uma distância limite considerada no TextTiling. Tendo como exemplo a Figura 4.4, verificase que todas as instâncias de A encontram-se dentro do limite aceitável, enquanto a terceira instância de B, por exemplo, está muito longe da segunda, contribuindo para determinar, assim, um novo segmento.

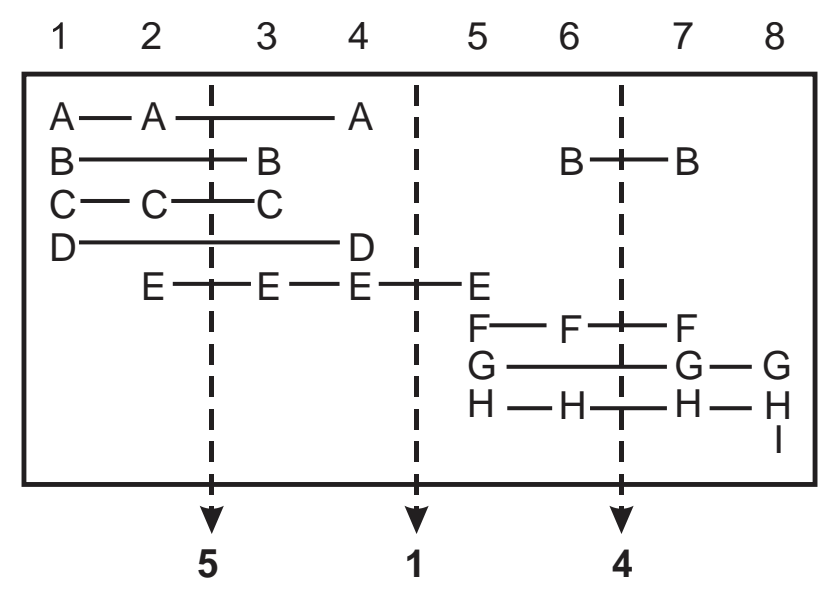

Figura 4.4: Exemplo da estratégia cadeias lexicais

Fonte: Hearst, 1997

Para identificar as grandes mudanças de subtópicos, blocos de textos são comparados entre si e as notas são normalizadas. O algoritmo monta um gráfico no qual é possível identificar 
vales profundos, que correspondem a quebras de subtópicos. De acordo com a autora, o TextTiling obteve 0.71 de precisão e 0.59 de cobertura. Na avaliação, Hearst utilizou um córpus de textos expositivos (descrito na Seção 4.2.1).

Seguindo na linha de reiteração de palavras, há o algoritmo C99 (Choi, 2000). Partindo das sentenças pré-processadas, o C99 calcula a similaridade entre cada par de sentenças pela medida do cosseno (equação 5) e produz uma matriz de similaridade. A partir da matriz, produz-se um ranque de similaridades: quanto mais similares as sentenças são com suas vizinhas, mais altas são suas pontuações. As menores pontuações na matriz de classificação indicam mudanças de subtópico. Na avaliação, Choi utilizou um córpus segmentado automaticamente em subtópicos (descrito na Seção 4.2.1) e alcançou mais acurácia que o TextTiling.

Para segmentar transcrição de monólogos, Passonneau e Litman (1997) experimentaram os atributos linguísticos pausa, palavras sinalizadoras e sintagmas nominais referenciais. A avaliação do atributo pausa foi de 0.92 de cobertura e 0.18 de precisão; do atributo palavras sinalizadoras foi de 0.72 de cobertura e 0.15 de precisão; e do atributo sintagmas nominais foi de 0.50 de cobertura e 0.31 de precisão. Nessa avaliação, utilizou-se um córpus de transcrições de narrações sobre um filme, já descrito na Seção 4.2.1. Embora os atributos pausa e palavras sinalizadoras tenham boa cobertura, a maior parte das quebras não é correta. Por outro lado, os sintagmas nominais tiveram melhores resultados para as duas medidas. Os autores relacionaram isso ao fato da definição de sintagmas nominais empregada ser mais rica do que a de outros atributos. Os autores sugerem que segmentar em subtópicos envolve muito mais do que usar conhecimento linguístico raso, que outras possibilidades poderiam ser investigadas, tais como a estrutura discursiva.

Chang e Lee (2003) desenvolveram um algoritmo de segmentação topical para textos curtos, como redações de estudantes. Para cada sentença, recupera-se um conjunto de palavras-chave, que podem ser substantivos, verbos e adjetivos. O conjunto inicial é expandido usando coocorrência e distância entre palavras-chave em uma passagem composta de uma quantidade fixa de sentenças. A coocorrência de duas palavras-chave em uma mesma passagem indica que estão no mesmo subtópico. $\mathrm{O}$ grau de correlação de duas palavras-chave também depende das suas distâncias na passagem, que nesse caso é o número de sentenças. No exemplo da Figura 4.5, a distância entre as palavras-chave k2 e k3 é 1, a distância entre as palavras-chave k3 e k4 é 3. O tamanho da passagem é 3, as palavras-chave k2, k3 e k4 são coocorrentes na passagem, mas k1 e k4 não. Baseando-se nos conceitos de coocorrência e 
distância, constrói-se uma matriz de correlação entre as palavras-chave por passagem textual. Conhecendo as palavras-chave comuns entre as sentenças, calcula-se a similaridade entre as sentenças. Os segmentos com baixa similaridade indicam locais de mudança de subtópico. Os autores usaram uma amostra de redações de estudantes escritas em chinês para avaliar o método. Eles descrevem que observaram boa acurácia.

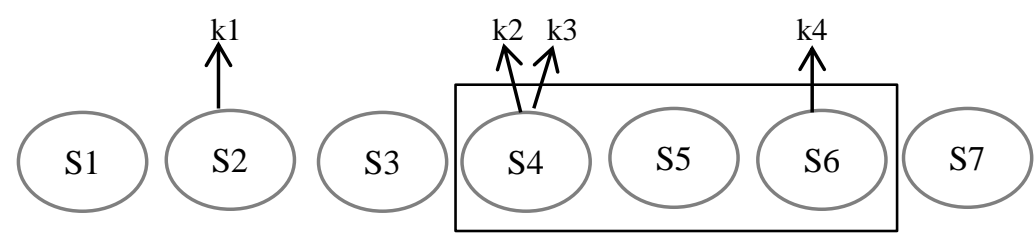

Figura 4.5: Exemplo de cálculo da similaridade entre palavras-chave

Fonte: Chang e Lee, 2003

$\mathrm{Na}$ área de segmentação em subtópicos, independente da aplicação, vê-se que as abordagens descritas basearam-se principalmente em similaridade entre palavras. Contudo, neste trabalho, investigaram-se estratégias de segmentação em subtópicos que considerem a estrutura discursiva do texto. Tais estratégias são descritas no Capítulo 7.

\subsubsection{Segmentação em subtópicos para $\mathrm{SA}$}

Na SA, a segmentação em subtópicos geralmente é uma etapa anterior à seleção de conteúdo (Salton et al., 1997; Hovy e Lin, 1998; Larocca Neto et al. 2000a e 2000b; Farzindar et al., 2005; Ercan e Cicekli, 2008; Zhan et al., 2009; Ribaldo, 2013). Contudo, há iniciativas de ordenação do conteúdo selecionado orientado pelos subtópicos (Stein et al., 2000; Bollegala et al., 2006). Esses trabalhos e seus resultados são descritos a seguir.

Salton et al. (1997) estão entre os primeiros autores a investigarem a segmentação de subtópicos para SA. Os autores investigaram a similaridade entre parágrafos de um texto por meio da sobreposição de vocabulário. Se a similaridade entre dois parágrafos é significativa, diz-se que os mesmos são semanticamente relacionados. Baseando-se nesse princípio, constrói-se um mapa de relacionamentos do texto, no qual os nós representam os parágrafos e as arestas indicam se há relacionamento. A partir do mapa, os autores recomendam três tipos de percurso: caminho denso, caminho profundo e caminho denso segmentado. No caminho denso (bushy path), os parágrafos são considerados independentes um do outro. O percurso do caminho denso é formado pela seleção de parágrafos que têm mais ligações no mapa de 
relacionamentos. Os sumários gerados com esse percurso são abrangentes (boa cobertura), cobrindo vários subtópicos do texto, mas são pouco coesos. O caminho profundo (depth-first path) tenta solucionar a falta de coesão gerada pelo percurso denso. Usando o caminho profundo, o primeiro parágrafo selecionado deve ser o mais denso, isto é, aquele possui o maior número de conexões. O próximo parágrafo selecionado será aquele com mais ligações com o anteriormente selecionado, e assim sucessivamente, até atingir a taxa de compressão. Dessa forma, somente parágrafos semanticamente relacionados são selecionados, isto é, parágrafos que tratam do mesmo subtópico. A crítica que se faz ao caminho profundo é que somente um subtópico, mesmo que seja irrelevante, formará o sumário e outras informações serão deixadas de lado. O caminho segmentado (segmented bushy path) tenta atenuar o problema da falta de coesão do caminho denso e da falta de abrangência do caminho profundo. Primeiramente, constroem-se vários caminhos densos para cada subtópico. Em seguida, concatena-os em ordem textual. Pelo menos um parágrafo de cada segmento é selecionado e um parágrafo de transição entre os subtópicos, respeitando a taxa de compressão. Dentre os três percursos, o caminho denso foi o que produziu sumários automáticos com boa cobertura $(45.6 \%)$. O caminho segmentado também obteve boa cobertura (45.48\%), contudo esperava-se um resultado melhor. Por esse percurso, em muitos casos, o primeiro parágrafo não era selecionado. Isso reduz a sobreposição de conteúdo com o sumário de referência, para o qual o humano muitas vezes seleciona o primeiro parágrafo/sentença. O caminho profundo obteve o menor resultado (43.98\%), mas ainda considerado satisfatório.

Hovy e Lin (1998) desenvolveram o sistema SUMMARIST para gerar sumários multilíngue. O sistema tem três etapas: identificação de subtópicos, interpretação de subtópicos e geração de sumário. Nessa proposta, assume-se o tópico é o assunto principal de um texto e que esse pode ter vários subtópicos. Para identificar os subtópicos, o sistema combina os pesos de vários atributos e atribui uma nota para as sentenças. Os atributos utilizados foram: 1) posição da sentença - baseando-se no fato de que certos gêneros apresentam regularidades na estrutura que facilitam a identificação de sentenças importantes; 2) palavras sinalizadoras - funcionam como indicadores de importância de uma sentença; e 3) topic signature ${ }^{21}$ - uma ou mais palavras-tópico semanticamente relacionadas que juntas identificam um subtópico. Nesse caso, os subtópicos são representados por conjuntos de palavras relacionadas. Na etapa de intepretação, subtópicos similares são unificados em um

\footnotetext{
${ }^{21}$ Uma topic signature é representada por TS $=\{$ topic, signature $\}$, onde topic é um conceito-alvo e signature é um vetor de termos altamente relacionados com o topic.
} 
conceito, por exemplo, garçom, cardápio e comida poderiam ser generalizados no conceito restaurante por esse último ser mais abrangente. Para isso, uma variedade de métodos pode ser aplicada. Em seguida, selecionam-se as sentenças que tenham os conceitos mais interessantes de acordo com várias métricas. Na etapa de geração, o conteúdo selecionado é organizado de forma coerente em um texto. Na avaliação considerando somente topic signature, o SUMMARIST obteve bons valores para cobertura (0.756) e precisão (0.693). Os autores utilizaram uma amostra de textos sobre diferentes tópicos da coleção TREC (Text REtrieval Conference) $)^{22}$.

Larocca Neto (2000) e Larocca Neto et al. (2000) desenvolveram um sistema de SA monodocumento baseado na importância relativa dos subtópicos. $\mathrm{O}$ sistema divide um texto em subtópicos, usando uma versão adaptada do TextTiling (Hearst, 1997), e seleciona as sentenças mais importantes de cada subtópico. A versão do TextTiling usa o tamanho do bloco $\mathrm{k}=3$ e suporta a representação de n-gramas de forma que não necessita dos préprocessamentos tradicionais e é, portanto, uma versão independente de língua. Após a segmentação do texto, o sistema atribui uma importância para cada subtópico de forma a estabelecer subtópicos prioritários e secundários. Para calcular a importância de cada subtópico, o sistema analisa a importância de todas as sentenças de um subtópico. Cada sentença é representada como um vetor de pesos TF-ISF (term frequency - inverse sentence frequency), que é uma medida similar ao TF-IDF (term frequency - inverse document frequency). A diferença é que a noção de documento do TF-IDF é substituída por sentença. O valor de TF-ISF das sentenças também determina sua importância no subtópico. Assim, a importância de um subtópico é a média dos valores de TF-ISF de suas sentenças. Dada uma taxa de compressão, o sistema decide quantas e quais serão as sentenças selecionadas de cada subtópico. Para cada subtópico relevante, as sentenças são selecionadas de acordo com a sua similaridade de TF-ISF em relação ao centroide do tópico. O sistema de Larocca Neto foi avaliado com um conjunto de textos da língua inglesa. Na comparação dos sumários automáticos (com 20\% de compressão) com sumários de referência, os valores tanto para precisão e cobertura foram 0.2783 . Segundo os autores, o método que utiliza informação topical obteve desempenho similar ou ligeiramente superior à métodos que selecionam as primeiras sentenças de um texto. Os autores concluem que tal método não foi muito vantajoso, pois resultados de qualidade semelhante poderiam ser obtidos com heurísticas mais simples.

\footnotetext{
${ }^{22}$ Coleção TREC disponível em http://trec.nist.gov/data.html
} 
Stein et al. (2000) desenvolveram um sistema de SA multidocumento, chamado XDOCTOOL, que produz sumários indicativos usando técnicas de agrupamento de subtópicos. O sistema recebe como entrada os textos-fonte e a descrição de um tópico de interesse do usuário. A tarefa do sistema é formar um sumário contendo os subtópicos que descrevem o tópico de interesse. No primeiro passo, produzem-se sumários monodocumento com base no tópico de interesse. A unidade de seleção utilizada é o parágrafo. No passo seguinte, o sistema decide quais os sumários monodocumento auxiliarão a formação do sumário multidocumento. Os sumários monodocumento são agrupados por medidas de similaridade em conjuntos de sumários que descrevem subtópicos similares. Os conjuntos de sumários monodocumento são a entrada para o módulo de SA multidocumento. De cada conjunto de sumários, seleciona-se um sumário modocumento. Considerando o agrupamento gerado anteriormente, cada sumário monodocumento selecionado descreverá um subtópico ou aspecto do tópico indicado pelo usuário. Por fim, organizam-se as passagens selecionadas usando a similaridade: quanto mais similares, mais próximas duas passagens devem ficar no sumário final. Os autores avaliaram a facilidade de uso do sistema e não relatam alguma avaliação dos sumários.

Farzindar et al. (2005) desenvolveram o CATS (Cats is an Answering Text Summarizer), que produz sumários multidocumento como resposta para uma pergunta do usuário (também conhecido por query-focused summary). O sistema é dividido em três etapas: análise da consulta do usuário, análise dos textos-fonte e seleção de sentenças. Primeiramente, o sistema mapeia as entidades nomeadas presentes na consulta do usuário. Tais entidades são classificadas em pessoa, organização, localização e tempo. Em seguida, verifica-se o número de vezes que uma palavra de uma categoria aparece na consulta, isso aumenta a probabilidade daquele tipo de entidade aparecer no sumário. Na análise dos textos-fonte ocorre mapeamento das expressões temporais e entidades nomeadas, e segmentação topical com o TextTiling (Hearst, 1997). Quando as sentenças são incluídas no sumário, elas perdem sua referência temporal e ficam sem sentido. Para solucionar esse problema, essas expressões temporais são convertidas para seus valores absolutos. Na etapa de seleção de sentenças, identificam-se os subtópicos mais similares com a consulta do usuário. As sentenças desses subtópicos são ordenadas de acordo com sua importância que é dada pela combinação de diversos atributos, como similaridade com a consulta, posição no texto e entidades nomeadas. No último passo, selecionam-se as melhores sentenças do ranque. Para tratar a redundância, as sentenças são comparadas entre si por meio de medidas de similaridade e entidades nomeadas presentes. Se 
duas sentenças têm em comum pelo menos duas entidades nomeadas, elas são consideradas similares e descarta-se a sentença com menor nota. Finalmente, o sistema produz um sumário extrativo com as sentenças mais similares à consulta. Na avaliação do CATS utilizou-se um conjunto de textos jornalísticos na língua inglesa, extraídos dos jornais Financial Times e Los Angeles Times. O CATS foi bem avaliado na DUC de 2005, tanto para a maioria dos critérios de qualidade linguística quanto para a relevância da resposta com a consulta. Por outro lado, a avaliação automática com a ROUGE não foi conclusiva.

Bollegala et al. (2006) utiliza a informação de subtópicos para organizar as sentenças de sumários multidocumento. No caso da SA monodocumento, é natural dispor as sentenças de um sumário seguindo a mesma ordem do texto fonte. Mas, para a SA multidocumento não é possível fazer o mesmo, uma vez que as sentenças são coletadas de textos distintos. Para organizar o conteúdo de um sumário multidocumento, os autores definiram quatro critérios: ordem cronológica, similaridade topical, precedência e sucessão. Esses critérios são integrados em uma função de aprendizado de máquina. Em relação ao critério de similaridade topical, assume-se que um conjunto de textos discutindo um evento particular, geralmente contém informações relacionadas a vários subtópicos. Por exemplo, um conjunto de notícias sobre um terremoto tipicamente contém informações sobre a magnitude do terremoto, sua localização, causas e medidas de resgate. O critério "topicalmente relacionadas" é baseado na similaridade lexical entre duas sentenças: quanto mais similares, mais próximas as sentenças devem ficar no sumário. Para avaliar a proposta, utilizou-se um córpus de sumários de referência de textos jornalísticos em japonês. Na comparação entre sumários ordenados automaticamente e sumários ordenados manualmente, o critério individual vencedor foi a ordem cronológica (Spearman=0.583), seguido dos critérios sucessão $(0.473)$, precedência (0.415) e por último, similaridade topical (0.414).

Ercan e Cicekli (2008) desenvolveram uma proposta de SA que modela a coesão lexical de um texto usando as relações semânticas entre as unidades textuais. As unidades textuais formam cadeias lexicais, que são grafos conectados, com os vértices representando os sentidos das palavras e as arestas, as relações semânticas entre esses sentidos. Nesse trabalho, os autores utilizam cadeias lexicais para identificar e segmentar em subtópicos. Inicialmente, o texto é segmentado em sentenças. Utilizando o algoritmo de Galley et al. (2003), formam-se as primeiras cadeias lexicais. Podem existir cadeias lexicais fracas, que são formadas dos sentidos de uma única palavra, e essas devem ser desconsideradas. As cadeias remanescentes são agrupadas usando informações de coocorrência. Por exemplo, se duas cadeias aparecem 
em uma mesma sentença, elas devem ser agrupadas, formando um conjunto de termos que representam um provável subtópico. Após o agrupamento das cadeias lexicais, ocorre a segmentação em subtópicos. De cada cadeia, sequências de sentenças conectadas são extraídas como segmentos. Considera-se que sentenças coesivamente conectadas descrevem o mesmo assunto. $\mathrm{O}$ número de sentenças em um segmento reflete o quanto aquele subtópico é discutido. Na etapa de seleção, o algoritmo extrai a primeira sentença de cada sequência e assume-se que essas sentenças são descrições gerais de cada subtópico e contém informações suficientes para formar o sumário. $\mathrm{Na}$ avaliação utilizou-se um conjunto de textos jornalísticos da DUC 2004 e a medida ROUGE. Os resultados foram 0.1954 (ROUGE-1), 0.0524 (ROUGE-2) e 0.1707 (ROUGE-L). Na DUC 2004, esse sistema ficou entre os 10 melhores do ranque.

Zhan et al. (2009) propõem noções de macro e micro informações para SA multidocumento com subtópicos. As macro informações representam subtópicos salientes compartilhados entre os documentos de uma dada coleção e micro informações são sentenças ou orações que elaboram ou complementam a macro informação. Para identificar a macro informação, busca-se nos documentos sequências frequentes de palavras (FS) que irão formar vários conjuntos de FS. Para diminuir o espaço de busca, os documentos são pré-processados para remoção de stopwords e aplicação de stemmer. Inicialmente, na extração de FS coletamse todos os pares frequentes de palavras. Os conjuntos são expandidos, acrescentando-se uma palavra, compondo conjuntos com 3 palavras. Esse processo é realizado iterativamente até que não haja mais expansão. Cada FS passa a representar um subtópico da coleção. Os subtópicos podem ser ranqueados de três diferentes formas relacionadas a frequência com que aparecem na coleção: $t f$, $t f . d f$ e $t f . i d f$. Os subtópicos bem posicionados no ranque constituem as macro informações, dos quais são extraídas as micro informações. As sentenças (micro) dos melhores subtópicos são selecionadas até atingir a taxa de compressão. Apesar de a técnica FS ser considerada superficial, os autores descrevem alguns resultados. Eles identificaram que os melhores subtópicos do ranque tem alta possibilidade de aparecer no sumário de referência e ser selecionado pela maioria dos produtores de texto, pois esses tendem a escolher aquilo que é comum a coleção. Observou-se também que quanto menor é a taxa de compressão, mais os produtores concordam nos detalhes (subtópicos importantes) incluídos no sumário. Em relação as micro informações, os resultados sugerem que sua inclusão no sumário dependem totalmente do produtor. 
Ribaldo (2013) desenvolveu um sistema de SA multidocumento extrativo que segmenta cada texto de uma coleção em subtópicos, usando uma versão adaptada do TextTiling, e agrupa-os os subtópicos com medidas de similaridades. Após o agrupamento, organiza-se um mapa de relacionamentos (grafo) e seleciona-se o conteúdo relevante pelo percurso caminho denso segmentado (adaptado de Salton et al., 1997). No grafo, os nós representam subtópicos e as arestas são relacionamentos entre eles. No caminho denso segmentado, selecionam-se as sentenças mais importantes de cada subtópico. Escolhida a primeira sentença, é necessário selecionar uma sentença de transição antes mesmo da escolha da próxima sentença mais relevante de outro subtópico. Essa sentença deve ser cronologicamente posterior a sentença precedente no sumário para que a passagem de um subtópico para outro se dê de forma coerente. Esse processo é realizado até atingir a taxa de compressão. Na avaliação, utilizou-se um córpus de textos jornalísticos CSTNews (descrito no Capítulo 5) e a medida ROUGE. Os resultados foram considerados satisfatórios, com 0.5472 de precisão, 0.3517 de cobertura e 0.4190 para medida-f. O sistema ficou conhecido como RSumm.

\subsection{CONSIDERAÇÕES FINAIS}

Neste capítulo, apresentaram-se os conceitos de tópico e subtópicos, córpus de referência sobre segmentação topical, algoritmos para segmentação e o uso de subtópicos em SA.

Observou-se no processo de criação de córpus de referência houve variações. Contudo, o estudo auxiliou o desenvolvimento de uma metodologia de anotação instanciada para subtópicos, que será descrita no Capítulo 6.

Os algoritmos de segmentação em subtópicos apresentados utilizaram atributos superficiais como frequência de palavras, palavras sinalizadoras ou organização em parágrafos e outros tiraram proveito das cadeias lexicais. Acredita-se que há outros indicadores da estrutura de subtópicos de um texto como sua estrutura discursiva. Como mencionado, por meio da árvore RST é possível representar a estrutura discursiva de um texto coerente. Sabe-se que textos bons manifestam uma estrutura de subtópicos bem definida, logo, deve ser possível extrair essa estrutura de sua representação RST. Essa possibilidade será discutida no Capítulo 6.

Uma observação que se faz sobre os trabalhos de SA que utilizaram segmentação topical, é que a maioria a fizeram como um passo anterior à seleção de conteúdos e relatam 
que alcançaram resultados satisfatórios (Salton et al.,1997; Hovy e Lin, 1998; Farzindar et al. 2005; Ribaldo, 2013). Dentre esses trabalhos, destaca-se Ribaldo (2013) por ter utilizado o mesmo córpus desta pesquisa e também considerar os subtópicos na SA multidocumento. 


\section{SELEÇÃO, ANOTAÇÃO E ANÁLISE DE CÓRPUS}

O CSTNews foi eleito para este trabalho de SA multidocumento por ser o maior córpus multidocumento disponível de que se tem conhecimento para o português do Brasil. O córpus possui 50 conjuntos de textos, organizados por assunto, que foram coletados manualmente no ano de 2007 (Aleixo e Pardo, 2008b; Cardoso et al., 2011a). No total, são 140 textos, que juntos contabilizam 2.088 sentenças e 47.240 palavras. As fontes dos textos são os jornais online Folha de São Paulo, Estadão, O Globo, Jornal do Brasil e Gazeta do Povo. Essas fontes foram escolhidas devido a grande popularidade na web e também por trazerem as principais notícias do dia corrente, que é o que importa para o córpus, ou seja, uma mesma notícia publicada em fontes diferentes.

Inicialmente, o córpus CSTNews se constituía de: (1) anotação manual dos textos-fonte com CST (descrito em Aleixo e Pardo, 2008 e Cardoso et al., 2011a); (2) anotação de expressões temporais dos textos-fonte; (3) análise sintática automática dos textos-fonte; e (4) anotação de sentidos dos substantivos e verbos mais frequentes em cada coleção de acordo com a Wordnet de Princeton (descritos em Nóbrega, 2013 e Sobrevilla Cabezudo et al., 2014); (5) sumários de referência e automáticos (monodocumento e multidocumento); (6) alinhamento manual das sentenças dos sumários multidocumento com as sentenças dos textos-fonte (descrito em Agostini et al., 2012), e (7) anotação manual de aspectos (exemplos: $o$ que, onde, quando, etc) nos sumários multidocumento (descrito em Di Felippo et al., 2014). Todos os sumários multidocumento seguem uma taxa de compressão de $70 \%$ sobre o tamanho do maior texto do grupo, medido em número de palavras. Para viabilizar esta pesquisa, foram produzidas outras camadas de anotação que se referem à RST, segmentação topical e agrupamento em subtópicos.

Este capítulo está organizado em cinco seções: na Seção 5.1, descreve-se a anotação CST; na Seção 5.2, descreve-se a anotação RST; na Seção 5.3, relata-se a anotação de subtópicos; na Seção 5.4, relata-se o agrupamento de subtópicos. Essas camadas de anotação são de especial interesse deste trabalho. Por fim, na Seção 5.5, faz-se as considerações finais deste capítulo. 


\subsection{ANOTAÇÃO CST DO CSTNews}

Como citado, o CSTNews foi previamente anotado com CST no trabalho de Aleixo e Pardo (2008b), no âmbito do projeto SUCINTO. Durante 3 meses, quatro linguistas computacionais exploraram a teoria e propuseram o refinamento do conjunto de relações, apresentado na Figura 3.5 (Maziero et al., 2010). O refinamento consistiu de: a) remoção de algumas relações CST que não foram encontradas nos textos de treinamento e não eram esperadas em textos da língua portuguesa; e b) fusão de algumas relações que eram consideradas idênticas pelos anotadores. Por exemplo, as relações REFINEMENT, DESCRIPTION e ELABORATION, existentes no conjunto original de Radev (2000), foram combinadas na relação ELABORATION. A anotação CST propriamente dita durou 2 meses com reuniões diárias de 1 hora.

Uma vez na semana, os anotadores anotavam o mesmo texto para calcular a concordância da tarefa. Para facilitar a anotação CST, foi usada a ferramenta semiautomática CSTTool (Aleixo e Pardo, 2008a). A frequência das relações CST no córpus é apresentada na Figura 5.1, na qual se observa que algumas relações são muito frequentes, por exemplo, ELABORATION e OVERLAP, enquanto outras são raras, como MODALITY e TRANSLATION. A definição de cada relação CST utilizada encontra-se no Apêndice B.

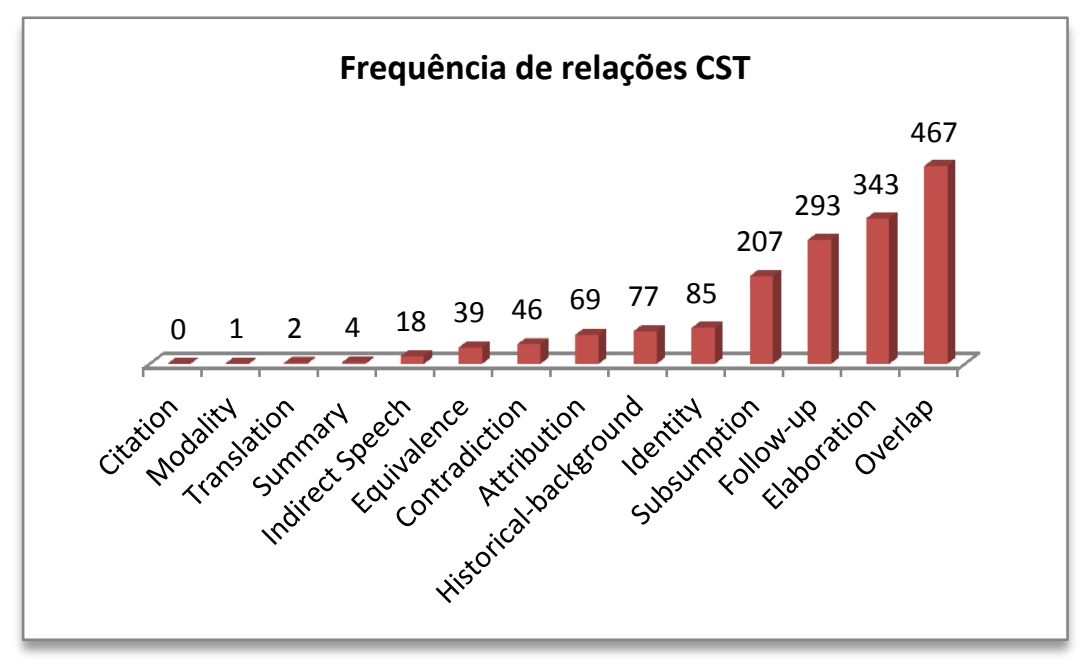

Figura 5.1: Relações CST no córpus

A concordância da anotação CST foi calculada com as medidas Kappa (Carletta, 1996) e percentual de concordância. Com a medida Kappa, verificou-se a concordância sobre a escolha das relações, a direcionalidade das relações e relações agrupadas de acordo com a 
tipologia (em vez de as próprias relações). Embora seja dependente da tarefa que está sob avaliação, um kappa de 0.6 é geralmente aceito como um valor mínimo para que a anotação seja considerada confiável. Para tarefas de análise de discurso, é natural se esperar um valor mais baixo. Na Tabela 5.1, mostram-se os valores de concordância obtidos na anotação CST do córpus. Pode-se ver que os resultados foram bons, considerando o quão subjetiva é a tarefa. A maior concordância alcançada foi quanto aos tipos de relações usadas.

A medida de porcentagem de concordância é baseada no número de vezes em que todos os anotadores concordavam (concordância total), a maioria dos anotadores concordava (concordância parcial) ou nenhuma das anteriores (sem concordância). Tal medida foi usada para comparar o resultado da anotação do CSTNews com a anotação do CSTBank (Zhang et al., 2002) para a língua inglesa. Embora sejam córpus em línguas diferentes, a comparação é feita para dar uma ideia do estado da arte na área. Mostram-se, na Tabela 5.1, os resultados da porcentagem de concordância para a anotação CST. Zhang et al. apontam $58 \%$ de concordância total e parcial (computados juntos) para as relações, enquanto que neste trabalho foi obtido mais de $80 \%$ de concordância. Zhang et al. não usaram a medida Kappa. Esses resultados mostram que houve $81 \%$ de concordância total e parcial para as relações, $85 \%$ de concordância total ou parcial para a direcionalidade, e $91 \%$ de concordância total e parcial para os tipos de relações. Os números da anotação demonstram que a anotação foi bem conduzida e que os resultados são confiáveis o suficiente para serem usados neste trabalho de doutorado.

Tabela 5.1: Kappa e porcentagem de concordância (em \%) da anotação CST

\begin{tabular}{c|c|c|c|c}
\hline $\begin{array}{c}\text { Parâmetros da } \\
\text { concordância }\end{array}$ & $\begin{array}{c}\text { Concordância } \\
\text { Kappa }\end{array}$ & Concordância total & Concordância parcial & Sem concordância \\
\hline Escolha de relações & 0.50 & 54 & 27 & 18 \\
\hline Direcionalidade & 0.44 & 58 & 27 & 14 \\
\hline Tipos das relações & 0.61 & 70 & 21 & 9 \\
\hline
\end{tabular}

\subsection{ANOTAÇÃO RST DO CSTNews}

Para viabilizar este trabalho, adicionou-se uma camada de anotação RST ao córpus CSTNews. Essa anotação foi executada por 8 anotadores, 4 deles com bastante conhecimento em RST e experiência em anotação de textos. Inicialmente, os participantes passaram por uma fase de treinamento de segmentação e anotação que durou aproximadamente 4 semanas, período em que estudaram principalmente o manual de anotação RST de Mann e Thompson 
(1987) e o manual de segmentação de Carlson e Marcu (2001), já utilizados em outros trabalhos da língua portuguesa (Seno e Rino, 2005; Collovini et al., 2007).

Durante a fase de treinamento, algumas regras de segmentação foram adaptadas para a língua portuguesa e são apresentadas no Quadro 5.1. Em seu manual, Carlson e Marcu (2001, p. 21) sugerem que toda oração subordinada relativa deve ser segmentada. Neste trabalho, adotou-se segmentar toda oração subordinada relativa, sem distinguir entre restritivas e explicativas (Regra 7). A razão para essa adaptação é devido à dificuldade de distinguir cláusulas restritivas de explicativas, como explica Rino et al. (2014). Os complementos de verbos de atribuição deveriam ser segmentados somente se o sujeito corresponde fosse animado ou mencionado (por exemplo, uma pessoa, um grupo de pessoas, organizações ou instituições, quando fizesse referência a grupo de pessoas) (Regra 8). A presença de marcadores discursivos fortes ("por exemplo", "por meio de", "quando", “mas”, etc.) também poderia indicar a segmentação adequada. (Regra 2).

\begin{tabular}{|c|c|c|}
\hline Regra \# & Descrição da regra & Exemplos \\
\hline \multirow[b]{2}{*}{1} & \multirow{2}{*}{$\begin{array}{l}\text { Segmentar sentenças que terminam com } \\
\text { ', '?' ou '!'. }\end{array}$} & É uma final. | \\
\hline & & $\begin{array}{l}\text { Qual é o programa mais importante de seu } \\
\text { computador? | }\end{array}$ \\
\hline \multirow{2}{*}{2} & \multirow{2}{*}{$\begin{array}{l}\text { Segmentar segmentos com verbo (oração) } \\
\text { e segmentos sem verbo que tenham } \\
\text { marcador discursivo forte }\end{array}$} & $\begin{array}{l}\text { Eu não sabia das estatísticas, | mas acredito nas } \\
\text { pessoas da Uefa. | }\end{array}$ \\
\hline & & $\begin{array}{l}\text { A partir da temporada 2012/2013, | a Alemanha terá } \\
\text { quatro vagas na Copa dos Campeões. | }\end{array}$ \\
\hline 3 & Segmentar interiores de falas & $\begin{array}{l}\text { "Torço pelo Rodrigão, | que é meu amigo, | mas } \\
\text { todos são merecedores." | }\end{array}$ \\
\hline 4 & $\begin{array}{l}\text { Não segmentar sujeitos e objetos } \\
\text { oracionais }\end{array}$ & $\begin{array}{l}\text { É muito raro alguém perder o jogo e arrancar a } \\
\text { classificação no campo do adversário. | }\end{array}$ \\
\hline \multirow{2}{*}{5} & \multirow{2}{*}{$\begin{array}{l}\text { Segmentar orações coordenadas com } \\
\text { sujeito explícito ou inferido e verbo } \\
\text { explícito ou elíptico }\end{array}$} & $\begin{array}{l}\text { Um dos macacos agarrou um livro de fotos I e } \\
\text { começou a olhar as imagens. I }\end{array}$ \\
\hline & & $\begin{array}{l}70 \% \text { dos recursos são pagos pelo Estado | e os 30\% } \\
\text { restantes, pelas prefeituras regionais. | }\end{array}$ \\
\hline \multirow[t]{2}{*}{6} & \multirow{2}{*}{$\begin{array}{l}\text { Segmentar orações reduzidas de particípio } \\
\text { ou gerúndio somente se elas estiverem } \\
\text { bem marcadas }\end{array}$} & $\begin{array}{l}\text { Eliminado do "BBB 11" no domingo passado, | } \\
\text { Maurício se manteve fiel ao seu grupo de amigos. I }\end{array}$ \\
\hline & & $\begin{array}{l}\text { O navegador da MS chegou a } 96 \% \text { do mercado, I } \\
\text { esmagando o finado Netscape Navigator. | }\end{array}$ \\
\hline
\end{tabular}

Quadro 5.1: Regras de segmentação adaptadas para o córpus CSTNews 
Continuação do Quadro 5.1.

\begin{tabular}{|c|c|c|}
\hline Regra \# & Descrição da regra & Exemplos \\
\hline \multirow[b]{2}{*}{7} & \multirow{2}{*}{$\begin{array}{l}\text { Segmentar todas as orações relativas, } \\
\text { explicativas ou restritivas }\end{array}$} & Ela é uma menina | que sonhou. | \\
\hline & & $\begin{array}{l}\text { Graham Waspe, | que perdeu a visão de um olho, | } \\
\text { disse que | não queria desistir... | }\end{array}$ \\
\hline \multirow{2}{*}{8} & \multirow{2}{*}{$\begin{array}{l}\text { Segmentar diante de verbos } \\
\text { públicos/atributivos, desde que (a) o } \\
\text { sujeito seja mencionado e seja animado } \\
\text { (pessoa ou grupo/organização/instituição } \\
\text { de pessoas), ou diante de marcadores } \\
\text { fortes de atribuição, e (b) haja verbo na } \\
\text { expressão/fala atribuída. }\end{array}$} & $\begin{array}{l}\text { Maurício disse à Folha que | sua torcida é para } \\
\text { Rodrigão. | }\end{array}$ \\
\hline & & $\begin{array}{l}\text { De acordo com o governo, | as santas casas } \\
\text { respondem por } 55 \% \text { das internações. | }\end{array}$ \\
\hline 9 & $\begin{array}{l}\text { Segmentar todos os parênteses e demais } \\
\text { sinais com significado similar (hifens, } \\
\text { barras, dois pontos, etc.) }\end{array}$ & $\begin{array}{l}\text { A resposta mais provável: | o navegador da internet. } \\
\text { | }\end{array}$ \\
\hline
\end{tabular}

Quadro 5.1: Regras de segmentação adaptadas para o córpus CSTNews

Após o treinamento, iniciou-se a anotação propriamente dita, que durou três meses e foi feita com a ferramenta RSTTool (O’Donnell, 2000). A anotação era executada durante 5 dias da semana com encontros que duravam uma hora, seguindo 5 diretrizes:

1. Idealmente, um conjunto de textos devia ser anotado por dia.

2. Grupos de 2 ou 3 analistas anotavam um texto do conjunto do dia.

3. Os grupos eram reorganizados a cada encontro para evitar tendências a vícios de anotação.

4. Quando os anotadores do grupo não chegavam a um consenso, eles apresentavam o problema para outro analista a fim de decidir pela relação ideal. Se o problema ainda persistisse, ou seja, caso a definição da relação não fosse tão clara, escolhiase uma relação mais genérica.

5. A cada 10 grupos de textos anotados, calculava-se a concordância. Nesse caso, todos os grupos segmentavam e anotavam o mesmo texto.

Em geral, os anotadores tentaram realizar uma análise de forma incremental, de modo a tirar proveito da organização do texto-fonte. Nessa análise, assume-se: que primeiramente as orações adjacentes dentro de sentenças devem ser relacionadas; em seguida, as sentenças adjacentes dentro de parágrafos são relacionadas; e, finalmente, os parágrafos adjacentes são relacionados. O conjunto de relações RST utilizado encontra-se no Apêndice A. Na Figura 5.2, ilustra-se o número de ocorrências de cada relação RST no córpus. Algumas relações são muito frequentes (por exemplo, as relações mais genéricas como ELABORATION e LIST), 
enquanto outras são menos frequentes (por exemplo, SUMMARY e OTHERWISE). É interessante observar o alto número de relações estruturais, tais como PARENTHETICAL e SAME-UNIT.

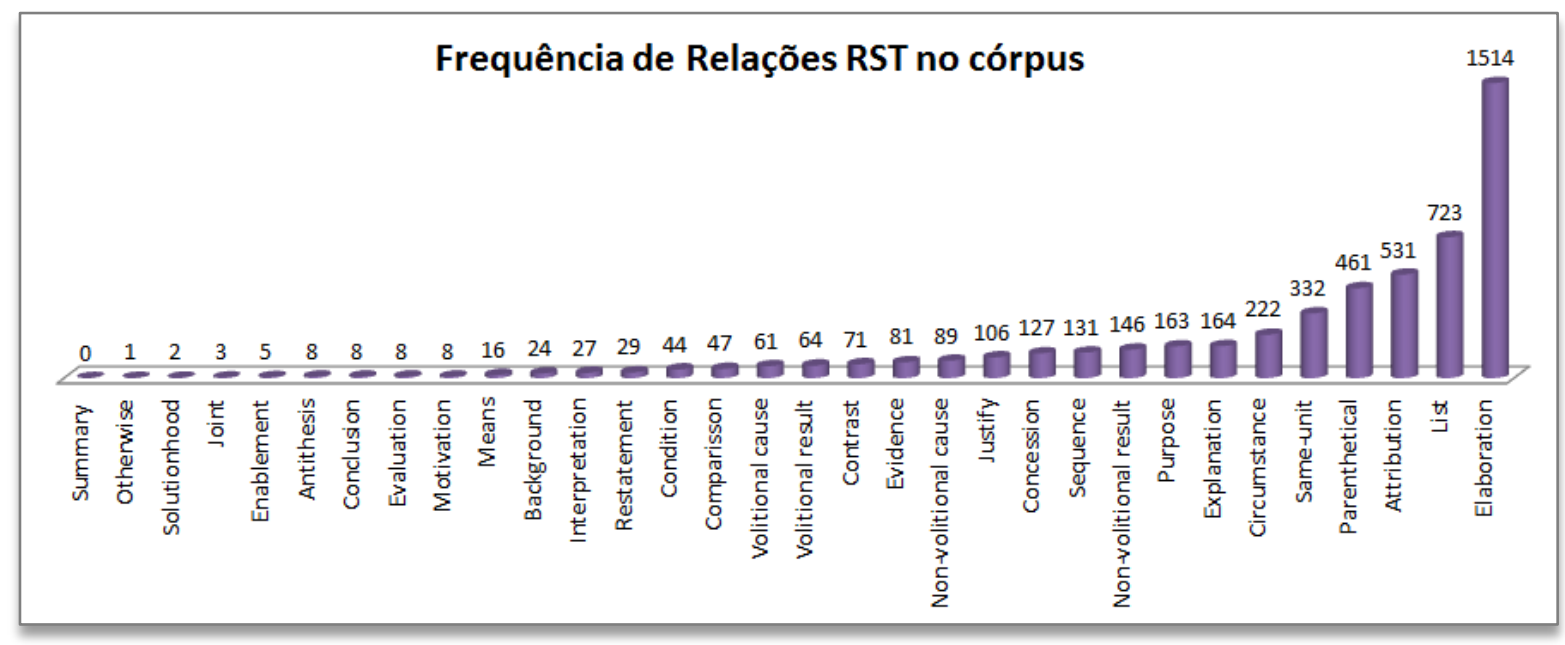

Figura 5.2: Frequência das relações RST no córpus

A concordância da anotação RST foi medida sobre os critérios de segmentação do texto, níveis internos da árvore, a nuclearidade de cada segmento e a relação entre proposições. As métricas utilizadas foram precisão (P), cobertura (C) e medida-f (F), calculadas automaticamente com a ferramenta RSTeval ${ }^{23}$ (Maziero e Pardo, 2009), baseada no trabalho de Marcu (2000b). Para exemplificar o processo, considere um grupo de quatro árvores RST. Uma das árvores é selecionada como ideal e as outras 3 são comparadas com ela, considerando os quatro critérios mencionados anteriormente. Esse processo é repetido quatro vezes, de modo que cada vez uma árvore diferente é selecionada como ideal. Na Tabela 5.2, apresenta-se a média da anotação de cada critério para o córpus CSTNews. Pelos resultados, é possível perceber que os melhores valores de concordância foram no processo de segmentação, que é a etapa menos subjetiva da anotação. Os valores de $\mathrm{P}$ e C são os mesmos porque todas as anotações foram comparadas entre si.

Tabela 5.2: Concordância da anotação RST do córpus CSTNews

\begin{tabular}{l|c|c|c}
\hline \multicolumn{1}{c|}{ Critérios Avaliados } & P & C & F \\
\hline Segmentação & 0.91 & 0.91 & 0.91 \\
\hline Níveis internos da árvore & 0.78 & 0.78 & 0.78 \\
\hline Nuclearidade dos segmentos & 0.78 & 0.78 & 0.78 \\
\hline Escolha de relações & 0.66 & 0.66 & 0.66 \\
\hline
\end{tabular}

\footnotetext{
${ }^{23}$ http://www.nilc.icmc.usp.br/rsteval/
} 
Para fins de comparação, usando a mesma estratégia de avaliação, Marcu (2000b) relata valores para um grupo de cinco textos anotados por dois analistas. $\mathrm{O}$ autor obteve o resultado apresentado na Tabela 5.3.

Tabela 5.3: Concordância da anotação RST de Marcu (2000b)

\begin{tabular}{l|c|c|c}
\hline \multicolumn{1}{c|}{ Critérios Avaliados } & P & C & F \\
\hline Segmentação & 0.88 & 0.88 & 0.88 \\
\hline Níveis internos da árvore & 0.90 & 0.90 & 0.90 \\
\hline Nuclearidade dos segmentos & 0.79 & 0.88 & 0.83 \\
\hline Escolha de relações & 0.83 & 0.83 & 0.83 \\
\hline
\end{tabular}

da Cunha et al. (2011) também realizaram o mesmo processo de avaliação para a anotação do córpus RST Spanish Treebank. O resultado da concordância para os 84 textos anotados por 10 analistas é apresentado na Tabela 5.4.

Tabela 5.4: Concordância da anotação RST de da Cunha et al., (2011)

\begin{tabular}{l|c|c|c}
\hline \multicolumn{1}{c|}{ Critérios Avaliados } & $\mathrm{P}$ & $\mathrm{C}$ & $\mathrm{F}$ \\
\hline Segmentação & 0.87 & 0.91 & 0.89 \\
\hline Níveis internos da árvore & 0.86 & 0.87 & 0.86 \\
\hline Nuclearidade dos segmentos & 0.82 & 0.85 & 0.83 \\
\hline Escolha de relações & 0.77 & 0.78 & 0.77 \\
\hline
\end{tabular}

Embora os textos, as línguas e o volume de dados utilizados por esses autores e neste trabalho sejam muito diferentes, tal comparação dá uma ideia da habilidade humana para concordar em um processo de anotação RST. Em geral, os valores da concordância neste trabalho foram considerados satisfatórios, dada a subjetividade da tarefa.

Os pontos considerados mais difíceis no processo de anotação foram em relação à segmentação ou não de orações subordinadas relativas, escolha da relação e da nuclearidade. A dificuldade do grupo de anotadores em diferenciar orações relativas explicativas das restritivas implicava em diferentes segmentações para um mesmo texto. Nos exemplos 1 e 2 a seguir, extraídos do córpus CSTNews, observa-se diferentes segmentações para a mesma sentença. Ambos anotadores encontram duas proposições, mas com limites em locais diferentes, identificados pela barra (/). Diante da dificuldade, a decisão final do grupo foi segmentar todas as orações relativas.

(1) Com o lucro anunciado hoje, o Itaú passa a ser o banco privado de capital aberto / que mais lucrou no primeiro semestre em pelo menos 20 anos.

(2) Com o lucro anunciado hoje, / o Itaú passa a ser o banco privado de capital aberto que mais lucrou no primeiro semestre em pelo menos 20 anos. 
Quanto à escolha de relações, também se observou algumas divergências. Por exemplo, na Figura 5.3 apresentam-se as análises de dois anotadores, extraídas do córpus CSTNews, para a sentença do exemplo 3. A identificação das proposições é dada entre colchetes.

(3) ${ }^{[1]}$ Após os ataques a tiros, ${ }^{[2]}$ todas as entradas do campus foram fechadas, ${ }^{[3]}$ e as aulas foram suspensas.

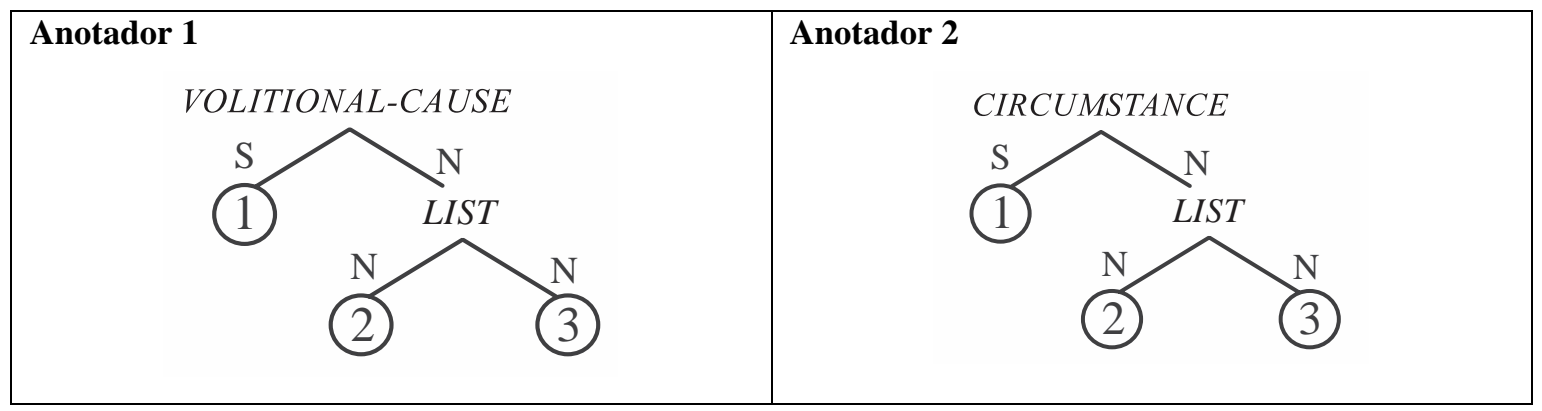

Figura 5.3: Divergências na escolha das relações RST

Fonte: Córpus CSTNews, C18

Apesar de ambos os anotadores concordarem que a proposição 1 é satélite da subárvore à direita, eles discordam quanto à relação entre as mesmas. Para o Anotador 1, a proposição 1 indica a situação na qual $\mathrm{N}$ (proposições 2 e 3 ) deve ser interpretado, logo, há uma relação de CIRCUNSTANCE. Por outro lado, o Anotador 2 entende que a proposição 1 é a causa da ação apresentada em N, portanto, há uma relação de VOLITIONAL-CAUSE. Outro anotador ainda poderia indicar outras relações. Algumas relações são bastante difíceis de distinguir, tais cOMO, INTERPRETATION E JUSTIFY.

Houve casos em que os anotadores discordavam sobre a nuclearidade. Para a sentença do exemplo 4, há duas representações retóricas na Figura 5.4.

(4) ${ }^{[1]}$ Os tucanos, no entanto, disseram que ${ }^{[2]}$ a proposta é ainda insuficiente, para 'seduzir' sua bancada no Congresso e ${ }^{[3]}$ existe um novo aumento do teto de isenção, ${ }^{[4]}$ ou um cronograma de redução da alíquota da CPMF, hoje em 0,38 por cento.

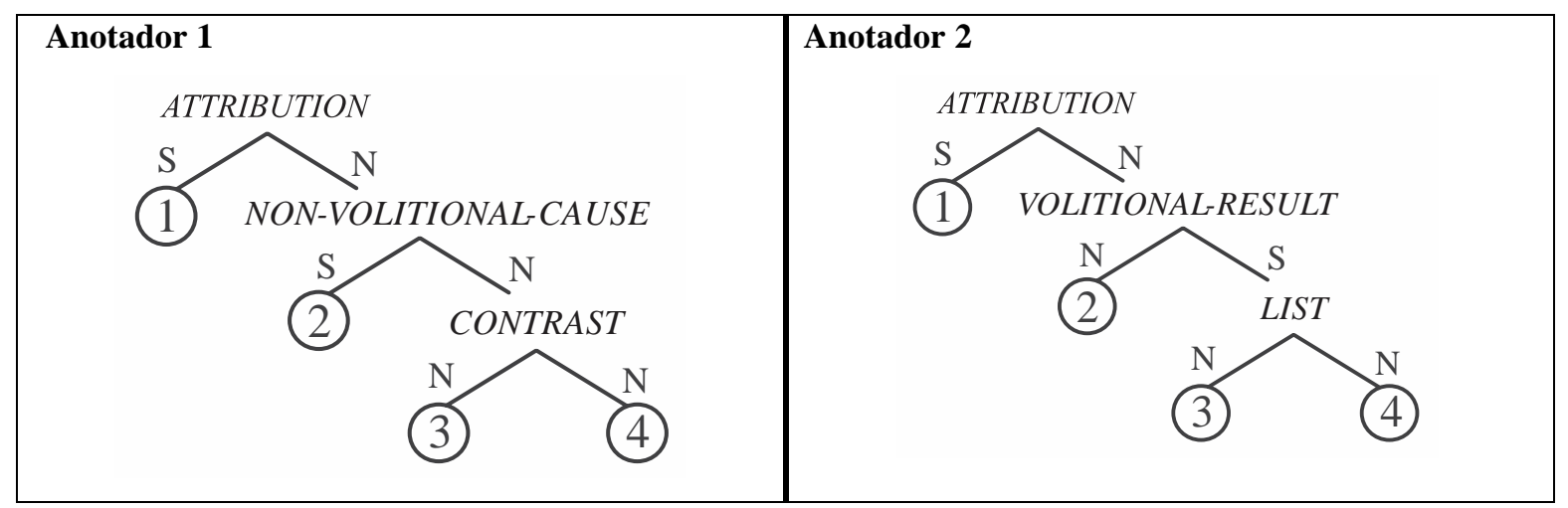

Figura 5.4: Divergências na escolha da nuclearidade

Fonte: Córpus CSTNews, C50 
Na Figura 5.4, o Anotador 1 disse que a informação nuclear de toda a sentença são as proposições 3 e 4, enquanto que para o Anotador 2, a nuclearidade recaí sobre a proposição 2 . Também se observa que os anotadores discordam sobre a relação entre as proposições 3 e 4: para o Anotador 1 é CONTRAST e para o Anotador 2 é LIST. Subindo um nível na árvore, o Anotador 1 colocou a relação NON-VOLITIONAL CAUSE entre as proposições 2 e a subárvore da direita, já o anotador 2, disse que há a relação VOLITIONAL-RESULT. Todas essas diferenças reforçam a ideia de subjetividade inerente ao processo de anotação.

O trabalho de anotação RST foi publicado em Cardoso et al. (2011a).

\subsection{ANOTAÇÃO DE SUBTÓPICOS}

Ainda para viabilizar recursos para este trabalho, adicionou-se a camada de anotação de subtópicos ao córpus CSTNews. Nessa anotação, participaram 14 anotadores com formação em linguística computacional. Durante 3 dias, os anotadores receberam um treinamento de segmentação topical usando um conjunto de textos que não pertencia ao córpus CSTNews, para evitar bias no processo de anotação. Nessa etapa, foram apresentados e discutidos os conceitos de tópico e subtópicos, e definidas as regras de segmentação. As diretrizes de segmentação em subtópicos foram as seguintes:

- A anotação foi individual.

- Não foi permitido diálogo entre anotadores.

- Após cada mudança de subtópico deveria ser acrescentada a seguinte marcação: <t label= "breve descrição do subtópico acima" >. A descrição deveria ser na forma de palavras-chave.

- Os títulos dos textos não foram utilizados, pois nem todos os textos do córpus tem o título disponível.

- Um mesmo texto foi anotado por no mínimo 5 pessoas. Nesse caso, as marcas indicadas por pelo menos 3 anotadores (a maioria) eram consideradas como a anotação final daquele texto.

- Granularidade não foi definida, ou seja, um subtópico poderia ser formado por uma ou mais sentenças. 
- Não foi permitido delimitar subtópicos dentro de sentenças, ou seja, a anotação deveria ser intersentencial.

Três dias de treinamento foram suficientes para que os anotadores tivessem uma noção intuitiva e adquirissem maturidade para executar a tarefa, fatores medidos pela concordância entre eles. Durante as discussões, observou-se concordância satisfatória, verificada empiricamente. Após o treinamento, 7 dias foram necessários para a anotação propriamente dita do córpus. Reuniões diárias foram organizadas, com duração de 1 hora, aproximadamente. Os anotadores foram organizados em grupos de 5 a 7 pessoas cada. Cada grupo recebia um pacote com 10 textos por dia. Os grupos eram formados aleatoriamente, para evitar possíveis tendências nas anotações.

Os anotadores utilizaram o editor de textos de sua preferência para fazer a anotação. Quanto a isso, Hovy e Lavid (2010) argumentam que uma interface projetada para anotação traz agilidade ao processo e evita bias. Por outro lado, Leech (2005) diz que um texto pode ser anotado usando um editor de textos de propósito geral, mas isso significa que algum trabalho manual para correção será necessário. Já que não havia um conjunto enorme de tags nesta anotação (somente 1), não foi desenvolvida uma interface específica para isso. Os anotadores tinham liberdade para ir e voltar no texto e realizar mudanças em partes já anotadas, devido a facilidade de estarem manipulando uma ferramenta que já conheciam. Ao final, algumas correções foram realizadas a fim de unificar a codificação dos textos.

Para certificar que as instruções foram suficientemente claras e os anotadores de fato anotaram o mesmo fenômeno, mediu-se a concordância por meio da medida Kappa (Carletta, 1996). Neste trabalho, era esperado um valor baixo, já que determinar subtópicos é uma tarefa subjetiva. Da esquerda para direita, a Tabela 5.5 mostra os dias de anotação, os grupos de anotadores (representados pelas letras A e B), o número de anotadores em cada grupo, o número de textos anotados em cada grupo por dia e a concordância alcançada. Pode ser observado que, no primeiro dia de anotação, houve a melhor concordância entre anotadores, com $\mathrm{k}=0.656$ para o grupo A e k=0.566 para o grupo B. Por outro lado, a concordância mais baixa aconteceu no segundo dia, com $\mathrm{k}=0.458$ para o grupo A e $\mathrm{k}=0.447$ para o grupo $\mathrm{B}$. A média geral foi $\mathrm{k}=0.560$. Esse valor é considerado satisfatório dada a subjetividade da tarefa. Por outro lado, é baixo, quando comparado com o experimento realizado por Hearst (1997), no qual se obteve $\mathrm{k}=0.647$. Isso pode ser explicado pelo fato de que Hearst usou um conjunto menor de textos (somente 12) do tipo expositivo, nos quais os subtópicos são mais claramente identificados. 
Tabela 5.5: Concordância por grupo de anotadores

\begin{tabular}{|c|c|c|c|c|}
\hline Dia & Grupos & Número de anotadores & Textos por grupo & Карра \\
\hline \multirow{2}{*}{1} & A & 6 & \multirow{2}{*}{10} & 0.656 \\
\hline & B & 7 & & 0.566 \\
\hline \multirow{2}{*}{2} & $A$ & 5 & \multirow{2}{*}{10} & 0.458 \\
\hline & B & 5 & & 0.447 \\
\hline \multirow{2}{*}{3} & $A$ & 7 & \multirow{2}{*}{10} & 0.515 \\
\hline & B & 5 & & 0.638 \\
\hline \multirow{2}{*}{4} & $A$ & 5 & \multirow{2}{*}{10} & 0.544 \\
\hline & B & 7 & & 0.562 \\
\hline \multirow{2}{*}{5} & $A$ & 5 & \multirow{2}{*}{10} & 0.643 \\
\hline & B & 5 & & 0.528 \\
\hline \multirow{2}{*}{6} & $A$ & 5 & 12 & 0.570 \\
\hline & B & 5 & 13 & 0.549 \\
\hline 7 & A & 5 & 15 & 0.611 \\
\hline \multicolumn{4}{|r|}{ Média } & 0.560 \\
\hline
\end{tabular}

Ressalta-se que nem todos os 14 anotadores participaram todos os dias, por isso, os números não coincidem na Tabela 5.5. Por exemplo, no primeiro dia, compareceram 13 anotadores que foram divididos em dois grupos: A, contendo 6 anotadores, e B, com 7 anotadores.

A partir dos textos anotados, foi estabelecida a segmentação de referência para cada texto. Hearst (1997) considerou a opinião de pelo menos três dos sete anotadores disponíveis. Para o córpus CSTNews, contabilizou-se a opinião da metade mais 1 de anotadores concordantes nas quebras. Apesar de ser considerada a opinião da maioria de anotadores, podem ser observadas diferentes segmentações para um mesmo texto. Para exemplificar variações na segmentação, na Figura 5.5 mostra-se um texto com 6 sentenças que descrevem uma explosão em um mercado de Moscou. Na Figura 5.6, mostra-se a segmentação desse texto por 6 anotadores. As linhas numeradas de 1 a 6 representam os anotadores, cada retângulo representa uma sentença e a segmentação é indicada por barras verticais. Final representa os locais de quebra de maior concordância, nesse caso, por pelo menos 3 anotadores. Com seis anotadores, é necessário que pelo menos quatro concordem com uma dada quebra. 


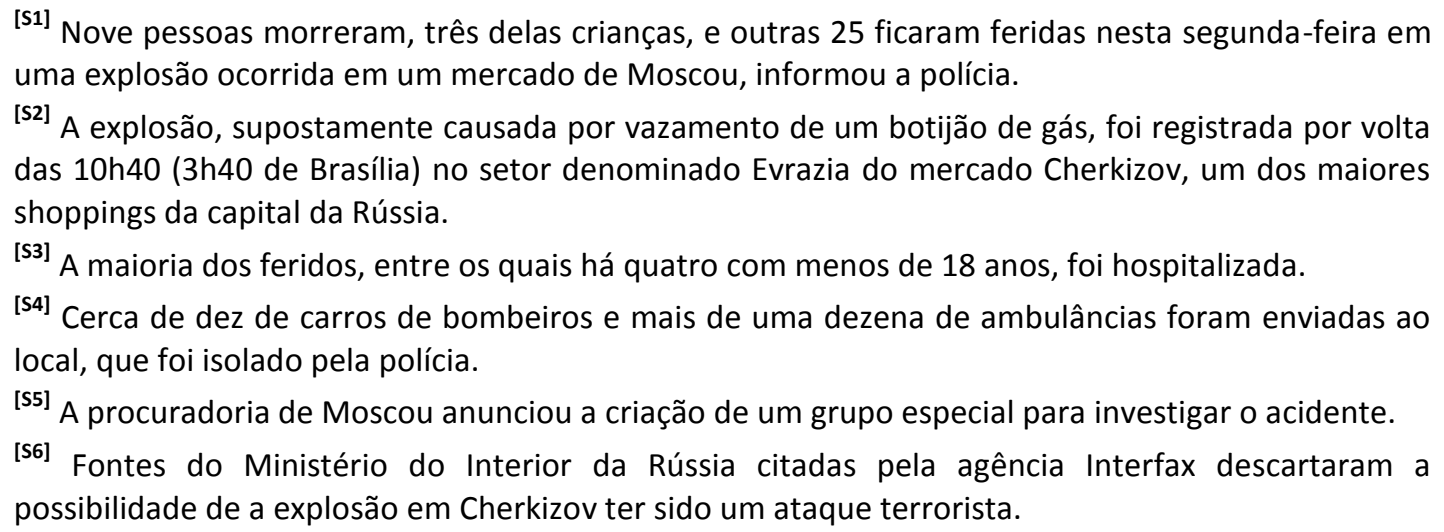

Figura 5.5: Texto-fonte "Explosão em Moscou"

Fonte: Córpus CSTNews, C15_D2

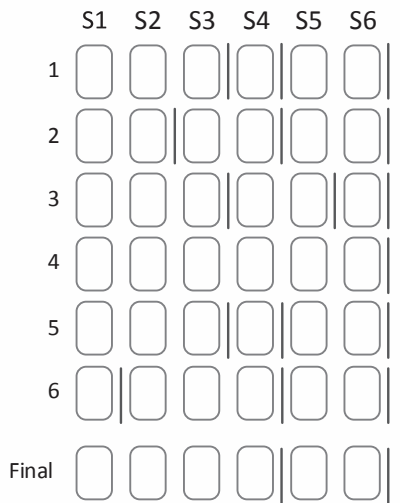

Figura 5.6: Segmentação topical do texto "Explosão em Moscou"

Fonte: Córpus CSTNews, C15_D2

Na Figura 5.6, observa-se que somente o anotador 4 não marcou subtópicos dentro do texto, por isso, ele colocou somente a quebra de fim, que existe independente de qualquer conhecimento. Nesse caso, diz-se que o anotador 4 interpretou que o texto não tinha mudança de subtópico. Três anotadores colocaram quebra após a sentença S3, mas nesse caso, era necessário mais um anotador para que essa quebra fosse validada. $\mathrm{O}$ mesmo acontece com a segmentação após as sentenças S1, S2 e S5, indicadas somente por um anotador. Portanto, nesse texto, as quebras que representam a opinião da maioria são após as sentenças S4 e S6. Se relaxarmos para opinião de pelo menos metade dos anotadores, a consequência será um número maior de subtópicos por texto que não teremos como assegurar que de fato são os grandes subtópicos.

No Quadro 5.2 exibem-se as descrições dos anotadores para alguns dos subtópicos da Figura 5.6. Observa-se que apesar de não ter se transformado em uma quebra válida por ter sido identificada por uma minoria, os anotadores 1, 3 e 5 colocaram descrições similares para 
o subtópico descrito nas sentenças de S1 a S3. Já na quebra indicada pela maioria de anotadores após a sentença S4, as descrições foram bem diferentes. Essa variedade na descrição do subtópico também reflete o fato de que as pessoas utilizam diferentes critérios/conhecimentos para delimitar segmentos topicais.

\begin{tabular}{|c|l|l|}
\hline \multirow{4}{*}{ S1 a S3 } & Anotador 1 & $<$ t label=" O acidente e suas vítimas"> \\
\cline { 2 - 3 } & Anotador 3 & $<$ t label=" O acidente e suas vítimas"> \\
\cline { 2 - 3 } & Anotador 5 & $<$ t label=" Feridos em uma explosão"> \\
\hline \multirow{4}{*}{ S4 } & Anotador 1 & $<$ t label=" O socorro"> \\
\cline { 2 - 3 } & Anotador 2 & $<$ t label=" Providências oficiais"> \\
\cline { 2 - 3 } & Anotador 5 & $<$ t label=" Controle da área"> \\
\cline { 2 - 3 } & Anotador 6 & $<$ t label=" Detalhes"> \\
\hline
\end{tabular}

Quadro 5.2: Descrições dos subtópicos para o texto “Explosão em Moscou”

Fonte: Córpus CSTNews, C15_D2

Ainda caracterizando as anotações de subtópicos do córpus, há algumas coleções que possuem textos-fonte idênticos em termos de conteúdo. Acredita-se que o fato de ter textos duplicados aconteceu naturalmente durante a atividade de coleta de textos-fonte, descrita por Aleixo e Pardo (2008b). Obviamente, cada texto-fonte foi segmentado por um grupo de anotadores diferentes. Como resultado, a segmentação de referência de cada grupo para o mesmo texto, sempre foi diferente. Isso aconteceu com o texto da Figura 5.7, que representa os textos D1 e D2 do cluster C13. O texto (D1 e D2 são idênticos) foi segmentado por 2 grupos (A e B) de anotadores, cada grupo contendo 5 anotadores.

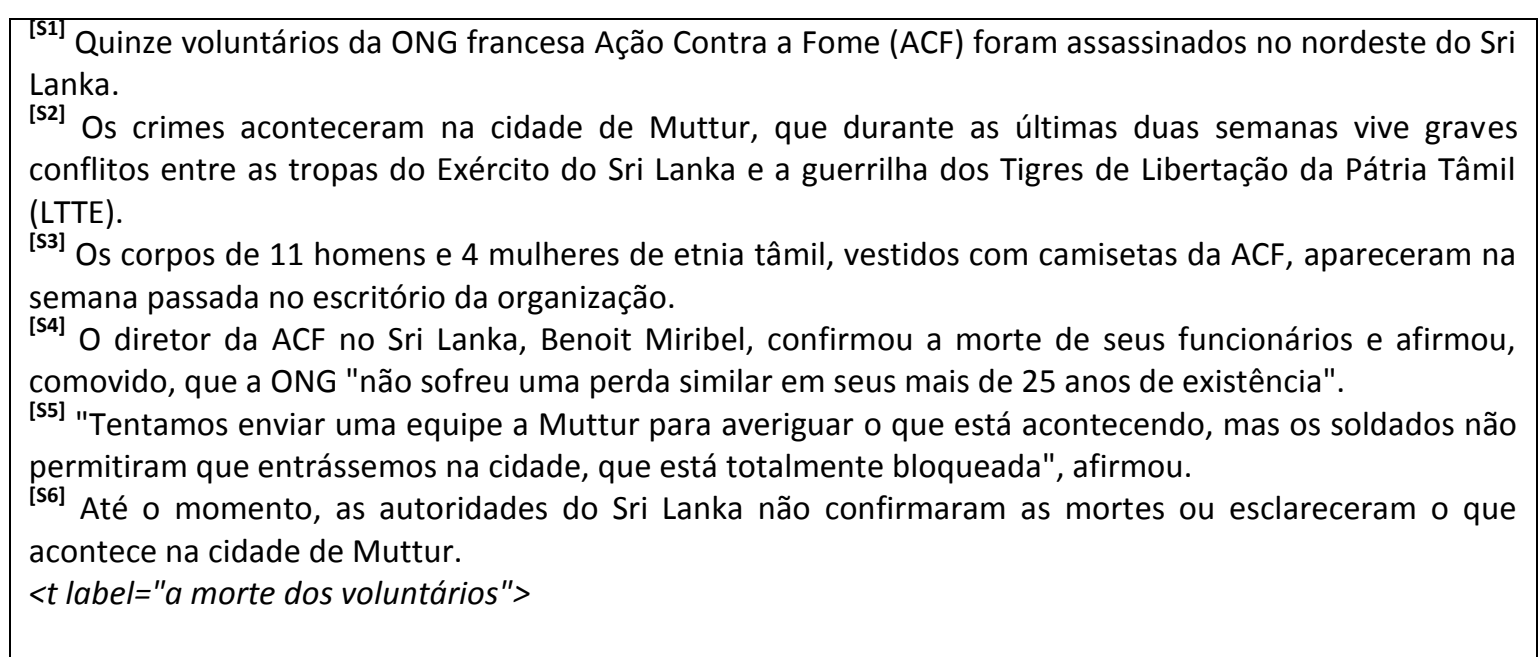

Figura 5.7: Texto com duas segmentações de referência

Fonte: Córpus CSTNews, C13, D1 e D3 
Continuação do texto da Figura 5.7.

${ }^{[57]} \mathrm{O}$ violento conflito começou em 26 de julho, quando as tropas aéreas do Governo bombardearam posições da guerrilha, depois que os rebeldes bloquearam uma represa situada em seu território por mais de uma semana, impedindo a provisão de água em localidades sob controle governamental.

[58] No domingo, o LTTE ofereceu o cessar-fogo em troca do desbloqueio da presa, mas o Governo rejeitou a oferta e lançou uma nova ofensiva sobre a área, de onde mais de 15 mil civis foram obrigados a fugir na última semana.

${ }^{\text {[59] }}$ Os rebeldes afirmaram que consideram o novo bombardeio do Exército equivalente a "uma declaração de guerra".

[510] O enviado especial da Noruega para a paz no Sri Lanka, Jon Hansse-Bauer, chegou na semana passada à ilha e manteve diferentes reuniões com as duas partes, na tentativa de reduzir a tensão e evitar a volta a uma guerra civil.

$<$ label="os conflitos" >

Figura 5.7: Texto com duas segmentações de subtópicos de referência

Fonte: Córpus CSTNews, C13, D1 e D3

Na Figura 5.7, representa-se a segmentação de referência produzida pelo grupo A. A opinião da maioria indicou que o texto (D1) tem 2 subtópicos: o primeiro subtópico contendo as sentenças S1 a S6, e o segundo, com as sentenças S7 a S10. Os anotadores do grupo B, por sua vez, discordaram em vários pontos da segmentação, dificultando achar quebras dentro do texto que houvesse concordância da maioria. Especificamente em D2, a concordância da maioria foi somente na quebra de fim. Mais uma vez, reforça-se a subjetividade da tarefa.

Se por um lado obtiveram-se casos de divergência na segmentação em subtópicos, por outro, houve casos de concordância total. Por exemplo, o texto da Figura 5.8 descreve sobre a participação do nadador Thiago Pereira nos Jogos Pan-Americanos. O texto tem 6 sentenças e está segmentado em 3 subtópicos: o primeiro descreve a vitória de Thiago Pereira, o segundo relata sobre outros atletas que participaram da competição e o terceiro traz um pouco do histórico de medalhas de Thiago. Para esse texto, houve 100\% de concordância na segmentação.

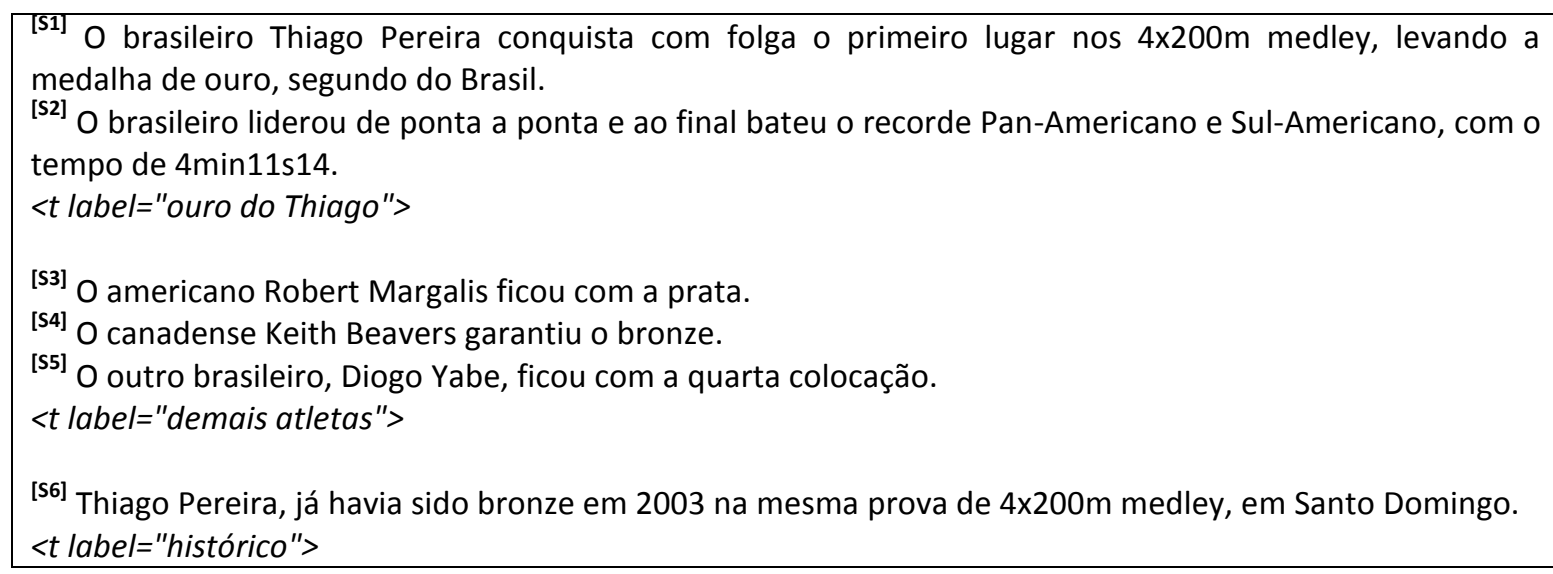

Figura 5.8: Texto com concordância total na segmentação de subtópicos

Fonte: Córpus CSTNews, C38, D4 
No Quadro 5.3, ilustram-se algumas das descrições (label) fornecidas pelos anotadores para os subtópicos do texto da Figura 5.8.

\begin{tabular}{|l|l|l|}
\hline \multirow{4}{*}{ S1 a S2 } & Anotador 1 & $<$ t label=" ouro conquistado por Thiago" \\
\cline { 2 - 3 } & Anotador 3 & $<$ t label=" vitória de Thiago nos 4x200"> \\
\cline { 2 - 3 } & Anotador 5 & $<$ t label=" ouro do Thiago"> \\
\hline \multirow{4}{*}{ S3 a S5 } & Anotador 1 & $<$ t label=" outros nadadores"> \\
\cline { 2 - 3 } & Anotador 2 & $<$ t label=" outras provas"> \\
\cline { 2 - 3 } & Anotador 5 & $<$ t label=" demais atletas"> \\
\hline
\end{tabular}

Quadro 5.3: Descrições para os subtópicos do texto "Brasil leva ouro no revezamento" Fonte: Córpus CSTNews, C38, D4

Mesmo que os anotadores forneçam descrições diferentes, é possível perceber que, nesse caso, elas têm significados muito próximos. Dizer que as sentenças S1 e S2 descrevem sobre o ouro conquistado por Thiago ou da vitória do atleta na prova tem o mesmo sentido, ainda que possuam referências linguísticas diferentes. Isso também se observa para a quebra após S5, na qual os anotadores concordam que as sentenças de S3 a S5 relatam outros nadadores e não inclui o atleta Thiago Pereira.

$\mathrm{Na}$ literatura descrita no Capítulo 4, muitos dos trabalhos pediram que os anotadores dessem uma descrição, mas não relataram como as utilizaram (por exemplo, Kazantseva e Szpakowicz, 2012; Ambwani e Davis, 2010; Passonneau e Litman, 1997). Neste trabalho, as descrições indicadas por cada anotador após as quebras em subtópicos não foram utilizadas para definir a marcação final. As descrições serviram para verificar empiricamente se os anotadores haviam compreendido a tarefa, de forma que alguma palavra da descrição deveria estar contida no subtópico correspondente. Se fosse realizado o cômputo das palavras das descrições com as palavras das sentenças, era possível verificar grande sobreposição de conteúdo.

Na Figura 5.9, mostra-se o número de subtópicos na anotação de referência. Observa-se que a menor quantidade de subtópicos encontrada foi de 1 em 8 textos (corresponde a $6 \%$ do córpus), 2 subtópicos em 24 textos (17\%), 3 subtópicos em 50 textos (36\%), 4 subtópicos em 31 textos (22\%), 5 subtópicos em 19 textos (14\%), 6 subtópicos em 4 textos (3\%), 7 subtópicos em 2 textos (1\%) e 8 subtópicos em 2 textos (1\%). Em média, foram apontados 3 
subtópicos por texto. Ressalta-se que para a Figura 5.9 não se verificou se havia subtópicos repetidos no mesmo texto, ou seja, contabilizou-se apenas a quantidade de quebras.

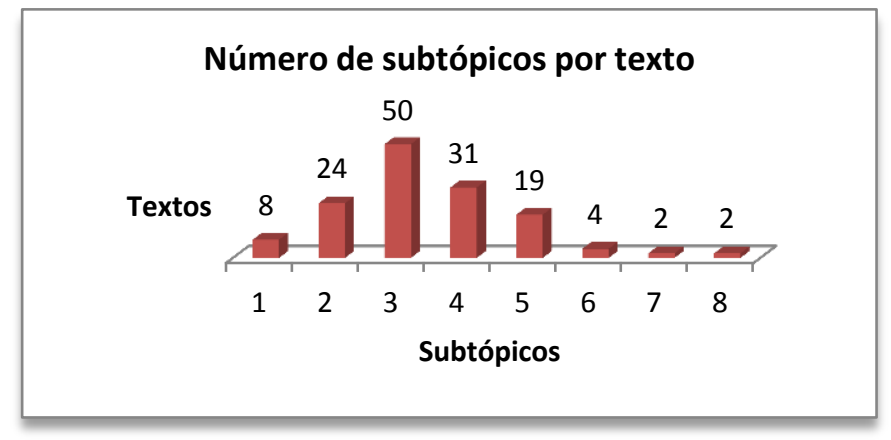

Figura 5.9: Número de subtópicos por texto-fonte

A maioria das quebras de subtópicos ocorre entre parágrafos. Somente em $4 \%$ do córpus (6 textos) aconteceram quebras dentro de parágrafos. Acredita-se que isso está relacionado a forma como as pessoas aprenderam a escrever, utilizando parágrafos como um recurso para organização do texto. O parágrafo é organizado em torno de uma ideia-núcleo, que é desenvolvida por ideias secundárias. Em geral, quando se pretende mudar de assunto, deve-se iniciar um novo parágrafo. Ainda que se faça tal consideração, ressalta-se que o anotador recebia os textos segmentados em sentenças para realizarem a anotação de subtópicos.

A anotação de subtópicos do córpus CSTNews foi publicada em Cardoso et al. (2013a).

\subsection{AGRUPAMENTO DE SUBTÓPICOS}

Após a segmentação em subtópicos, realizou-se agrupamento manual dos subtópicos de cada coleção de textos. Nessa etapa, o objetivo era encontrar subtópicos de diferentes textos que eventualmente fossem semelhantes, já que se tratam de textos relacionados. Um anotador realizou a leitura dos subtópicos de referência e atribuiu identificadores iguais quando os subtópicos de diferentes textos tratassem do mesmo assunto. Em alguns casos, o identificador de um subtópico poderia aparecer mais de uma vez em um mesmo texto, mas nunca para subtópicos adjacentes, mantendo a segmentação de referência. Os dois textos da Figura 5.10 exemplificam a segmentação monodocumento de referência. Os textos pertencem a uma mesma coleção, cujo tópico principal é "a vitória da seleção brasileira masculina de vôlei". 


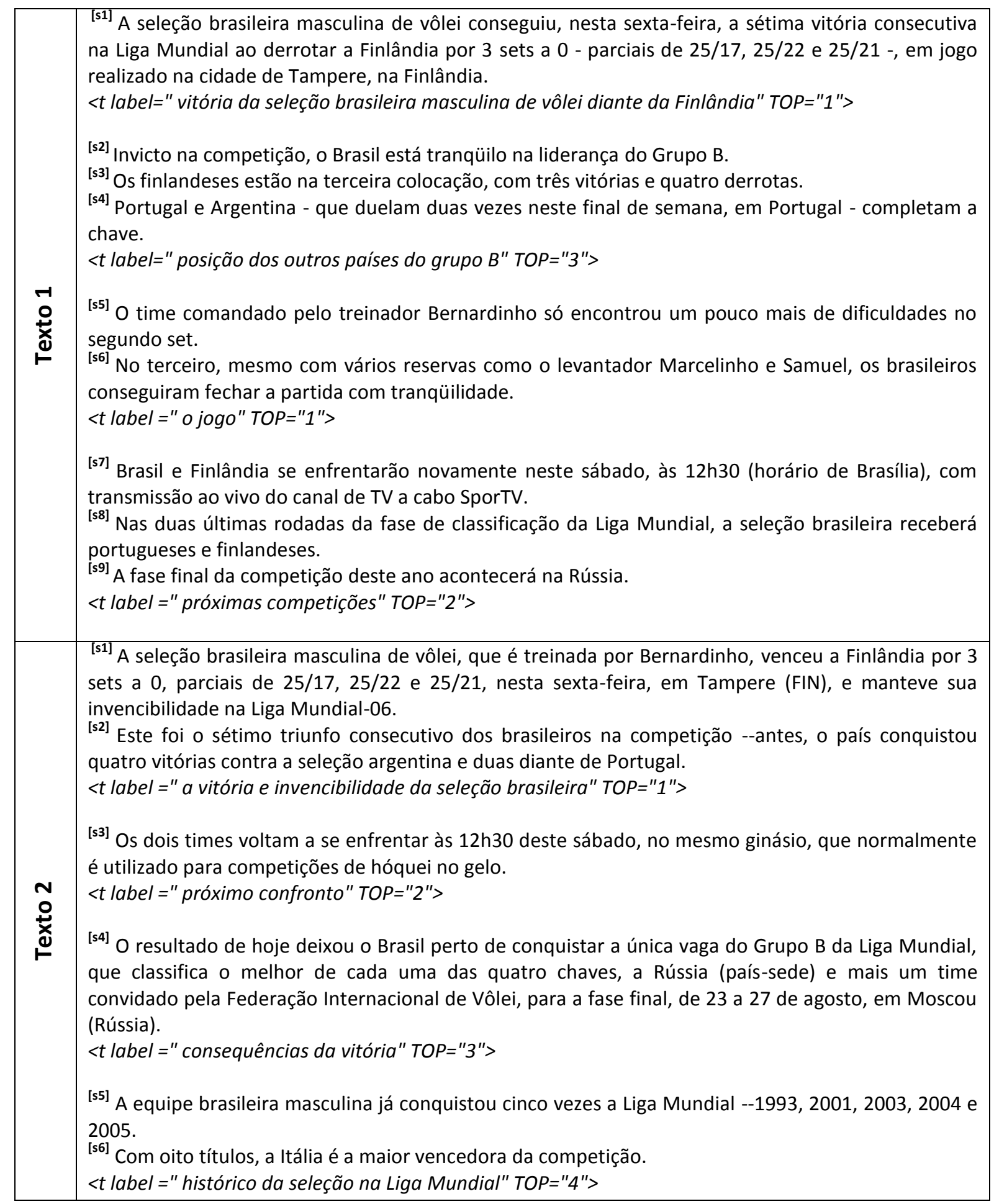

Figura 5.10: Exemplo de agrupamento manual de subtópicos

Fonte: Córpus CSTNews (D1 e D2 do C8)

O texto 1 da Figura 5.10 foi segmentado em 4 partes, rotuladas de: "vitória da seleção brasileira masculina de vôlei diante da Finlândia", "posição dos outros países do grupo B”, "o jogo" e "próximas competições". Ao analisar a segmentação desse texto, o anotador determinou que o subtópico formado pela sentença S1 e o subtópico formado pelas sentenças 
S5-S6 tratam do mesmo subtópico, portanto, deveriam ser agrupados. O agrupamento é indicado pela tag TOP e um número-identificador. Quando dois subtópicos são agrupados, a tag TOP deve receber o mesmo valor. Nesse caso, os dois subtópicos recebem TOP=1. O subtópico formado pelas sentenças S2-S4 não poderiam ser agrupados com o bloco acima ou abaixo, pois o humano já os tinha separados. De acordo com o anotador, o conteúdo dos subtópicos de S2-S4 e S7-S9 não possuem uma relação direta, portanto, devem ficar separados. Nesse caso, o subtópico de sentenças $\mathrm{S} 2-\mathrm{S} 4$ do texto é identificado por TOP=3 e o bloco de S7-S9 é TOP=2. Assim, o texto 1 possui 3 subtópicos, identificados por 1, 2 e 3.

$\mathrm{O}$ texto 2 da Figura 5.10 também foi segmentado em 4 partes: "a vitória e invencibilidade da seleção brasileira", "próximo confronto", "consequências da vitória" e “histórico da seleção na Liga Mundial”, referenciados nos labels. Ao analisar o texto 2, o anotador identificou que alguns subtópicos eram similares aos do texto 1 , logo, deveriam ser agrupados. O primeiro subtópico do texto 2, formado pelas sentenças S1-S2 foi agrupado ao subtópico 1 e por isso tem $\mathrm{TOP}=1$. O subtópico formado pela sentença $\mathrm{S} 3$ no texto 2 foi agrupado ao subtópico 2 do texto 1 (S7-S9). O subtópico formado pela sentença S4 foi agrupado ao subtópico 3 do texto 1 (S2-S4). Para o último subtópico do texto 2 não foi encontrado um subtópico correspondente no texto, portando, esse subtópico não foi agrupado e recebeu como identificador $\mathrm{TOP}=4$.

O anotador fez essa análise para todo o córpus e agrupou os subtópicos. O agrupamento foi indicado em cada texto segmentado pelo acréscimo da tag TOP junto da descrição fornecida na segmentação monodocumento de referência. Além disso, para cada cluster se produziu um arquivo-resumo contendo o agrupamento de um cluster, na seguinte forma:

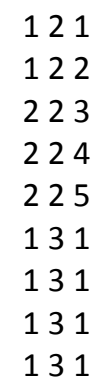

na qual, a primeira coluna indica o identificador do subtópico, a segunda coluna representa o identificador do documento e a terceira coluna indica o número da sentença. Nesse caso, estariam representados dois documentos acima ( 2 e 3 na segunda coluna); o documento 2 tem 2 subtópicos (1 e 2 na primeira coluna); as sentenças de 1-2 do documento 2 pertencem ao subtópico 1 e as sentenças de 3-4 do mesmo documento estão no subtópico 2. O documento 3, 
por sua vez, só tem o subtópico 1. Pela representação é possível saber que ambos os documentos possuem o subtópico 1, mas somente o documento 2 tem o subtópico 2.

Após o agrupamento, há uma nova frequência de subtópicos no córpus, ilustrada na Figura 5.11. Observa-se que 8 textos contém somente 1 subtópico, 49 textos tem apenas 2, 51 possuem textos 3 subtópicos e assim por diante.

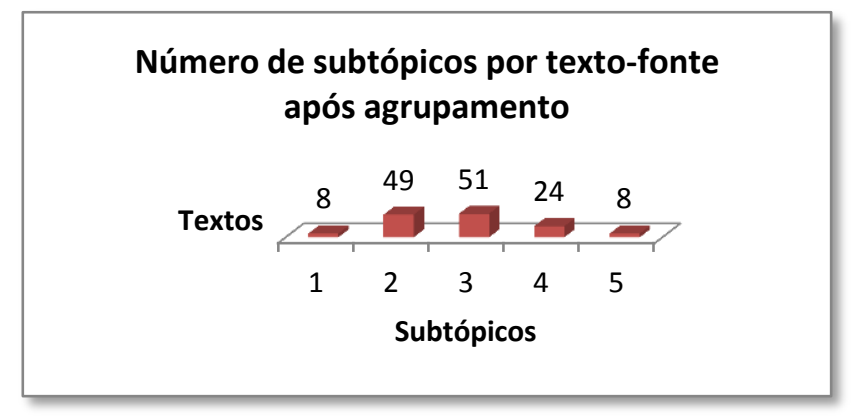

Figura 5.11: Número de subtópicos por texto-fonte após agrupamento

Na Tabela 5.6, apresenta-se o total de subtópicos por coleção. Há 4 coleções com 2 subtópicos, 6 coleções com 3, 19 coleções com 4, 11 coleções com 5, 7 coleções com 6 e 3 coleções com 7. A média de subtópicos por coleção é 4.

Tabela 5.6: Total de subtópicos por coleção de texto-fonte

\begin{tabular}{c|c}
\hline Número de coleções de textos & Número de subtópicos \\
\hline 4 & 2 \\
\hline 6 & 3 \\
\hline 19 & 4 \\
\hline 11 & 5 \\
\hline 7 & 6 \\
\hline 3 & 7 \\
\hline
\end{tabular}

\subsection{CONSIDERAÇÕES FINAIS}

Este capítulo apresentou o córpus CSTNews que foi utilizado para validar este trabalho. Para tanto, além da anotação CST previamente disponível, foram acrescentadas anotações de subtópicos e RST. Todas as anotações foram sistematizadas, atingindo níveis de concordância aceitáveis, que permitem que o córpus CSTNews subsidie esta pesquisa.

Na sequência, apresentam-se os métodos de segmentação e agrupamento de subtópicos. 


\section{DESENVOLVIMENTO DE MÉTODOS DE SEGMENTAÇÃO E AGRUPAMENTO DE SUBTÓPICOS}

Neste Capítulo, descrevem-se os métodos de segmentação e agrupamento de subtópicos desenvolvidos neste trabalho.

\subsection{MÉTODOS DE SEGMENTAÇÃO AUTOMÁTICA EM SUBTÓPICOS}

Para identificar e segmentar um texto em subtópicos propõem-se quatro métodos baseline e seis métodos inéditos baseados em atributos discursivos.

Os métodos baseline segmentam o texto em parágrafos, sentenças, aleatoriamente e com base na reiteração de palavras. Sabe-se que o parágrafo é uma unidade constituída por um ou mais períodos, em que se desenvolve determinada ideia central. Por esse motivo, a segmentação em parágrafos é considerada um forte baseline e já foi preferida em outros trabalhos (Hearst, 1997; Salton et al., 1997; Kazantseva et al., 2012;). Igualmente, pode-se pensar que os subtópicos são organizados em sentenças, pois elas possuem sentido completo, e, portanto, indicam um forte baseline. Assim como o parágrafo, a sentença já foi adotada como unidade em outros trabalhos de segmentação em subtópicos (Chang et al., 2003; Riedl et al., 2012). O método que faz quebras aleatórias (a quantidade e locais de quebras são decididos aleatoriamente) é para fins de comparação. A motivação para essa estratégia é fornecer um limite inferior para o desempenho de qualquer outra estratégia, pois se espera que todas as outras apresentem resultados acima do aleatório. A estratégia de reiteração de palavras trata-se de uma adaptação do TextTiling (Hearst, 1997), um dos métodos mais conhecidos da área, portanto, outro forte baseline. Segundo Hearst, os parâmetros pseudosentenças ( $\mathrm{w}=$ tamanho médio da sentença) e tamanho do bloco ( $\mathrm{k}=$ aproximadamente o tamanho do parágrafo em número de sentenças) podem ser configurados para o tipo de texto de entrada. Neste trabalho, com base em análise do córpus empregado, adotou-se w=20 e k=2.

Hovy e Lin (1998) sugerem que conhecer a estrutura discursiva ajuda na identificação dos subtópicos de um texto. Segundo Pinheiro (2002), a organização tópica de diferentes gêneros textuais, falados e escritos, a noção de topicalicade se evidencia. Como anteriormente citado, a topicalidade funciona como um princípio organizador do discurso. Neste trabalho, 
assume-se que bons textos possuem uma boa estrutura de subtópicos, que pode ser representada em uma estrutura discursiva, neste caso, uma árvore RST. Com isso em mente, foram elaborados seis métodos de segmentação em subtópicos que utilizam como atributos nuclearidade e as relações RST. O primeiro algoritmo, referenciado por Cosseno Simples, é baseado no trabalho de Marcu (1998b, 2000a) para medir a qualidade de uma árvore discursiva. $\mathrm{O}$ autor assume que uma árvore discursiva é melhor se ela exibe uma estrutura que se assemelha a estrutura de subtópicos do texto para o qual foi construída. Marcu associa uma pontuação de agrupamento para cada nó da árvore. Para as folhas, essa pontuação é zero; para os nós internos, a pontuação é dada pela similaridade lexical entre os filhos imediatos. A hipótese subjacente a essa medida é que as melhores árvores exibem alta similaridade entre seus nós. Neste trabalho, adotou-se essa mesma ideia usando a medida do cosseno (equação 5) e propõe-se que: 1) segmentos com vocabulário similar provavelmente fazem parte do mesmo subtópico e; 2) nós com notas abaixo da média supostamente indicam quebras de subtópicos.

Para exemplificar a aplicação do método Cosseno Simples e dos outros métodos de segmentação em subtópicos, considere o texto da Figura 6.1, já com a segmentação (anotação) de referência. O texto está organizado em três parágrafos e tem como tópico principal "parlamentares acusados de superfaturar ambulâncias", que está estruturado em dois subtópicos: 1) sentenças de 1 a 3 descrevem a "abertura dos processos por quebra de decoro"; e 2) sentenças de 4 a 5 descrevem candidatos que possivelmente vão renunciar e outros que já o fizeram. Na Figura 6.2, representa-se a árvore retórica desse texto e cada nó-folha simboliza uma sentença. As linhas tracejadas representam as quebras de subtópicos atribuídas pelo método Cosseno Simples: uma quebra entre as sentenças 1 e 2 e outra entre as sentenças 4 e 5 . Nesse exemplo, o método Cosseno Simples segmentou bem próximo da quebra de referência. O TextTiling não segmentou dentro do texto. Vale lembrar que a quebra de fím (após a última sentença) está implícita, independente do método que se aplica. 


\begin{tabular}{|c|c|}
\hline Parágrafo & \\
\hline P1 & $\begin{array}{l}\text { [1] Os parlamentares acusados de envolvimento com o esquema de superfaturamento das } \\
\text { ambulâncias têm até a meia-noite desta segunda-feira, dia } 21 \text {, para renunciar ao mandato, caso } \\
\text { queiram escapar do julgamento por quebra de decoro. } \\
\text { [2] O prazo foi definido pela direção da Câmara. }\end{array}$ \\
\hline P2 & $\begin{array}{l}\text { [3] Na terça-feira, dia 22, o presidente do Conselho de Ética, Ricardo Izar (PTB-SP), deve } \\
\text { começar a abrir processos contra os parlamentares acusados que permanecerem em seus } \\
\text { cargos. } \\
\text { <label="abertura dos processos por quebra de decoro"> }\end{array}$ \\
\hline P3 & $\begin{array}{l}\text { [4] Um membro da cúpula da Câmara que conversou com } 30 \text { acusados calcula que pelo menos } \\
\text { sete podem renunciar, entre eles: Nilton Capixaba (PTB-RO), Marcelino Fraga (PMDB-ES), César } \\
\text { Bandeira (PFL-MA), Benedito Dias (PP-AP) e Carlos Nader (PL-RJ). } \\
\text { [5] O pefelista Coriolano Sales (PFL) já apresentou sua renúncia desde a semana passada. } \\
\text { <label="renúncias possíveis e concretizadas"> }\end{array}$ \\
\hline
\end{tabular}

Figura 6.1: Texto "Parlamentares" com a segmentação de subtópicos de referência

Fonte: Córpus CSTNews, C16_D3

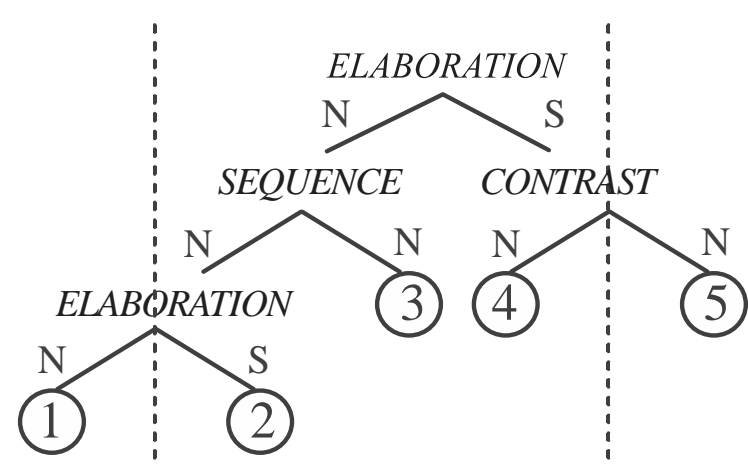

Figura 6.2: Estrutura RST com segmentação de subtópicos pelo método Cosseno Simples

O segundo método, referenciado por Cosseno entre Núcleos, também se baseia em uma proposta de Marcu para identificar boas árvores discursivas (1998b, 2000a). Nessa formalização, assume-se que sempre que uma relação discursiva ocorre entre dois spans, ela acontece entre as unidades mais salientes (núcleos) associados com tais spans. No método Cosseno entre Núcleos, calcula-se a similaridade exclusivamente entre unidades salientes associadas a dois spans. Novamente, nós com pontuação abaixo da média supostamente indicam quebras topicais. Para o texto da Figura 6.1, a segmentação pelo método Cosseno entre Núcleos foi igual a do método Cosseno Simples (já representado na Figura 6.2).

Neste trabalho, buscou-se pelos grandes subtópicos de um texto que provavelmente ocorrem nos níveis mais altos de uma estrutura discursiva. Assim, os nós mais altos (posição na árvore) são mais fracamente conectados e podem melhor representar os limites topicais. Para simular isso, elaboraram-se dois métodos chamados de Cosseno Simples com Altura e Cosseno dos Núcleos com Altura, ambos são variações dos métodos Cosseno Simples e 
Cosseno dos Núcleos com Altura. Nessas duas novas estratégias, a similaridade entre dois nós é dividida pela altura onde ocorre, percorrendo a árvore no sentido bottom-up (das folhas para a raiz: do nível zero para o topo da árvore). Novamente, nós com nota abaixo da média supostamente indicam as quebras topicais.

Na Figura 6.3, representa-se árvore do texto "Parlamentares" com as linhas tracejadas indicando as quebras de subtópicos, atribuídas pelo método Cosseno dos Núcleos com Altura. A nota de similaridade entre os nós 1 e 2 (o núcleo de uma folha é a própria folha) é dividida por 1 (estão no nível mais baixo); a similaridade entre o conjunto promocional de ELABORATION (nó 1) e o nó 3 é dividida por 2 (estão em um nível maior); a similaridade entre os nós 4 e 5 é dividida por 1; a nota entre o conjunto promocional de SEQUENCE (nós 1 e 3) e o conjunto promocional de CONTRAST (nós 4 e 5) é dividida por 3, que corresponde a altura da árvore. Diferentemente dos métodos anteriores, o método Cosseno dos Núcleos com Altura colocou uma quebra entre as sentenças 3 e 4, totalizando três quebras dentro do texto. No caso do método Cosseno Simples com Altura, a segmentação ficou igual a dos métodos Cosseno Simples e Cosseno entre Núcleos (já representada na Figura 6.2).

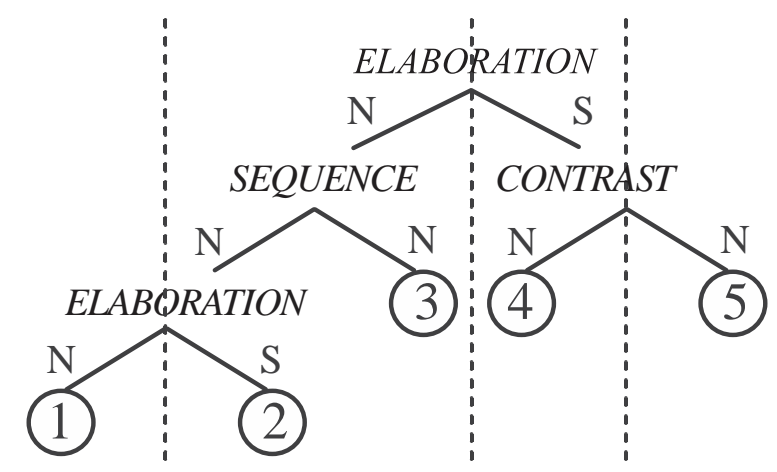

Figura 6.3: Estrutura RST do texto "Parlamentares" com segmentação em subtópicos pelo método Cosseno dos Núcleos com Altura

Além de medidas de similaridade entre segmentos, investigou-se a segmentação em subtópicos com base nas relações discursivas. Para isso, realizou-se análise do córpus anotado manualmente com RST e subtópicos a fim de encontrar relações que possivelmente indicariam mudança de subtópico. No córpus, existem 29 tipos de relações RST que podem conectar sentenças, as quais podem ser vistas na Figura 6.4, juntamente com suas frequências. Para esse estudo, desconsideram-se as relações PARENTHETICAL, ATTRIBUTION e SAMEUNIT, que normalmente ocorrem dentro de sentenças. Há um desbalanceamento de relações e é uma questão importante a ser considerada. Por exemplo, a relação ELABORATION tem quase 
800 exemplos, enquanto outras relações têm menos de 10 amostras, tais como as relações JOINT E SOLUTIONHOOD.

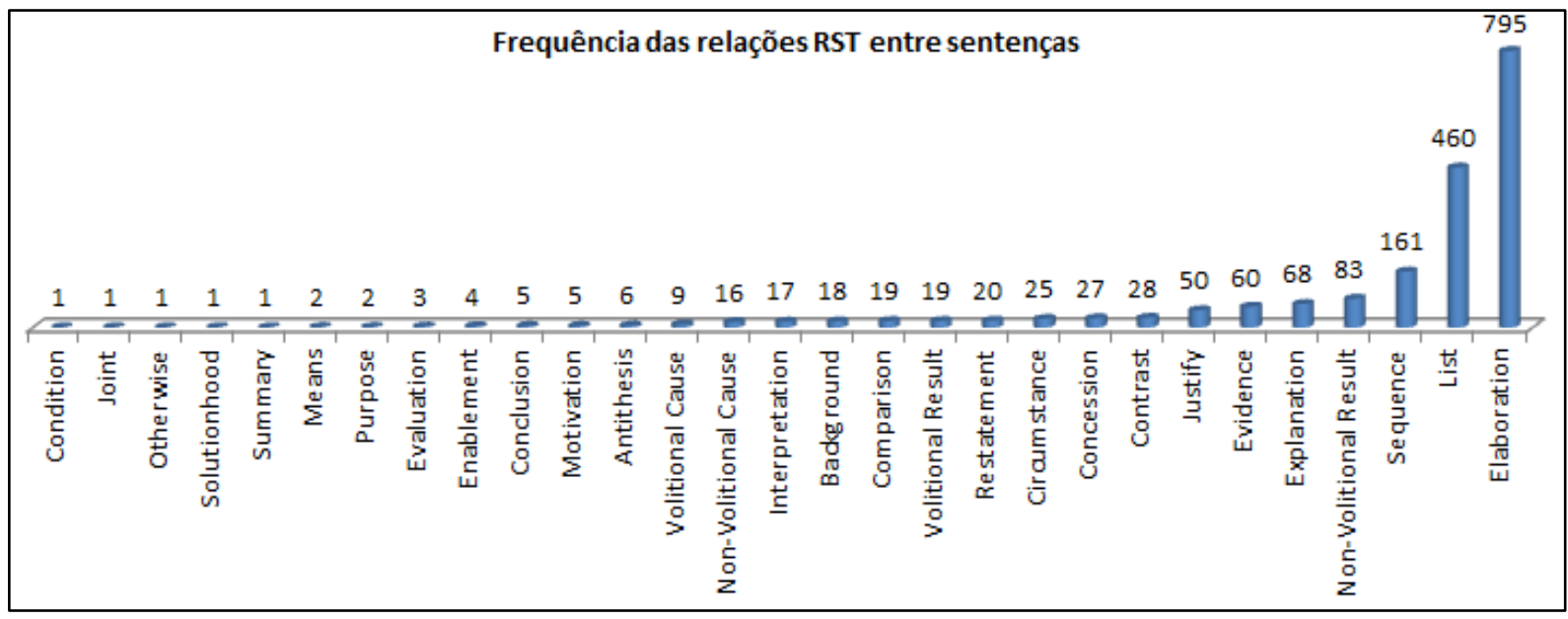

Figura 6.4: Frequência das relações RST entre sentenças no córpus CSTNews

A partir da análise de córpus, observou-se que nas mudanças de subtópicos algumas relações foram mais frequentes enquanto outras nunca ocorreram. Na Figura 6.5, mostram-se somente as relaçoes RST com frequência acima de 3 nos locais de mudança de subtópico.

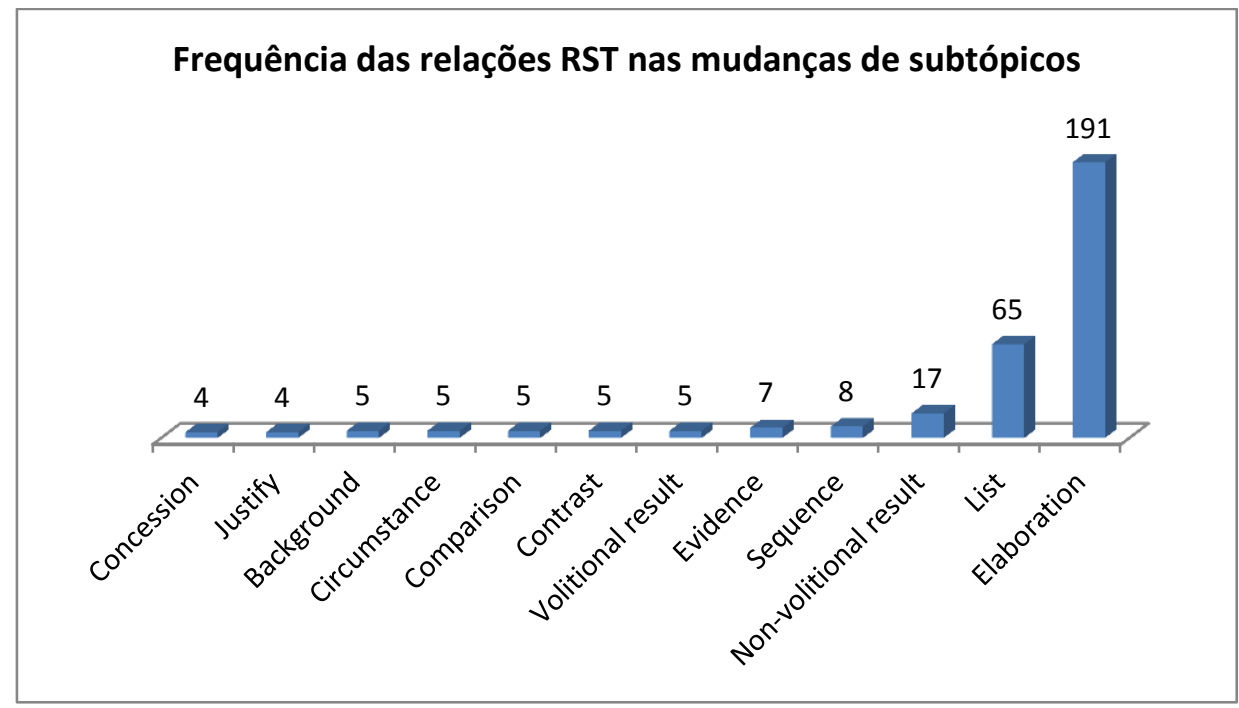

Figura 6.5: Frequência das relações RST nas mudanças de subtópicos encontradas no córpus CSTNews

Foram 12 relações RST mais frequentes. Como esperado, a relação ELABORATION foi a mais frequente, aparecendo em 191 casos (corresponde a 57\% das mudanças de subtópicos). As relações LIST e NON-VOLITIONAL RESULT apareceram em 65 vezes (19\%) e 17 vezes (5\%), respectivamente. As relações EVIDENCE e SEQUENCE apareceram em 2\% das quebras 
topicais. BACKGROUND, CIRCUMSTANCE, COMPARISON, CONCESSION, CONTRAST, JUSTIFY, e VOLITIONAL-RESULT foram menos frequentes, cada relação apareceu somente em $1 \%$ das mudanças de subtópicos. As demais relações foram menos frequentes e totalizam 8\%, são elas: ANTITHESIS, JOINT, MOTIVATION, PURPOSE, INTERPRETATION, NONVOLITIONAL CAUSE, VOLITIONAL CAUSE e EXPLANATiON. As relações RST que nunca apareceram nas mudanças de subtópicos foram 8: CONDITION, OTHERWISE, SOLUTIONHOOD, SUMMARY, EVALUATION, ENABLEMENT, CONCLUSION E RESTATEMENT.

Mesmo havendo uma diferença significativa entre as relações RST presentes no córpus e aquelas nas mudanças de subtópicos, buscou-se uma forma de utilizar essa informação sobre a frequência. Na literatura, encontram-se trabalhos que atribuíram pesos para as relações com base em alguma classificação. Por exemplo, O’Donnell (1997) e Uzêda et al. (2010) desenvolveram métodos de SA que assumem que cada relação RST tem associada uma pontuação de relevância que indica quão importante os respectivos segmentos são para o sumário. Da mesma forma, neste trabalho atribuiu-se um peso associado com a possibilidade de uma relação RST indicar mudança de subtópico, de acordo com sua frequência na segmentação de referência e sua definição, descrita em Mann e Thompson, 1987. No Quadro 6.1, mostram-se como as 29 relações foram distribuídas e seus respectivos pesos, definidos empiricamente.

\begin{tabular}{|c|l|}
\hline \multicolumn{1}{|c|}{ Classe } & \multicolumn{1}{|c|}{ Relações } \\
\hline Fraca (0.4) & ELABORATION, CONTRAST, JOINT, LIST \\
\hline Média (0.6) & $\begin{array}{l}\text { ANTITHESIS, COMPARISON, EVALUATION, MEANS, NON-VOLITIONAL } \\
\text { CAUSE, NON-VOLITIONAL RESULT, SOLUTIONHOOD, VOLITIONAL CAUSE, } \\
\text { VOLITIONAL RESULT, SEQUENCE }\end{array}$ \\
\hline \multirow{2}{*}{ Forte (0.8) } & $\begin{array}{l}\text { BACKGROUND, CIRCUMSTANCE, CONCESSION, CONCLUSION, CONDITION, } \\
\text { ENABLEMENT, EVIDENCE, EXPLANATION, INTERPRETATION, JUSTIFY, } \\
\text { MOTIVATION, OTHERWISE, PURPOSE, RESTATEMENT, SUMMARY }\end{array}$ \\
\hline
\end{tabular}

Quadro 6.1: Classificação das relações RST para segmentação em subtópicos

Uma relação é classificada como fraca se ela geralmente indica uma quebra; neste caso, seu peso é 0.4. Uma relação é média porque ela pode indicar ou não uma quebra de subtópicos; portanto, seu peso é 0.6. Por outro lado, uma relação forte quase nunca indica mudança de subtópico; portanto, seu peso é 0.8. Uma observação que se faz é todas as relações intencionais foram classificadas como fortes, com exceção de ANTITHESIS. Isso está 
relacionado à definição das relações intencionais, e ANTITHESIS foi encontrada na segmentação de referência, mesmo que com baixa frequência.

Apesar de essa classificação das relações RST ter sido baseada na análise do córpus e na definição da relação, já se esperava que relações indicadas como fracas pudessem indicar mudanças de subtópicos. A partir da classificação do Quadro 6.1, outras duas estratégias de segmentação em subtópicos foram criadas: Relação retórica com Altura e Cosseno dos Núcleos com Relação retórica e Altura. O método Relação retórica com Altura associa uma nota para os nós dividindo o peso da relação pela altura da árvore onde ele ocorre, percorrendo a árvore de forma bottom-up. Para a árvore da Figura 6.6, a nota entre os nós 1 e 2 é 0.4 (peso de ELABORATION) dividido por 1; a nota entre elaboration e 3 é 0.6 (peso de SEQUENCE) dividida por 2; a nota entre 4 e 5 é 0.4 (peso de CONTRAST) dividido por 1; a nota entre a subárvore sequence e contrast é 0.4 dividido por 3. Em seguida, somam-se as notas e calcula-se a média entre elas. Assim como nas outras estratégias, também foi considerado que nós abaixo da média são pouco similares.

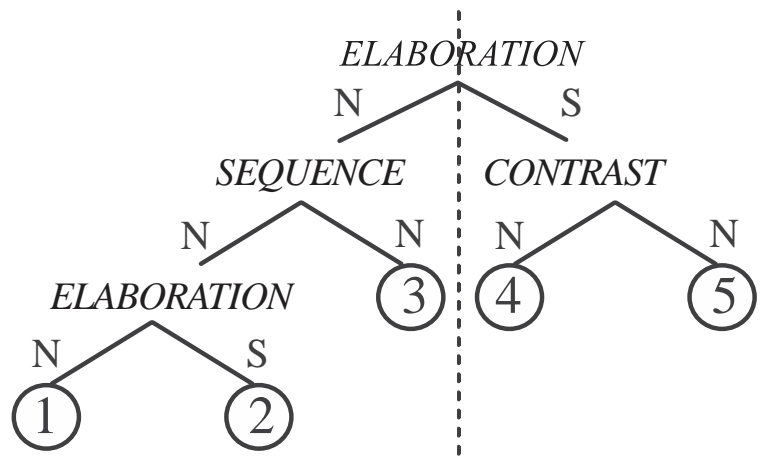

Figura 6.6: Estrutura RST do texto "Parlamentares" com segmentação em subtópicos pelo método Relação retórica com Altura

Observou-se que alguma melhoria era alcançada sempre que a nuclearidade era considerada. Dessa forma, tentou-se combinar a melhor estratégia que considera os núcleos com a que utiliza pesos para relações. Assim, selecionou-se a pontuação do método Cosseno dos Núcleos com Altura, multiplicada pelo peso das relações onde ocorriam. Esta estratégia é referenciada por Cosseno dos Núcleos com Relação e Altura. Para o texto da Figura 6.1, a segmentação pelo método Cosseno dos Núcleos com Relação retórica e Altura foi idêntica à segmentação pelo método Cosseno dos Núcleos com Altura, já representada na Figura 6.3. Nesse caso, diz-se que esse último método enriquece o método original Cosseno dos Núcleos com Altura. 
Os métodos TextTiling, Cosseno Simples, Cosseno entre Núcleos, Cosseno Simples com Altura, Cosseno dos Núcleos com Altura e Cosseno dos Núcleos com Relação retórica e Altura realizam uma etapa de pré-processamento das unidades textuais, que inclui remoção de stopwords e uso de stemmer (utilizou-se o projeto SnowBall ${ }^{24}$ ).

\subsection{AVALIAÇÃO DOS MÉTODOS DE SEGMENTAÇÃO EM SUBTÓPICOS}

Geralmente o desempenho dos métodos de segmentação em subtópicos é avaliado com as medidas cobertura, precisão e medida-f. Nessa tarefa, a precisão $(\mathrm{P})$ representa a porcentagem de quebras identificadas pelo algoritmo que de fato são verdadeiras (equação 7). A cobertura (C) representa a porcentagem de quebras verdadeiras que são identificadas pelo algoritmo (equação 8). A medida-f (F) é a média harmônica entre precisão e cobertura, já apresentada na equação 3, consistindo em uma medida única de avaliação.

$$
\begin{gathered}
\text { Precisão }=\frac{\text { Número de quebras em comum com a referência }}{\text { Número de quebras automáticas }} \\
\text { Cobertura }=\frac{\text { Número de quebras em comum com a referência }}{\text { Número de quebras de referência }}
\end{gathered}
$$

Como mencionado, as duas medidas são inversamente proporcionais. Quanto mais um algoritmo segmenta um texto, mais chances ele tem de ter boa cobertura. No entanto, quanto mais um algoritmo segmenta, menos chance ele tem de conseguir boa precisão, pois provavelmente segmentará em locais errados. Sabendo que precisão e cobertura não melhoram necessariamente no mesmo sentido, o principal objetivo é manter as duas medidas altas reforçando uma ou outra dependendo da aplicação. No caso da segmentação em subtópicos, almeja-se principalmente uma boa cobertura.

As notas de $\mathrm{P}, \mathrm{C}$ e $\mathrm{F}$ não quantificam quão próxima a segmentação automática corresponde àquela produzida manualmente. Tais medidas comparam a correspondência entre as quebras, sem considerar se elas estão próximas: se elas não são as mesmas (independente do fato de serem mais perto ou longe uma da outra), sua nota é zero. Contudo, também é importante conhecer quão próximas as quebras automáticas estão daquelas esperadas, pois

\footnotetext{
${ }^{24}$ http://snowball.tartarus.org/
} 
isso ajuda identificar se os erros produzidos por um algoritmo são muito sérios. Dependendo da aplicação da segmentação textual, diferentes tipos de erros tornam-se importantes.

Para amenizar esses problemas relacionados com cobertura e precisão, outra medida bastante utilizada é a WindowDiff (WD - Pevzner e Hearst, 2002). A métrica funciona da seguinte forma: para cada intervalo em avaliação, compara-se a quantidade de quebras de subtópicos na segmentação de referência com a segmentação automática no mesmo intervalo. Os intervalos são pontuados como corretos se eles têm o mesmo número de quebras.

Dessa forma, seja $r i$ um intervalo de quebras de referência e ai um intervalo de quebras automáticas, o algoritmo de segmentação em subtópicos é penalizado se $r i \neq a i$ em relação à quantidade de quebras. Na equação 9, descreve-se a fórmula de WD, onde $b(i, j)$ representa o número de quebras de subtópicos entre as posições $i$ e $j$ no texto, $N$ é o número de sentenças e $k$ é o tamanho do intervalo em avaliação, que representa metade do tamanho de um segmento ou média de sentenças nos subtópicos (Pevzner e Hearst, 2002). Em seguida, as penalizações são somadas e esse valor é normalizado. Pela medida WD, quebras perdidas ou próximas da referência são menos penalizadas do que somente considerar P e C. Quanto menor for o valor WD de um método de segmentação, melhor é seu desempenho em detectar quebras subtopicais. Para achar o valor de k, usa-se a equação 10 (Scaiano e Inkpen, 2012).

$$
\begin{gathered}
\text { WindowDiff }=\frac{1}{N-K} \sum_{i=1}^{N-k}\left(\left|b\left(r_{i}, r_{i+k}\right)-b\left(a_{i}, a_{i+k}\right)\right|>0\right) \\
K=\frac{N}{2 * \text { número de segmentos }}
\end{gathered}
$$

Para exemplificar a aplicação da medida WD, considere a Figura 6.7, que ilustra um texto com 6 sentenças representadas por retângulos (S1...S6). Referência indica a segmentação manual e Automático 1 e Automático 2 representam a segmentação de duas estratégias automáticas hipotéticas. As quebras são indicadas por linhas verticais. Tanto Automático 1 e Automático 2 perderam a quebra entre S2 e S3 (falso negativo). Contudo, Automático 1 colocou uma quebra entre S1 e S2 (falso positivo), e Automático 2 quebrou entre S4 e S5 (falso positivo). Considerando $\mathrm{k}=2$, Automático 1 teve um intervalo com mais quebras que a referência, enquanto que Automático 2 teve quatro intervalos diferentes. Após a normalização, os valores de WD para Automático 1 e Automático 2 foram 0.2 e 0,8, respectivamente, indicando que Automático 1 se aproxima mais da segmentação de referência. 

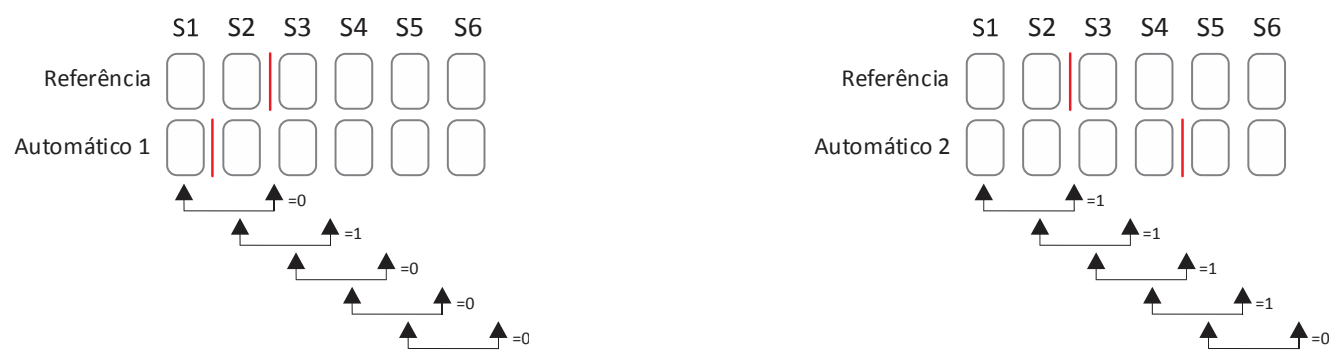

Figura 6.7: Exemplo de segmentações para cálculo de WD

Neste trabalho se propõem uma medida simples chamada Desvio (D) da anotação de referência (equação 11). Considere dois algoritmos que propõem diferentes quebras de subtópicos para um mesmo texto e cometem um único erro cada um (eles têm o mesmo valor de $\mathrm{P}, \mathrm{C}$ e F): o melhor será aquele que desvia menos da referência. Para cada quebra automática, calcula-se a distância em relação a referência mais próxima. Se a quebra automática é na mesma posição que a referência, esse desvio é 0. Para as quebras que não são na mesma posição da referência, contabiliza-se a distância em relação a quebra de referência mais próxima. O desvio total é dado pela soma de todos os desvios, normalizando pelo maior desvio de todas as entradas automáticas. Considerando a representação da Figura 6.7, Automático 1 tem d=0.5 e Automático 2 tem d=1. Quanto menor for o desvio, melhor será seu desempenho em detectar quebras subtropicais.

$$
\frac{1}{\max D} \sum_{i=1}^{N} \text { menor_dist }\left(a_{i}, r_{j}\right)
$$

A diferença entre WD e D é que, a primeira compara dois segmentos e basta que eles sejam diferentes para que o algoritmo seja penalizado, não importando se a quebra automática está distante da referência no intervalo, e a segunda verifica a menor distância entre uma quebra automática e uma de referência. Ambas as medidas geram valores entre 0 e 1, sendo 1 muito ruim. Tais medidas visam amenizar os resultados de $\mathrm{C}, \mathrm{P}$ e F, que penalizam bastante um algoritmo que não segmenta nos locais exatos da segmentação de referência.

$\mathrm{Na}$ Tabela 6.1, apresenta-se a avaliação dos métodos de segmentação subtopical investigados. Nas primeiras 4 linhas, mostram-se os resultados para os métodos baselines e as últimas 6 linhas são os métodos baseados em RST. A última linha representa o desempenho humano, referenciado por topline. É interessante ter um topline para ser possível indicar os limites que os métodos automáticos podem alcançar em uma tarefa. Para determinar o topline, 
um anotador do córpus foi aleatoriamente selecionado para cada texto e sua anotação foi comparada com a referência (alcançada pela maioria das indicações). Os valores ideais para C, P, F, WD e D são: 1, 1, 1, 0 e 0 , respectivamente.

Tabela 6.1: Avaliação de algoritmos de segmentação subtopical

\begin{tabular}{l|l|c|c|c|c|c}
\hline $\mathbf{L}$ & \multicolumn{1}{|c|}{ Algoritmo } & C & P & F & WD & D \\
\hline 1 & TextTiling & 0.405 & 0.773 & 0.497 & 0.375 & 0.042 \\
\hline 2 & Parágrafo & 0.989 & 0.471 & 0.613 & 0.591 & 0.453 \\
\hline 3 & Sentença & 1.000 & 0.270 & 0.415 & 0.892 & 1.000 \\
\hline 4 & Aleatoriamente & 0.674 & 0.340 & 0.416 & 0.669 & 0.539 \\
\hline 5 & Cosseno Simples & 0.549 & 0.271 & 0.345 & 0.694 & 0.545 \\
\hline 6 & Cosseno entre Núcleos & 0.631 & 0.290 & 0.379 & 0.691 & 0.556 \\
\hline 7 & Cosseno simples com Altura & 0.873 & 0.364 & 0.489 & 0.711 & 0.577 \\
\hline 8 & Cosseno dos Núcleos com Altura & 0.899 & 0.370 & 0.495 & 0.710 & 0.586 \\
\hline 9 & Relação retórica com Altura & 0.901 & 0.507 & 0.616 & 0.525 & 0.335 \\
\hline 10 & Cosseno dos Núcleos com Relação retórica e Altura & 0.908 & 0.353 & 0.484 & 0.729 & 0.626 \\
\hline 11 & Topline & 0.807 & 0.799 & 0.767 & 0.182 & 0.304 \\
\hline
\end{tabular}

Como esperado, do conjunto baseline, o método do parágrafo (linha 2 na Tabela 6.1) foi muito bem, alcançando os melhores valores pela medida-f. Isso mostra que, na maioria dos textos, os subtópicos estão organizados em parágrafos. Embora o baseline sentença (linha 3) tenha a melhor $\mathrm{C}$, tem o pior $\mathrm{D}$. Isso é devido ao fato de que nem toda sentença representa um subtópico, e segmentar em todas elas torna-se um problema quando se procura pelos grandes grupos de subtópicos. Nota-se que os baselines sentença e aleatório (linha 4) possuem o mesmo valor para medida-f, resultado que aconteceu naturalmente.

Apesar de o TextTiling ter alcançado bons valores de P, WD e D, o método teve a menor C (linha 1). Isto ocorre porque o TextTiling é muito conservador e detecta somente algumas mudanças de subtópicos, fazendo com que o mesmo tenha uma boa pontuação em relação a $\mathrm{P}, \mathrm{WD}$ e $\mathrm{D}$, mas penalizando fortemente $\mathrm{C}$.

No caso dos algoritmos baseados em RST (linhas 5 a 10), nota-se que produzem os melhores resultados em termos de C, P e F e com valores aceitáveis de D. Observa-se que, toda vez que as unidades salientes são usadas, $\mathrm{C}$ e $\mathrm{P}$ aumentam em relação à versão do mesmo método sem núcleos, exceto para Cosseno dos Núcleos com Relação retórica e Altura (linha $10)$.

Observa-se que o valor de F do método do parágrafo é muito similar ao método Relação retórica com Altura (linha 9). Contudo, ao se analisar as cinco medidas dos dois métodos, o método discursivo erra menos que o parágrafo segundo as medidas $\mathrm{WD}$ e $\mathrm{D}$, e tem $\mathrm{C}, \mathrm{P}$ e $\mathrm{F}$ aceitáveis, e, portanto, tem o melhor desempenho. 
Como esperado, o topline (linha 11) tem o melhor resultado em termos de medida-f e com valores de D aceitáveis. Seu valor de F é provavelmente o melhor que um método automático pode alcançar. Ele é $25 \%$ melhor (valor F) do que a melhor estratégia apresentada, Relação retórica com Altura (linha 10). Existe, portanto, espaço para melhorias, possivelmente o uso de outras características, tais como marcadores discursivos. Por exemplo, Pardo (2005b), Iruskieta e da Cunha (2010) e Taboada e Das (2013) já investigaram e mapearam marcadores discursivos que sinalizam relações retóricas. Uma vez que se sabe quais relações retóricas podem indicar mudança de subtópicos e os possíveis marcadores discursivos que as identificam, esses conhecimentos poderão ser combinados de forma que possa melhorar o desempenho dos segmentadores automáticos de subtópicos.

$\mathrm{Na}$ Tabela 6.2, apresenta-se a média de segmentos de cada algoritmo por texto. O TextTiling (linha 1 na Tabela 6.2) segmenta menos do que todos os outros algoritmos. Isto está relacionado ao tamanho dos textos, que em sua maioria são curtos e o TextTiling não tem bom desempenho com textos pequenos (embora tenhamos adaptado para as características do nosso córpus). Pode-se observar que a combinação Relação retórica com Altura (linha 9) não segmenta tanto como os outros métodos, sendo um pouco mais conservador em número de segmentos. Isso não é surpreendente para textos jornalísticos, que, como já mostrado, têm em média três subtópicos. Portanto, isso mostra o melhor relacionamento custo-benefício: melhores valores de C, P e F, e com WD e D aceitável para o método Relação retórica com Altura. Assim, comprova-se a hipótese (1) de que é possível extrair a estrutura de subtópicos de um texto a partir da estrutura discursiva.

Tabela 6.2: Média de segmentos por algoritmos

\begin{tabular}{c|l|c}
\hline $\mathbf{L}$ & \multicolumn{1}{|c|}{ Algoritmo } & Média de segmentos \\
\hline 1 & TextTiling & 1.6 \\
\hline 2 & Parágrafo & 8.1 \\
\hline 3 & Sentenças & 14.8 \\
\hline 4 & Aleatório & 8.0 \\
\hline 5 & Cosseno Simples & 8.1 \\
\hline 6 & Cosseno entre Núcleos & 8.5 \\
\hline 7 & Cosseno simples com Altura & 9.5 \\
\hline 8 & Cosseno dos Núcleos com Altura & 9.8 \\
\hline 9 & Relação retórica com Altura & 6.9 \\
\hline 10 & Cosseno dos Núcleos com Relação retórica e Altura & 10.15 \\
\hline
\end{tabular}

Aplicou-se o teste-t pareado para esses dados para verificar se havia alguma diferença estatisticamente significativa. Como esperado, a diferença de $\mathrm{F}$ não é significativa para os métodos Relação retórica com Altura e do Parágrafo, mas foi significativa com $95 \%$ de confiança para a comparação do método Relação retórica com Altura com o método Cosseno 
dos Núcleos com Altura, e para a comparação do método Relação retórica com Altura com TextTiling. Finalmente, a diferença entre o topline e Relação retórica com Altura também foi significativa.

Nas Figuras 6.8 e 6.9, resumem-se a avaliação dos algoritmos de segmentação em subtópicos com as 5 medidas. Na Figura 6.8, representa-se a avaliação com as medidas cobertura, precisão e f-measure, que quanto mais próximo de 1 , melhor é o resultado. $\mathrm{Na}$ Figura 6.9, representa-se a avaliação com as medidas desvio e windowdiff, que quanto mais próximas de zero, melhor é o desempenho do algoritmo. $\mathrm{O}$ algoritmo Relação retórica com Altura aparece em destaque.

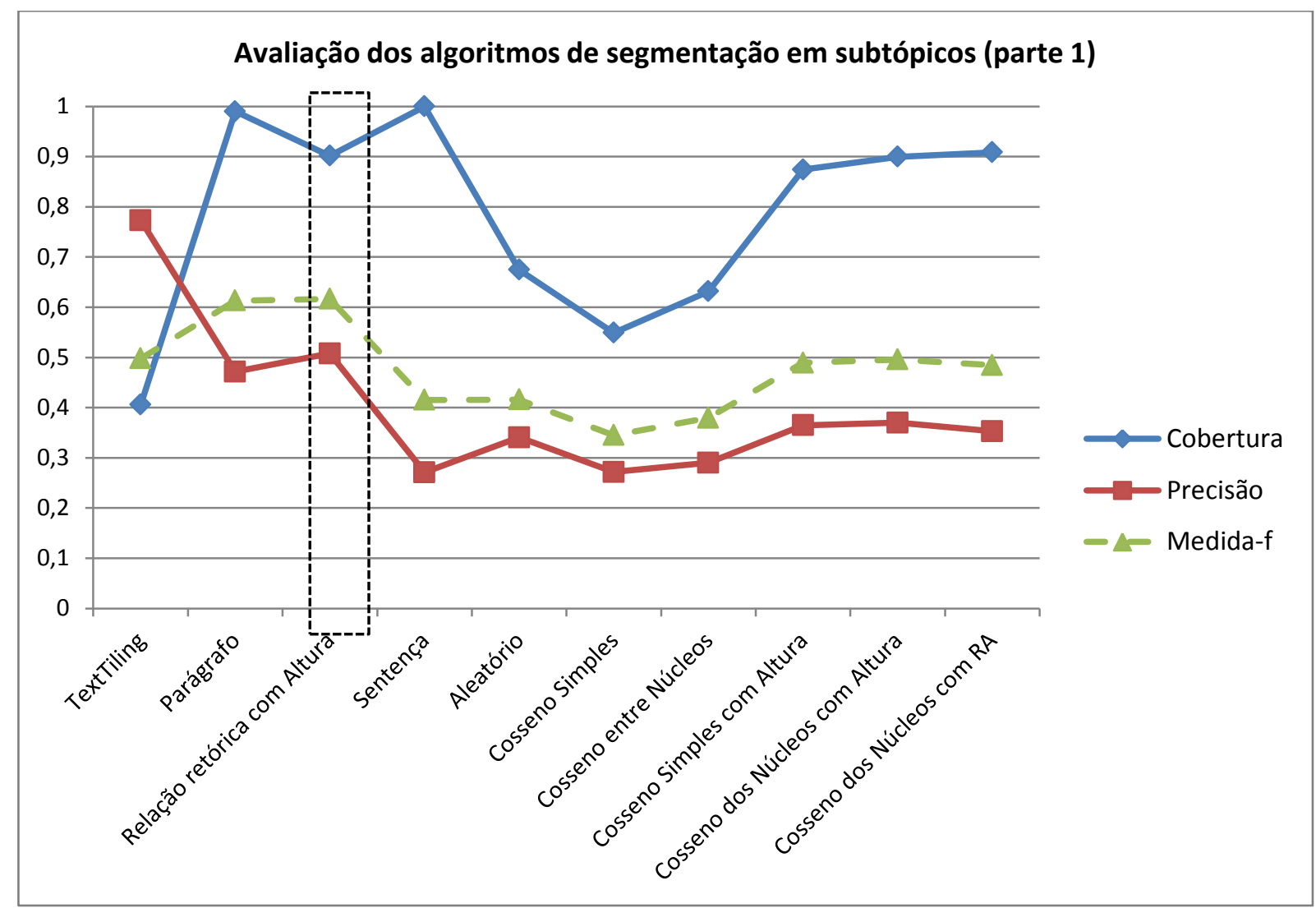

Figura 6.8: Resumo da avaliação dos algoritmos de segmentação em subtópicos (parte 1) 


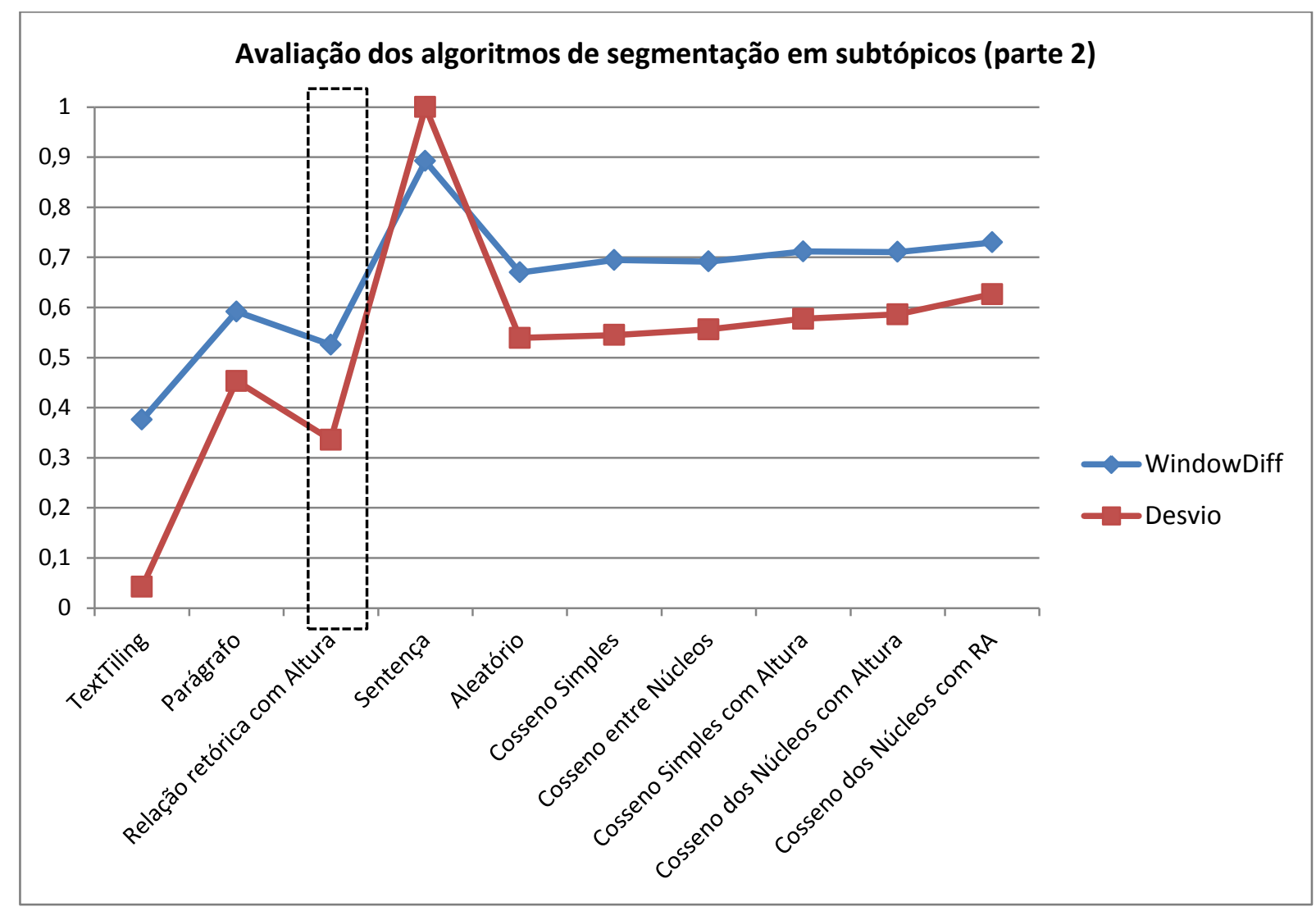

Figura 6.9: Resumo da avaliação dos algoritmos de segmentação em subtópicos (parte 2)

\subsection{AVALIAÇÃO DO AGRUPAMENTO DOS SUBTÓPICOS}

É necessário considerar que subtópicos de diferentes textos (cenário multidocumento) podem, eventualmente, ser semelhantes, uma vez que textos que versam sobre o mesmo assunto podem conter passagens muito parecidas. Nesse caso, pesquisadores incorporam a ideia de agrupamento de sentenças similares. Geralmente, o agrupamento de sentenças é realizado como um passo anterior ao de seleção de conteúdo em SA (por exemplo, em Radev et al., 2000, 2001), mas há aqueles que o utilizam para organizar as sentenças de um sumário com base na similaridade (por exemplo, Bollegala et al., 2006). Um algoritmo conhecido para agrupamento de sentenças é o Single-pass (Van Rijsbergen, 1979). Trata-se de um método não supervisionado, simples e eficiente, já aplicado em Recuperação de Informação (por exemplo, Klampanos et al., 2006) e fusão de sentenças (por exemplo, Seno e Nunes, 2009).

Ribaldo et al. (2013) adaptaram o Single-pass para agrupar subtópicos de um conjunto de textos, anteriormente segmentados (segmentação topical monodocumento). Na Figura 6.10, mostra-se o algoritmo Single-pass, já adaptado para agrupamento de subtópicos. O 
algoritmo requer uma única passagem sequencial ao longo do conjunto de subtópicos a serem agrupados. Dado como entrada um conjunto de documentos segmentados individualmente em subtópicos, o primeiro subtópico da lista de entrada constiui-se no primeiro grupo. A partir desse grupo, inicia-se o agrupamento com todos os subtópicos remanescentes. Em cada análise dos grupos, o algoritmo verifica se um subtópico recém-selecionado deve ser colocado em um grupo existente ou se um novo grupo será criado. Essa decisão é feita de acordo com a condição especificada pela função de similaridade empregada, isto é, um limite de similaridade previamente determinado. A decisão do limiar baseou-se na média de similaridade entre todos os grupos.

Na próxima iteração, se o novo subtópico for adjacente ao anterior (significa que estão no mesmo documento), cria-se um novo grupo. Isso é feito devido ao documento já ter sido segmentado internamente, e, portanto, dois subtópicos adjacentes não podem ser agrupados. Por outro lado, se o novo subtópico não for adjacente ao anterior, verifica-se se ele pertence a algum grupo já existente ou se um novo grupo deve ser criado para aquele subtópico. $\mathrm{O}$ Single-pass requer um único passo sequencial sob todo conjunto de subtópicos a ser agrupado.

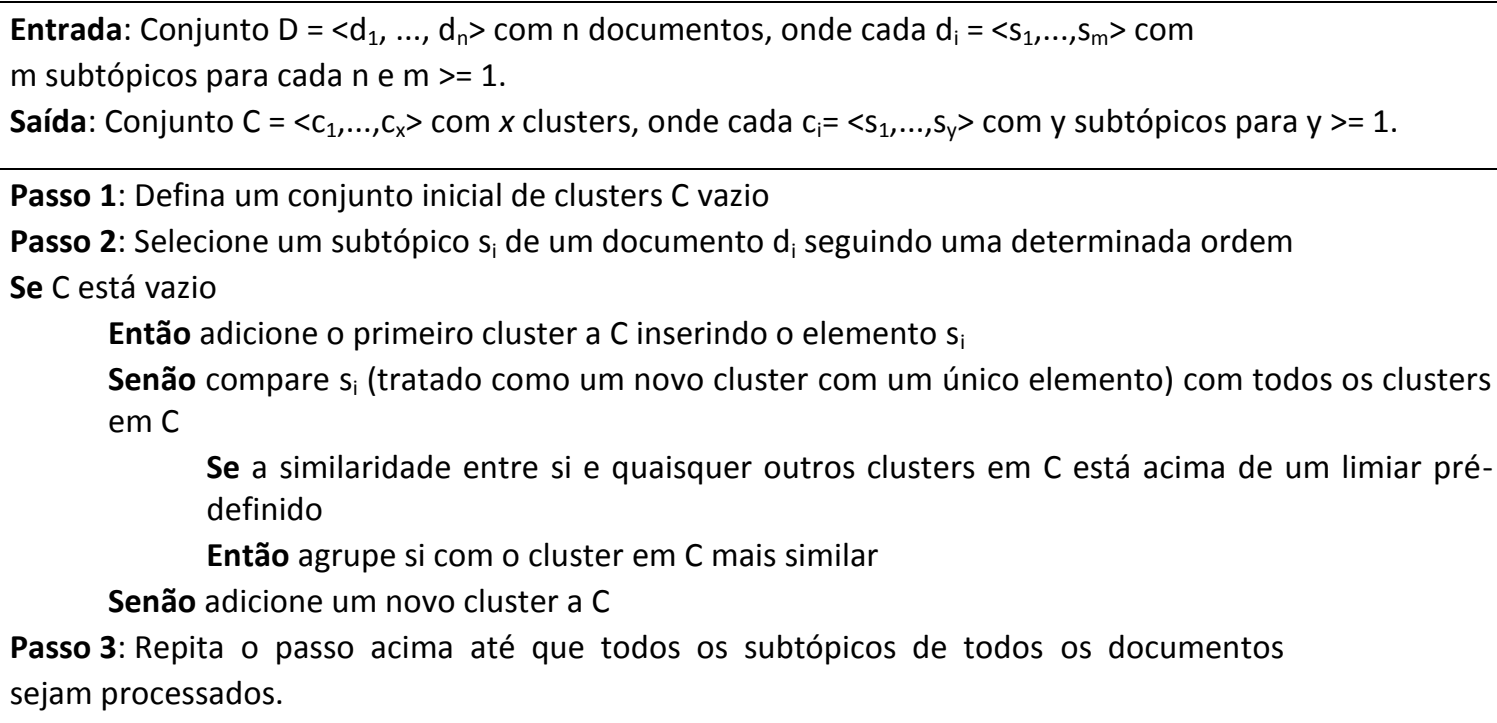

Passo 3: Repita o passo acima até que todos os subtópicos de todos os documentos sejam processados.

Figura 6.10: Algoritmo Single-pass adaptado para subtópicos

Fonte: Ribaldo et al., 2013

Ribaldo et al. (2013) experimentaram diversas formas para calcular a similaridade entre subtópicos, tais como: 1) similaridade entre as palavras-chave mais frequentes nos subtópicos; 2) similaridade subtopical entre todas as palavras dos subtópicos; 3) número de relações CST, 
isto é, quanto maior o número de conexões entre dois subtópicos, maior a chance de serem correlacionados; e 4) CST com peso, isto é, cada relação CST recebe uma pontuação entre 0 e 1 , de forma que que quanto mais próximo de 1 , mais similares são os segmentos. Nesse último caso, quanto maior for a soma de cada relação CST para um par de subtópicos, maior será a chance de agrupá-los. No caso da similaridade entre as palavras-chave mais frequentes e entre todas as palavras dos subtópicos, utilizou-se a medida do cosseno. Os autores compararam as quatro formas e concluíram que a similaridade entre as palavras-chave mais frequentes nos subtópicos fornece melhores resultados, como se mostra na Tabela 6.3, considerando a medida-f. Os valores representam o resultado do agrupamento automático da segmentação de referência versus o agrupamento de referência que está disponível no córpus CSTNews.

Tabela 6.3: Avaliação do agrupamento automático da segmentação de subtópicos de referência

\begin{tabular}{c|c|c|c}
\hline Palavras-chave & Similaridade subtopical & CST sem peso & CST com peso \\
\hline 0.7227 & 0.5072 & 0.4850 & 0.4789 \\
\hline
\end{tabular}

Neste trabalho, a técnica de agrupamento de Ribaldo et al. (2013) foi aplicada nos subtópicos da segmentação de referência, do TextTiling e do método Relação retórica com Altura da RST. Na Tabela 6.4, mostra-se a média de subtópicos por coleção, com a primeira coluna representando a média de subtópicos do agrupamento de referência e as outras três indicando as médias dos agrupamentos automáticos de diferentes técnicas de segmentação em subtópicos.

Tabela 6.4: Média de subtópicos por coleção

\begin{tabular}{c|c|c|c}
\hline $\begin{array}{c}\text { Agrupamento de } \\
\text { referência }\end{array}$ & $\begin{array}{c}\text { Segmentação de } \\
\text { Referência }\end{array}$ & $\begin{array}{c}\text { Segmentação com } \\
\text { TextTiling }\end{array}$ & $\begin{array}{c}\text { Segmentação com Relação } \\
\text { retórica com Altura (RST) }\end{array}$ \\
\hline 4.4 & 3.8 & 2.5 & 5 \\
\hline
\end{tabular}

No agrupamento de referência (descrito na Seção 5.4), há em média 4.4 subtópicos por coleção. Se a segmentação de referência for agrupada pela técnica de Ribaldo et al., a média de subtópicos por coleção será 3.8. O agrupamento dos subtópicos indicados pelo TextTiling gerou em média 2.5 subtópicos por coleção. Esse resultado era esperado, uma vez que o TextTiling segmenta bem menos que o método baseado em RST. Quando se aplica o agrupamento para os subtópicos identificados pelo método de segmentação Relação retórica com Altura (RST), tem se uma média de 5 subtópicos por coleção. Se for considerada somente a parte inteira dos valores da tabela, pode-se dizer que a média do agrupamento dos 
subtópicos produzidos pelo segmentador discursivo está próxima da média do agrupamento de referência.

\subsection{CONSIDERAÇÕES FINAIS}

A partir da investigação de diferentes métodos de segmentação topical baseados em discurso, é possível afirmar que características discursivas espelham a organização de subtópicos de um texto. Os algoritmos apresentados foram avaliados sobre um córpus de referência produzido para subsidiar este trabalho. Em particular, com relação ao uso da estrutura retórica baseada na RST, os atributos relação e altura da árvore destacaram-se na indicação das mudanças de subtópicos. Quanto à técnica de agrupamento, destaca-se aquela baseada em palavras-chave, que será utilizada neste trabalho.

Apesar de ter sido utilizado um córpus de textos jornalísticos anotado manualmente com RST, os métodos de segmentação e agrupamento de subtópicos são independentes de língua. Sabe-se que o processo de anotação de textos é custoso, mas atualmente já existem analisadores discursivos automáticos para a língua portuguesa (Pardo e Nunes, 2008) e para a língua inglesa (Marcu, 2000a), que podem ser utilizados na etapa de anotação de córpus. Este último, 


\section{EXPLORAÇÃO DE MÉTOdOS DE SUMARIZAÇÃO AUTOMÁTICA COM BASE EM CONHECIMENTO SEMÂNTICO-DISCURSIVO}

Neste trabalho, objetiva-se mostrar o impacto que o conhecimento semântico-discursivo tem na tarefa de SA. Para isso, vários métodos de SA foram desenvolvidos com base nas teorias RST e CST, considerando a relevância das informações, os fenômenos multidocumento e a representatividade dos subtópicos, como atributos para selecionar conteúdo.

Conforme foi apresentado, uma coleção de textos relacionados possui informações redundantes, contraditórias e complementares. Os textos geralmente descrevem um tópico principal, organizado em uma sequência de subtópicos. Além disso, a relevância de uma sentença é influenciada pela: (a) sua correlação com os fenômenos multidocumento, dados pela CST; (b) pela sua saliência, dada pela RST; e (c) subtópico a que pertence. Todas essas características devem ser consideradas na estratégia de seleção de conteúdo para um sumário multidocumento.

Para o desenvolvimento de métodos de SA, primeiramente, analisou-se a influência de cada conhecimento semântico-discursivo na tarefa de SA multidocumento. Posteriormente, investigaram-se formas de selecionar conteúdo relevante a partir da combinação dos conhecimentos semântico-discursivo.

Este Capítulo está organizado da seguinte forma: na Seção 7.1, descrevem-se os métodos produzidos de SA; na Seção 7.2, discute-se a avaliação; e por fim na Seção 7.3 são feitas as considerações finais.

\subsection{DESENVOLVIMENTO DE MÉTODOS DE SA}

Conforme se mostra na Figura 7.1, os métodos de SA foram divididos em quatro grupos, totalizando 13 métodos distintos para selecionar conteúdo. O primeiro grupo, apresentado na Subseção 7.1.1, discute-se o uso da RST em SA multidocumento; no segundo grupo, na Subseção 7.1.2, descrevem-se métodos baseados na informação de subtópicos; no terceiro grupo, na Subseção 7.1.3, apresentam-se os métodos que combinam RST e CST; por fim, na Subseção 7.1.4, descrevem-se várias formas de utilizar RST, CST e subtópicos em conjunto. Não foi desenvolvida uma abordagem totalmente baseada em CST, pois se considerou o 
sistema multidocumento CSTSumm ( Jorge e Pardo, 2010 e 2012). Esse sistema foi avaliado com o mesmo córpus de textos utilizado neste trabalho.

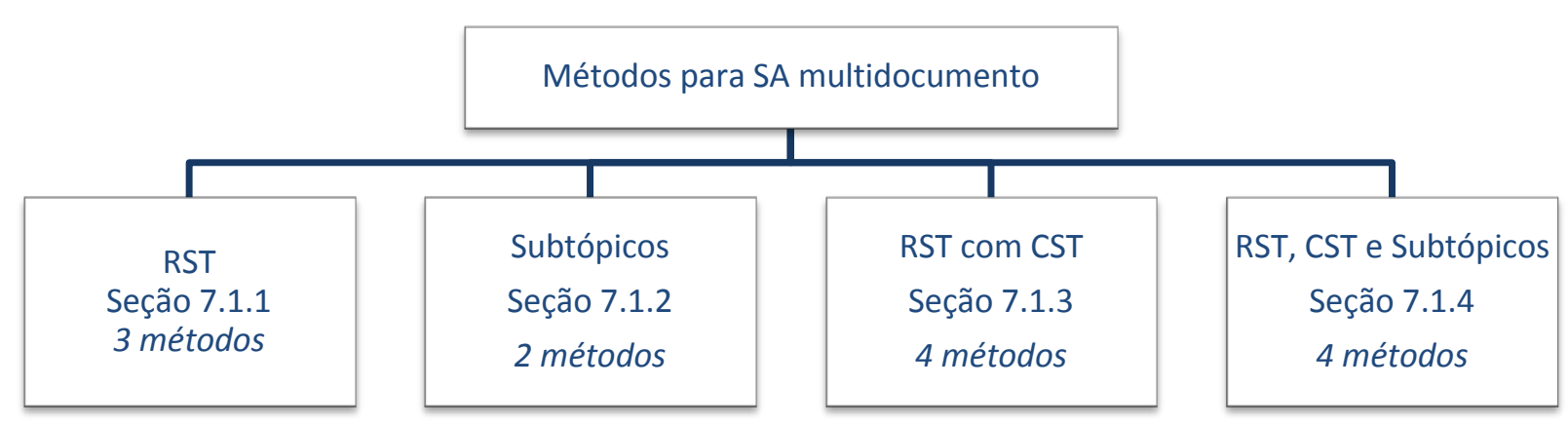

Figura 7.1: Organização dos métodos de SA

Neste trabalho, a fim de evitar que erros na anotação automática comprometam os resultados, utilizou-se textos anotados manualmente. Para fins de avaliação e comparação com outras abordagens automáticas adota-se a mesma taxa de compressão dos sumários manuais do córpus que é de $70 \%$ sobre o tamanho do maior texto do grupo, medido em número de palavras.

\subsubsection{Uso da RST na SA multidocumento}

A nuclearidade, como definida na RST, é relevante para a SA monodocumento, como já atestaram Ono et al., 1994; O’Donnell, 1997; Marcu, 1997. Seguindo essa constatação, uma das propostas dessa tese é expandir seu uso na SA multidocumento e, assim, verificar se a RST ainda pode ser útil. Os métodos desta seção baseiam na proposta de sumarização de Marcu (1997), na qual as proposições mais nucleares geralmente conseguem as notas mais altas. Logo, se aplicarmos a RST para os textos de uma coleção e no final organizarmos um ranque único, será possível identificar as unidades textuais mais relevantes. Inicialmente, apresentam-se três métodos baseados em RST, descritos resumidamente na Figura 7.2. Os métodos RST 1, RST 2 e RST 3 diferem quanto à unidade de análise, que pode ser proposição ou sentença. Em todos os casos parte-se do princípio de que a fase de análise está pronta. 


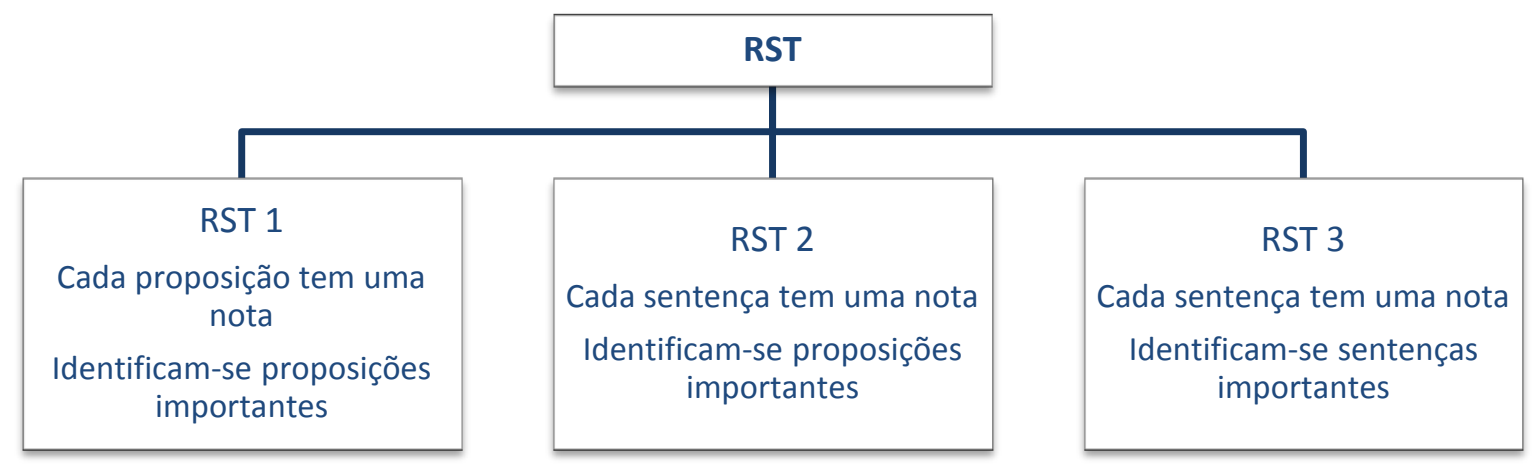

Figura 7.2: Métodos de SA multidocumento com RST

No Quadro 7.1, apresenta-se o método RST 1, organizado nas fases tradicionais de um sistema de SA.

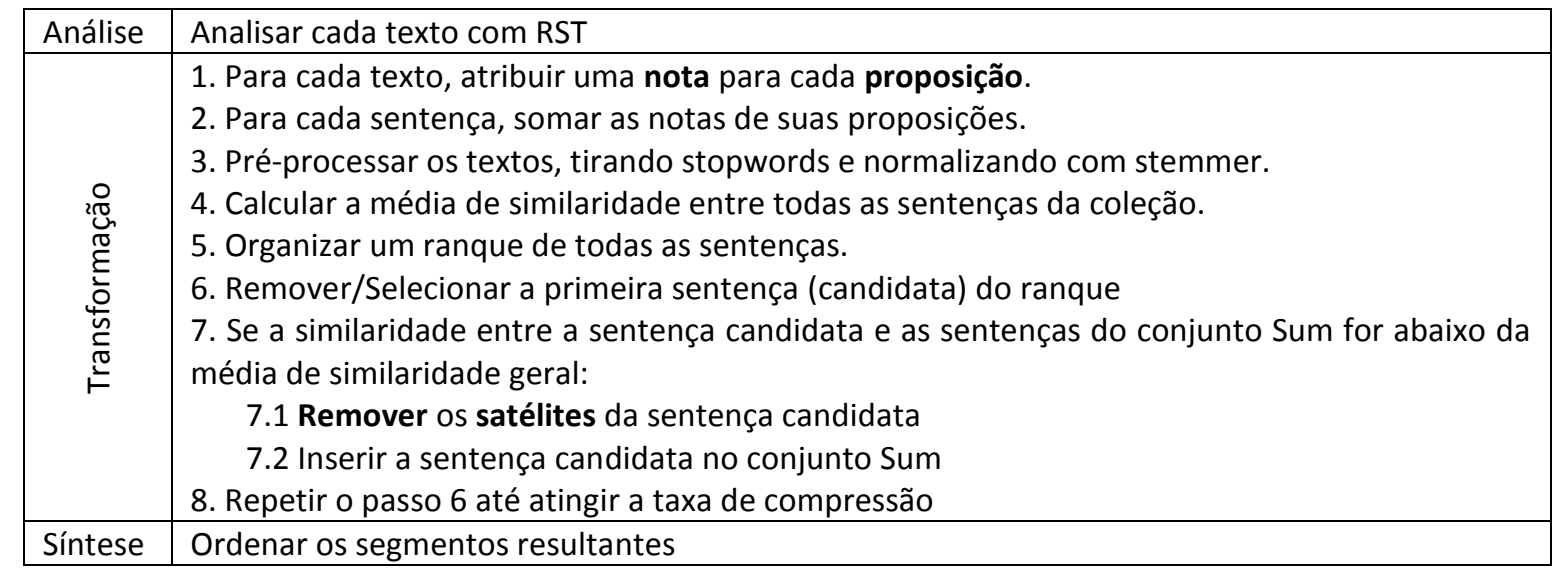

Quadro 7.1: Método de sumarização automática RST 1

Na fase de Transformação, primeiramente aplica-se da forma tradicional o método de Marcu (1997) e calcula-se uma nota para cada proposição (passo 1). O ranque é de sentenças, por isso, a nota de uma sentença corresponde à soma das notas de suas proposições (passo 2). Os textos são pré-processados para retirada de stopwords e normalização das palavras de conteúdo com um stemmer (passo 3). Por se tratarem de textos relacionados, a possibilidade de informações repetidas é sempre alta, portanto, precisam ser tratadas antes de serem selecionadas para o sumário. Como a RST não aponta se há redundância entre sentenças, neste trabalho optou-se por verificá-la usando uma medida de similaridade. Assim, no passo 4, adota-se a medida do cosseno (Salton, 1988) para calcular a similaridade entre sentenças. No passo 5, organiza-se um ranque de sentenças candidatas, considerando a nota do método de Marcu. No passo 6, seleciona-se a primeira sentença (candidata) do ranque e, no passo 7 , 
verifica-se a similaridade entre ela e o conjunto Sum, que contém as sentenças já selecionadas para o sumário. Se a similaridade for abaixo da média geral, eliminam-se os satélites da sentença candidata (passo 7.1) e insere-a no conjunto Sum (passo 7.2). O passo 6 é repetido até preencher a taxa de compressão.

Por fim, na fase de Síntese, organizam-se os segmentos resultantes usando a ordem em que originalmente aparecem nos textos-fonte. A tarefa de ordenação de sentenças em SA multidocumento é difícil quando comparada com a SA monodocumento, pois o conteúdo é extraído de diferentes fontes e, portanto, nenhum documento pode fornecer ordenação adequada (Barzilay et al., 2001). Neste trabalho, aplica-se um método de ordenação pela posição da sentença no texto-fonte, desenvolvido por Lima e Pardo (2012). O critério de desempate entre sentenças que possuem a mesma posição no texto-fonte é seu tamanho em palavras, sendo que as sentenças menores devem aparecer antes no sumário.

Enquanto nas abordagens da literatura de SA multidocumento coletavam-se sentenças completas, no método RST 1 selecionam-se somente proposições nucleares. Um exemplo de sumário pelo método RST 1 é dado na Figura 7.3, com as sentenças já ordenadas. O primeiro número no colchete é um identificador para a sentença no sumário depois de ordenado, e o segundo número, após o sinal de ponto-e-vírgula, indica o texto-fonte e a posição da sentença na origem. Nesse caso, lê-se que a sentença S1 do sumário corresponde a sentença s1 do documento D2 dessa coleção. O sumário descreve um "acidente aéreo no Congo".

[S1; D2_S1] Um acidente aéreo na localidade de Bukavu, no leste da República Democrática do Congo, matou 17 pessoas na quinta-feira à tarde,

[S2; D2_S3] Todos morreram quando o avião, não conseguiu chegar à pista de aterrissagem

[S3; D2_S5] O avião explodiu

[S4; D2_S7] o avião, um Soviet Antonov-28 de fabricação ucraniana e propriedade de uma companhia congolesa, a Trasept Congo, também levava uma carga de minerais.

Figura 7.3: Exemplo de sumário pelo método RST 1

Fonte: Córpus CSTNews, C1

Com a eliminação de proposições satélites, algumas sentenças do sumário iniciam com letra minúscula ou não possuem sinal de pontuação indicando seu fim, conforme se observa na Figura 7.3. Apesar disso, é possível recuperar o quem, quando, onde e víitmas desse acidente, representando a informação principal. Observa-se que o conteúdo foi selecionado somente do texto-fonte D2, cujo motivo é explicado mais adiante. 
Outro exemplo de sumário produzido com o método RST 1 é dado na Figura 7.4. O sumário descreve o "anúncio do presidente Lula sobre investimentos no Brasil”.

[S1; D2_S2] quando voltar da viagem irá começar a anunciar as obras de infra-estrutura em transporte [S2; D2_S3] "Algumas já estão em andamento, outras vão começar a andar agora, outras ainda precisam de licenciamento".

[S3; D2_S4] R\$ 6 bilhões em investimentos do Programa de Aceleração do Crescimento

[S4; D2_S8] serão investidos R\$ 504 bilhões no PAC até 2010.

[S5; D2_S12] junto vai chegar uma escola, junto vai chegar uma área de lazer, junto vai chegar um ponto de cultura, junto vai chegar, sabe, uma melhoria na segurança pública naquele bairro".

[S6; D2_S12] além de melhorar a qualidade de vida dos brasileiros, as obras vão gerar empregos.

[S7; D2_S13] "O nosso desejo, agora, é que essas obras até fevereiro elas estejam licitadas e estejam gerando os empregos e a melhoria de vida

Figura 7.4: Exemplo de sumário ruim pelo método RST 1

Fonte: Córpus CSTNews, C6

Nesse sumário apontam-se algumas questões. Na sentença S1, o sujeito da oração subordinada "quando voltar de viagem" e da oração principal "irá começar..." está elíptico. Como essa é a primeira sentença do sumário, não é possível recuperar seu antecedente. A sentença S3 não corresponde a uma sentença completa, pois consiste apenas em um sintagma nominal. As sentenças de S5 e S7 são falas incompletas. Na sentença S7, também não é possível recuperar o antecedente do pronome possessivo "nosso", já que não se identifica o locutor da frase, ou seja, fala-se em "nosso desejo", mas não é possível reconhecer de quem é o desejo. Todas essas questões afetam a qualidade linguística e informatividade e são provavelmente causadas pela eliminação de alguns satélites. No caso das falas, por exemplo, geralmente a fonte é uma proposição satélite de uma relação ATTRIBUTION. A maioria das sentenças do sumário representa falas do presidente Lula, contudo não há indicação disso no sumário. No entanto, é possível depreender o sentido do texto. Observa-se também que o conteúdo selecionado foi somente do texto-fonte D2, cujo motivo é explicado mais adiante.

A escolha somente de proposições nucleares pode causar prejuízos à qualidade linguística dos sumários, o que já era esperado (Seno, 2005; Carbonel, 2007). Pela teoria, os núcleos deveriam ser compreensíveis independentemente de seus satélites, mas não viceversa. Mas na prática, conforme se apresentou no sumário 7.4, muitas vezes torna-se impossível a compreensão do núcleo sem o seu satélite.

Quanto à nota de uma sentença ser composta pela soma das notas de suas proposições, observou-se que não era a forma mais efetiva de destacar sua relevância considerando o 
cenário multidocumento. Para exemplificar, considere a árvore A de altura 4, na Figura 7.5. A nota de cada nó é indicada em negrito. Imagine que a sentença 1 é formada pela proposição 1; a sentença 2, pela proposição 2; e uma terceira sentença, formada pelas proposições de 3 a 5 . Pelo método RST 1, as notas das sentenças 1, 2 e 3 seriam 4, 4 e 6, que correspondem à soma das notas de suas proposições. Embora as sentenças 1 e 2 sejam as mais nucleares, elas teriam notas menores do que sentenças com mais proposições e menos nucleares, que é o caso da sentença 3. Note que, em uma coleção, os textos não possuem tamanhos iguais e essa maneira de ranquear, pode não refletir adequadamente a importância de cada sentença.

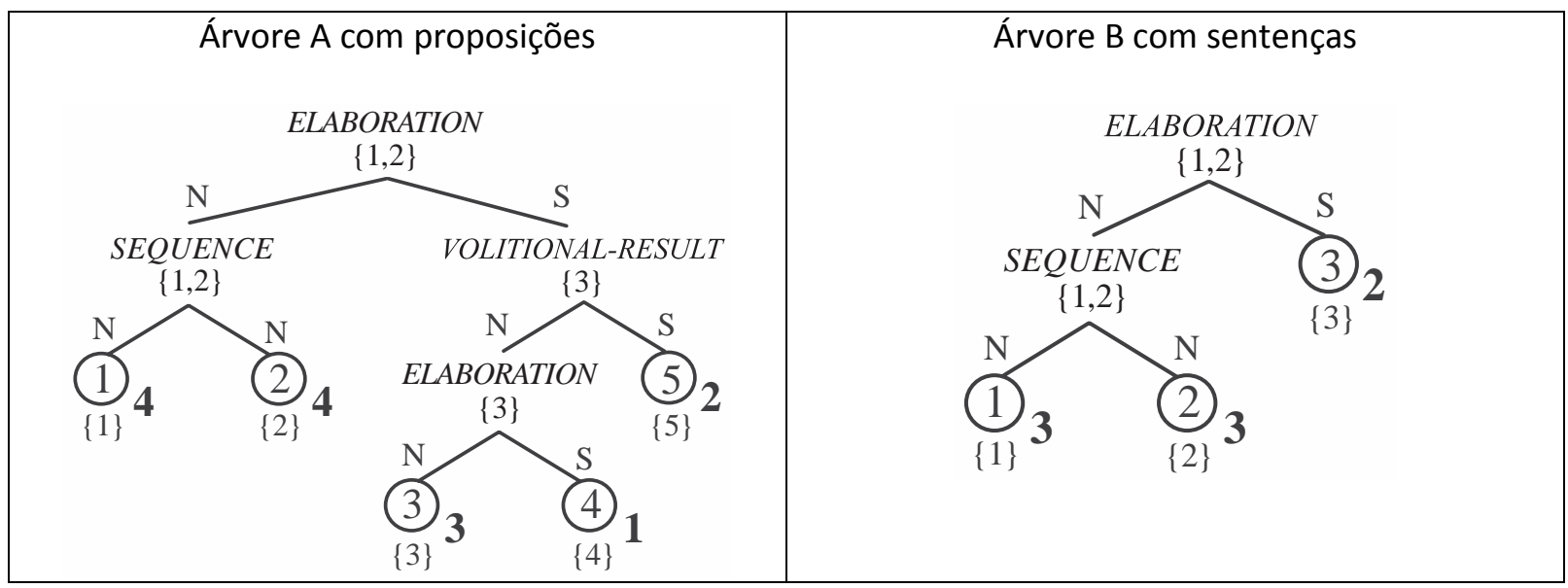

Figura 7.5: Exemplos de árvores discursivas com alturas diferentes

Como se observou na árvore A da Figura 7.5, quanto mais proposições uma sentença tiver, provavelmente mais alta será sua nota. Na maioria das vezes, tais notas não estão de acordo com a verdadeira relevância das sentenças. Louis et al. (2010) também observaram o mesmo problema ao utilizar o algoritmo de Marcu (1997) para atribuir notas para sentenças. Para amenizar esse problema, as autoras sugerem que a nota de uma sentença seja igual a nota máxima que suas proposições receberam. Contudo, isso ainda não é suficiente, pois novamente, depende do tamanho do documento. Buscando aperfeiçoar o esquema de pontuação, investigou-se se a atribuição de notas para sentenças, e não mais para EDUs, melhorava o ranque via RST. Para isso, decidiu-se reagrupar as unidades de uma árvore RST para sentenças. Para exemplificar, considere a árvore B da Figura 7.5, com as EDUs reagrupadas em três sentenças. A altura da árvore que antes era 4 (árvore A), passou a ser 3. Após a reorganização da estrutura da árvore para sentenças e aplicação do método de Marcu (1997) nessa nova estrutura (árvore B), as sentenças 1 e 2 que são as mais nucleares, recebem nota 3 e a sentença 3 , que é menos nuclear, recebe nota 2 . 
Outro fator que influencia as notas das sentenças é a altura da árvore. Se considerarmos que, na Figura 7.5, as árvores A e B representam os documentos D1 e D2, respectivamente, e cada nó representa uma sentença, teríamos o seguinte ranque de sentenças: \{D1_S1, D1_S2\} $>\{$ D1_S3, D2_S1, D2_S2 $\}>\{$ D1_S5, D2_S3 $\}>\{$ D1_S4 $\}$. As duas primeiras sentenças de D2 são as mais nucleares na Árvore B e ficaram com igual importância a sentenças do meio de D1. Imagine que, em um texto com 5 sentenças e outro com 10, muitas sentenças do segundo terão notas superiores às notas das sentenças do primeiro texto. Neste trabalho, utilizam-se textos jornalísticos, cujas primeiras sentenças são as mais relevantes (Canavillas, 2007; Saggion and Poibeau, 2013), logo, espera-se que estejam bem posicionadas no ranque. Apesar da reorganização da árvore em sentenças, isso ainda não é suficiente para construir um ranque adequado. Assim, sugere-se normalizar as notas das sentenças pela altura da árvore onde ocorrem, resultando em um valor entre 0 e 1 , sendo 1 para as sentenças mais nucleares. Isso seria uma maneira de reduzir a influência da altura da árvore na construção do ranque. Nesse caso, o novo ranque para as árvores A e B da Figura 7.5 seria: \{D1_S1, D1_S2, D2_S1, D2_S2 $\}>\{$ D1_S3 $\}>\{$ D2_S3 $\}>\{$ D1_S5 $\}>\{$ D1_S4 $\}$.

Com essas duas modificações - reorganização da estrutura da árvore para sentenças e normalização das notas pela altura da árvore - surgiu o método RST 2, cuja fase de Transformação é descrita no Quadro 7.2.

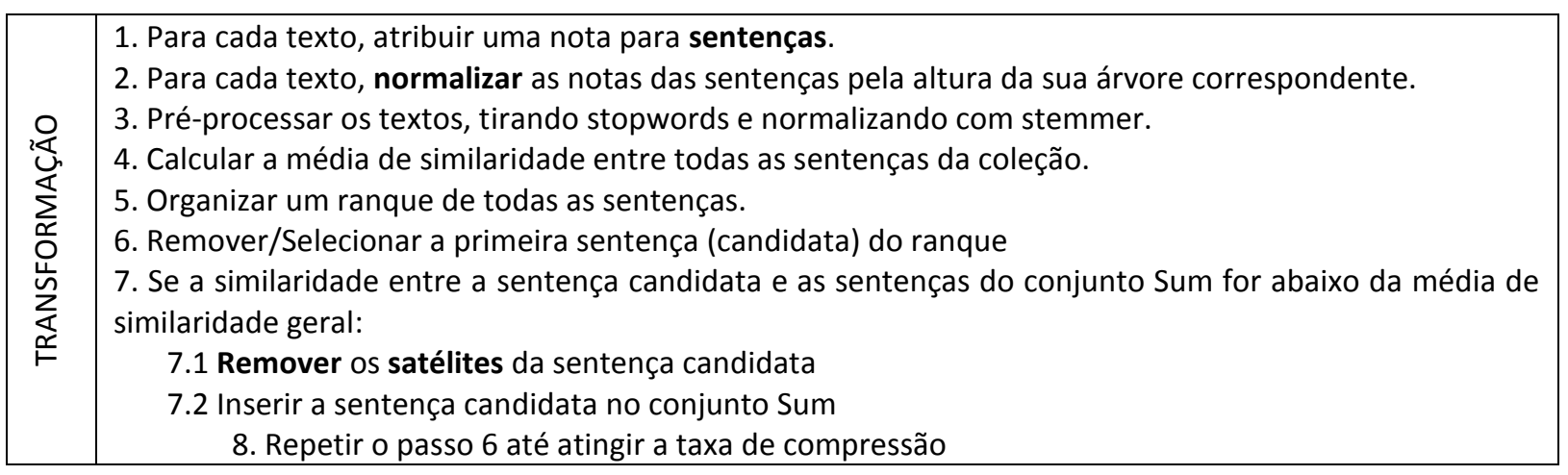

Quadro 7.2: Método de sumarização automática RST 2

A diferença entre os métodos RST 1 e RST 2 está nos passos 1 e 2 da fase de Transformação: o primeiro atribui notas para proposições e o segundo, para sentenças. O método RST 2 ainda normaliza a nota de cada sentença pela altura da árvore. Ambos os métodos selecionam somente proposições nucleares. A fase de Síntese do método RST 2 é similar à mesma fase no RST 1. 
Na Figura 7.6, ilustra-se um exemplo de sumário pelo método RST 2. O sumário contém 13 sentenças que descrevem um "terremoto no Japão e possível vazamento nuclear".

[S1; D2_S1] Os chefes da usina nuclear do Japão atingida por terremotos na última segunda-feira admitiram que ocorreram mais vazamentos radioativos no local.

[S2; D2_S2] Além do vazamento de água contendo material radioativo, gases radioativos também escaparam da usina nuclear de Kashiwazaki,

[S3; D2_S6] A central permanece fechada desde a última segunda,

[S4; D2_S7 ] o terremoto foi mais forte do que a usina de Kashiwazaki, uma das maiores do mundo, foi planejada para agüentar.

[S5; D2_S10] Ainda não se sabe quando a empresa poderá retomar o funcionamento de três geradores. [S6; D2_S13] que agravariam a devastação.

[S; D2_S14] Casas desabaram, muitas delas de madeira e com tradicionais telhados de tijolos pesados, e estradas apresentaram rachaduras devido ao tremor de segunda-feira, cujo epicentro foi na mesma área do noroeste japonês

[S8: D2_S16] Niigata foi atingida em outubro de 2004 por um tremor também de magnitude 6,8,

[S9: D2_S17] Aquele foi o terremoto mais devastador no Japão, um dos países mais propensos a terremotos no mundo, desde o de Kobe, com magnitude 7,3,

Figura 7.6: Exemplo de sumário pelo método RST 2

Fonte: Córpus CSTNews, C32

Os sumários do método RST 2 também apresentam problemas semelhantes de qualidade linguística aos do método RST 1. No sumário da Figura 7.6, a sentença S3 apresenta o substantivo central, que são substitutos anafóricos de usina nuclear. O antecedente de central aparece nas sentenças S1 e S2 e pode ser facilmente identificado por meio de resolução anafórica. A sentença S6 é uma oração subordinada e, portanto, deveria ser acompanhada de uma oração principal. Como não há oração principal em S6, a coerência fica fortemente comprometida. Uma sentença com sentido incompleto pode não ser ruim para o sumário, mas, se várias sentenças apresentam essa característica, podem prejudicar o sumário por completo. Apesar de o sumário ter somente informação nuclear, a conservação de alguns satélites melhoraria não só a interpretação, como também a qualidade linguística. Observa-se que o conteúdo selecionado foi somente do texto-fonte D2, cujo motivo é explicado mais adiante.

Os sistemas de SA devem gerar sumários linguisticamente bem formados. Para reduzir os problemas de qualidade linguística que afetam diretamente a informatividade, investigouse se havia benefício em manter alguns satélites no sumário. Adotou-se remover somente se for uma sentença satélite, formada de uma proposição, que por sua vez, é satélite. Considerando novamente a árvore A na Figura 7.5, imagine que há três sentenças: S1 formada pelas unidades 1 e 2; S2 formada pelas unidades 3 e 4 e, S3 formada pela unidade 5 . Apenas a 
sentença S3 seria eliminada, pois ela tem somente uma proposição, que por sua vez é satélite. Assim, surge o método RST 3: gera o mesmo ranque do método RST 2, mas elimina somente sentenças satélites. Dessa forma, espera-se que as sentenças do sumário apresentem menos problemas em relação a qualidade linguística.

Na Figura 7.7, mostra-se um sumário pelo método RST 3, contendo 7 sentenças $\operatorname{completas}^{25}$. O tópico principal do sumário é “terremoto no Japão e possível vazamento nuclear".

[S1; D2_S1] Os chefes da usina nuclear do Japão atingida por terremotos na última segunda-feira admitiram que ocorreram mais vazamentos radioativos no local.

[S2; D2_S6] A central permanece fechada desde a última segunda, quando houve um terremoto de 6,8 graus de magnitude a poucos quilômetros da instalação.

[S3; D2_S7] A Companhia de Energia Elétrica de Tóquio afirmou que o terremoto foi mais forte do que a usina de Kashiwazaki, uma das maiores do mundo, foi planejada para agüentar.

[S4; D2_S10] Ainda não se sabe quando a empresa poderá retomar o funcionamento de três geradores.

[S5; D2_13] A previsão de dois dias de chuva na área aumenta os temores de novos deslizamentos de terra, que agravariam a devastação.

[S6; D2_S16] Niigata foi atingida em outubro de 2004 por um tremor também de magnitude 6,8, que deixou mais de 3 mil feridos.

[S7; D2_S17] Aquele foi o terremoto mais devastador no Japão, um dos países mais propensos a terremotos no mundo, desde o de Kobe, com magnitude 7,3, que matou mais de 6.400 pessoas em 1995.

\section{Figura 7.7: Exemplo de sumário com o método RST 3}

\section{Fonte: Córpus CSTNews, C32}

Observa-se que o sumário da Figura 7.7 contém a informação principal e não apresenta problemas de encadeamento de sentido ou de qualidade linguística, podendo ser mais bem avaliado do que sua versão contendo somente núcleos (Figura 7.6). O conteúdo selecionado foi somente do texto-fonte D2; esse detalhe é explicado mais adiante.

Em todos os métodos que eliminam satélites, é possível que uma sentença bem posicionada no ranque seja um satélite no seu texto de origem e, por isso, seja eliminada pelo método proposto. Considere o ranque a seguir, em que a primeira e a segunda coluna representam identificadores para documento e sentença, a terceira coluna indica a nota da sentença e, por último, a coluna tamSentenca exibe o tamanho da sentença após a eliminação de satélites.

\footnotetext{
${ }^{25}$ São sentenças que não tiveram nenhuma proposição removida e podem possuir núcleos e satélites.
} 


$\begin{array}{rccc}<\text { Doc } & \text { Sent } & \text { nota } & \text { tamsentenca }> \\ \text { D2 } & 3 & 6 & 0 \\ \text { D2 } & 4 & 6 & 13 \\ \text { D1 } & 2 & 5 & 29\end{array}$

Apesar de a sentença 3 do documento D2 estar bem posicionada no ranque, ela foi eliminada por ser satélite. Se isso acontece, sentenças de tamanho zero são eliminadas do ranque.

Em relação ao uso da RST em SA multidocumento, ressaltam-se alguns pontos:

a) Dependendo da estratégia de eliminação de satélites, pode-se ter um sumário com informações incompletas. A fim de evitar isso, sugere-se eliminar somente aquelas sentenças que são formadas de uma proposição e que essa proposição seja satélite (solução adotada no método RST 3).

b) Qualquer um dos algoritmos clássicos de SA com RST (O’Donnell, 1997; Ono, 1994; Marcu, 1997 e 1998; Uzêda et al., 2010) atribui notas para as proposições de uma sentença. Segundo esses autores, essa estratégia é adequada no cenário monodocumento, geralmente selecionando-se proposições de notas mais altas no ranque. Contudo, se essa mesma classificação de proposições fosee aplicada no cenário multidocumento para selecionar conteúdo, pode-se afirmar que o sumário final seria praticamente incompreensível. Nesse caso, sugere-se utilizar os mesmos algoritmos clássicos, mas considerando as sentenças como unidades elementares.

c) Como geralmente os textos de uma coleção possuem tamanhos diversos, suas árvores RST tem diferentes alturas (profundidade). Se for considerada somente a altura de cada árvore como limite superior para a ponderação de notas, sentenças nucleares de árvores mais baixas (menores) ficarão muito abaixo no ranque. Provavelmente as sentenças nucleares das árvores mais altas sempre ocuparão as melhores posições do ranque. A fim de amenizar essa diferença, sugere-se normalizar as notas das sentenças pelas alturas de suas árvores. Dessa forma, todas as notas estarão dentro do mesmo limiar e ainda será possível recuperar as sentenças mais nucleares dos textos.

d) Para amenizar a redundância no sumário, utilizou-se a medida de similaridade do cosseno. Contudo, observou-se que na maioria das vezes ( $94 \%$ do córpus), os métodos selecionam sentenças de um único texto. Isso pode ser observado nos sumários das Figuras 7.3, 7.4, 7.3 e 7.7 Isso se deve ao critério de selecionar somente sentenças abaixo da média geral de similaridade, que faz com que tais sentenças sejam mais facilmente encontradas em um único texto. Nos 47 conjuntos de textos em que isso aconteceu, escolheram-se sentenças do mesmo texto a que a primeira sentença do ranque pertencia. 
Todas essas considerações sobre a RST orientam os próximos métodos deste trabalho. A avaliação dos métodos com RST é discutida na Seção 7.2.

\subsubsection{Uso dos subtópicos na SA multidocumento}

Para investigar a influência dos subtópicos em SA, formalizaram-se duas propostas, como se mostra resumidamente na Figura 7.8. O método Subtópico Denso seleciona uma sentença de cada subtópico e o método Maior Subtópico recupera somente sentenças do subtópico com mais sentenças. Nas duas propostas, considera-se que os textos foram segmentados e os subtópicos já estão agrupados. Essses métodos não há conhecimento sobre núcleos e satélites, portanto, selecionam-se sentenças completas.

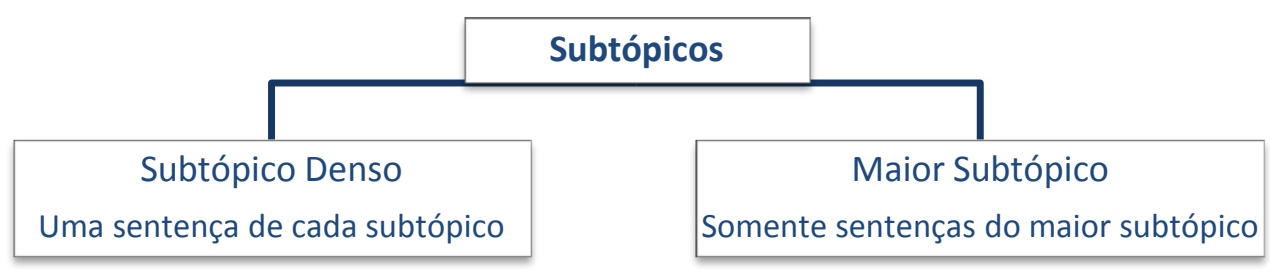

Figura 7.8: Métodos de SA multidocumento baseados em subtópicos

Segundo Boros et al. (2001), os assuntos de uma coleção de textos devem ser vistos como um conjunto finito de subtópicos e um bom sumário deve cobrir o maior número de subtópicos, respeitando o limite da taxa de compressão. Alguns pesquisadores supõem que a primeira sentença de cada subtópico corresponde uma descrição geral do mesmo e, por isso, deve ser inserida no sumário (Boros et al., 2001; Ercan e Cicekli, 2008). Essas suposições serviram de base para o método Subtópico Denso, no qual pelo menos uma sentença de cada subtópico é selecionada. O método Subtópico Denso é ilustrado no Quadro 7.3. A fase de Síntese é similar à dos métodos já apresentados. 


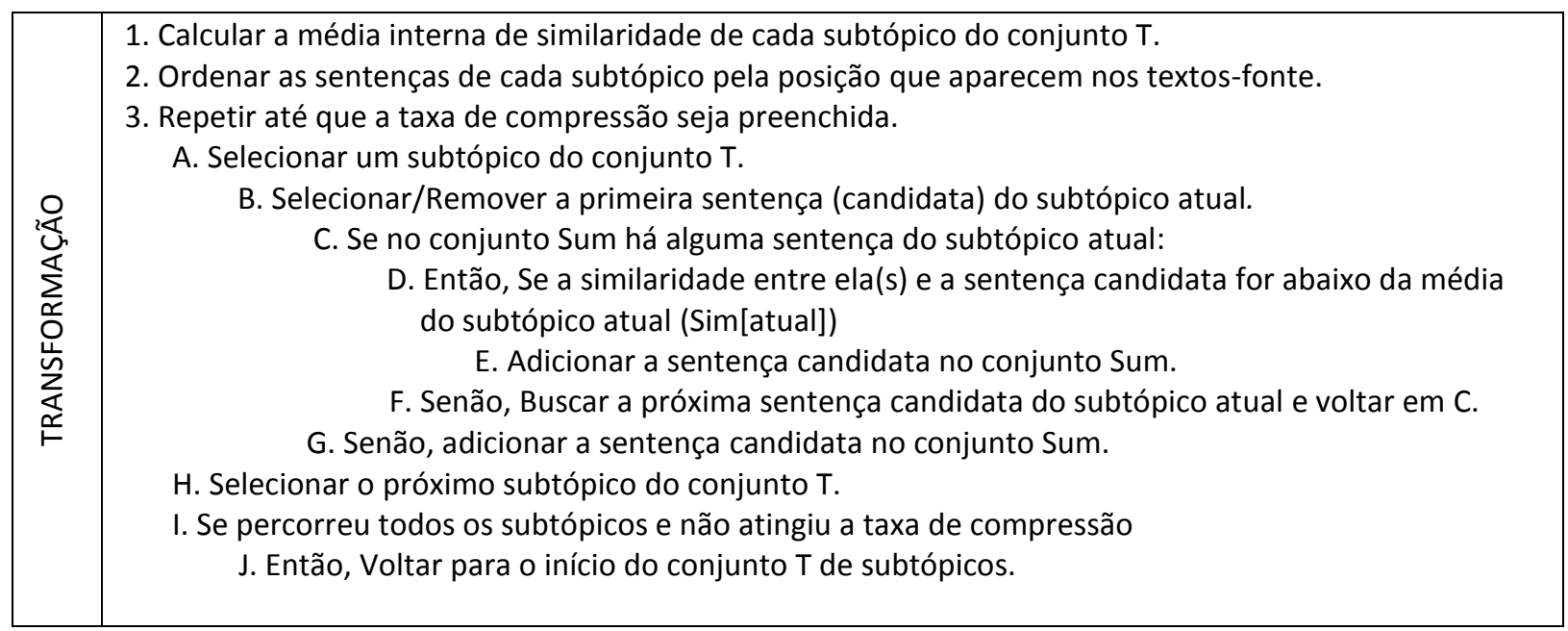

Quadro 7.3: Método de sumarização automática Subtópico Denso

Considera-se que há um conjunto de subtópicos $\mathrm{T}\left\{\mathrm{t}_{1}, \mathrm{t}_{2}, \ldots, \mathrm{t}_{\mathrm{n}}\right\}$, onde $n$ é o tamanho do conjunto T. Em cada subtópico do conjunto T, há um conjunto de sentenças $S\left\{\mathrm{~s}_{1}, \mathrm{~s}_{2}, \ldots, \mathrm{s}_{\mathrm{m}}\right\}$, onde $m$ é tamanho do conjunto S. As sentenças em cada subtópico podem pertencer ou não a documentos diferentes, dependendo do agrupamento. A saída Sum será um conjunto de sentenças de subtópicos diferentes, que formarão o sumário.

No passo 1 do método Subtópico Denso, calcula-se a média de similaridade de cada subtópico do conjunto T, ou seja, busca-se a média de similaridade entre as sentenças de um subtópico. Assim, será formado o conjunto Sim de médias de similaridades $\left\{\operatorname{simt}_{1}, \operatorname{simt}_{2}, \ldots\right.$, $\operatorname{simt}_{\mathrm{n}}$ \}, onde $n$ é tamanho do conjunto. No passo 2, para cada subtópico, organiza-se suas sentenças pela posição que elas aparecem nos textos.

O passo 3 é repetido até atingir a taxa de compressão. Inicialmente, seleciona-se o primeiro subtópico do conjunto $\mathrm{T}$ (passo A). Do subtópico (atual), seleciona-se a primeira sentença candidata (passo B). Se no conjunto Sum de sentenças já selecionadas para o sumário, houver alguma sentença do subtópico atual (passo C), deve-se verificar qual a similaridade entre elas. Se a similaridade entre a sentença candidata e as sentenças do subtópico atual que estão no conjunto Sum for abaixo da média (passo D), insere-se a sentença candidata no conjunto Sum (passo E). Caso a similaridade entre a sentença candidata e as sentenças do subtópico atual do conjunto Sum for alta, deve-se escolher a próxima sentença do subtópico atual e verificar novamente a similaridade (passo F). Após a seleção da sentença, deve-se passar para o próximo subtópico do conjunto $\mathrm{T}$ (passo $\mathrm{H}$ ) e repetir o processo até atingir a taxa de compressão. Caso se tenha percorrido uma vez cada subtópico e 
a taxa de compressão não tenha sido atingida (passo I), deve-se voltar ao início do conjunto T (passo J) e repetir o processo.

É importante ressaltar que o controle de similaridade é realizado em cada subtópico, mas não entre os subtópicos. Essa decisão deve-se ao fato de que os textos-fonte já foram segmentados e os subtópicos foram agrupados, reduzindo a redundância entre grupos. Para exemplificar o método Subtópico Denso, considera-se a Figura 7.9, que contém dois documentos, identificados por D1 e D2 (parte a).

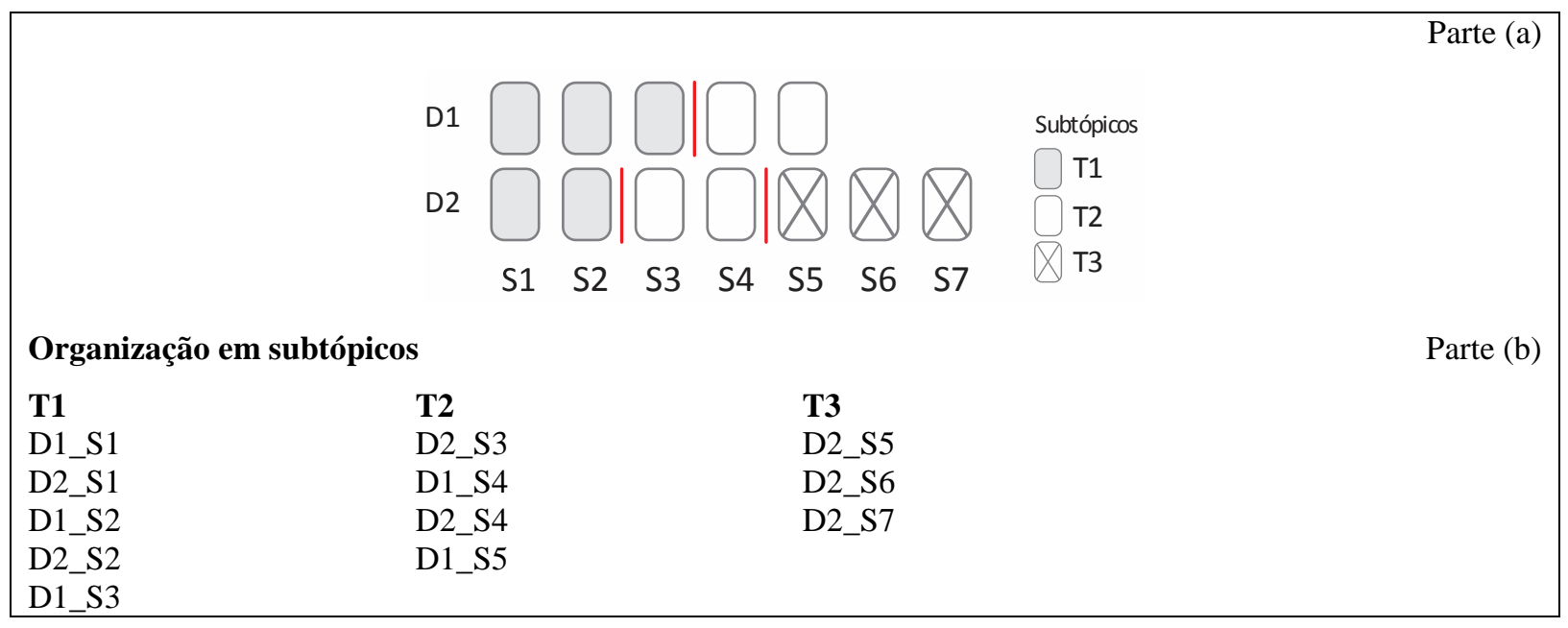

Figura 7.9: Representação do método Subtópico Denso

Cada retângulo representa uma sentença, logo, D1 tem 5 sentenças e D2 tem 7 sentenças. Barras verticais entre sentenças indicam a segmentação topical. O documento D1 está segmentado em dois subtópicos, chamados de T1 e T2. T1 contém as sentenças de 1 a 3, e T2 as sentenças 4 e 5 . O documento D2, por sua vez, está organizado em três subtópicos: T1 contendo as sentenças 1 e 2; T2, com as sentenças 3 e 4; e T3, com as sentenças de 5 a 7 . Observa-se que os subtópicos T1 e T2 ocorrem nos dois textos, enquanto o subtópico T3 aparece somente no documento D2. Pelo método Subtópico Denso, as sentenças são organizadas em seus subtópicos na ordem em que aparecem nos textos, conforme se mostra na Figura 7.9 (parte b). Todas as sentenças que possuem o mesmo número identificador ficam próximas umas das outras. Após essa organização, o método selecionará a primeira sentença dos subtópicos T1, T2 e T3. No método Subtópico Denso não é verificado quais subtópicos são mais importantes. Os subtópicos são considerados independentes um do outro.

Na Figura 7.10, apresenta-se um exemplo de sumário obtido pelo método Subtópico Denso. O segundo valor nos colchetes é um identificador para o subtópico da sentença. $\mathrm{O}$ sumário descreve "Polícia prende desembargadores, juízes e parlamentares em Rondônia". 
$[\mathbf{S 1}, \mathbf{1}]$ A PF (Polícia Federal) prendeu na manhã desta sexta-feira 23 pessoas suspeitas de envolvimento em esquema da Assembléia Legislativa do Estado de Rondônia para desvio de recursos públicos e influência indevida sobre Poder Judiciário, Ministério Público, Tribunal de Contas e Poder Executivo do Estado.

[S2, 2] O grupo é acusado de lesar os cofres públicos em cerca de R\$ 70 milhões, desde 2004.

$[\mathbf{S 3}, 4]$ Essa investigação demonstra a existência de uma grande organização criminosa no estado de Rondônia, que teve início na Assembléia Legislativa e estendeu seus "tentáculos" para parte dos poderes do Estado, comprometendo e envolvendo pessoas do Tribunal de Justiça, do Tribunal de Contas, do Ministério Público e do Poder Executivo, resumiu Mesquita.

$[\mathbf{S 4}, \mathbf{3}]$ As informações coletadas pela PF durante as investigações foram enviadas ao TJ (Tribunal de Justiça) do Estado de Rondônia e ao STJ (Superior Tribunal de Justiça).

\section{Figura 7.10: Exemplo de sumário pelo método Subtópico Denso}

\section{Fonte: Córpus CSTNews, C9}

Para o sumário da Figura 7.10, a coleção tinha 4 subtópicos e foi possível recuperar uma sentença de cada. Os subtópicos estão organizados como segue: 1) operação da PF e os presos, 2) motivo das prisões, 3) novas investigações e 4) detalhes da investigação. Um detalhe que chama atenção na sentença S3 é que não é possível identificar quem é Mesquita. A primeira ocorrência dessa entidade estava em uma sentença do subtópico 1, que não foi selecionada para o sumário devido à taxa de compressão. O método Subtópico Denso é similar ao Caminho Denso de Salton et al. (1997), descrito no Capítulo 4. Os autores utilizam um mapa de relacionamentos entre parágrafos de um texto e selecionam os parágrafos que receberam mais ligações. Apesar de os métodos Caminho Denso (Salton et al., 1997) e Subtópico Denso selecionarem um pouco de cada subtópico, formando sumários abrangentes, não há garantias de coesão nos extratos.

Segundo Ercan e Cicekli (2008), um subtópico relevante é aquele que possui mais sentenças que outros subtópicos, indicando que ele foi bem discutido entre as fontes. Salton et al. (1997) também selecionaram sentenças de um único subtópico pelo chamado Caminho Profundo: (i) localiza-se o parágrafo que tem mais ligações com os demais, e (ii) seleciona-se esse parágrafo para o sumário. O próximo parágrafo selecionado será aquele que tem mais ligações com o anteriormente selecionado. Pelo Caminho Profundo (descrito no Capítulo 4), o sumário final terá somente parágrafos semanticamente relacionados. Apoiando-se nos trabalhos de Ercan e Cicekli (2008) e Salton et al. (1997), elaborou-se o método Maior Subtópico, que coleta sentenças do maior subtópico de uma coleção. Considerando os subtópicos da Figura 7.9, pelo método Maior Subtópico, somente sentenças do subtópico T1 
seriam selecionadas. Ao final, o sumário estaria concentrado em informações de um único subtópico. No Quadro 7.4, apresenta-se o passo-a-passo do método Maior Subtópico.

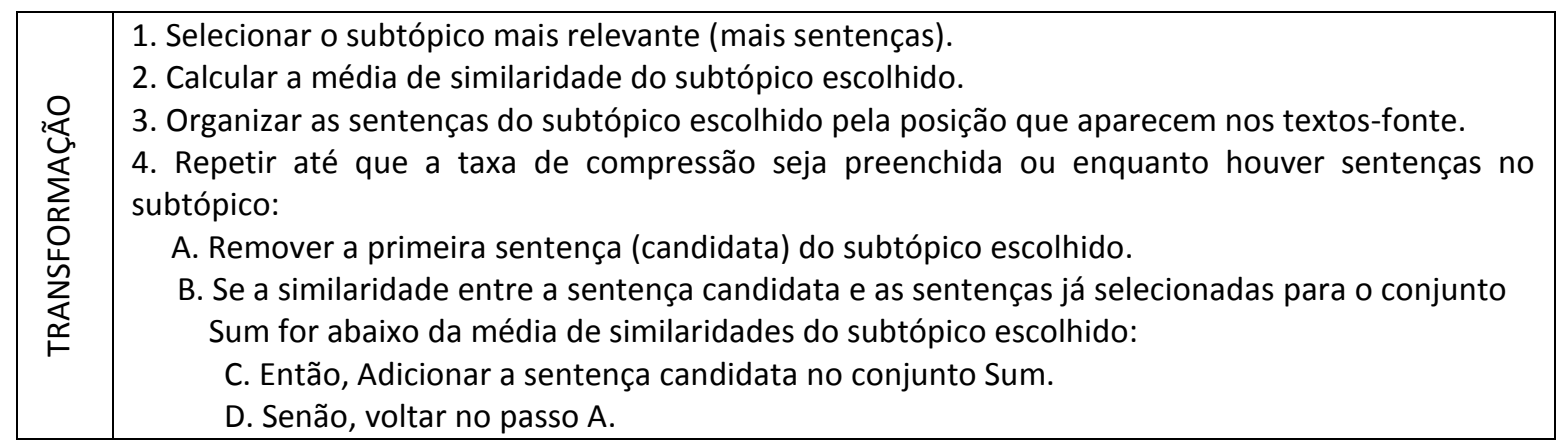

Quadro 7.4: Método de sumarização automática Maior Subtópico

No passo 1, seleciona-se o subtópico com mais sentenças. No passo 2, calcula-se a média de similaridade do subtópico escolhido. No passo 3, organizam-se as sentenças desse subtópico pela posição que aparecem nos textos-fonte. $\mathrm{O}$ passo 4 deve ser repetido até atingir a taxa de compressão ou enquanto houver sentenças no subtópico. Inicialmente, no passo A, remove-se a primeira sentença do subtópico. Se o conjunto Sum de sentenças selecionadas para o sumário não estiver vazio, deve-se verificar a similaridade entre a sentença candidata e as sentenças do conjunto Sum. Assim, se a similaridade entre a sentença candidata e o conjunto Sum for abaixo da média (passo B), adiciona-se a sentença candidata no conjunto Sum (passo C). Caso contrário, deve-se voltar no passo A e escolher a primeira sentença disponível. Por esse método, é possível que se esgotem as opções de sentenças do subtópico escolhido e que não haja conteúdo suficiente para formar o sumário, devido à alta similaridade. Se isso acontece, forma-se um sumário com tamanho menor ao que era esperado.

Na Figura 7.11, apresenta-se um exemplo de sumário pelo método Maior Subtópico, usando o mesmo conjunto de textos-fonte do sumário da Figura 7.10. No sumário, percebe-se que o subtópico selecionado (identificado como 1) descreve sobre a operação da Polícia Federal e os presos. 
$[\mathbf{S 1}, \mathbf{1}]$ A PF (Polícia Federal) prendeu na manhã desta sexta-feira 23 pessoas suspeitas de envolvimento em esquema da Assembléia Legislativa do Estado de Rondônia para desvio de recursos públicos e influência indevida sobre Poder Judiciário, Ministério Público, Tribunal de Contas e Poder Executivo do Estado.

$[\mathbf{S 2}, \mathbf{1}]$ Entre os presos estão o presidente do TJ (Tribunal de Justiça) de Rondônia, desembargador Sebastião Teixeira Chaves, e o presidente da Assembléia Legislativa, deputado José Carlos de Oliveira. $[\mathbf{S 3}, 1]$ A polícia informou que o grupo já desviou $\mathrm{R} \$ \mathbf{7 0}$ milhões.

$[\mathbf{S 4}, \mathbf{1}]$ Também foram presos o juiz José Jorge Ribeiro da Luz, o conselheiro do Tribunal de Contas Edilson de Souza Silva, o procurador de Justiça José Carlos Vitachi, o diretor geral da Assembléia Legislativa, José Ronaldo Palitot, servidores, assessores e familiares de deputados.

$[\mathbf{S 5}, \mathbf{1}]$ Oito dos presos pela PF serão mandados para Brasília.

\section{Figura 7.11: Exemplo de sumário pelo método Maior Subtópico}

\section{Fonte: Córpus CSTNews, C9}

Um problema do método Maior Subtópico é que outras informações relevantes são desprezadas. Por outro lado, poder-se ia pensar em sumarização com foco no interesse do usuário, na qual o usuário informa o subtópico de seu interesse e o sistema responde com um sumário relacionado.

Quanto aos métodos Subtópico Denso e Maior Subtópico apontam-se duas questões interessantes:

a) Se o foco for a representatividade dos subtópicos, deve-se selecionar um pouco de cada subtópico, respeitando a taxa de compressão. Embora o sumário final seja abrangente em relação ao conteúdo, ele poderá ser desconexo.

b) Se o foco for a produção de um sumário centrado em um subtópico, nesse caso devem-se estabelecer estratégias para encontrar o subtópico desejado.

A avaliação dos métodos Subtópico Denso e Maior Subtópico é discutida na Seção 7.2

\subsubsection{Combinação de RST e CST em estratégias de SA}

Para estudar as teorias RST e CST no contexto da SA multidocumento, assume-se que a relevância de uma sentença é influenciada pela sua saliência, dada pela RST, e pela sua correlação com os fenômenos multidocumento, indicada pela CST. Na Figura 7.12, resumemse os quatro métodos propostos, que codificam RST e CST em diferentes estratégias de SA multidocumento: RC-1, RC-2, RC-3 e RC-4. Em todos os métodos, considera-se que a fase de Análise está pronta. Acredita-se que os métodos desta seção terão desempenho melhor do que os métodos RST (subseção 7.1.1). 


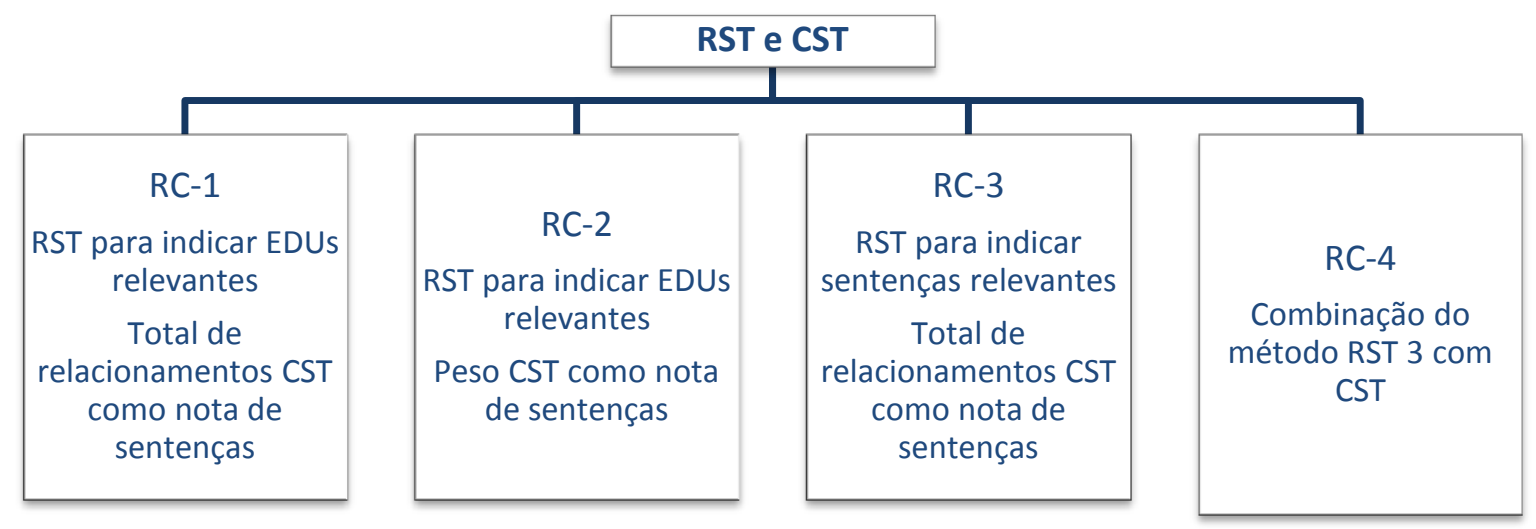

Figura 7.12: Métodos de SA multidocumento baseados em RST e CST

Como mencionado anteriormente, as sentenças mais repetidas e elaboradas entre as fontes são as mais relevantes e, provavelmente, contêm mais relações CST (Zhang et al., 2002; Jorge e Pardo, 2010 e 2011). Logo, se encontrarmos as sentenças relevantes no cenário multidocumento, poderemos eliminar seus segmentos satélites e abrir espaço para mais informações. Assim, no método RC-1, toma-se como ponto de partida as sentenças com mais relações CST, para em seguida eliminar seus satélites, caso houver. No Quadro 7.5, apresentase o método RC-1.

\begin{tabular}{|c|c|}
\hline Análise & $\begin{array}{l}\text { 1. Analisar cada texto com RST } \\
\text { 2. Analisar cada texto com CST }\end{array}$ \\
\hline 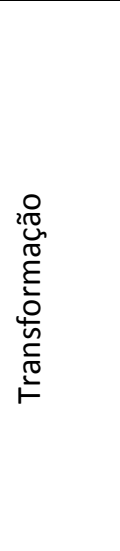 & $\begin{array}{l}\text { 1. Calcular total de relações CST para cada sentença } \\
\text { 2. Organizar de forma decrescente as sentenças pelo número de relações CST } \\
\text { 3. Repetir até atingir a taxa de compressão: } \\
\text { A. Remover a primeira sentença do ranque } \\
\text { B. Se há redundância entre a sentença candidata e o conjunto Sum (selecionadas): } \\
\text { B.1: Se a relação for redundância total: tratar as sentenças usando as restrições do } \\
\text { Quadro } 7.6 \\
\text { B.2: Se a relação for de redundância parcial: } \\
\text { Se OVERLAP, manter a sentença candidata } \\
\text { Se SUBSUMPTION, manter a sentença que subsume a outra e esta será excluída } \\
\text { B.3: Se for qualquer outra relação ou não houver relacionamento, manter (inserir) a } \\
\text { sentença candidata } \\
\text { B.4: Eliminar os satélites da sentença selecionada }\end{array}$ \\
\hline
\end{tabular}

\section{Quadro 7.5: Método de sumarização automática RC-1}

$\mathrm{Na}$ fase de Transformação, cada sentença recebe uma nota que corresponde ao total de relações CST que ela possui (passo 1). No passo 2, organiza-se um ranque de sentenças candidatas pelo número de relações CST. 
O passo 3, dividido nos passos A e B, é repetido até atingir a taxa de compressão. No passo A, remove-se (seleciona-se) a primeira sentença (candidata) do ranque. No passo B, verifica-se se há similaridade entre a sentença candidata e o conjunto Sum, que contém as sentenças já selecionadas. Sabe-se que a redundância indica importância, mas ela deve ser tratada para garantir qualidade do sumário. Diferentemente dos métodos anteriores, os métodos desta seção tiram proveito das relações CST para reconhecer e tratar informações redundantes. Se a redundância for total (passo B.1), isto é, a relação pode ser IDENTITY, EQUIVALENCE ou SUMMARY, aplica-se o tratamento descrito no Quadro 7.6: se for IDENTITY, isso implica na exclusão da sentença candidata; e, se for EQUIVALENCE ou SUMMARY, isso implica na seleção da sentença com o menor número de palavras. Por outro lado, se a redundância for parcial (passo B.2), a relação será de OVERLAP ou SUBSUMPTION: se for OVERLAP, a sentença candidata é aprovada para o grupo de sentenças do sumário; se for SUBSUMPTION, se a sentença candidata $X$ subsume uma sentença $Y$, então $Y$ pode ser excluída do sumário, pois X já contém essa informação. Nesse caso, pode haver troca com a sentença anteriormente selecionada. Caso seja qualquer outra relação CST, a sentença candidata tornase aprovada para o grupo de sentenças do sumário (passo B.3) e eliminam-se seus satélites (passo B.4). O restante da sentença é inserido no conjunto Sum.

a) se a relação entre a sentença já selecionada e a sentença candidata (sentença atual) for IDENTITY, mantem-se a sentença já selecionada e descarta-se a candidata.

b) se a relação entre a sentença já selecionada e a sentença candidata (sentença atual) for EQUIVALENCE ou SUMMARY, fica a sentença com o menor número de palavras. Neste caso, pode haver troca de sentenças, se a sentença já selecionada para o sumário for maior que a sentença candidata. Considera-se aqui o número de palavras após a poda de satélites, quando for o caso.

Quadro 7.6: Tratamento para os relacionamentos de redundância total

Graficamente, o método RC-1 é representado como na Figura 7.13. Na Figura, há duas árvores RST identificadas por D1 e D2. Cada nó da árvore indica uma proposição. Cada sentença é indicada pela letra $s$ e um número. O texto D1 tem 5 sentenças e D2, 8 sentenças. As linhas pontilhadas representam os relacionamentos CST. Imagine que a sentença S2 do documento D2 é a que tem o maior número de relacionamentos CST. Como o método RC-1 corta todos os satélites da sentença, sobrariam somente as proposições 3, 4 e 5 . O que sobrou de D2_S2 seria a primeira sentença do sumário. Caso a taxa de compressão não for preenchida, busca-se a próxima sentença com mais relações CST. 


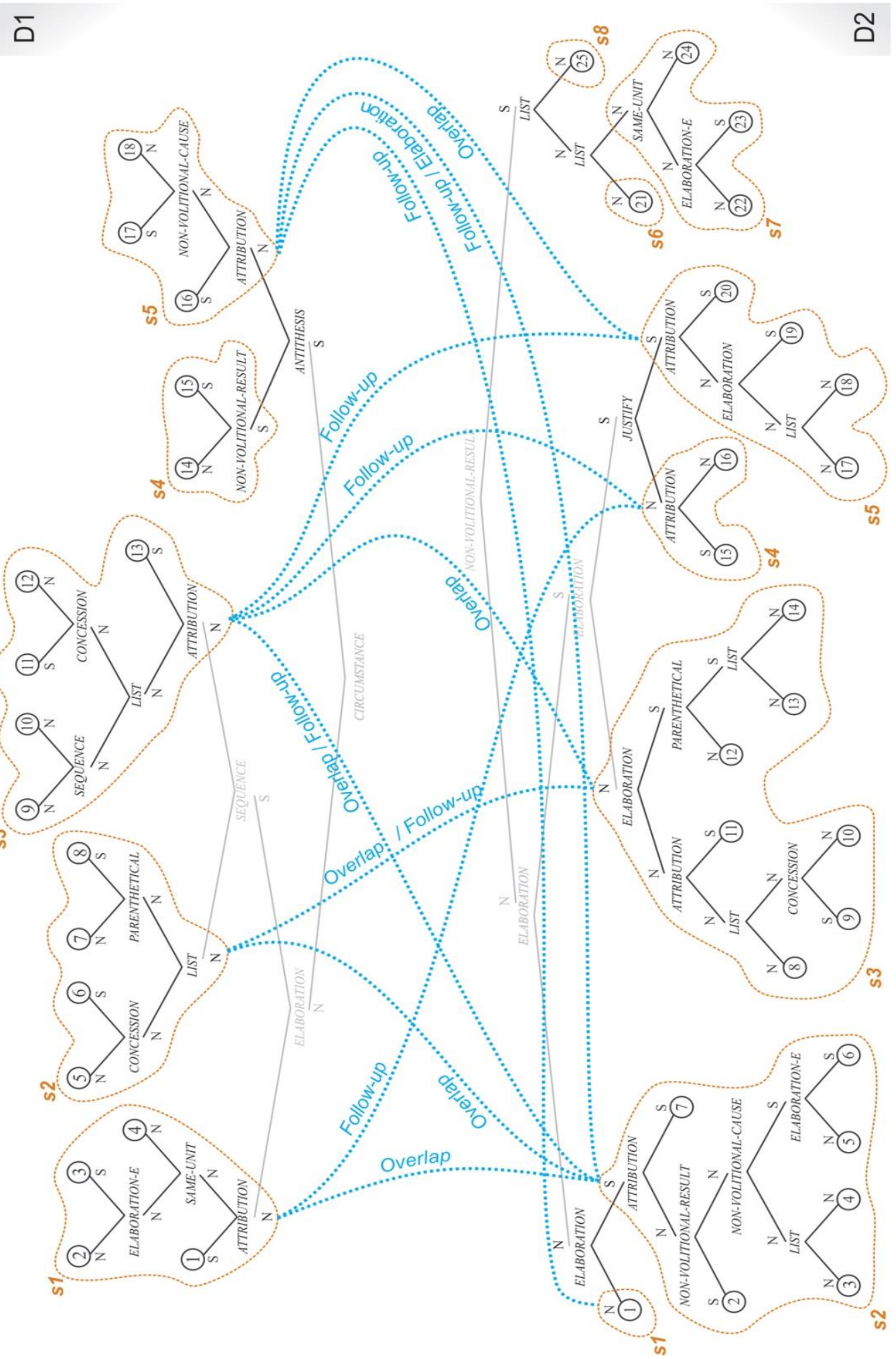

Figura 7.13: Representação de relacionamentos para o método RC-1

Fonte: Córpus CSTNews, C19 
Na Figura 7.14, apresenta-se um sumário sobre "enchentes na Coréia do Norte", produzido pelo método RC-1.

[S1] Um total de 549 pessoas morreram, 3.043 ficaram feridas e 295 estão desaparecidas em razão das enchentes informou hoje um jornal pró norte-coreano publicado no Japão,

[52] Segundo o jornal "Choson Sinbo", publicado pela Associação de Residentes Coreanos no Japão, as fortes chuvas provocaram "muitos danos".

[S3] Além do número de mortos e desaparecidos, o "Choson Sinbo" acrescenta um total de 3.043 feridos.

[S4] o número de mortos ou desaparecidos pode chegar a 10 mil,

[55] A Coréia do Norte recusou ofertas de agências internacionais para o lançamento de campanhas de ajuda ao país, Pyongyang aceitaria ajuda da Coréia do Sul

\section{Figura 7.14: Sumário com o método RC-1}

Fonte: Córpus CSTNews, C12

Conforme se discutiu na seção 7.1.1, quando há corte de satélites, nem sempre é possível compreender o sumário final. Apesar de o sumário da Figura 7.14 reter somente informações nucleares, é possível compreendê-lo. Outro detalhe é que o sumário repete a informação sobre o número de feridos nas sentenças S1 e S3. Nesse caso, as duas sentenças possuem uma relação de OVERLAP, que por sua vez, indica que as sentenças possuem informações em comum e ambas apresentam informações adicionais distintas entre si. A relação OVERLAP precisa de um tratamento mais complexo para eliminar a redundância nas sentenças, pois é necessário juntar todas as informações sem repetição. Esse processo requer métodos que não foram inseridos na seleção de conteúdo deste trabalho. Contudo, o tratamento dessa relação poderá ser realizado na fase de Síntese.

Nos primeiros experimentos, observaram-se alguns casos em que após o corte de satélites de sentenças que tinham alguma relação CST entre si, o conteúdo restante indicava que aquela relação CST era eliminada ou surgiam novas. Isso pode ser verificado no exemplo da Figura 7.15, que contêm duas sentenças, chamadas de D1_S1 e D2_S3, para D representando o documento e $S$, a sentença. As sentenças foram segmentadas em proposições, que são identificadas por números entre colchetes, segundo a RST. Na Figura 7.15, também se mostram as árvores RST de cada sentença e os relacionamentos CST, estes identificados pelas linhas entre as duas árvores. Suponha que D1_S1 e D2_S3 são as sentenças com mais relações CST e com satélites para serem eliminados. Observa-se que, antes da poda, as duas sentenças se conectam pelas relações CST de ATTRIBUtion e OVERLAP. Com o corte, representado pela linha tracejada, as duas relações CST são eliminadas. Nesse caso, se fosse realizada uma nova análise CST utilizando somente o núcleo das sentenças, o analista poderia 
encontrar outras relações CST, por exemplo, SEQUENCE, ou achar que não há nenhuma outra relação entre as informações restantes.

\begin{tabular}{l|l}
\hline D1_S1: & $\begin{array}{l}\text { D2_S3: } \\
\text { [1] Segundo uma porta-voz da ONU, [2] o avião, } \\
\text { [6] Todos morreram [7] quando o avião, [8] } \\
\text { prejudicado pelo mau tempo, [9] não conseguiu } \\
\text { aeroporto de Bukavu em meio a uma tempestade. } \\
\text { chegar à pista de aterrissagem e [10] caiu numa } \\
\text { floresta a 15 quilômetros do aeroporto de } \\
\text { Bukavu. }\end{array}$
\end{tabular}

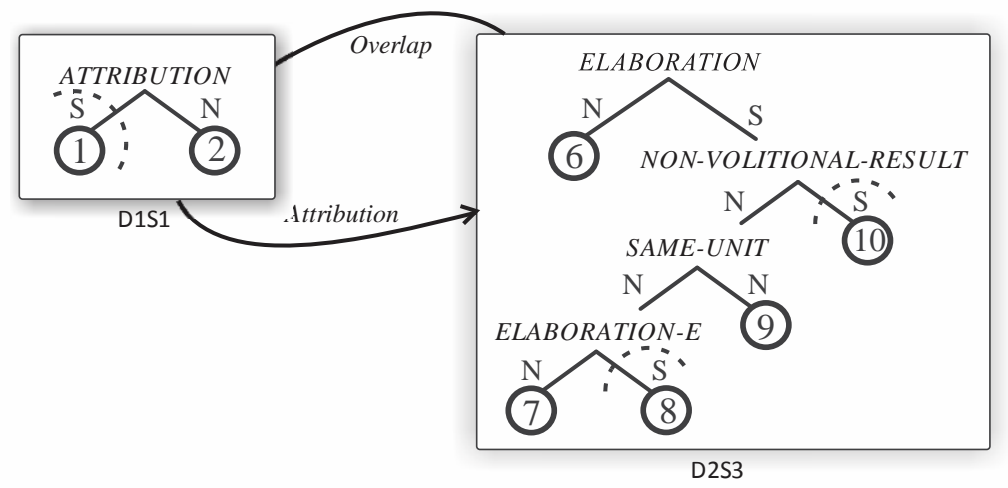

Figura 7.15: Exemplo de eliminação de satélites e mudança da relação CST

Fonte: Córpus CSTNews, C1

Sabe-se que o ideal seria realizar nova anotação após o corte de satélites, mas no estágio atual isso não é desejável. Os fatores que contribuem para que não seja feita uma nova anotação são: a) a hipótese de que, ao perder algumas relações e surgir outras não afetará significativamente o processo de sumarização multidocumento; e b) a anotação depende de esforço humano, o que torna a tarefa cara. Nesta situação, decidiu-se que nenhuma alteração fosse feita nas anotações RST e CST. Se ocorresse algo similar ao exemplo da Figura 7.15, as anotações deveriam ser mantidas, mesmo que implique na eliminação de alguma relação.

Outra forma de utilizar a CST seria atribuindo pesos para as relações. Essa estratégia já foi empregada em SA monodocumento com RST. Por exemplo, O’Donnell (1997) atribuiu pesos para as relações RST pelo seu grau de importância. Neste trabalho, adota-se como critério o grau de redundância que uma relação CST representa: quanto mais redundante, mais peso terá a relação. Assim, surge o método RC-2, no qual a nota CST de uma sentença é a soma dos pesos de suas relações. Os pesos são definidos empiricamente, conforme a proposta inicial disposta na Figura 7.16.

a) As relações de redundância total ocorrem entre informações que são muito repetidas entre as fontes, e, portanto, são informações relevantes. As relações desse grupo recebem peso máximo de 1.0 . 
b) As relações de redundância parcial ocorrem entre sentenças que contêm informações em comum e também alguma informação nova e, nesse caso, recebem um peso de 0.5.

c) A relação CONTRADICTION ocorre entre sentenças que, apesar de contraditórias, apresentam muita informação em comum e, nesse caso, recebem um peso intermediário de 0.8 .

d) As relações de complemento conectam sentenças que trazem informações complementares, uma sobre a outra e, nesse caso, as relações desse grupo recebem a pontuação 0.5 .

e) As relações de apresentação e forma não atuam diretamente sobre o conteúdo e, por isso, recebem a pontuação 0.1 .

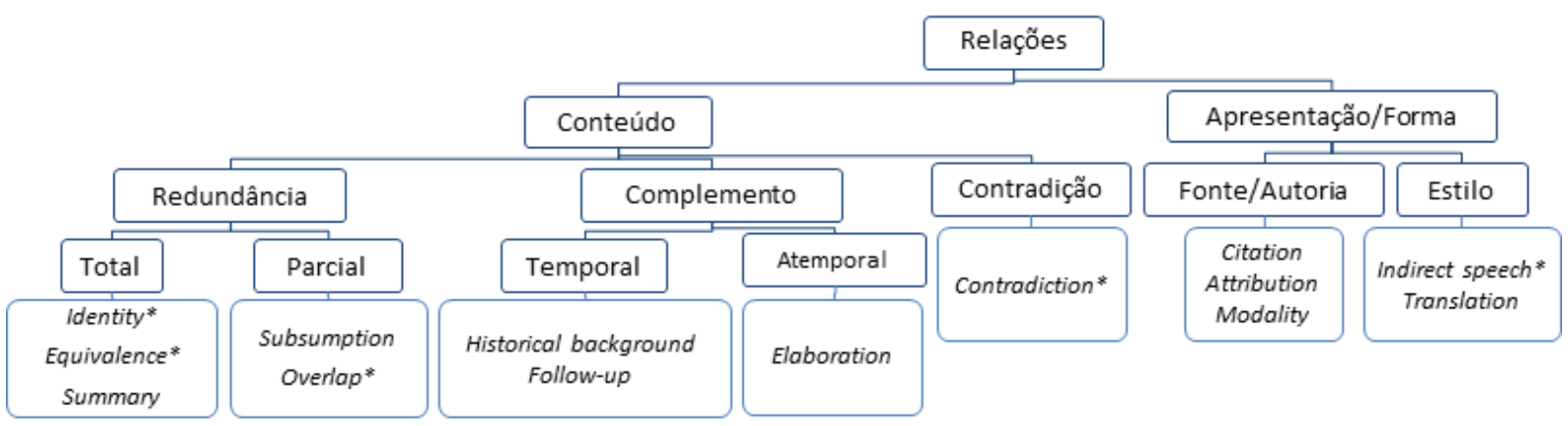

Figura 7.16: Proposta de pesos para relações CST

As outras etapas do método RC-2 são semelhantes às do método RC-1. Na Figura 7.17 apresenta-se um sumário produzido pelo método RC-2. O sumário descreve "enchentes na Coréia do Norte".

[S1] Ao menos 549 pessoas morreram e outras 295 ainda estão desaparecidas em conseqüência das enchentes

[S2] Segundo o jornal "Choson Sinbo", publicado pela Associação de Residentes Coreanos no Japão, as fortes chuvas provocaram "muitos danos".

[S3] No entanto, a publicação, desmentiu o número de até 10 mil mortos pelas inundações, calculado por algumas ONGs

[S4] Além do número de mortos e desaparecidos, o "Choson Sinbo" acrescenta um total de 3.043 feridos.

[S5] o número de mortos ou desaparecidos pode chegar a 10 mil,

[56] A Coréia do Norte recusou ofertas de agências internacionais para o lançamento de campanhas de ajuda ao país, Pyongyang aceitaria ajuda da Coréia do Sul

Figura 7.17: Sumário com o método RC-2

Fonte: Córpus CSTNews, C12 
O sumário da Figura 7.17 é bastante similar em termos de conteúdo ao sumário da Figura 7.14. Ambos possuem somente unidades nucleares e ainda têm 4 sentenças em comum. Embora sejam métodos de SA diferentes, a similaridade é justificada pelo ranque 'total de relações CST de uma sentença' (método RC-1) ser bastante similar ao ranque 'soma dos pesos das relações de uma sentença' (método RC-2). Na maioria das vezes, o que se altera é a ordem em que as sentenças são selecionadas. Apesar da semelhança, o método RC-1 alcançou desempenho sutilmente superior ao método RC-2, conforme será discutido na Seção 7.2.

Considerando-se as observações dos métodos com RST (subseção 7.1.1), principalmente que a eliminação de satélites pode gerar sumários incompletos, investigou-se se a conservação de alguns satélites das sentenças selecionadas via CST poderia influenciar a informatividade dos sumários. Assim, surgiu o método RC-3, uma adaptação do método RC1. No método RC-3 somente sentenças satélites, formadas de uma proposição, são eliminadas. As outras etapas do RC-3 são similares as do método RC-1.

Na Figura 7.18, apresenta-se um sumário pelo método RC-3. O sumário contém quatro sentenças que descrevem que os "parlamentares sanguessugas" têm um prazo para renunciar.

[S1] Os deputados acusados de envolvimento na máfia dos sanguessugas têm até a meia-noite desta segunda-feira para renunciar aos mandatos se quiserem escapar da cassação.

[S2] Os parlamentares acusados de envolvimento com o esquema de superfaturamento das ambulâncias têm até a meia-noite desta segunda-feira, dia 21, para renunciar ao mandato, caso queiram escapar do julgamento por quebra de decoro.

[S3] O horário-limite para que o parlamentar renuncie - 20 horas - foi estabelecido pela direção da Câmara a fim de que o ato seja oficializado com a sua publicação já no Diário Oficial do Congresso de amanhã.

[S4] As renúncias têm que ser publicadas até terça-feira, quando o presidente do Conselho de Ética, deputado Ricardo Izar (PTB-SP), vai instaurar os processos de perda de mandato contra os 69 deputados acusados pela CPI dos Sanguessugas de envolvimento com a máfia das ambulâncias.

Figura 7.18: Sumário com o método RC-3

\section{Fonte: Córpus CSTNews, C16}

No sumário, verificam-se informações redundantes entre as sentenças S1 e S2, devido ao não tratamento da relação OVERLAP, anteriormente explicado.

Os métodos RC-1, RC-2 e RC-3 não utilizam a RST para destacar a relevância de uma sentença em seu texto-fonte juntamente com sua importância no cenário multidocumento. Nesses métodos, a RST é empregada para eliminar satélites. Com base no estudo dos métodos somente com RST (seção 7.1.1), constatou-se que: (a) considerar as sentenças como unidades a serem selecionadas é melhor para o sumário multidocumento; e (b) atribuir notas para 
sentenças de acordo com sua nuclearidade e posição na árvore discursiva reflete um bom ranque multidocumento. Logo, uma quarta possibilidade a ser explorada é considerar tanto o ranque RST e CST de sentenças para encontrar conteúdo relevante. Assim, surge o método RC-4, cujos passos da fase de Transformação são apresentados no Quadro 7.7.

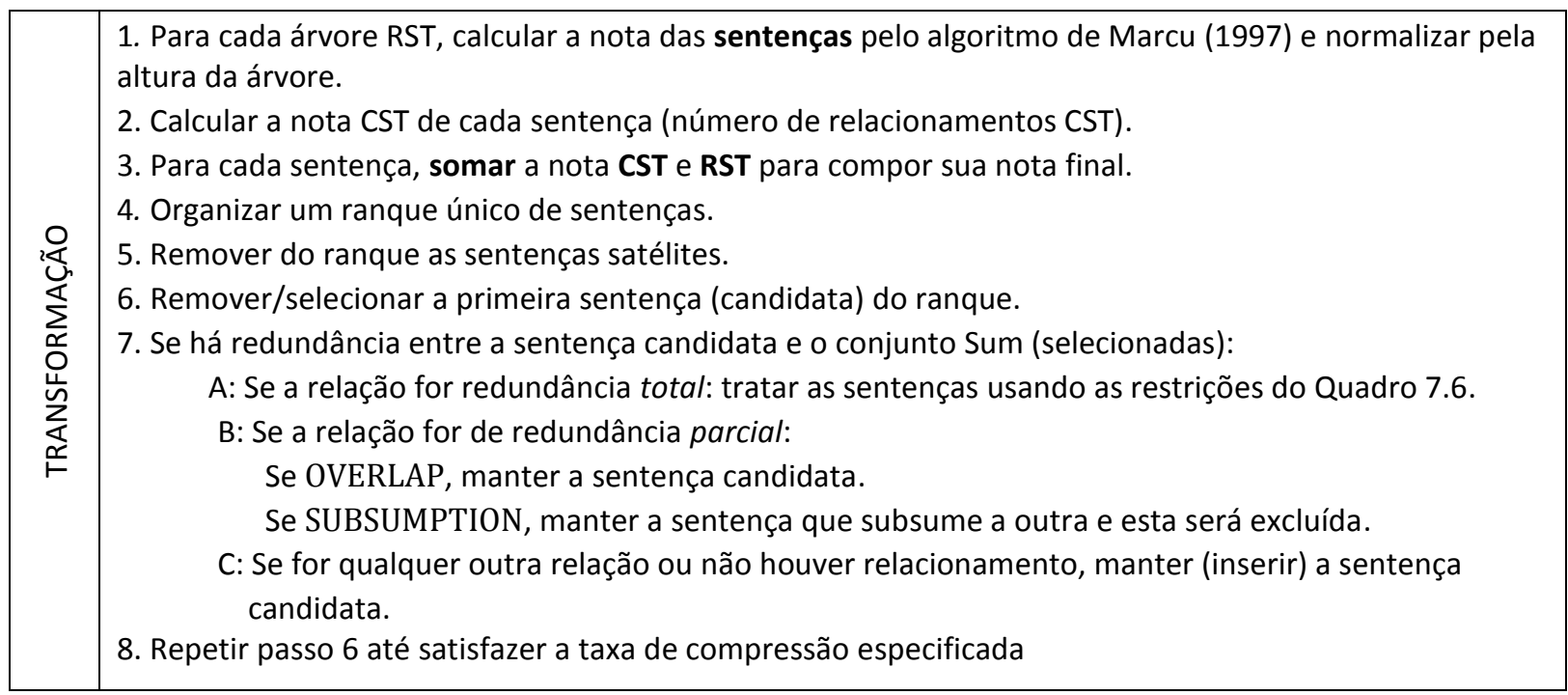

Quadro 7.7: Método de sumarização automática RC-4

Nesse método, no passo 1, calcula-se a nota RST de uma sentença pelo método de Marcu (1997) e normaliza-se pela altura da árvore. No passo 2, calcula-se o total de relações CST que cada sentença recebeu. No passo 3, calcula-se a nota final de cada sentença, que corresponderá à soma da sua nota RST (passo 1) com sua nota CST (passo 2). No passo 4 , organiza-se um ranque único de sentenças. No passo 5, antes de iniciar a seleção de conteúdo, removem-se do ranque todas as sentenças satélites, que são aquelas formadas somente por uma proposição e esta é um satélite. No passo 6, inicia-se a seleção de conteúdo, removendose a primeira sentença do ranque. $\mathrm{O}$ restante do processo é semelhante aos métodos $\mathrm{RC}-1$, RC-2 e RC-3. O passo 6 deve ser repetido até preencher a taxa de compressão.

Na Figura 7.19, apresenta-se um sumário pelo método RC-4. O sumário contém três sentenças que descrevem "Enchentes na Coréia do Norte". 
[S1] Ao menos 549 pessoas morreram e outras 295 ainda estão desaparecidas em conseqüência das enchentes que atingiram a Coréia do Norte em julho, segundo um jornal japonês pró-Pyongyang.

[S2] Segundo o jornal "Choson Sinbo", publicado pela Associação de Residentes Coreanos no Japão, que é próxima ao regime comunista da Coréia do Norte, as fortes chuvas que alagaram grande parte desse país na segunda metade de julho provocaram "muitos danos".

[S3] A Coréia do Norte recusou ofertas de agências internacionais para o lançamento de campanhas de ajuda ao país, mas uma autoridade local disse na semana passada que Pyongyang aceitaria ajuda da Coréia do Sul se fosse dada sem condições.

Figura 7.19: Sumário com o método RC-4

\section{Fonte: Córpus CSTNews, C12}

Em todos os métodos desta seção, é possível que uma sentença que era importante no cenário multidocumento seja um satélite no seu texto de origem e, por isso, seja eliminada pelo método proposto. Isso é similar ao que acontece com os métodos baseados em RST da subseção 7.1.1. Contudo, nos métodos com RST e CST é possível perceber a importância de uma sentença para a coleção e para o seu texto de origem. Quando uma sentença tem boa posição no ranque multidocumento, mas seu tamanho é zero, significa que ela não era tão importante no seu texto de origem. O contrário também pode acontecer: uma sentença pode ser saliente no seu texto-fonte, mas não ser tão importante para a coleção de textos.

Em relação aos métodos desta seção, ressaltam-se alguns pontos:

a) Entre utilizar o total de relacionamentos CST (métodos RC-1, RC-3 e RC-4) e a soma dos pesos das relações (método RC-2) como nota de uma sentença, a primeira forma é preferida. Como será discutido mais adiante, os sumários do método RC-2 apresentaram baixa informatividade.

b) Utilizar a nota RST de sentenças aliada à nota CST (método RC-4) para destacar sentenças significa dar prioridade tanto à importância das sentenças no seu textofonte como no relacionamento entre textos. Como será apresentado mais adiante, os sumários do método RC-4 foram os melhores em termos de informatividade.

\subsubsection{Combinação de RST, CST e subtópicos em estratégias de SA}

Nesta seção, descrevem-se métodos que combinam RST, CST e subtópicos, usando as lições aprendidas nos métodos anteriores:

a) Utilizar RST para destacar sentenças relevantes de cada texto-fonte.

b) Utilizar CST para destacar sentenças relevantes entre as fontes. 
Quanto ao uso de subtópicos, ainda não é possível tirar conclusões. Neste trabalho, busca-se a representatividade dos subtópicos, ou seja, tenta-se cobrir um pouco de cada subtópico.

Na Figura 7.20, ilustra-se o funcionamento básico dos métodos desta seção. A partir de um conjunto de textos de entrada, ocorre a segmentação topical de cada texto, o agrupamento de subtópicos similares e seleção de conteúdo.

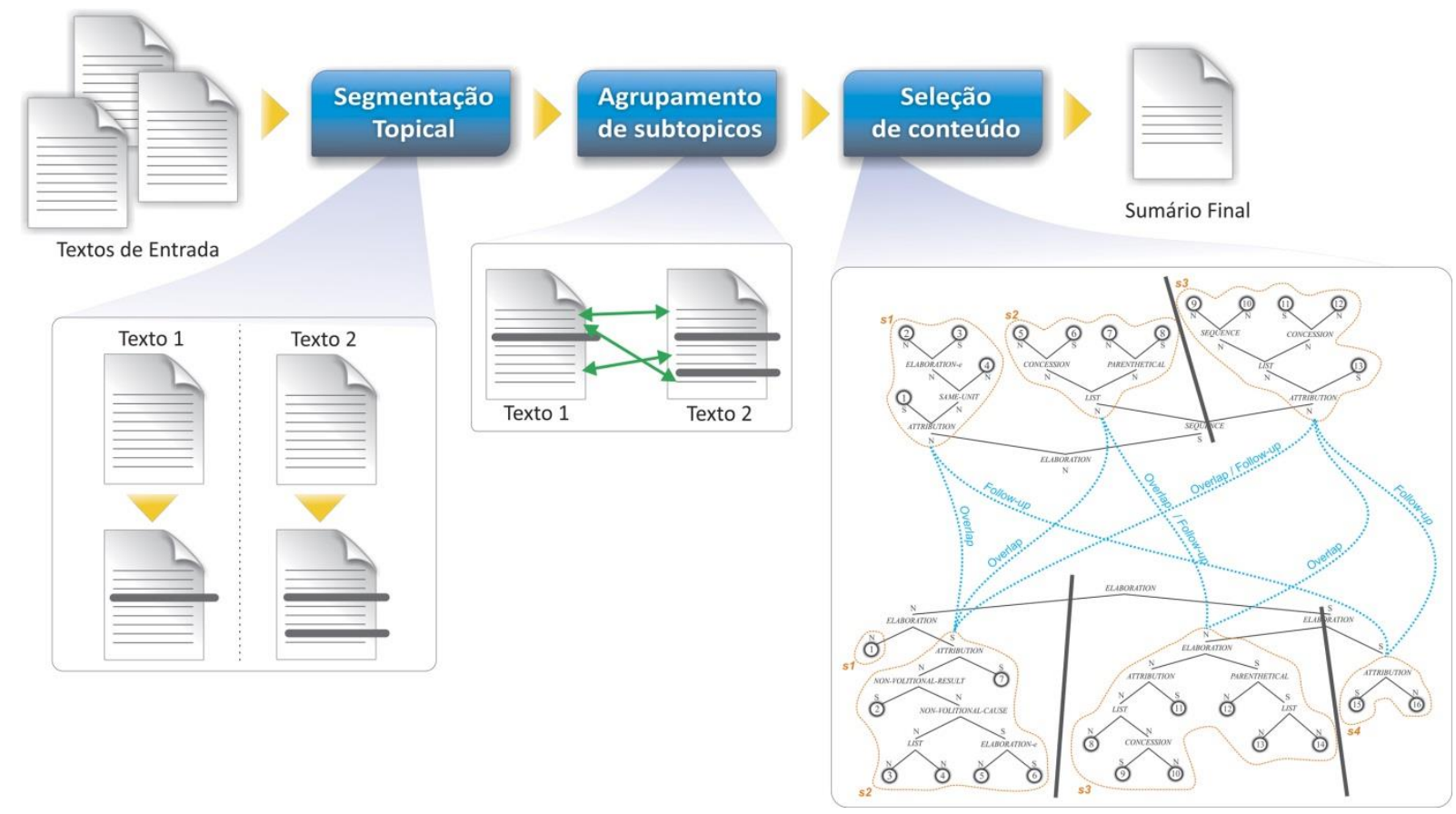

Figura 7.20: Etapas de sumarização dos métodos que combinam RST, CST e subtópicos

Na Figura 7.21, apresentam-se resumidamente os 4 métodos desta seção, chamados de RCT1, RCT-2, RCT-3 e RCT-4. Todos os métodos consideram a sentença como unidade elementar a ser selecionada. A diferença entre eles está na maneira que a RST indica relevância de uma sentença: nos métodos RCT-1 e RCT-2, a maior nota que uma sentença pode receber é a altura da árvore, e, nos métodos RCT-3 e RCT-4, a nota RST de uma sentença é normalizada pela altura da sua árvore discursiva. Essas decisões têm origem na análise dos métodos da subseção 7.1.1. Quanto à CST, a nota de uma sentença corresponde ao total de relações CST que ela recebe. Quanto aos subtópicos, priorizam-se aqueles mais elaborados ou que contenham mais sentenças, buscando boa representividade dentro do limite da taxa de compressão. 


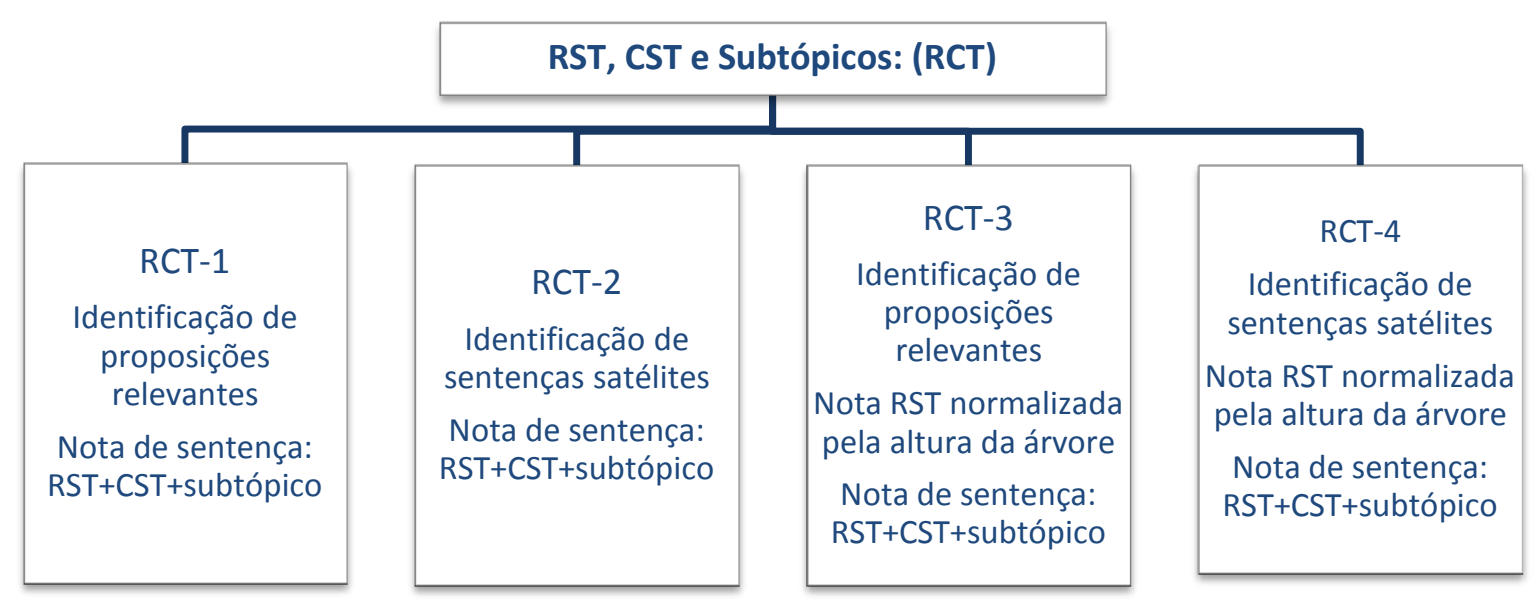

Figura 7.21: Métodos baseados em RST, CST e subtópicos para SA multidocumento

O método RCT-1 é apresentado no Quadro 7.8. A fase de Análise se inicia com as anotações CST e RST dos textos (passos A1 e A2), descritas no Capítulo 5. No passo A3, ocorre a segmentação de cada texto-fonte em subtópicos. No passo A4, acontece o agrupamento dos subtópicos.

\begin{tabular}{|c|c|}
\hline$\frac{w}{\stackrel{w}{\frac{\pi}{\alpha}}}$ & $\begin{array}{l}\text { A1. Analisar cada grupo de texto usando a CST } \\
\text { A2. Analisar cada texto usando a RST } \\
\text { A3. Segmentar cada texto-fonte em subtópicos } \\
\text { A4. Agrupar os subtópicos da coleção de textos }\end{array}$ \\
\hline 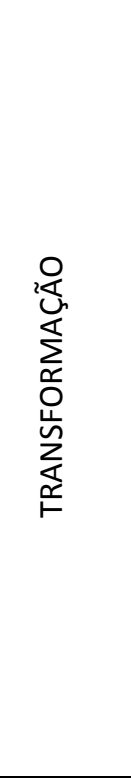 & $\begin{array}{l}\text { T5. Para cada árvore RST, calcular a nota das sentenças pelo algoritmo de Marcu. } \\
\text { T6. Calcular a nota CST de cada sentença (número de relacionamentos CST). } \\
\text { T7. Para cada sentença, somar a nota CST e RST. } \\
\text { T8. Em cada subtópico, organizar as sentenças pela nota CST+RST de forma descrescente. } \\
\text { T9. Para os subtópicos que aparecem em mais de um texto, calcular a diferença das notas das duas } \\
\text { primeiras sentenças do seu ranque e acrescentar na nota de todas as suas sentenças. } \\
\text { T10. Organizar um ranque único de sentenças. } \\
\text { T11. Remover/selecionar a primeira sentença (candidata) do ranque. } \\
\text { T12. Se há redundância entre a sentença candidata e o conjunto Sum (selecionadas): } \\
\text { A: Se a relação for redundância total: tratar as sentenças usando as restrições do Quadro 7.6. } \\
\text { B: Se a relação for de redundância parcial: } \\
\text { Se OVERLAP, manter a sentença candidata. } \\
\text { Se SUBSUMPTION, manter a sentença que subsume a outra e esta será excluída. } \\
\text { C: Se for qualquer outra relação ou não houver relacionamento, manter (inserir) a } \\
\text { sentença candidata. } \\
\text { D: Eliminar os satélites da sentença candidata. } \\
\text { T13. Repetir passo T11 até satisfazer a taxa de compressão especificada }\end{array}$ \\
\hline SÍNTESE & S14. Ordenar os segmentos resultantes. \\
\hline
\end{tabular}

Quadro 7.8: Método de sumarização multidocumento RCT-1 
Na fase de Transformação, ocorre a seleção de conteúdo. Especificamente no passo T5, percorre-se a estrutura RST de cada texto e atribui-se uma nota para as sentenças. Neste trabalho, utiliza-se o método de Marcu (1997) para encontrar notas para sentenças.

No passo T6, percorre-se o grafo CST e calcula-se o número de relações de cada sentença, isso corresponderá à segunda nota da sentença. Em seguida, no passo T7, computase a nota parcial de cada sentença, que corresponde à soma das notas de RST e CST. No passo T8, cada subtópico é organizado internamente de forma decrescente pelas notas parciais de suas sentenças.

No passo T9, verificam-se quais subtópicos aparecem em mais de um texto e, para esses, atribui-se uma pontuação extra. Os subtópicos repetidos entre as fontes são mais relevantes e, de alguma forma devem estar destacados no ranque. Para isso, calcula-se a diferença entre as duas primeiras sentenças do ranque interno de um subtópico e acrescenta-se na nota de cada sentença do subtópico. Esse processo é exemplificado no Quadro 7.9.

\begin{tabular}{|c|c|c|c|c|c|c|c|c|c|c|c|c|c|}
\hline $\mathbf{L}$ & \multicolumn{6}{|c|}{ Ranque interno RST+CST } & \multicolumn{7}{|c|}{ Ranque interno destacando subtópico } \\
\hline $\begin{array}{l}1 \\
2\end{array}$ & & $\begin{array}{l}\text { Doc Sen } \\
\text { idTop }\end{array}$ & $\begin{array}{l}\mathrm{mSe} \\
\mathbf{2}>\end{array}$ & & $\operatorname{lar}$ & st > & $\begin{array}{l}< \\
<\end{array}$ & $\begin{array}{l}\text { Sen } \\
\text { op: }\end{array}$ & $\begin{array}{l}\mathrm{nSe} \\
2>\end{array}$ & & $\operatorname{lar}$ & st & \\
\hline 3 & 1 & 3 & 27 & 5 & 2 & 7 & 1 & 3 & 27 & 5 & 2 & 7 & 8 \\
\hline 4 & 2 & 3 & 35 & 3 & 3 & 6 & 2 & 3 & 35 & 3 & 3 & 6 & 7 \\
\hline 5 & 2 & 4 & 7 & 2 & 2 & 4 & 2 & 4 & 7 & 2 & 2 & 4 & 5 \\
\hline 6 & 2 & 5 & 26 & 2 & 1 & 3 & 2 & 5 & 26 & 2 & 1 & 3 & 4 \\
\hline 7 & & & & & & & & & & & & & \\
\hline 8 & $<$ & idTop & $4>$ & & & & $<$ & op: & $4>$ & & & & \\
\hline 9 & 2 & 6 & 19 & 0 & 4 & 4 & 2 & 6 & 19 & 0 & 4 & 4 & 4 \\
\hline 10 & 2 & 7 & 25 & 0 & 4 & 4 & 2 & 7 & 25 & 0 & 4 & 4 & 4 \\
\hline 11 & 2 & 8 & 9 & 0 & 4 & 4 & 2 & 8 & 9 & 0 & 4 & 4 & 4 \\
\hline
\end{tabular}

Quadro 7.9: Ranque interno de um subtópico

A primeira coluna indica o número da linha para fins de explicação, a segunda coluna representa o ranque RST+CST de cada subtópico, e a terceira coluna representa o ranque interno, destacando subtópicos importantes. No exemplo, há dois subtópicos, identificados por 2 e 4 (linhas 2 e 8). Na linha 3 da segunda coluna, lê-se Documento 1 Sentença 3 Tamanho 27 tem nota igual 5 pela CST e nota igual 2 pela RST, totalizando 7 (RST+CST). O subtópico 2 apareceu nos documentos 1 e 2 enquanto o subtópico 4 apareceu somente no documento 2, logo, o subtópico 2 é mais relevante que o 4 . Calcula-se a diferença entre as duas maiores notas do ranque RST+CST do subtópico 2 e acrescenta-se para a nota de cada sentença. $\mathrm{Na}$ terceira coluna no campo notFi (nota final), exibe-se as notas finais de cada 
sentença. Na linha 3 da terceira coluna, a sentença 3 do documento 1 alcançou nota final igual 8. As sentenças do subtópico 4 não tiveram alterações nas notas.

No passo T10 do método RCT-1, organiza-se um ranque único de sentenças em função da nota final das sentenças. Utilizando as sentenças do Quadro 7.9 para exemplificar, o ranque seria como segue:

$\begin{array}{lccrrrr}< & \text { Doc } & \text { Sent } & \text { tamSe relCst } & \text { scoMar } & \text { rstCst } & \text { notFi> } \\ 1 & 3 & 27 & 5 & 2 & 7 & 8 \\ 2 & 3 & 35 & 3 & 3 & 6 & 7 \\ 2 & 4 & 7 & 2 & 2 & 4 & 5 \\ 2 & 5 & 26 & 2 & 1 & 3 & 4 \\ 2 & 6 & 19 & 0 & 4 & 4 & 4 \\ 2 & 7 & 25 & 0 & 4 & 4 & 4 \\ 2 & 8 & 9 & 0 & 4 & 4 & 4\end{array}$

No passo T11, seleciona-se a primeira sentença do ranque. A partir do passo T12, realiza-se o tratamento de informações redundantes com as sentenças já selecionadas para o conjunto Sum. Esse passo é similar ao dos outros métodos já descritos. Após verificar a redundância (passos de A a C) e caso a sentença candidata se torne aprovada para o sumário, no passo D, elimina-se os seus satélites e insere-se a sentença no conjunto Sum. O passo T12 é repetido até que a taxa de compressão seja atingida. Na etapa de Síntese, o conteúdo selecionado é ordenado cronologicamente pelo método de Lima e Pardo (2012).

Um exemplo de sumário pelo método RCT-1 é dado na Figura 7.22. O tópico principal do sumário é "relator do caso Renan quer suspender o processo no Senado".

$[\mathbf{S 1}, \mathbf{1}]$ O senador João Pedro relator da segunda representação contra Renan Calheiros no Senado, confirmou que vai apresentar nesta quarta-feira, 26, na reunião do Conselho de Ética, pedido de sobrestamento das investigações sobre o caso.

$[\mathbf{S 2}, \mathbf{1}]$ O relator da segunda representação contra o senador Renan Calheiros no Conselho de Ética do Senado, João Pedro vai recomendar o "sobrestamento" das investigações ao invés do arquivamento imediato do processo contra o presidente da Casa.

$[\mathbf{S 3}, 1]$ O conselho se reúne amanhã com a recomendação para o sobrestamento.

$[\mathbf{S 4}, \mathbf{1}]$ Na segunda representação, Renan é acusado de trabalhar

$[\mathbf{S 5}, \mathbf{1}]$ "Os trabalhos da Câmara já estão adiantados e podem trazer novos elementos ao processo. Vamos ter acesso aos autos e aos depoimentos"

$[\mathbf{S 6}, 4]$ O presidente do Conselho de Ética do Senado, senador Leomar Quintanilha admitiu que vai trabalhar para tentar unificar pelos menos duas das três representações em curso contra o Renan, na reunião do órgão marcada para esta quarta.

$[\mathbf{S 7}, 4]$ A reunião do conselho foi marcada para analisar o parecer do relator João Pedro exatamente sobre o processo relacionado à Schincariol.

Figura 7.22: Sumário (a) pelo Método RCT-1

Fonte: Córpus CSTNews, C42 
As duas primeiras sentenças possuem informações repetidas (“João Pedro vai pedir o sobrestamento das investigações contra Renan Calheiros") devido ao não tratamento da relação OVERLAP. Como o método RCT-1 corta proposições satélites, faz-se com que algumas sentenças do sumário iniciem com letra minúscula ou não possuam o ponto final, pois o segmento que tinha essa marcação de início ou de fim foi eliminado. A sentença S5 é claramente uma fala, cuja informação do seu autor foi perdida no corte de satélites. Apesar do corte, nesse caso, é possível entender o sumário. Nos textos-fonte havia 4 subtópicos, dos quais recuperou-se somente sentenças dos subtópicos 1 (denominado investigações) e 4 (denominado unificação dos processos contra Renan).

Outro exemplo de sumário pelo método RCT-1 é dado na Figura 7.23. O sumário descreve em oito sentenças que "Israel ataca o Líbano". A coleção de textos possui 6 subtópicos, dos quais recuperou-se conteúdo dos subtópicos 1 (conflitos Hezbolá entre Israel), 5 (proposta para o fim dos conflitos) e 6 (outros confrontos). Observe que a sentença S8 perdeu sua oração principal após o corte de satélites, implicando na redução da coerência do sumário.

[S1, 1] A aviação israelense atacou 150 alvos na madrugada de hoje no Líbano, enquanto soldados do Estado judeu mataram 10 milicianos do Hisbolá nas aldeias libanesas de Bint Djebeil e Kafr Hula,

$[\mathbf{S 2}, \mathbf{1}]$ foram travadas lugas sangrentas.

[S3, 1] também no domingo foram mortos 30 milicianos do Hezbolá, enquanto um oficial e dois soldados israelenses ficaram feridos hoje em Oleado.

$[\mathbf{S 4}, \mathbf{1}]$ Os foguetes e ataques do Hezbollah causaram a morte de 15 pessoas e deixaram mais de 200 feridas.

$[\mathbf{S 5}, \mathbf{1}]$ Comandos israelenses mataram outros três guerrilheiros libaneses na cidade de Tiro, onde destruíram sete plataformas de lançamento de foguetes,

$[\mathbf{S 6}, \mathbf{6}]$ Os militares isralenses justificaram os ataques, porque o grupo militante Hezbollah continua a lançar mísseis contra "alvos civis" em Israel.

$[\mathbf{S 7}, 6]$ A ofensiva israelense foi lançada depois de uma seqüência de ataques do Hezbollah no domingo

$[\mathbf{S 8}, \mathbf{5}]$ que submeteu uma emenda ao esboço franco-americano,

Figura 7.23: Sumário (b) pelo método RCT-1

Fonte: Córpus CSTNews, C10

Na tentativa de amenizar o corte de satélites que comprometem a leitura do sumário, propôsse o método RCT-2, para eliminar somente as sentenças satélites formadas de uma proposição, que por sua vez, é um satélite. Dessa forma, o método RCT-2 tem o mesmo ranque que o RCT-1, mas com uma diferença no critério de corte no passo T12.D (Quadro 7.7). Na Figura 7.24, exemplifica-se um sumário pelo método RCT-2. O tópico principal é 
“fim de uma rebelião em um presídio no Maranhão". Nos textos-fonte havia 4 subtópicos, dos quais recuperaram-se somente sentenças dos subtópicos 1 (fim da rebelião), 3 (informação histórica) e 4 (dados sobre o líder da rebelião).

$[\mathbf{S 1}, \mathbf{1}]$ Terminou a rebelião de presos no Centro de Custódia de Presos de Justiça (CCPJ), em São Luís, no começo da tarde desta quarta-feira (17).

$[\mathbf{S 2}, \mathbf{1}]$ Após quase 24 horas de tensão, terminou no fim da manhã desta quarta-feira a rebelião na Central de Custódia de Presos de Justiça (CCJP) no Maranhão.

$[\mathbf{S 3}, 4]$ Segundo informações da polícia, o líder da rebelião foi transferido para o Presídio de Pedrinhas, na capital maranhense.

[S4, 3] A CCPJ tem capacidade para cerca de 80 presos, mas abriga 203 homens.

\section{Figura 7.24: Sumário pelo Método RCT-2}

\section{Fonte: Córpus CSTNews, C37}

Visto que nos métodos RST 2, RST 3 (subseção 7.1.1) e RC-4 (subseção 7.1.3), as notas das sentenças via RST foram normalizadas pela altura da árvore, repercutindo em adequada classificação das sentenças e bons sumários, propôs-se estudar se essa mesma alternativa em conjunto com a CST e subtópicos produzia sumários informativos. Assim, surgiram os métodos RCT-3 e RCT-4, ambos são extensões dos métodos RCT-1 e RCT-2, respectivamente.

Nos métodos RCT-3 e RCT-4, a nota RST de cada sentença é dividida pela altura da árvore. Considerando o método do Quadro 7.8, isso ocorre no passo T5. O método RCT-3 corta todos os satélites das sentenças selecionadas e o método RCT-4 elimina somente as sentenças satélites, formadas de uma proposição.

Na Figura 7.25, ilustra-se um sumário produzido pelo método RCT-3, cujo tópico principal é o "prazo para os parlamentares sanguessugas renunciarem". Os textos-fonte apresentavam 3 subtópicos, dos quais foi possível recuperar somente informações do subtópico 1, que descreve sobre o prazo para renúncia dos deputados. Novamente, observa-se a eliminação de satélites prejudicando a interpretação. Por exemplo, em S1, devido à falta da oração principal, dificulta seu entendimento. 
$[\mathbf{S 1}, \mathbf{1}]$ caso queiram escapar do julgamento

$[\mathbf{S 2}, \mathbf{1}]$ Os deputados acusados de envolvimento na máfia dos sanguessugas têm até a meia-noite desta segunda-feira para renunciar aos mandatos

$[\mathbf{S 3}, \mathbf{1}]$ Termina hoje, às 20 horas, o prazo para que os deputados acusados de participar do esquema dos sanguessugas renunciem

$[\mathbf{S 4}, \mathbf{1}]$ o presidente do Conselho de Ética, Ricardo Izar, deve começar a abrir processos contra os parlamentares acusados

[S5, 1] Integrante da cúpula da Câmara calcula que sete podem renunciar - Nilton Capixaba Marcelino Fraga César Bandeira Benedito Dias Carlos Nader João Caldas e Reginaldo Germano

[S6, 1] O horário-limite foi estabelecido pela direção da Câmara

$[\mathbf{S 7}, 1]$ O regimento da Câmara determina que as renúncias sejam lidas no plenário e publicadas no Diário Oficial.

$[\mathbf{5 8}, \mathbf{1}]$ As renúncias têm que ser publicadas até terça-feira, quando o presidente do Conselho de Ética, deputado Ricardo Izar vai instaurar os processos de perda de mandato contra os 69 deputados

\section{Figura 7.25: Exemplo de sumário pelo método RCT-3}

Fonte: Córpus CSTNews, C16

Na Figura 7.26, mostra-se um exemplo de sumário pelo método RCT-4, tendo como tópico principal o "cancelamentos de voos no aeroporto de Congonhas". Os textos-fonte apresentavam 5 subtópicos, mas recuperou-se informações somente do subtópico 1 (atrasos e cancelamentos em Congonhas).

[S1, 1] Quase metade dos vôos previstos para decolar na manhã desta terça-feira (24) no Aeroporto de Congonhas, na Zona Sul de São Paulo, foi cancelada, de acordo com informações da Infraero.

$[\mathbf{S 2}, \mathbf{1}]$ Aeroporto de Congonhas continuava fechado para pousos na manhã desta terça-feira, 24, por conta do nevoeiro que cobria a região sul de São Paulo, e metade dos vôos programados entre 6 e 8 horas foram cancelados.

[S3, 1] Com o fechamento de Congonhas e a interdição da pista principal, que está fechada desde a terça-feira, 17, por conta do acidente com o vôo 3054 da TAM, algumas empresas transferiram vôos para o Aeroporto Internacional de São Paulo (Cumbica), em Guarulhos.

[S4, 1] A TAM cancelou 68 vôos previstos para esta terça em Congonhas e transferiu outros 22 para Cumbica.

\section{Figura 7.26: Exemplo de sumário pelo método RCT-4}

Fonte: Córpus CSTNews, C22

Em relação ao uso de RST, CST e subtópicos, evidenciam-se alguns pontos:

a) Assim como nos métodos anteriores, a eliminação de satélites prejudica a coerência do sumário. Os principais problemas são: sentenças incompletas; falta de referentes e fonte de falas; informações desconexas. Isso é amenizado ao selecionar sentenças completas no lugar de somente proposições nucleares. 
b) Considerar que a nota de uma sentença é dada pelos três pilares - RST, CST e subtópicos - espelha sua verdadeira importância para o cenário multidocumento.

\subsection{AVALIAÇÃO E DISCUSSÃO}

Nesta seção, relata-se a avaliação dos métodos de SA propostos por meio das medidas ROUGE (Lin, 2004) e taxa de retenção (Hovy, 2009). Tais medidas foram detalhadas no Capítulo 2. Na Tabela 7.1, apresentam-se os valores para medida ROUGE. Na Tabela, as letras C, P e F representam Cobertura, Precisão e medida F, para ROUGE-1 (unigrama) e ROUGE-2 (verifica a correspondência de bigramas). Ressalta-se que o córpus CSTNews, utilizado para avaliação, contém somente um sumário de referência (abstract) para cada grupo de textos.

Em todos os métodos de SA que se utilizou o conhecimento dos subtópicos, aplicou-se a segmentação monodocumento pelo método baseado na estrutura retórica (método Relação com Altura, descrito no Capítulo 6). Para fins de comparação, consideram-se os sistemas CSTSumm (Jorge e Pardo, 2010) e RSumm (Ribaldo, 2013). O CSTSumm fundamenta-se na CST e é classificado como o estado da arte da abordagem profunda para textos jornalísticos em Português do Brasil. O RSumm, por sua vez, utiliza características superficiais e é considerado o melhor sistema de SA da abordagem superficial. Os dois sistemas foram descritos no Capítulo 3.

Tabela 7.1: Avaliação ROUGE

\begin{tabular}{l|l|c|c|c|c|c|c}
\cline { 3 - 8 } \multicolumn{2}{c}{} & \multicolumn{3}{c|}{ ROUGE 1 } & \multicolumn{3}{c}{ ROUGE 2 } \\
\hline \multicolumn{1}{c}{ Método } & C & P & F & C & P & F \\
\hline 1 & RST 1 & 0.3198 & 0.3238 & 0.3206 & 0.1456 & 0.1489 & 0.1467 \\
\hline 2 & RST 2 & 0.3579 & 0.3809 & 0.3671 & 0.1720 & 0.1836 & 0.1766 \\
\hline 3 & RST 3 & 0.3874 & 0.3728 & 0.3781 & 0.2074 & 0.1977 & 0.2015 \\
\hline 4 & Subtópico Denso & 0.3811 & 0.3830 & 0.3806 & 0.2101 & 0.2080 & 0.2082 \\
\hline 5 & Maior Subtópico & 0.3863 & 0.4028 & 0.3924 & 0.2007 & 0.2143 & 0.2099 \\
\hline 6 & RC-1 & 0.4270 & 0.4557 & $\mathbf{0 . 4 3 9 1}$ & 0.2469 & 0.2643 & 0.2542 \\
\hline 7 & RC-2 & 0.4174 & 0.4497 & 0.4312 & 0.2415 & 0.2601 & 0.2495 \\
\hline 8 & RC-3 & 0.4370 & 0.4488 & $\mathbf{0 . 4 4 0 5}$ & 0.2528 & 0.2576 & 0.2538 \\
\hline 9 & RC-4 & $\mathbf{0 . 4 3 7 4}$ & $\mathbf{0 . 4 5 1 1}$ & $\mathbf{0 . 4 4 1 9}$ & $\mathbf{0 . 2 5 7 1}$ & $\mathbf{0 . 2 6 3 0}$ & $\mathbf{0 . 2 5 8 6}$ \\
\hline 10 & RCT-1 & 0.3987 & 0.4313 & 0.4128 & 0.2189 & 0.2381 & 0.2272 \\
\hline 11 & RCT-2 & 0.4199 & 0.4399 & 0.4269 & 0.2534 & 0.2656 & $\mathbf{0 . 2 5 7 4}$ \\
\hline 12 & RCT-3 & 0.4151 & 0.4446 & 0.4274 & 0.2342 & 0.2504 & 0.2410 \\
\hline 13 & RCT-4 & $\mathbf{0 . 4 2 7 9}$ & $\mathbf{0 . 4 4 5 4}$ & $\mathbf{0 . 4 3 4 6}$ & $\mathbf{0 . 2 4 4 7}$ & $\mathbf{0 . 2 5 2 3}$ & $\mathbf{0 . 2 4 7 3}$ \\
\hline 14 & CSTSumm & 0.3557 & 0.4472 & 0.3864 & 0.1917 & 0.2339 & 0.2059 \\
\hline 15 & RSumm & 0.3517 & 0.5472 & 0.4190 & 0.3028 & 0.4186 & 0.3434 \\
\hline
\end{tabular}


A investigação das diferentes combinações de conhecimentos semântico-discursivos se apresentam de forma evolutiva na Tabela 7.1. Na avaliação dos métodos de SA que utilizaram a RST isoladamente (linhas de 1 a 3 na Tabela 7.1), observa-se que:

a) O método RST 1, que constrói o ranque de sentenças a partir da soma das notas de proposições, tem a menor C, P e F. Durante a investigação observou-se que essa maneira de classificar sentenças não reproduzia adequadamente o ranque multidocumento. O principal problema encontrado foi que sentenças que eram esperadas estarem bem posicionadas no ranque ficavam em posições menos privilegiadas. Quanto mais proposições uma sentença tivesse, mais alta seria sua nota. No caso do gênero jornalístico, as informações localizadas no início dos textos expressam o fato principal de uma notícia, e por isso, devem estar bem dispostas no ranque. É interessante como essas questões se refletem na avaliação ROUGE.

b) A alternativa sugerida para melhor espelhar a importância das sentenças foi dada pelo método $R S T$ 2, no qual se altera a estrutura de uma árvore, reagrupando as proposições em sentenças. Dessa forma, atribuem-se notas diretamente para sentenças, utilizando o método de Marcu (1997). As notas de sentenças também eram normalizadas pela altura da árvore RST. Embora esse método selecione somente proposições nucleares, pelo resultado ROUGE evidencia-se melhoria em relação ao método RST 1. Isso nos indica que a maneira de definir a nota de sentenças do método RST 2 é melhor do que no RST 1.

c) O método $R S T$ 3, que seleciona sentenças completas, tem a melhor avaliação do grupo RST. É interessante esse resultado, pois a decisão de manter sentenças completas deve-se a uma tentativa de amenizar os problemas de qualidade linguísticas observados de forma empírica nos sumários dos métodos RST 1 e RST 2.

d) Todos esses métodos têm resultados inferiores aos sistemas CSTSumm e RSumm quando se considera a medida f para ROUGE-1 e ROUGE-2.

Dentre os métodos que utilizam conhecimento de subtópicos (linhas 4 e 5), observou-se que:

a) Os valores ROUGE dos métodos Subtópico Denso e Maior Subtópico são muito próximos, que torna difícil afirmar se no sumário de referência (abstract) há um pouco de cada subtópico ou informações centradas em um único subtópico. 
b) Os métodos desse grupo possuem desempenho levemente superior aos métodos do grupo RST (linhas de 1 a 3). Mais análises ainda são necessárias para tirar conclusões entre esses dois grupos.

A partir da análise dos métodos que combinam RST e CST (linhas 6 a 9), pode-se dizer que:

a) Não há muita diferença entre os valores ROUGE desse grupo de métodos. Contudo, utilizar o total de relações CST como indicador de importância de uma sentença traz uma sutil melhoria nos resultados do que considerar pesos para relações CST. Na Tabela 7.1, isso está representado na comparação entre $R C-1$ e $R C-2$, o primeiro método apresentando os melhores valores para C, P e F, tanto para ROUGE-1 quanto para ROUGE-2. Os dois métodos selecionam proposições nucleares, indicadas pela RST.

b) Sabendo que os pesos para relações CST não ajudaram na geração de bons sumários, os próximos métodos da Tabela 7.1 seguem considerando o total de relacionamentos CST para indicar a importância das sentenças para uma coleção de textos. O método $R C$-3, que seleciona sentenças completas, é ligeiramente melhor pela medida-f da ROUGE-1 em relação ao RC-1 e RC-2. Isso indica que (1) usar o número de relações CST como critério de relevância e (2) coletar sentenças completas produz uma boa estratégia de sumarização. Contudo, o mesmo efeito não ocorre para a medida-f quando ROUGE-2 é considerada. Nota-se que o resultado do RC-3 é tão próximo dos métodos RC-1 e RC-2, que dificulta julgamentos mais precisos. Ressalta-se que a ROUGE fornece indicativos de avaliação, que em alguns casos não são consistentes e assim, mais análises são necessárias.

c) No método $R C-4$, a importância de uma sentença é dada pela (1) sua relevância para a coleção de textos (CST) e pela (2) sua relevância no seu texto de origem (RST), ou seja, os dois conhecimentos semântico-discursivos são combinados para formar o ranque de sentenças. A avalição do método RC-4 foi considerada muito boa em relação a todos os métodos seu grupo e do grupo que utiliza isoladamente RST. O resultado indica que ponderar a relevância da sentença entre textos (neste caso, via CST) e no seu texto-fonte (neste caso, via RST) produz bons sumários, segundo a medida ROUGE. 
d) Assim como o método RST 3, o método RC-4 também seleciona sentenças completas. Ambos possuem a melhor avaliação no grupo que pertencem. Isso reforça que selecionar sentenças completas implica positivamente para informatividade, segundo a medida ROUGE.

e) Um ponto interessante é que todos os métodos que combinam RST e CST são melhores que aqueles que utilizam RST ou CST isoladamente (CSTSumm) para todas as medidas. Considerando somente os métodos RC-1, RC-3 e RC-4 que utilizam a CST de forma semelhante ao sistema CSTSumm, o resultado sugere que a RST é um atributo forte para indicar relevância de conteúdo mesmo no cenário multidocumento. O resultado também expressa que combinação de conhecimentos semântico-discursivos de forma adequada em estratégias de seleção de conteúdo gera sumários informativos.

f) Ao comparar o método RC-4 e RSumm, o primeiro tem melhor resultado para ROUGE-1, mas o mesmo efeito não se mantem para ROUGE-2. Mais análises ainda são necessárias para justificar essas diferenças nos valores ROUGE.

A partir da análise dos métodos que combinam os três conhecimentos semânticodiscursivos (RST, CST e subtópicos) (linhas 10 a 13), destacam-se alguns pontos:

a) Mais uma vez, reforça-se a ideia de que coletar sentenças completas produz sumários melhores, segundo a medida ROUGE. Os métodos RCT-1 e RCT-3 selecionam somente proposições nucleares, enquanto os métodos RCT-2 e RCT-4 mantêm sentenças completas. Os métodos RCT-2 e RCT-4 têm melhor avaliação ROUGE do que as suas versões que selecionam somente núcleos.

b) Nesse momento da análise, sabem-se alguns pontos positivos dos outros métodos: (1) usar RST para atribuir notas para sentenças (e não para proposições) e normalizar pela altura da árvore é uma boa estratégia; (2) manter as sentenças completas gera sumários informativos; e (3) utilizar o total de relações CST para indicar a relevância de uma sentença para coleção é melhor do que pesos de relações. Esses pontos foram combinados com os subtópicos, formando o método RCT-4 (linha 13), alcançando a melhor avaliação desse grupo.

c) Um resultado interessante é que o método RCT-4 é ligeiramente inferior ao método RC-4 (que se fundamenta somente em RST e CST). Vários fatores podem contribuir para isso: (1) a segmentação/agrupamento topical ainda não são tão bons quanto 
poderiam ser; (2) a forma de destacar subtópicos relevantes não é adequada; ou que (3) não é muito vantajoso investir em subtópicos.

d) O método RCT-4 supera em termos de cobertura e medida-f (ROUGE-1 e ROUGE-2) o sistema CSTSumm, cuja seleção de conteúdo apoia-se na CST. Esse resultado evidencia que a combinação de conhecimentos semântico-discursivos afeta positivamente a produção de sumários.

e) Na comparação do RCT-4 com o sistema RSumm, o último é melhor que o primeiro para todas as medidas. O método RCT-4 obteve melhor resultado somente para $\mathrm{C}$ e $\mathrm{F}$ com ROUGE-1. A diferença não é tão significativa, de forma que o método baseado em conhecimento discursivo tem desempenho similar àquele baseado em conhecimento superficial.

Se considerarmos somente os valores de F para ROUGE-1 como se faz na maioria dos trabalhos, os quatro métodos com melhor desempenho seriam: RC-4, RC-3, RC-1 e RCT-4, nessa ordem. Se julgarmos que entre os quatro, o método RC-1 produz sumários com muitos problemas de qualidade linguística devido à eliminação de satélites, os três melhores métodos seriam RC-4, RC-3 e RCT-4. Se observarmos os valores de F para a ROUGE-2, teremos um ranque diferente.

Outra comparação interessante é entre os métodos de segmentação em subtópicos. Nesse caso, o objetivo é verificar alterações na avaliação ROUGE ao se utilizar um segmentador de subtópicos baseado em características discursivas (método Relação com Altura) ou um segmentador baseado na frequência de palavras (TextTiling adaptado), como uma etapa no processo de SA. Na Tabela 7.2, mostra-se a comparação entre os métodos de SA utilizando os dois segmentadores. Ao final do nome de cada método de SA, acrescentouse a palavra RST ou Tiling para diferenciar o segmentador utilizado.

Na Tabela 7.2, observa-se que com exceção do método RCT-2 com RST, todos os outros métodos de SA com segmentação pelo TextTiling alcançaram resultados ligeiramente superiores à aqueles que utilizaram o segmentador RST. Conforme descrito na Tabela 6.2, a média de quebras de subtópicos por texto com o método TextTiling é de 1.6. Após a segmentação com essa técnica, 51 textos-fonte (36.4\%) apresentavam 1 subtópico; 85 (60.7\%), 2 subtópicos; e 4 (2.9\%), 3 subtópicos. Com o agrupamento, cada coleção de textos tinha em média 2.5 subtópicos. Quanto à segmentação pelo método RST, a média de subtópicos por texto é de 6.9. A quantidade de quebras por texto para o método discursivo 
varia de 1 até 20 subtópicos. Após o agrupamento, a média de subtópicos por coleção de textos é 2.5 .

Tabela 7.2: Segmentação RST x TextTiling na SA

\begin{tabular}{|c|c|c|c|c|c|c|}
\hline \multirow[b]{2}{*}{ Método } & \multicolumn{3}{|c|}{ ROUGE 1} & \multicolumn{3}{|c|}{ ROUGE 2} \\
\hline & C & $\mathbf{P}$ & $\mathbf{F}$ & C & $\mathbf{P}$ & $\mathbf{F}$ \\
\hline Subtópico Denso RST & 0.3811 & 0.3830 & 0.3806 & 0.2101 & 0.2080 & 0.2082 \\
\hline Subtópico Denso Tiling & 0.3906 & 0.3995 & 0.3941 & 0.2219 & 0.2281 & 0.2244 \\
\hline Maior Subtópico RST & 0.3863 & 0.4028 & 0.3924 & 0.2077 & 0.2143 & 0.2099 \\
\hline Maior Subtópico Tiling & 0.4071 & 0.4219 & 0.4132 & 0.2286 & 0.2345 & 0.2309 \\
\hline RCT-1 RST & 0.3987 & 0.4313 & 0.4128 & 0.2189 & 0.2381 & 0.2272 \\
\hline RCT-1 Tiling & 0.4106 & 0.4337 & 0.4205 & 0.2296 & 0.2429 & 0.2352 \\
\hline RCT-2 RST & 0.4199 & 0.4399 & 0.4269 & 0.2534 & 0.2656 & 0.2574 \\
\hline RCT-2 Tiling & 0.4171 & 0.4394 & 0.4248 & 0.2522 & 0.2656 & 0.2565 \\
\hline RCT-3 RST & 0.4151 & 0.4446 & 0.4274 & 0.2342 & 0.2504 & 0.2410 \\
\hline RCT-3 Tiling & 0.4272 & 0.4534 & 0.4379 & 0.2417 & 0.2569 & 0.2480 \\
\hline RCT-4 RST & 0.4279 & 0.4454 & 0.4346 & 0.2447 & 0.2523 & 0.2473 \\
\hline RCT-4 Tiling & 0.4416 & 0.4520 & 0.4445 & 0.2614 & 0.2644 & 0.2615 \\
\hline
\end{tabular}

Se as coleções de textos apresentam poucos subtópicos (segementados com TextTiling), provavelmente os subtópicos agrupados terão muitas sentenças, fazendo com que esses sejam privilegiados na etapa de seleção de conteúdo. Quando há ocorre muitas quebras de subtópicos nos textos, o agrupamento resulta em alguns subtópicos que não são muito similares aos de outros textos, fazendo que com que não sejam agrupados. Pode acontecer que sentenças relevantes estejam nos subtópicos não agrupados. O resultado da Tabela 7.2 indica que o segmentador discursivo ainda precisa de mais investigação.

Ainda considerando a Tabela 7.2, observa-se que (1) o método RCT-4 com TextTiling também supera o sistema CSTSumm para ROUGE-1 e ROUGE-2; e (2) tem resultados ligeiramente superiores para C e F da ROUGE-1 em relação ao sistema RSumm. Além disso, a avaliação do RCT-4 com TextTiling é superior a do RC-4 (Tabela 7.1, linha 9). Isso demonstra que conhecer os subtópicos dos textos-fonte e utilizá-los na etapa de seleção de conteúdo ajuda produzir bons sumários. Além disso, ao superar o sistema CSTSumm, o resultado do método RCT-4 com TextTiling reforça que a combinação de diferentes conhecimentos semântico-discursivos afeta positivamente a SA do que utilizar os conhecimentos de forma isolada. 
Além da ROUGE, avalia-se a taxa de retenção (TR) em relação aos textos-fontes. Neste trabalho, optou-se por contabilizar TR em função de proposições, isto é, calcula-se a quantidade de proposições coletadas dos textos-fonte (equação 12). O córpus de trabalho possui 5.529 unidades discursivas, divididas em 3.316 (66\%) núcleos e 2.213 (44\%) satélites. Na Tabela 7.3, apresenta-se a porcentagem de proposições nos sumários em relação aos textos-fonte. A coluna "Somente Núcleo" indica os métodos que coletam somente núcleos. Os métodos, que usam subtópicos, utilizaram o segmentador discursivo (Relação com Altura, descrito no Capítulo 6). Embora os sistemas CSTSumm e RSumm não empregarem RST em suas estratégias de sumarização, foi realizado o mapeamenteo das sentenças dos seus sumários com as representações discursivas dos textos-fonte para fins de comparação.

TRproposições $=($ proposições nos sumários $) /($ proposições nos textos $)$

Tabela 7.3: Porcentagem de proposições nos sumários em relação aos textos-fonte

\begin{tabular}{l|l|c|c}
\hline Linha & \multicolumn{1}{|c|}{ Método } & Total\% & Somente Núcleo \\
\hline 1 & RST 1 & 15.5 & X \\
\hline 2 & CSTSumm & 14.4 & \\
\hline 3 & RST 3 & 14.1 & \\
\hline 4 & Subtópico Denso & 13.7 & \\
\hline 5 & RC-3 & 13.4 & \\
\hline 6 & RSumm & $\mathbf{1 3 . 3}$ & \\
\hline 7 & RCT-4 & $\mathbf{1 3 . 1}$ & \\
\hline 8 & RC-4 & $\mathbf{1 3 . 1}$ & \\
\hline 9 & Maior Subtópico & 14.1 & \\
\hline 10 & RCT-2 & 12.3 & \\
\hline 11 & RST 2 & 11.8 & $\mathrm{X}$ \\
\hline 12 & RC-1 & 11.5 & $\mathrm{X}$ \\
\hline 13 & RC-2 & 11.4 & $\mathrm{X}$ \\
\hline 14 & RCT-3 & 11.3 & $\mathrm{X}$ \\
\hline 15 & RCT-1 & 10.8 & \\
\hline
\end{tabular}

Apesar de RST 1 ter a pior avaliação ROUGE (Tabela 7.1), é o método que mais seleciona proposições. Os outros métodos, que selecionam somente núcleos, coletam menos de $12 \%$ do conteúdo dos textos-fonte (linhas de 11 a 15). Em geral, os métodos que escolhem sentenças completas (representados nas linhas 2 a 10) recuperaram entre 12 a 15\% das proposições dos textos-fonte. Outra observação é que os melhores métodos pela medida ROUGE, RCT-4 e RC-4, selecionam a mesma porcentagem de proposições e estão bem próximos do sistema RSumm

Na Tabela 7.4, apresenta-se a porcentagem de proposições núcleos nos sumários em relação aos núcleos dos textos-fonte (equação 13). 
Tabela 7.4: Porcentagem de núcleos nos sumários em relação aos núcleos dos textos-fonte

\begin{tabular}{l|l|c|c}
\hline Linha & \multicolumn{1}{|c|}{ Método } & Total\% & Somente Núcleo \\
\hline 1 & RST 1 & 25.8 & X \\
\hline 2 & RST 2 & 19.6 & X \\
\hline 3 & RC-1 & 19.2 & X \\
\hline 4 & RC-2 & 19.1 & X \\
\hline 5 & RCT-3 & 18.9 & X \\
\hline 6 & RCT-1 & 18.1 & \\
\hline 7 & CSTSumm & 14.2 & \\
\hline 8 & RST 3 & 14.5 & \\
\hline 9 & Maior Subtópico & 14.1 & \\
\hline 10 & Subtópico Denso & 13.7 & \\
\hline 11 & RSumm & 13.6 & \\
\hline 12 & RC-3 & 13.3 & \\
\hline 13 & RC-4 & 13.2 & \\
\hline 14 & RCT-4 & 13.1 & \\
\hline 15 & RCT-2 & 12.4 & \\
\hline
\end{tabular}

É esperado que os métodos que selecionam somente núcleos ocupem as melhores posições na Tabela 7.4 (linhas de 1 a 6). Na primeira linha indica-se, por exemplo, que os $100 \%$ de núcleos recuperados pelo método RST 1 correspondem a $25.8 \%$ de todos os núcleos do córpus. Mas, nem todos esses métodos foram bem avaliados pela ROUGE (Tabela 7.1). Por exemplo, o método RST 1 tem pior avaliação ROUGE. Contudo, os métodos RC-3, RC-4 e RCT-4 coletam bem menos núcleos que o método RST 1, mas possuem os melhores resultados ROUGE. A relação entre ROUGE e porcentagem de núcleos demonstra que núcleos são importantes, mas satélites também são.

Na Tabela 7.5, evidencia-se a porcentagem de núcleos e satélites em cada método. Esse valor é calculado em função da porcentagem de proposições nos sumários (equação 14), dada na Tabela 7.3. Para essa análise, consideram-se somente métodos que coletam núcleos e satélites, isto é, sentenças completas.

TRproposições $N=($ proposições $N$ nos sumários $) /($ proposições nos textos $)$ 
Tabela 7.5: Proporção de núcleos e satélites no sumários

\begin{tabular}{l|c|c}
\hline \multicolumn{1}{c|}{ Método } & Núcleos\% & Satélites\% \\
\hline RST 3 & 8.7 & 5.4 \\
\hline CSTSumm & 8.5 & 5.9 \\
\hline Maior Subtópico & 8.4 & 5.7 \\
\hline Subtópico Denso & 8.2 & 5.4 \\
\hline RSumm & 8.1 & 5.2 \\
\hline RC-3 & 8.0 & 5.4 \\
\hline RC-4 & 7.9 & 5.2 \\
\hline RCT-4 & 7.8 & 7.2 \\
\hline RCT-2 & 7.5 & 4.9 \\
\hline
\end{tabular}

Na Tabela 7.5, indica-se na primeira linha que, dentre $14.1 \%$ de proposições que o método RST 3 selecionou, $8.7 \%$ são núcleos e 5.4\% são satélites. Observa-se que há uma distribuição equilibrada de núcleos e satélites entre os métodos, por exemplo, o método RST 3 selecionou apenas $1.3 \%$ a mais de núcleos e $0.5 \%$ a mais de satélites que o método RCT-2. Em geral, os métodos escolhem mais núcleos que satélites.

\subsection{CONSIDERAÇÕES FINAIS}

Em linhas gerais, pode-se dizer que os métodos baseados em conhecimento semânticodiscursivo apresentaram bom desempenho em selecionar conteúdo relevante. Os melhores métodos deste trabalho foram RC-4 e RCT-4, conforme se mostrou na Tabela 7.1. Para determinar se os resultados desses dois métodos são estatisticamente significativos em relação àqueles considerados estado da arte e entre si, foi aplicado o teste-t, com um fator de confiança de $95 \%$ ( $p$-value $<0.05$ ) para a medida-f. Os resultados apontam que:

a) A diferença estatística entre o método RC-4 e o sistema CSTSumm é significativa. Entretanto, não existe diferença entre RC-4 e RSumm.

b) A diferença estatística entre o método RCT-4 e o sistema CSTSumm é significativa. Entretanto, não existe diferença entre RCT-4 e RSumm.

c) Não há diferença estatisticamente significativa entre os métodos RC-4 e RCT-4.

Em suma, os resultados confirmam a hipótese de que o uso do conhecimento semânticodiscursivo tem impacto positivo na tarefa de SA. Contudo, não se pode descartar totalmente o conhecimento superficial: os dois melhores métodos profundos deste trabalho (RC-4 e RCT4) possuem valores ROUGE muito próximos do sistema RSumm. 
A hipótese de que a RST ajuda na indicação de unidades textuais relevantes em uma estratégia de SA multidocumento se confirmou. No entanto, utilizar somente RST para selecionar conteúdo não produz bons sumários multidocumento. Percebeu-se também que somente CST não garante sumários tão bons quanto poderiam ser. Os resultados mostram que mapear a relevância de uma sentença por meio da estrutura retórica em conjunto com sua importância para a coleção de textos-fonte produz um ranque refinado de sentenças.

Confirma-se também a hipótese de que a modelagem do processo de SA combinando diferentes modelos semântico-discursivos gera sumários mais informativos, conforme a medida ROUGE. Embora os métodos descritos tenham sido aplicados apenas à língua portuguesa, eles podem ser adequados para outras línguas. Afirma-se que os métodos de SA apresentados nesta tese dão mais um passo na direção de estimular mais investigações com o conhecimento discursivo. 


\section{CONCLUSÕES E CONSIDERAÇÕES FINAIS}

Nesta tese de doutorado, apresentou-se uma nova abordagem de SA multidocumento com base em teorias semântico-discursivas para textos em português do Brasil. Foram desenvolvidos 13 métodos inéditos de SA que levam em consideração a relevância das informações e a representatividade dos subtópicos em conjunto com os fenômenos multidocumento, almejando bons sumários informativos e representativos dos textos-fonte. No trabalho, mostrou-se como modelar o processo de SA usando as teorias discursivas RST e CST e o impacto disso para a produção de sumários informativos.

Os métodos de SA multidocumento foram avaliados e refinados sobre o córpus multidocumento CSTNews, constituído de textos jornalísticos em português do Brasil. Os resultados confirmam a hipótese de que o uso de conhecimentos discursivos afetam positivamente a produção de sumários automáticos. Diante dos experimentos realizados, discutem-se neste capítulo algumas contribuições e limitações deste trabalho. Ademais, propõem-se alguns trabalhos futuros.

\subsection{CONTRIBUIÇÕES}

Uma das contribuições deste trabalho diz respeito à adição de camadas de anotação ao córpus CSTNews, que permitiram o desenvolvimento desta pesquisa e a especificação de novos métodos para segmentação em subtópicos e de sumarização automática. Para cada texto, produziram-se anotações de referência com RST e de segmentação em subtópicos de forma manual. A análise da segmentação em subtópicos mostrou que nos textos jornalísticos os subtópicos organizam-se em parágrafos. Para cada coleção, ainda foi realizado o agrupamento manual de subtópicos similares. Todas essas camadas de anotação adicionadas às já existentes enriquecem o córpus CSTNews, que está disponível e pode subsidiar outras pesquisas que utilizam conhecimentos discursivos.

Outra contribuição é a adaptação do clássico algoritmo de segmentação de subtópicos, chamado TextTiling (Hearst, 1997), para textos jornalísticos. A versão adaptada demonstrou resultados satisfatórios e torna-se mais um recurso disponível para os pesquisadores da área. 
No total, foram desenvolvidos 10 métodos de segmentação em subtópicos, sendo 4 superficiais e 6 métodos profundos.

A partir da análise do córpus CSTNews observou-se que há regularidades no discurso e que algumas relações discursivas normalmente indicam mudança de subtópico, como as relações Contrast e Joint. As relações RST foram classificadas em fracas, médias e fortes, de acordo com a possibilidade de indicar ou não uma mudança de subtópico, descrito no Capítulo 6. Uma relação fraca geralmente indica uma quebra de subtópicos; uma relação média pode indicar ou não uma quebra; e uma relação forte nunca aponta mudança de subtópicos. A caracterização de relações e o conhecimento da estrutura discursiva dos textos gerou conhecimento para elaboração de um segmentador em subtópicos baseado em discurso, cujo desempenho foi considerado satisfatório e superior ao TextTiling adaptado. Consequentemente, confirma-se uma das hipóteses de pesquisa e evidencia-se como contribuição teórica a correlação entre discurso e subtópicos: textos bem escritos exibem boa organização topical e essa pode ser recuperada pela estrutura discursiva subjacente.

Foram desenvolvidos 13 métodos de SA multidocumento (descritos no Capítulo 7), utilizando o córpus CSTNews como recurso e as teorias RST e CST e subtópicos. Inicialmente, a teoria RST foi analisada isoladamente, buscando a melhor maneira de indicar conteúdo relevante no cenário multidocumento. Verificou-se que as características da árvore influenciavam a classificação das sentenças de uma coleção. Dessa forma, algumas adaptações foram necessárias, como a reorganização da estrutura de proposições para sentenças. Essas modificações em conjunto com o método de Marcu (1997) auxiliaram na elaboração de um ranque de sentenças compatível com o cenário multidocumento de textos jornalísticos. Em relação ao corte de proposições satélites tão usado em SA monodocumento (Ono et al., 1994; O’Donnell, 1997; Marcu, 1997), neste trabalho, optou-se por coletar sentenças completas, pois isso gerava sumários mais informativos, segundo a avaliação com a medida ROUGE. A análise de como usar RST para uma coleção de textos forneceu pistas para que a teoria fosse combinada com outros conhecimentos semântico-discursivos. Destacase que é a primeira vez que a RST é utilizada para sumarização multidocumento.

O processo de SA também foi modelado com RST e CST, produzindo os melhores sumários deste trabalho, em termos de informatividade. Apesar da intervenção da RST, com a CST, que é uma das teorias mais empregadas em SA multidocumento, foi possível tratar os fenômenos multidocumento, identificando informações redundantes, contraditórias e complementares. 
A distribuição de subtópicos também foi investigada em conjunto com as informações da RST e CST a fim de orientar outras possíveis estratégias de seleção de conteúdo. Os sumários automáticos gerados foram considerados tão bons quanto aqueles baseados somente em CST e RST, segundo a medida ROUGE.

Os melhores métodos de SA deste trabalho (chamados RC-4 e RCT-4) produzem sumários melhores que os do sistema CSTSumm (Jorge e Pardo, 2010), que é considerado o estado da arte da abordagem profunda, e se aproximam daqueles obtidos com o sistema RSumm (Ribaldo, 2013), considerado o estado da arte da abordagem superficial. Portanto, neste trabalho, mostra-se que o uso de diferentes conhecimentos semântico-discursivos contribui na produção de sumários mais informativos e representativos dos textos-fontes. A comprovação se deu por meio da elaboração exaustiva de diferentes formas de encontrar a informação principal, tratar os fenômenos multidocumentos e a distribuição de subtópicos, usando CST e RST, até então não exploradas em conjunto para SA multidocumento. Esse resultado pode estimular mais investigações envolvendo o conhecimento semânticodiscursivo.

Como resultado do doutorado, em termos de publicação, têm-se: (i) artigos publicados em eventos da área de Linguística Computacional, que são (Cardoso et al., 2011a), (Cardoso et al., 2011b), (Cardoso et al., 2013a) e (Cardoso et al., 2013b); e relatório técnico que descreve a abordagem de anotação de subtópicos (Cardoso et al., 2012). Cardoso et al. (2011a) apresentam o córpus CSTNews e as anotações RST e CST, incluindo regras de anotação. Cardoso et al. (2011b) descrevem as estratégias iniciais de SA que deram origem a todo o estudo realizado neste trabalho. Cardoso et al. (2013a) descrevem preocupações com o processo de anotação de córpus e uma metodologia de anotação, instanciada para a anotação de subtópicos. A metodologia, que se fundamenta em Hovy e Lavid (2010), incluem desde a etapa de estudo do fenômeno a ser investigado à etapa de avaliação. Cardoso et al. (2013b), descrevem os métodos de segmentação em subtópicos e os resultados.

Ainda em termos de publicação, há artigos relacionados com esta pesquisa, escritos em colaboração com outros pesquisadores, por exemplo, Di Felippo et al. (2014) e Ribaldo et al. (2013). Di Felippo et al. (2014) relatam a anotação de aspectos textuais nos sumários manuais multidocumento. Os aspectos indicam diferentes tipos de informação que podem ser veiculadas em um texto. Ribaldo et al. (2013) descrevem o método de agrupamento de subtópicos utilizado neste trabalho. 


\subsection{LIMITAÇÕES}

Apesar das contribuições oferecidas por esta tese, identificaram-se também algumas limitações, como à que se refere às características do córpus de trabalho CSTNews, que é o único córpus multidocumento disponível para língua portuguesa de que se tem conhecimento. Embora tenha apoiado diversas pesquisas, trata-se de um córpus pequeno que possui somente um sumário de referência. Conforme se discutiu no Capítulo 2, a produção de sumários de referência é uma tarefa subjetiva: diferentes pessoas tendem produzir sumários diferentes para um mesmo conjunto de textos-fonte. Ao utilizar somente um sumário de referência, acreditase que de alguma está influenciando o resultado da avaliação. Medidas como a ROUGE correlacionam melhor com o julgamento humano quando são utilizados mais sumários de referência.

Outra limitação do trabalho é a necessidade de um córpus anotado, pois, apesar de existirem parsers discursivos tanto para RST e CST, as anotações automáticas ainda estão sujeitas a erros. O tempo de execução dos parsers também é muito demorado. Para não comprometer a investigação, ainda se utiliza córpus anotado manualmente, o que resulta em um processo custoso, trabalhoso e subjetivo.

\subsection{TRABALHOS FUTUROS}

Tendo em vista a continuação deste trabalho, sugerem-se alguns trabalhos futuros.

Quanto à segmentação em subtópicos, os rótulos, atribuídos por anotadores, poderão ser explorados de forma a aperfeiçoar os algoritmos de segmentação. Tais rótulos foram citados, mas não efetivamente utilizados neste trabalho. Os rótulos poderão ser combinados com a estrutura retórica, marcadores discursivos e informações semânticas, tais como cadeias lexicais, a fim de melhorar a segmentação em subtópicos.

Em relação às diferenças observadas na anotação de subtópicos, poderá ser investigado se há perfis de anotadores. Apesar da formação em linguística computacional comum ao grupo, os anotadores vêm de campos de conhecimentos distintos, o que pode causar padrões difrentes de anotação. Uma observação empírica foi que em um mesmo grupo de anotadores, os linguistas concordavam entre si e os cientistas da computação, entre si. Algumas possíveis justificativas para isso podem ser: (1) o fato de que os linguistas têm mais conhecimentos 
sobre a estrutura textual do gênero jornalístico; e (2) linguistas são mais detalhistas e por isso segmentam mais vezes que os cientistas da computação, esses por sua vez, anotam somente as mudanças de subtópicos mais proeminentes. Acredita-se que esse estudo poderá espelhar padrões de concordância diferentes daquele relatado no Capítulo 5.

Quanto à eliminação de satélites, poderá ser examinado se todas as unidades satélites realmente deveriam ser descartadas. Marcu (1999), analisando a produção de sumários manuais, observou que alguns satélites não foram removidos do texto final. Diante disso, baseando-se em marcadores discursivos, o autor classificou os satélites em fracos, que raramente vão para o sumário, e fortes, que podem ir para o sumário. Neste trabalho, a eliminação indiscriminada de satélites gerou alguns sumários difíceis de serem entendidos, pois era nítida a falta de uma informação extra. Com um estudo mais aprofundado sobre satélites, outras decisões de corte poderão ser tomadas.

Em alguns sumários, aparecem expressões anafóricas cujos antecedentes não estão presentes, quebrando a coesão referencial e, consequentemente, dificultando a leitura. Isso ocorre principalmente quando na eliminação de satélites, há perda dos elos referenciais. No futuro, sugere-se planejar uma solução como a inserção da Veins Theory (Cristea et al., 1998), pois a partir da estrutura retórica, essa teoria ajuda na criação de regras de manutenção dos satélites que contêm antecedentes de termos anafóricos, já inclusos nos sumário.

Algumas relações discursivas não são tratadas neste trabalho, por exemplo, a relação de Overlap. Assim, o aprimoramento do tratamento de informações redundantes poderá ser realizado com sistemas de fusão de sentença, tal como o Zíper (Seno e Nunes, 2009). O Zíper permite fusão por interseção, que produz sentenças que capturam somente as informações mais relevantes das sentenças de entrada, por união, que gera sentenças que capturam todas as informações da entrada. Aplicando-se esse tratamento, informações repetidas poderão ser fundidas, melhorando os sumários automáticos.

Com o avanço no estudo e desenvolvimento de parsers discursivos, em breve será possível utilizar anotações automáticas, que permitirão avaliar/expandir os métodos de SA para outros gêneros textuais.

Quanto à avaliação dos sumários, a literatura sugere comparar um sumário automático com vários sumários de referência. Assim, recomenda-se ampliar o conjunto de sumários de referência para que a avaliação automática possa melhor correlacionar-se com o julgamento humano. Isso vale tanto para medida ROUGE, como outras medidas descritas no Capítulo 2, por exemplo, o método de avaliação da pirâmide (Nenkova e Passonneau, 2004). 
Ainda em relação à avaliação, os sumários automáticos poderão ser julgados quanto à qualidade linguística por meio dos critérios da DUC (2005) e do modelo de coerência de Dias et al. (2014). Essa avaliação se faz necessária para apontar se além de informativos, os sumários automáticos não apresentam problemas que dificultem sua interpretação.

Futuramente, novas possibilidades de modelagem conjunta de conhecimentos semântico-discursivos com outras características textuais que possam melhorar a SA poderão ser examinadas, almejando melhorar a informatividade. Por exemplo, poderão ser identificados aspectos textuais (Di Felippo et al., 2014) que auxiliem na determinação de informações relevantes dos textos-fonte. 


\section{REFERÊNCIAS}

Afantenos, S. D.; Doura, I.; Kapellou, E.; Karkaletsis, V. (2004). Exploiting cross-document relations for multi-document evolving summarization. In: Methods and Applications of Artificial Intelligence, pp. 410-419. Springer Berlin Heidelberg.

Afantenos, S.D.; Karkaletsis, V; Stamatopoulos, P; Halatsis, C. (2007). Using synchronic and diachronic relations for summarization multiple documents describing evolving events. Journal of Intelligent Information Systems. Vol. 30, N. 3, pp. 183-226.

Agostini, V.; Camargo, R.T.; Di Felippo, A.; Pardo, T.A.S. (2012). Alinhamento Manual dos Sumários Humanos e dos Textos-Fonte do Corpus Multidocumento CSTNews. Série de Relatórios Técnicos do Instituto de Ciências Matemáticas e de Computação, Universidade de São Paulo, no. 380. NILC-TR-01-12. São Carlos-SP, Junho, 20p.

Aleixo, P. e Pardo, T.A.S. (2008a). CSTTool: Uma Ferramenta Semi-automática para Anotação de Córpus pela Teoria Discursiva Multidocumento CST. Série de Relatórios Técnicos do Instituto de Ciências Matemáticas e de Computação, Universidade de São Paulo, no. 321. São Carlos-SP, 14p.

Aleixo, P. e Pardo, T.A.S. (2008b). CSTNews: Um Córpus de Textos Jornalísticos Anotados segundo a Teoria Discursiva Multidocumento CST. Série de Relatórios Técnicos do Instituto de Ciências Matemáticas e de Computação, Universidade de São Paulo, no. 326. São Carlos-SP, 15p.

Almahy, I.; Salim, N.; Kumar, Y.J.; Tawfik, A. (2014). Discussion summarization based on Crossdocument relation using model selection technique. In: Advances in Neural Networks, Fuzzy Systems and Artificial Intelligence, pp. 218-229.

Allen, J. (1995). Natural Language Understanding. Benjamin/Cummings, 2ed.

Ambwani, G. e Davis, A. R. (2010). Contextually-mediated semantic similarity graphs for topic segmentation. In: Proceedings of the 2010 Workshop on Graph-based Methods for Natural Language Processing, pp. 60-68. Association for Computational Linguistics.

Barzilay, R.; Elhadad, N.; Mckeown, K. (2001). Sentence ordering in multidocument summarization. In: Proceedings of the first international conference on Human language technology research (HLT 01), pp.1-7, San Diego, USA.

Baxendale, P. (1958). Machine-made index for technical literature - an experiment. IBM Journal of Research Development, Vol. 2, N. 4, pp. 354-361.

Biryukov, M.; Angheluta, R.; Moens, M-F. (2005). Multidocument question answering text summarization using topic signatures. Journal on Digital Information Management. Vol. 3, N. 1, pp. 27-33.

Bollegala, D.; Okazaki, N.; Ishizuka, M. (2006). A bottom-up approach to sentence ordering for multidocument summarization. In: Proceedings of the 21st International Conference on Computational Linguistics and 44th Annual Meeting of the Association for Computational Linguistics, pp. 385-392.

Boros, E.; Kantor, P.; Neu, D.J. (2001). A clustering based approach to creating multi-document summaries. In: Proceedings of the 24th Annual International ACM SIGIR Conference on Research and Development in Information Retrieval, New Orleans, LA. 
Burger, S.; MacLaren, V.; Yu, H. (2002). The ISL meeting corpus: The impact of meeting type on speech style. In: Proceedings of the International Conference Spoken Language Processing, pp. 1-4.

Canavilhas, J. (2007). Webjornalismo: Da pirâmide invertida à pirâmide deitada. In: BARBOSA, S. (Org.) Jornalismo Digital de Terceira Geração. Coleção Estudos em Comunicação. Covilhã: LabcomBooks, pp. 23-36.

Carbonel, T.I. (2007). Estudo e validação de teorias do domínio linguístico com vistas à melhoria do tratamento de cadeias de co-referência em Sumarização Automática. Dissertação de Mestrado. Universidade Federal de São Carlos, São Carlos-SP.

Cardoso, P.C.F.; Maziero, E.G.; Jorge, M.L.C.; Seno, E.M.R.; Di Felippo, A.; Rino, L.H.M.; Nunes, M.G.V.; Pardo, T.A.S. (2011a). CSTNews - A Discourse-Annotated Corpus for Single and MultiDocument Summarization of News Texts in Brazilian Portuguese. In: Proceedings of the 3rd RST Brazilian Meeting, pp. 88-105. Cuiabá/MT, Brasil.

Cardoso, P.C.F.; Rassi, A.P.; Maziero, E.G.; Nóbrega, F.A.A.; Souza, J.W.C.; Dias, M.S.; Castro Jorge, M.L.R.; Balage Filho, P.P.; Camargo, R.T.; Agostini, V.; Di Felippo, A.; Rino, L.H.M.; Pardo, T.A.S. (2012). Anotação de Subtópicos do Córpus Multidocumento CSTNews. Série de Relatórios Técnicos do Instituto de Ciências Matemáticas e de Computação, Universidade de São Paulo, no. 389. NILC-TR-12-07. São Carlos-SP, Junho, 18p.

Cardoso, P.C.F.; Pardo, T.A.S.; Nunes, M.G.V. (2011b). Métodos para Sumarização Automática Multidocumento Usando Modelos Semântico-Discursivos. In: Proceedings of the 3rd RST Brazilian Meeting, pp. 59-74. Cuiabá/MT, Brasil.

Cardoso, P.C.F.; Taboada, M.; Pardo, T.A.S. (2013a). Subtopic annotation in a corpus of news texts: Steps towards automatic segmentation. In: Proceedings of the 9th Brazilian Symposium in Information and Human Language Technology (STIL), pp. 49-58.

Cardoso, P.C.F.; Taboada, M.; Pardo, T.A.S. (2013b). On the contribution of discourse to topic segmentation. In: Proceedings of the 14th Annual SIGDial Meeting on Discourse and Dialogue, pp. 92-96. Metz, França.

Carenini, G. e Cheung, J.C.K. (2008). Extractive vs. NLG-based abstractive summarization of evaluative text: The effect of corpus controversiality. In: Proceedings of the Fifth International Natural Language Generation Conference, pp. 33-41. Association for Computational Linguistics.

Carletta, J. (1996). Assessing Agreement on Classification Tasks: The Kappa Statistic. Computational Linguistic. Vol. 22, N. 2, pp. 249-254.

Carlson, L. e Marcu, D. (2001). Discourse Tagging Reference Manual. Technical Report ISI-TR-545, University of Southern, California.

Carlson, L; Marcu, D.; Okurowski, M.E. (2003). Building a Discourse-Tagged Corpus in the Framework of Rhetorical Structure Theory. In J.V. Kuppevelt and R. Smith (eds.), Current Directions in Discourse and Dialogue, pp. 85-112. Kluwer Academic Publishers.

Chang, T. H. e Lee, C. H. (2003). Topic segmentation for short texts. In: Proceedings of the 17th Pacific Asia Conference Language, pp. 159-165.

Chenlo, J.M.; Hogenboom, A.; Losada, D.E. (2013). Sentiment-based ranking of blog posts using Rhetorical Structure Theory. In: $18^{\text {th }}$ International Conference on Applications of Natural Language to Information Systems, pp. 13-24. Salford, UK. 
Choi, F.Y.Y. (2000). Advances in domain independent linear text segmentation. In: Proceedings of the 1st Meeting of the North American Chapter of the Association for Computational Linguistics, pp. 26-36. Seattle, Washington

Collovini, S.; Carbonel, T.I.; Fuchs, J.T.; Coelho, J.C.; Rino, L.; Vieira, R. (2007). Summ-it: um córpus anotado com informações discursivas visando à sumarização automática. In: Anais do $V$ Workshop em Tecnologia da Informação e da Linguagem Humana - TIL'2007. Rio de Janeiro-RJ.

Cristea, D.; Ide, N.; Romary, L. (1998). Veins theory: A Model of Global Discourse Cohesion and Coherence. In: Proceedings of the Coling/ACL Conference, pp. 281-285. Montreal, Canadá.

da Cunha, I.; Torres-Moreno, J-M.; Sierra, G. (2011). On the Development of the RST Spanish Treebank. In: Proceedings of the 5th Linguistic Annotation Workshop, pp. 1-10. Portland-Oregon.

da Cunha, I. (2008). Hacia un modelo lingüístico de resumen automático de artículos médicos en español. Barcelona: Institut Universitari de Lingüística Aplicada, Universitat Pompeu Fabra. [CDROM] (Sèrie Tesis; 23)] ISBN 978-84-89782-37-2.

Dang, H. T. (2005). Overview of DUC 2005. In: Proceedings of the Document Understanding Conference.

Dias, M.S.; Feltrim, V.D.; Pardo, T.A.S. (2014). Using Rhetorical Structure Theory and Entity Grids to Automatically Evaluate Local Coherence in Texts. In: Proceedings of the 11st International Conference on Computational Processing of Portuguese - PROPOR (LNAI 8775). October 6-9. São Carlos-SP/Brazil.

Di Felippo, A.; Rino, L.H.M.; Pardo, T.A.S.; Cardoso, P.C.F.; Seno, E.R.M.; Balage Filho, P.P.; Rassi, A.P.; Dias, M.S.; Castro Jorge, M.L.R.; Maziero, E.G.; Zacarias, A.C.I.; Souza, J.W.C.; Camargo, R.T.; Agostini, V. (2014). Corpus Annotation of Textual Aspects in Multi-document Summaries. In S.M. Aluísio and S.E.O. Tagnin (eds.), New Language Technologies and Linguistic Research: A Two-Way Road, pp. 171-192. Cambridge Scholars Publishing.

Edmundson, H. P. (1969). New methods in automatic extracting. Journal of the ACM (JACM), Vol. 16 , N. 2, pp. 264-285.

Ercan, G.; Cicekli, I. (2008). Lexical cohesion based topic modeling for summarization. In: Computational Linguistics and Intelligent Text Processing, pp. 582-592. Springer Berlin Heidelberg.

Farzindar, A.; Rozon, F.; Lapalme, G. (2005). CATS a topic-oriented multi-document summarization system at DUC 2005. In: 2005 Document Understanding Workshop (DUC 2005).

Galley, M.; Mckeown, K.; Fosler-Lussier, E.; Jing, H. (2003). Discourse segmentation of multi-party conversation. In: Proceedings of the $41^{\text {st }}$ Annual Conference of the Association for Computational Linguistics, pp. 562-569. Sapporo, Japão.

Grosz, B. e Sidner, C. (1986). Attention, Intentions and the Structure of Discourse. Computational Linguistics, Vol. 12, N. 3, pp. 175-204.

Gruenstein, A.; Niekrasz, J.; Purver, M. (2007). Meeting structure annotation: Annotations collected with a general purpose toolkit. In: Recent Trends in Discourse and Dialogue. Series Text, Speech and Language Technology Springer Dordrecht, Vol. 39, pp. 247-274. 
Guzmán, F.; Joty, S.; Màrquez, L.; Nakov, P. (2014). Using discourse structure improves Machine Translation Evaluation. In: Proceedings of the 52nd Annual Meeting of the Association for Computational Linguistics, pp. 687-698, Balitmore, Maryland.

Harman, D. e Over, P. (2004). The effects of human variation in DUC summarization evaluation. In: Proceedings of the ACL-04 Workshop: Text Summarization Branches Out, pp. 10-17.

Hearst, M. (1997). TextTiling: Segmenting Text into Multi-Paragraph Subtopic Passages. Computational Linguistics, Vol. 23, N. 1, pp. 33-64.

Hennig, L. (2009). Topic-based multi-document summarization with probabilistic latent semantic analysis. In: Recent Advances in Natural Language Processing, pp. 144-149.

Hovy, E. (2009). Text Summarization. In: Ruslan Mitkov. The Oxford Handbook of Computational Linguistics, pp. 583-598. United States: Oxford University.

Hovy, E. e David, J. (2010) Towards a science of corpus annotation: a new methodological challenge for Corpus Linguistics. In: International Journal of Translation Studies, Vol. 22, N. 1, pp. 13-36.

Hovy, E. e Lin, C-Y. (1998). Automated Text Summarization and the SUMMARIST System. In: Proceedings of a Workshop on Held at Baltimore. Séries TIPSTER '98, pp. 197-214. Baltimore, Maryland.

IDC, International Data Corporation. (2012). Big Data: Como criar vantagens competitivas a partir da informação. Disponível em: < http://www.idc.pt/events/eventos_2012-11-27.jsp>. Acesso em 15 set. 2014.

Iruskieta, M.; Aranzabe, M. J.; Ilarraza, A. D.; G-D, I.; Lersundi, M.; Lacalle, O. L. (2013). The RST Basque Treebank: an online search interface to check rhetorical relations. In: Proceedings of $4^{\text {th }}$ Workshop RST and Discourse Studies, pp. 40-49. Fortaleza/CE, Brasil.

Iruskieta, M. e da Cunha, I. (2010). Marcadores y relaciones discursivas en el ámbito médico: un estudio en español y euskera. In: Analizar datos> Describir variación: XXVIII Congreso Internacional AESLA, pp. 146-159.

Iruskieta, M.; da Cunha, I.; Taboada, M. (2014). A qualitative comparison method for rhetorical structures: identifying different discourse structures in multilingual corpora. In: Language Resources and Evaluation, pp. 1-47.

Janin, A.; Baron, D.; Edwards, D.E.; Gelbart, D.; Morgan, N.; Peskin, B.; Pfau, T.; Shriberg, E.; Stolcke, A.; Wooters, C. (2003). The ICSI meeting corpus. In: Proceedings of the International Conference on Acoustics, Speech and Signal Processing, pp. 364-367.

Jordan, M.P. (1992). An Integrated Three-Pronged Analysis of a Fund-Raising Letter. Discourse Description: Diverse Linguistic Analyses of a Fund-Raising Text, pp. 171-226.

Jorge, M.L.C.; Pardo, T.A.S. (2010). Formalizing CST-based Content Selection Operations. In the Proceedings of the 9th International Conference on Computational Processing of Portuguese Language - PROPOR (Lecture Notes in Artificial Intelligence 6001), pp. 25-29. April 27-30, Porto Alegre/RS, Brasil.

Jorge, M.L.C.; Agostini, V.; Pardo, T.A.S. (2011). Multi-document Summarization Using Complex and Rich Features. In Anais do VIII Encontro Nacional de Inteligência Artificial, pp. 1-12. July 19-22, Natal/RN, Brasil. 
Jorge, M.L.C. e Pardo, T.A.S. (2011). A Generative Learning Approach for Multi-document Summarization Using Semantic-Discursive Information. In: Proceedings of the 8th Brazilian Symposium in Information and Human Language Technology, pp. 224-228. October 24-26, Cuiabá/MT, Brasil.

Jorge, M.L.C. e Pardo, T.A.S. (2012). Multi-Document Summarization: Content Selection based on CST Model (Cross-document Structure Theory). In the (on-line) Proceedings of the PROPOR 2012 PhD and MSc/MA Dissertation Contest, pp. 1-8. Abril 17-20, Coimbra, Portugal.

Jubran, C.C.A.S; Urbano, H; Fávero, L.L.; Koch, I.G.V. (1992). Organização tópica da conversação. In: ILARI, R. (org.). Gramática do português falado, Vol. II. Campinas/SP: UNICAMP, São Paulo: FAPESP, pp. 322-384.

Kazantseva, A. e Szpakowicz, S. (2012). Topical Segmentation: a study of human performance and a new measure of quality. In: Proceedings of the 2012 Conference of the North American Chapter of the Association for Computational Linguistics: Human Language Technologies, pp. 211-220. Montreal, Canadá.

Klampanos, I. A.; Jose, J. M.; van Rijsbergen, C. J. (2006). Single-pass clustering for peer-to-peer information retrieval: the effect of document ordering. In: Proceedings of the 1st international conference on Scalable information systems, pp. 36. ACM.

Koch, I.G.V. (2009). Introdução à linguística textual. São Paulo: Contexto.

Koch, I.G.V. e Travaglia, L.C. (1996). A Coerência Textual. Editora Contexto.

Larocca Neto, J. (2000) Contribuição ao estudo de técnicas para sumarização automática de textos. Dissertação de Mestrado. Pontifícia Universidade Católica do Paraná. 109p.

Larocca Neto, J.; Santos, A. D.; Kaestner, C. A.; Freitas, A. A. (2000). Generating text summaries through the relative importance of topics. In: Advances in Artificial Intelligence, pp. 300-309. Springer Berlin Heidelberg.

Leech, G. (2005) Adding linguistic annotation. In: Martin Wynne. Developing Linguistic Corpora: a guide to good practice, pp. 25-38. Oxford: Oxbow Books.

Leite, D.S.; Rino, L.H.M.; Pardo, T.A.S.; Nunes, M.G.V. (2007). Extractive automatic summarization: Does more linguistic knowledge make a difference? In: Proceedings of the HLT/NAACL Workshop on TextGraphs-2: Graph-Based Algorithms for Natural Language Processing, pp. 17-24.

Lima, J.B.P. e Pardo, T.A.S. (2012). Ordenação de Sentenças em Sumários Multidocumento. Série de Relatórios Técnicos do Instituto de Ciências Matemáticas e de Computação, Universidade de São Paulo, no. 382. NILC-TR-12-02. São Carlos-SP, Junho, 37p.

Lin, C-Y. (2004). ROUGE: a Package for Automatic Evaluation of Summaries. In: Proceedings of the Workshop on Text Summarization Branches Out (WAS 2004), pp. 74-81. Barcelona, Spain.

Lin, C-Y.e Hovy, E. (2000). The automated acquisition of topic signatures for text summarization. In: Proceedings of the 18th conference on Computational linguistics, Vol. 1, pp. 495-501. Association for Computational Linguistics. 
Louis, A.; Joshi, A.; Nenkova, A. (2010). Discourse indicators for content selection in summarization. In: Proceedings of the 11th Annual Meeting of the Special Interest Group on Discourse and Dialogue, pp. 147-156. Association for Computational Linguistics.

Louis, A. e Nenkova, A. (2009). Automatically evaluating content selection in summarization without human models. In: Proceedings of the 2009 Conference on Empirical Methods in Natural Language Processing. Vol. 1, pp. 306-314. Association for Computational Linguistics.

Louis, A. e Nenkova, A. (2013). Automatically assessing machine summary content without a gold standard. Computational Linguistics, Vol. 39, N. 2, pp. 267-300.

Luhn, H. P. (1958). The automatic creation of literature abstracts. IBM Journal of research and development, Vol. 2, N. 2, pp. 159-165.

Mani, I. (2001). Automatic Summarization. John Benjamins Publishing Co., Amsterdam.

Mani, I. e Maybury, M.T. (Eds.) (1999). Advances in automatic text summarization.Vol. 293. Cambridge: MIT press.

Mann, W.C. e Thompson, S.A. (1987). Rhetorical Structure Theory: A Theory of Text Organization. Technical Report ISI/RS-87-190.

Marcu, D. (1997). The Rhetorical Parsing, Summarization, and Generation of Natural Language Texts. PhD Thesis, Department of Computer Science, University of Toronto.

Marcu, D. (1998a). To build text summaries of high quality, nuclearity is not sufficient. The Working Notes of the AAAI-98 Spring Symposium on Intelligent Text Summarization, pp. 1-8, Stanford, CA.

Marcu, D. (1998b). Improving summarization through rhetorical parsing tuning. In: the 6th Workshop on Very Large Corpora, pp. 206-215.

Marcu, D. (1999). The automatic construction of large-scale corpora for summarization research. In the Proceedings of the 22nd annual international ACM SIGIR conference on Research and development in information retrieval, pp. 137-144, Berkeley, California, USA.

Marcu, D. (2000a). The Theory and Practice of Discourse Parsing and Summarization. The MIT Press. Cambridge, Massachusetts.

Marcu, D. (2000b). The Rhetorical Parsing of Unrestricted Texts: A Surface-based Approach. Computational Linguistics, Vol. 26, pp. 396-448.

Marcu, D.; Carlson, L.; Watanabe, M. (2000). The automatic translation of discourse structures. In: Proceedings of the 1st Meeting of the North American Chapter of the Association for Computational Linguistics (NAACL'OO), Vol. 1, pp. 9-17. Seattle, Washington.

Maziero, E.G.; Jorge, M.L.C.; Pardo, T.A.S. (2010). Identifying Multidocument Relations. In: Proceedings of the 7th International Workshop on Natural Language Processing and Cognitive Science - NLPCS, pp. 60-69. Funchal/Madeira, Portugal.

Maziero, E.G.; Jorge, M.L.C.; Pardo, T.A.S. (2014). Revisiting Cross-document Structure Theory for multi-document discourse parsing. Information Processing \& Management, Vol. 50, N. 2, pp. 297314. 
Maziero, E.G. e Pardo, T.A.S. (2009). Automatização de um Método de Avaliação de Estruturas Retóricas. In: Proceedings of the RST Brazilian Meeting, pp. 1-9. September 10, São Carlos-SP, Brasil.

Maziero, E.G. e Pardo, T.A.S. (2012). Automatic Identification of Multi-document Relations. In: Proceedings of the PROPOR 2012 PhD and MSc/MA Dissertation Contest, pp. 1-8. Coimbra, Portugal.

Maziero, E.G.; Pardo, T.A.S.; da Cunha, I.; Torres-Moreno, J.M.; SanJuan, E. (2011). DiZer 2.0 - An Adaptable On-line Discourse Parser. In: Proceedings of the 3rd RST Brazilian Meeting, pp. 1-17. October 26, Cuiabá/MT, Brasil.

Mckeown, K.; Barzilay, R.; Chen, J.; Elson, D.; Evans, D.; Klavans, J.; Nenkova, A.; Barry, S.; Sigelman, S. (2003). Columbia's Newsblaster: new features and future directions. In: Proceedings of the 2003 Conference of the North American Chapter of the Association for Computational Linguistics on Human Language Technology: Demonstrations, Vol. 4, pp. 15-16.

Nenkova, A.e Passonneau, R. J. (2004). Evaluating Content Selection in Summarization: The Pyramid Method. In: HLT-NAACL, Vol. 4, pp. 145-152.

Nóbrega, F.A.A. (2013). Desambiguação lexical de sentidos para o português por meio de uma abordagem multilíngue mono e multidocumento. Dissertação de Mestrado. Instituto de Ciências Matemáticas e de Computação, Universidade de São Paulo. São Carlos-SP, May, 123p

O'Donnell, M. (1997). Variable-Length On-Line Document Generation. In: Proceedings of the 6th European Workshop on Natural Language Generation, Gerhard-Mercator University, Duiburg, Germany.

O'Donnell, M. (2000). RSTTool 2.4 - A Markup Tool for Rhetorical Structure Theory. In: Proceedings of the International Natural Language Generation Conference, pp. 253-256. Mitzpe Ramon, Israel.

Oh, H-J; Myaeng, S.H.; Jang, M-G. (2007). Semantic passage on sentence topics for question answering. Information Sciences, Vol. 177, N. 18, pp. 3696-3717.

Ono, K.; Sumita, K.; Miike, S. (1994). Abstract Generation Based on Rhetorical Structure Extraction. In: Proceedings of the International Conference on Computational Linguistic - Coling-94, pp. 344348, Japão.

Otterbacher, J.C.; Radev, D.R.; Luo, A. (2002). Revisions that improve cohesion in multidocument summaries: a preliminary study. In: Proceedings of the Workshop on Automatic Summarization, pp. 27-36. Philadelphia.

Pardo, T.A.S. (2005a). GistSumm - GIST SUMMarizer: Extensões e Novas Funcionalidades. Série de Relatórios do NILC. NILC-TR-05-05. São Carlos-SP, Fevereiro, 8p.

Pardo, T.A.S. (2005b). Métodos para análise discursiva automática. Tese de doutorado. Instituto de Ciências Matemáticas e de Computação, Universidade de São Paulo. São Carlos-SP, Junho, 211p.

Pardo, T.A.S. e Nunes, M.G.V. (2004). Relações Retóricas e seus Marcadores Superficiais: Análise de um Corpus de Textos Científicos em Português do Brasil. Série de Relatórios Técnicos do Instituto de Ciências Matemáticas e de Computação, Universidade de São Paulo, N. 231. São Carlos-SP, Abril, $73 p$. 
Pardo, T.A.S. e Nunes, M.G.V. (2008). On the Development and Evaluation of a Brazilian Portuguese Discourse Parser. Journal of Theoretical and Applied Computing, Vol. 15, N. 2, pp. 43-64.

Pardo, T.A.S e Rino, L.H.M. (2002). DMSumm: Um Gerador Automático de Sumários. In: Anais do I Workshop de Teses e Dissertações em Inteligência Artificial - WTDIA, pp. 1-10. Recife/PE, Brasil.

Pardo, T.A.S. e Seno, E.R.M. (2005). Rhetalho: um corpus de referência anotado retoricamente. In: Anais do V Encontro de Corpora. São Carlos-SP.

Passonneau, R.J. e Litman, D.J. (1997). Discourse segmentation by human and automated means. Computational Linguistics, Vol. 23, N. 1, pp. 103-109.

Pevzner, L. e Hearst, M. (2002). A Critique and Improvement of an Evaluation Metric for Text Segmentation. Computational Linguistics, Vol. 28, N. 1, pp. 19-36.

Pinheiro, C.L. (2002) Aspectos da organização tópica na fala e na escrita. Comunicação apresentada na XIX Jornada Nacional de Estudos Lingüísticos do GELNE, UFC, Fortaleza.

Prasad, R.; Dinesh, N.; Lee, A.; Miltsakaki, E.; Robaldo, L.; Joshi, A.; Webber, B. (2008). The Penn Discourse Treebank 2.0. In: Proceedings of the 6th International Conference on Language Resources and Evaluation. Marrakech/Morocco.

Prince, V. e Labadié, A. (2007). Text segmentation based on document understanding for information retrieval. In: Proceedings of the $12^{\text {th }}$ International Conference on Applications of Natural Language to Information Systems, pp. 295-304.

Radev, D.R. (2000). A common theory of information fusion from multiple text sources, step one: Cross-document structure. In: Proceedings of the 1st ACL SIGDIAL Workshop on Discourse and Dialogue, pp. 74-83. Hong Kong-China.

Radev, D.R.; Blair-Goldensohn, S.; Zhang, Z. (2001). Experiments in single and multidocument summarization using MEAD. In: Proceedings of 1st Document Understanding Conference. New Orleans, LA.

Radev, D. R.; Jing, H.; Budzikowska, M. (2000). Centroid-based summarization of multiple documents: sentence extraction, utility-based evaluation, and user studies. In: Proceedings of the 2000 NAACL-ANLP Workshop on Automatic Summarization, pp. 21-30. Association for Computational Linguistics.

Radev, D.R.; Jing, H.; Stys, M.; Tam, D. (2004a). Centroid-based summarization of multiple documents. In: Information Processing and Management, Vol. 40, N. 6, pp. 919-938.

Radev, D.R. e McKeown, K. (1998). Generating natural language summaries from multiple on-line sources. Computational Linguistics, Vol. 24, N. 3, pp. 469-500.

Radev, D.R.; Otterbacher, J.; Zhang, Z. (2004b). CST Bank: A Corpus for the Study of Crossdocument Structural Relationships. In: Proceedings of 4th International Conference on Language Resources and Evaluation.

Radev, D.R. e Tam, D. (2003). Summarization evaluation using Relative Utility. In: Proceedings of the twelfth international conference on Information and knowledge management, pp. 508-511. New Orleans, LA, USA. 
Ribaldo, R. (2013). Investigação de Mapas de Relacionamento para Sumarização Multidocumento. Monografia de Conclusão de Curso. Instituto de Ciências Matemáticas e de Computação, Universidade de São Paulo. São Carlos-SP, November, 61p.

Ribaldo, R.; Cardoso, P.C.F.; Pardo, T.A.S. (2013). Investigação de Métodos de Segmentação e Agrupamento de Subtópicos para Sumarização Multidocumento. In: Anais do $3 o$ Workshop de Iniciação Científica em Tecnologia da Informação e da Linguagem Humana - TILic, pp. 25-27. October 21-23, Fortaleza/Brasil.

Riedl, M. e Biemann, C. (2012). How text segmentation algorithms gain from topic models. In: Proceedings of the 2012 Conference of the North American Chapter of the Association for Computational Linguistics: Human Language Technologies, pp. 553-557. Montreal, Canadá.

Rino, L.H. M. (1996). Modelagem de Discurso para o Tratamento da Concisão e Preservação da Idéia Central na Geração de Textos. Tese de Doutorado. IFSC/USP, São Carlos-SP.

Rino, L.H.M.; Di Felippo, A.; Pardo, T.A.S. (2013). Insights for better RST segmentation of texts in Portuguese? In: Proceedings of the 4th Workshop "RST and Discourse Studies", pp. 30-39. October 23, Fortaleza/Brazil.

Saggion, H. e Thierry, P. (2013). Automatic text summarization: Past, present and future. Multisource, Multilingual Information Extraction and Summarization. Springer Berlin Heidelberg, pp. 3-21.

Salton, G. (1988).Automatic text processing. Addison-Wesley Longman Publishing Co., Inc., Boston, MA, USA.

Salton, G. (1989). Automatic Text Processing: The Transformation, Analysis, and Retrieval of. Addison-Wesley.

Salton, G.; Singhal, A.; Buckley, C.; Mitra, M. (1996). Automatic text decomposition using texts segments and text themes. In: Proceedings of the Seventh ACM Conference on Hypertext, pp. 53-65. Bethesda, Maryland, USA.

Salton, G.; Singhal A.; Mitra, M; Buckley, C. (1997). Automatic text Structuring and summarization. Information Processing \& Management, Vol. 33, N. 2, pp. 193-207.

Scaiano, M. e Inkpen, D. (2012). Getting more from segmentation evaluation. In: Proceedings of NAACL-Human Language Technologies, pp. 362-366, Montreal, Canadá.

Seno, E.R.N. (2005). RHeSumaRST: Um Sumarizador Automático de Estruturas RST. Dissertação de Mestrado. Universidade Federal de São Carlos. 92p.

Seno, E.R.M. e Nunes, M.G.V. (2009). Reconhecimento de Informações Comuns para a Fusão de Sentenças Comparáveis do Português. Linguamática, Vol. 1, pp. 71-87.

Seno, E.R.M. e Rino, L.H.M. (2005). Co-referential chaining for coherent summaries through retorical and linguistic modeling. In: Proceedings of the Workshop on Crossing Barriers in Text Summarization Research/RANLP, pp. 70-75, Borovets-Bulgaria.

Sobrevilla Cabezudo, M.A.; Maziero, E.G.; Souza, J.W.C.; Dias, M.S.; Cardoso, P.C.F.; Balage Filho, P.P.; Agostini, V.; Nóbrega, F.A.A.; Barros, C.D.; Di Felippo, A.; Pardo, T.A.S. (2014). Anotação de Sentidos de Verbos em Notícias Jornalísticas em Português do Brasil. In the Proceedings of the XII Encontro de Linguística de Corpus - ELC. November 6-7. Uberlândia-MB/Brazil. 
Sparck Jones, K. (1993). What might be in a summary?. Information Retrieval. Vol. 93, pp. 9-26.

Sparck Jones, K. (1998). Automatic summarizing: factors and directions. In: Mani, I. and Maybury, M. T. (Eds.), Advances in automatic text summarization, chapter 1, pp. 1-12. The MIT Press, 1999.

Stede, M. (2004). The Potsdam Commentary Corpus. In: 2004 ACL Workshop on Discourse Annotation, pp. 96-102, Barcelona, Espanha.

Stein, G.C.; Bagga, A.; Wise, G.B. (2000). Multi-document summarization: methodologies and evaluations. In: Proceedings of the 7th Conference on Automatic Natural Language Processing (TALN), pp. 337-346.

Taboada, M. e D. Das (2013) Annotation upon annotation: Adding signalling information to a corpus of discourse relations. Dialogue and Discourse, Vol. 4, N. 2, pp. 249-281.

Taboada, M. e Renkema, J. (2008). Discourse Relations Reference Corpus. Simon Fraser University and Tilburg University.

Taufer, P. (2013). Massa de informações digitais pode ser usada em benefício da população. Jornal da Globo, 26 dez. 2013. Disponível em: <http://g1.globo.com/jornal-da-globo/noticia/2013/12/massa-deinformacoes-digitais-pode-ser-usada-em-beneficio-da-populacao.html>. Acesso em 24 dez. 2013.

Tosta, F.E.S.; Di-Felippo, A.; Pardo, T.A.S. (2013). Estudo de métodos clássicos de sumarização no cenário multidocumento multilíngue. In: Student Workshop on Information and Human Language Technology (TILic), Fortaleza/CE.

Trigg, R. (1983). A Network-Based Approach to Text Handling for the Online Scientific Community. PhD Thesis. University of Maryland, College Park MD.

Ulrich, J.; Murray, G.; Carenini, G. (2008). A publicly available annotated corpus for supervised email summarization. In: Proceedings of AAAi email-2008 workshop, Chicago, USA.

Uzêda, V.R.; Pardo, T.A.S.; Nunes, M.G.V. (2010). A Comprehensive Comparative Evaluation of RST-Based Summarization Methods. ACM Transactions on Speech and Language Processing, Vol. 6, N. 4, pp. 1-20.

van der Vliet, N., Berzlánovich, I., Bouma, G., Egg, M., and Redeker, G. (2011). Building a discourseannotated dutch text corpus. Bochumer Linguistische Arbeitsberichte, Vol. 3, pp. 157-171.

Van Rijsbergen, C.J. (1979). Information Retrieval. 2nd edition, Butterworths, Massachusetts.

Wan, X. (2008). An exploration of document impact on graph-based multi-document summarization. In: Proceedings of the Conference on Empirical Methods in Natural Language Processing, pp. 755762.

Wan, X. e Yang, J. (2008). Multi-document summarization using cluster-based link analysis. In: Proceedings of the 31st annual international ACM SIGIR conference on Research and development in information retrieval, pp. 299-306, ACM.

Wolf, F. e Gibson, E. (2006). Coherence in natural language: data structures and applications. MIT Press. 
Zhang, Z.; Goldenshon, S.B.; Radev, D.R. (2002). Towards CST-Enhanced Sumarization. In: Proceedings of the $18^{\text {th }}$ National Conference on Artificial Intelligence, pp. 439-446. Edmonton/Canada.

Zhan, J.; Loh, H.T.; Liu, H. (2009). On macro and micro-level information in multiple documents and its influence on summarization. In: International Journal of Information Management, Vol. 29, No. 1, pp. 57-66, February 2009.

Zhang, Z.; Otterbacher, J.; Radev, D. (2003). Learning cross-document structural relationships using boosting. In: Proceedings of the Twelfth International Conference on Information and Knowledge Management CIKM 2003, pp. 124-130. New Orleans, Louisiana, USA.

Zhang, Z.e Radev, D. (2005). Combining labeled and unlabeled data for learning cross-document structural relationships. In: Natural Language Processing-IJCNLP 2004, pp. 32-41. Springer Berlin Heidelberg. 


\section{APÊNDICE A - DEFINIÇÃO DAS RELAÇÕES RST}

Nessa Seção, apresentam-se as definições das relações RST utilizadas na anotação do córpus CSTNews.

\section{Nome da relação: ANTITHESIS}

Restrições sobre N: o escritor julga $\mathrm{N}$ válido

Restrições sobre $\mathbf{S}$ : não há

Restrições sobre $\mathbf{N}+\mathbf{S}$ : $\mathbf{N}$ e $\mathbf{S}$ estão em contraste; por causa da aparente incompatibilidade, não se pode julgar $\mathrm{N}$ e $\mathrm{S}$ válidos ao mesmo tempo; a compreensão de $\mathrm{S}$ e da incompatibilidade entre $\mathrm{N}$ e $\mathrm{S}$ faz o leitor aceitar melhor $\mathrm{N}$

Efeito: o leitor aceita melhor $\mathrm{N}$

\section{Nome da relação: ATTRIBUTION}

Restrições sobre N: N apresenta uma expressão, fala ou pensamento de alguém ou algo

Restrições sobre $\mathbf{S}$ : $\mathrm{S}$ apresenta alguém ou algo que produz $\mathrm{N}$

Restrições sobre $\mathbf{N}+\mathbf{S}$ : $\mathrm{S}$ e $\mathrm{N}$ indicam, respectivamente, a fonte de uma mensagem e a mensagem

Efeito: o leitor é informado sobre a mensagem e sobre quem ou o que a produziu

\section{Nome da relação: BACKGROUND}

Restrições sobre N: o leitor não compreenderá suficientemente $\mathrm{N}$ antes de ler $\mathrm{S}$

Restrições sobre S: não há

Restrições sobre N+S: S aumenta a habilidade do leitor em compreender algum elemento em $\mathbf{N}$

Efeito: a habilidade do leitor para compreender $\mathrm{N}$ aumenta

\section{Nome da relação: CIRCUMSTANCE}

Restrições sobre N: não há

Restrições sobre S: apresenta uma situação (realizável)

Restrições sobre $\mathbf{N}+\mathbf{S}$ : S provê uma situação na qual o leitor pode interpretar $\mathrm{N}$

Efeito: o leitor reconhece que S provê uma situação na qual $\mathrm{N}$ deve ser interpretado

\section{Nome da relação: COMPARISON}

Restrições sobre N: apresenta uma característica de algo ou alguém

Restrições sobre $\mathbf{S}$ : apresenta uma característica de algo ou alguém comparável com o que é apresentado em $\mathrm{N}$

Restrições sobre $\mathbf{N}+\mathbf{S}$ : as características de $\mathbf{S}$ e $\mathbf{N}$ estão em comparação

Efeito: o leitor reconhece que $\mathrm{S}$ é comparado a $\mathrm{N}$ em relação a certas características 
Nome da relação: CONCESSION

Restrições sobre N: o escritor julga N válido

Restrições sobre S: o escritor não afirma que $S$ pode não ser válido

Restrições sobre $\mathbf{N}+\mathbf{S}$ : o escritor mostra uma incompatibilidade aparente ou em potencial entre $\mathrm{N}$ e $\mathrm{S}$; o reconhecimento da compatibilidade entre $\mathrm{N}$ e $\mathrm{S}$ melhora a aceitação de $\mathrm{N}$ pelo leitor

Efeito: o leitor aceita melhor N

\section{Nome da relação: CONCLUSION}

Restrições sobre N: não há

Restrições sobre S: S baseia-se no que é apresentado em N

Restrições sobre N+S: S apresenta um fato concluído a partir da interpretação de N

Efeito: o leitor reconhece que $\mathrm{S}$ é uma conclusão produzida devido à interpretação de $\mathrm{N}$

\section{Nome da relação: CONDITION}

Restrições sobre N: não há

Restrições sobre S: S apresenta uma situação hipotética, futura ou não realizada

Restrições sobre $\mathbf{N}+\mathbf{S}$ : a realização de $\mathbf{N}$ depende da realização de $\mathrm{S}$

Efeito: o leitor reconhece como a realização de $\mathrm{N}$ depende da realização de $\mathrm{S}$

Nome da relação: ELABORATION

Restrições sobre N: não há

Restrições sobre $S$ : não há

Restrições sobre $\mathbf{N}+\mathbf{S}$ : $\mathbf{S}$ apresenta detalhes adicionais sobre a situação ou algum elemento de $\mathrm{N}$

Efeito: o leitor reconhece S como apresentando detalhes adicionais sobre $\mathrm{N}$

\section{Nome da relação: ENABLEMENT}

Restrições sobre N: apresenta uma ação do leitor não realizada

Restrições sobre S: não há

Restrições sobre $\mathbf{N}+\mathbf{S}$ : a compreensão de $\mathbf{S}$ pelo leitor aumenta sua habilidade para realizar a ação em N

Efeito: a habilidade do leitor para realizar a ação em $\mathrm{N}$ aumenta

\section{Nome da relação: EVALUATION}

Restrições sobre N: não há

Restrições sobre S: não há

Restrições sobre $\mathbf{N}+\mathbf{S}$ : $\mathrm{S}$ se relaciona a $\mathrm{N}$ pelo grau de avaliação positiva do escritor por $\mathrm{N}$

Efeito: o leitor reconhece que $\mathrm{S}$ avalia $\mathrm{N}$ e reconhece o valor que ele atribui 
Nome da relação: EVIDENCE

Restrições sobre N: o leitor poderia não acreditar em $\mathrm{N}$ de forma satisfatória para o escritor

Restrições sobre S: o leitor acredita em $\mathrm{S}$ ou o achará válido

Restrições sobre $\mathbf{N}+\mathbf{S}$ : a compreensão de $\mathrm{S}$ pelo leitor aumenta sua convicção em N

Efeito: a convicção do leitor em $\mathrm{N}$ aumenta

\section{Nome da relação: EXPLANATION}

Restrições sobre N: apresenta um evento ou situação

Restrições sobre S: não há

Restrições sobre $\mathbf{N}+\mathbf{S}$ : S explica como e/ou porque o evento ou situação apresentado em $\mathbf{N}$ ocorre ou veio a ocorrer

Efeito: o leitor reconhece que $\mathrm{S}$ é a razão para $\mathrm{N}$ ou que $\mathrm{S}$ explica como $\mathrm{N}$ ocorre

\section{Nome da relação: INTERPRETATION}

Restrições sobre N: não há

Restrições sobre S: não há

Restrições sobre $\mathbf{N}+\mathbf{S}$ : $\mathbf{S}$ apresenta um conjunto de ideias que não é expresso em $\mathrm{N}$ propriamente, mas derivado deste

Efeito: o leitor reconhece que $\mathrm{S}$ apresenta um conjunto de ideias que não é propriamente expresso no conhecimento fornecido por $\mathrm{N}$

\section{Nome da relação: JUSTIFY}

Restrições sobre N: não há

Restrições sobre S: não há

Restrições sobre $\mathbf{N}+\mathbf{S}$ : a compreensão de $\mathbf{S}$ pelo leitor aumenta sua prontidão para aceitar o direito do escritor de apresentar $\mathrm{N}$

Efeito: a prontidão do leitor para aceitar o direito do escritor de apresentar $\mathrm{N}$ aumenta

\section{Nome da relação: MEANS}

Restrições sobre N: uma atividade

Restrições sobre S: não há

Restrições sobre $\mathbf{N}+\mathbf{S}$ : $\mathbf{S}$ apresenta um método ou instrumento que faz com que a realização de $\mathbf{N}$ seja mais provável

Efeito: o leitor reconhece que o método ou instrumento em $\mathrm{S}$ faz com que a realização de $\mathrm{N}$ seja mais provável

Nome da relação: MOTIVATION

Restrições sobre N: uma ação volitiva não realizada

Restrições sobre S: não há

Restrições sobre $\mathbf{N}+\mathbf{S}$ : a compreensão de $\mathrm{S}$ motiva a realização de $\mathbf{N}$

Efeito: o leitor reconhece que $\mathrm{S}$ motiva a realização de $\mathrm{N}$ 
Nome da relação: NON-VOLITIONAL CAUSE

Restrições sobre N: apresenta uma ação não volitiva

Restrições sobre S: não há

Restrições sobre N+S: S apresenta uma situação que pode ter causado N; sem S, o leitor poderia não reconhecer o que causou a ação em N; $\mathrm{N}$ é mais central para a satisfação do objetivo do escritor do que $\mathrm{S}$

Efeito: o leitor reconhece a situação apresentada em S como a causa da ação apresentada em N

\section{Nome da relação: NON-VOLITIONAL RESULT}

Restrições sobre N: não há

Restrições sobre S: apresenta uma ação não volitiva

Restrições sobre $\mathbf{N}+\mathbf{S}$ : $\mathrm{N}$ apresenta uma situação que pode ter causado $\mathrm{S}$; sem N, o leitor poderia não reconhecer o que causou a ação em $\mathrm{S} ; \mathrm{N}$ é mais central para a satisfação do objetivo do escritor do que $S$

Efeito: o leitor reconhece a situação apresentada em N como a causa da ação apresentada em S

\section{Nome da relação: OTHERWISE}

Restrições sobre N: apresenta uma situação não realizada

Restrições sobre $\mathbf{S}$ : apresenta uma situação não realizada

Restrições sobre $\mathbf{N}+\mathbf{S}$ : a realização de $\mathbf{N}$ impede a realização de $\mathrm{S}$

Efeito: o leitor reconhece que a realização de $\mathrm{N}$ impede a realização de $\mathrm{S}$

\section{Nome da relação: PARENTHETICAL}

Restrições sobre N: não há

Restrições sobre S: apresenta informação extra relacionada a $\mathrm{N}$ que não está expressa no fluxo principal do texto

Restrições sobre $\mathbf{N}+\mathbf{S}$ : $\mathrm{S}$ apresenta informação extra relacionada a $\mathrm{N}$, complementado $\mathrm{N}$; $\mathrm{S}$ não pertence ao fluxo principal do texto

Efeito: o leitor reconhece que S apresenta informação extra relacionada a N, complementando N

\section{Nome da relação: PURPOSE}

Restrições sobre N: apresenta uma ação

Restrições sobre $\mathbf{S}$ : apresenta uma situação não realizada

Restrições sobre $\mathbf{N}+\mathbf{S}$ : $\mathbf{S}$ apresenta uma situação que pode realizar N

Efeito: o leitor reconhece que a atividade em $\mathrm{N}$ pode ser iniciada por meio de $\mathrm{S}$

\section{Nome da relação: RESTATEMENT}

Restrições sobre N: não há

Restrições sobre S: não há

Restrições sobre $\mathbf{N}+\mathbf{S}$ : $\mathrm{S}$ se relaciona a $\mathrm{N}$; ambos apresentam conteúdo comparável; $\mathrm{N}$ é mais importante para a satisfação do objetivo do escritor

Efeito: o leitor reconhece que $\mathrm{S}$ expressa o mesmo conteúdo de $\mathrm{N}$, mas de forma diferente 
Nome da relação: SOLUTIONHOOD

Restrições sobre N: não há

Restrições sobre S: apresenta um problema

Restrições sobre $\mathbf{N}+\mathbf{S}$ : N é uma solução para o problema em $\mathbf{S}$

Efeito: o leitor reconhece $\mathrm{N}$ como uma solução para o problema em $\mathrm{S}$

Nome da relação: SUMMARY

Restrições sobre N: não há

Restrições sobre S: não há

Restrições sobre $\mathbf{N}+\mathbf{S}$ : $\mathbf{S}$ apresenta o conteúdo de N resumido

Efeito: o leitor reconhece $\mathrm{S}$ como um resumo do conteúdo de $\mathrm{N}$

\section{Nome da relação: VOLITIONAL CAUSE}

Restrições sobre N: apresenta uma ação volitiva ou uma situação que poderia surgir de uma ação volitiva

Restrições sobre S: não há

Restrições sobre $\mathbf{N}+\mathbf{S}$ : $\mathbf{S}$ apresenta uma situação que pode ter acarretado o fato do agente da ação volitiva em $\mathrm{N}$ ter realizado a ação; sem $\mathrm{S}$, o leitor poderia não reconhecer a motivação da ação; N é mais central para a satisfação do objetivo do escritor do que $S$

Efeito: o leitor reconhece a situação apresentada em S como a causa da ação apresentada em N

\section{Nome da relação: VOLITIONAL RESULT}

Restrições sobre N: não há

Restrições sobre $\mathbf{S}$ : apresenta uma ação volitiva ou uma situação que poderia surgir de uma ação volitiva

Restrições sobre $\mathbf{N}+\mathbf{S}$ : $\mathbf{N}$ apresenta uma situação que pode ter acarretado o fato do agente da ação volitiva em $\mathrm{S}$ ter realizado a ação; sem $\mathrm{N}$, o leitor poderia não reconhecer a motivação da ação; $\mathrm{N}$ é mais central para a satisfação do objetivo do escritor do que $\mathrm{S}$

Efeito: o leitor reconhece a situação apresentada em $\mathrm{N}$ como a causa da ação apresentada em $\mathrm{S}$

\section{Nome da relação: CONTRAST}

Restrições sobre os Ns: não mais do que dois Ns; as situações nos Ns são (a) compreendidas como similares em vários aspectos, (b) compreendidas como diferentes em vários aspectos e (c) comparadas em relação a uma ou mais dessas diferenças

Efeito: o leitor reconhece as similaridades e diferenças resultantes da comparação sendo feita

\section{Nome da relação: JOINT}

Restrições sobre os Ns: não há

Efeito: não há

\section{Nome da relação: LIST}

Restrições sobre os Ns: itens comparáveis apresentados nos Ns

Efeito: o leitor reconhece como comparáveis os itens apresentados 
Nome da relação: SAME-UNIT

Restrições sobre os Ns: os Ns apresentam informações que, juntas, constituem uma única proposição Efeito: o leitor reconhece que as informações apresentadas constituem uma única proposição; separadas, não fazem sentido

Nome da relação: SEQUENCE

Restrições sobre os Ns: as situações apresentadas nos Ns são realizadas em sequência

Efeito: o leitor reconhece a sucessão temporal dos eventos apresentados 


\section{APÊNDICE B - DEFINIÇÃO DAS RELAÇÕES CST}

Nessa Seção, descrevem-se as relações CST utilizadas na anotação do córpus CSTNews. Para cada relação, é descrita sua posição na tipologia, direcionalidade, as restrições de aplicação e alguns comentários.

Nome da relação: Identity

Tipo da Relação: Conteúdo->Redundância->Total

Direcionalidade: Nula

Restrições: As sentenças devem ser idênticas

Comentários:

\section{Nome da relação: Equivalence}

Tipo da Relação: Conteúdo->Redundância->Total

Direcionalidade: Nula

Restrições: As sentenças apresentam o mesmo conteúdo, mas expresso de forma diferente

Comentários:

Nome da relação: Summary

Tipo da Relação: Conteúdo->Redundância->Total

Direcionalidade: $\mathrm{S} 1<-\mathrm{S} 2$

Restrições: S2 apresenta o mesmo conteúdo que S1, mas de forma mais compacta.

Comentários: Summary é um tipo de equivalence, mas summary deve haver diferença significativa de tamanho entre as sentenças.

Nome da relação: Subsumption

Tipo da Relação: Conteúdo->Redundância->Parcial

Direcionalidade: S1->S2

Restrições: S1 apresenta as informações contidas em S2 e informações adicionais.

Comentários: S1 contém X e Y, S2 contém X.

\section{Nome da relação: Overlap}

Tipo da Relação: Conteúdo->Redundância->Parcial

Direcionalidade: Nula

Restrições: S1 e S2 apresentam informações em comum e ambas apresentam informações adicionais distintas entre si.

Comentários: S1 contém X e Y, S2 contém X e Z. 
Nome da relação: Historical background

Tipo da Relação: Conteúdo->Complemento->Temporal

Direcionalidade: $\mathrm{S} 1<-\mathrm{S} 2$

Restrições: S2 apresenta informações históricas/passadas sobre algum elemento presente em S1

Comentários: O elemento explorado em S2 deve ser o foco de S2; se forem apresentadas informações repetidas, considere outra relação (por exemplo, overlap); se os eventos em S1 e S2 forem relacionados, pondere sobre a relação follow-up

Nome da relação: Follow-up

Tipo da Relação: Conteúdo->Complemento->Temporal

Direcionalidade: S1<-S2

Restrições: S2 apresenta acontecimentos que acontecem após os acontecimentos em S1; os acontecimentos em S1 e em S2 devem ser relacionados e ter um espaço de tempo relativamente curto entre si.

Comentários:

Nome da relação: Elaboration

Tipo da Relação: Conteúdo->Complemento->Atemporal

Direcionalidade: $\mathrm{S} 1<-\mathrm{S} 2$

Restrições: S2 detalha/refina/elabora algum elemento presente em S1, sendo que S2 não deve repetir informações presentes em $\mathrm{S} 1$.

Comentários: O elemento elaborado em S2 deve ser o foco de S2; se forem apresentadas informações repetidas, considere outra relação (por exemplo, overlap); se forem apresentadas informações temporais, pondere sobre a relação historical background

Nome da relação: Contradiction

Tipo da Relação: Conteúdo->Contradição

Direcionalidade: Nula

Restrições: S1 e S2 divergem sobre algum elemento das sentenças.

Comentários:

Nome da relação: Citation

Tipo da Relação: Apresentação/Forma->Fonte/Autoria

Direcionalidade: $\mathrm{S} 1<-\mathrm{S} 2$

Restrições: S2 cita explicitamente informação proveniente de S1.

Comentários: Dada a natureza desta relação, ela não pode coocorrer com relações de redundância total.

Nome da relação: Attribution

Tipo da Relação: Apresentação/Forma->Fonte/Autoria

Direcionalidade: $\mathrm{S} 1<-\mathrm{S} 2$

Restrições: S1 e S2 apresentam informação em comum e S2 atribui essa informação a uma fonte/autoria.

Comentários: S1 e S2 apresentam informação em comum e S2 atribui essa informação a uma fonte/autoria. 
Nome da relação: Modality

Tipo da Relação: Apresentação/Forma->Fonte/Autoria

Direcionalidade: $\mathrm{S} 1<-\mathrm{S} 2$

Restrições: S1 e S2 apresentam informação em comum e em S2 a fonte/autoria da informação é indeterminada/relativizada/amenizada

Comentários: Dada a natureza desta relação, ela não pode coocorrer com relações de redundância total.

Nome da relação: Modality

Tipo da Relação: Apresentação/Forma->Fonte/Autoria

Direcionalidade: S1<-S2

Restrições: S1 e S2 apresentam informação em comum e em S2 a fonte/autoria da informação é indeterminada/relativizada/amenizada

Comentários: Dada a natureza desta relação, ela não pode coocorrer com relações de redundância total.

\footnotetext{
Nome da relação: Translation

Tipo da Relação: Apresentação/Forma->Estilo

Direcionalidade: Nula

Restrições: S1 e S2 apresentam informação em comum em línguas diferentes.

Comentários:
} 